\title{
Studien zur Pathogenese humaner Leukoenzephalopathien
}

\author{
DISSERTATION \\ zur Erlangung des Doktorgrades \\ der Mathematisch-Naturwissenschaftlichen Fakultäten \\ der Georg-August-Universität zu Göttingen
}

vorgelegt von

SIMONE DIEKMANN

aus Warburg

Göttingen 2009 
D 7

Referent:

Prof. Dr. Ralf Heinrich

Korreferent:

Prof. Dr. Oliver Einsle

Tag der mündlichen Prüfung:

09. Juli 2009 


\section{Inhaltsverzeichnis}

1. Einleitung $\quad 1$

1.1. Leukoenzephalopathien . . . . . . . . . . . . . . . . . . . . 1

1.2. Myelin und Myelinisierung im Zentralnervensystem . . . . . . . . . . . . 3

1.3. GJA12-assoziierte PMLD . . . . . . . . . . . . . . . 4

1.3.1. Gap Junction Proteine/Connexine . . . . . . . . . . . . . 6

1.3.1.1. Bildung und Abbau von Gap Junction Kanälen . . . . . . . . 8

1.3.1.2. Connexin 46.6/Gap Junction Protein $\alpha 12$ (GJA12) . . . . . . . 9

1.4. CLminusM/RNASET2 defiziente zystische Leukoenzephalopathie . . . . . . 11

1.4.1. Ribonukleasen . . . . . . . . . . . . . . . . . . . . . . . 11

1.4.2. Familie der T2-Typ RNasen . . . . . . . . . . . . . . . . . . 12

1.4.3. Die humane RNASET2 . . . . . . . . . . . . . . . . . 13

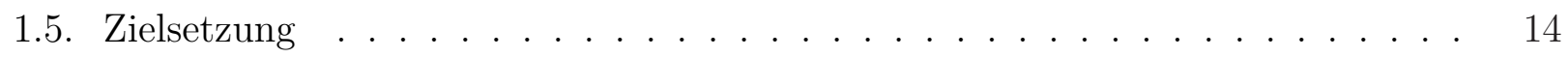

2. Material $\quad 15$

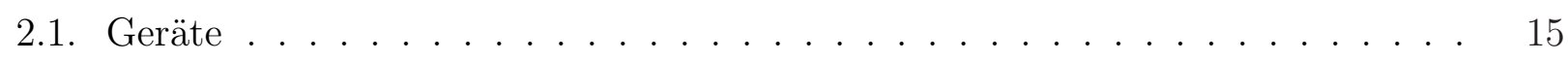

2.2. Chemikalien . . . . . . . . . . . . . . . . . 16

2.3. Restriktionsendonukleasen und Standards . . . . . . . . . . . . . 16

2.4. Kits zur Bearbeitung von DNA/RNA . . . . . . . . . . . . . . . 17

2.5. Antikörper und Immunreagenzien . . . . . . . . . . . . . . . . 17

2.6. Bakterienstämme, Zelllinien und Tiere . . . . . . . . . . . . 18

2.7. Puffer und Nährmedien . . . . . . . . . . . . . . . . . . . 20

2.7.1. Häufig verwendete Puffer und Stammlösungen . . . . . . . . . . . . . 20

2.7.2. Denaturierendes RNA-Gel . . . . . . . . . . . . . . . 20

2.7.3. SDS-Polyacrylamid-Gelelektrophorese . . . . . . . . . . . . . 21

2.7.4. Medien für Bakterienkulturen . . . . . . . . . . . . . . 22

2.7.5. Medien für Zellkulturen . . . . . . . . . . . . . . . . . . . 22

2.7.6. Medien für Xenopus laevis Oozyten . . . . . . . . . . . . . . . . . 22

2.8. Plasmide und Oligonukleotide . . . . . . . . . . . . . . . . 23 
$\begin{array}{ll}\text { 3. Methoden } & 27\end{array}$

3.1. DNA: Molekularbiologische Methoden . . . . . . . . . . . . . 27

3.1.1. Konzentrationsbestimmung von Nukleinsäuren . . . . . . . . . . . . . . 27

3.1.2. Phenol-Chloroform-Isoamylalkohol-Extraktion . . . . . . . . . . . . 27

3.1.3. Ethanol-Präzipitation . . . . . . . . . . . . . . . . . 28

3.1.4. Polymerase-Kettenreaktion . . . . . . . . . . . . . . . . . 28

3.1.4.1. Aufreinigung von PCR-Produkten . . . . . . . . . . . . . . . 29

3.1.5. Mutagenese-PCR . . . . . . . . . . . . . . . . 29

3.1.6. Agarose-Gelelektrophorese . . . . . . . . . . . . . . . . . . . . . 30

3.1.7. Isolierung von DNA-Fragmenten aus Agarosegelen . . . . . . . . . . . . 31

3.1.8. Klonierung von PCR-Fragmenten . . . . . . . . . . . . . . . . . . . . . 31

3.1.9. Spaltung von DNA mit Restriktionsendonukleasen . . . . . . . . . . . 32

3.1.10. Ligation von DNA-Fragmenten . . . . . . . . . . . . . . . . 32

3.1.11. Herstellung kompetenter Bakterien . . . . . . . . . . . . . . . . . 33

3.1.12. Transformation kompetenter Bakterien . . . . . . . . . . . . . . 33

3.1.13. Isolierung von DNA . . . . . . . . . . . . . . . . . . . . . . 34

3.1.14. DNA-Sequenzierung und Sequenzanalyse . . . . . . . . . . . . 35

3.2. RNA: Molekularbiologische Methoden . . . . . . . . . . . . . . . 36

3.2.1. Präparation von RNA aus Gewebe und Zellen . . . . . . . . . . . . . 36

3.2.2. Denaturierendes RNA-Agarose-Gel . . . . . . . . . . . . . . . 37

3.2.3. Reverse Transkriptase-PCR . . . . . . . . . . . . . . . . . 38

3.2.4. Expressionsanalyse mittels RealTime-PCR . . . . . . . . . . . 39

3.2.5. In vitro Transkription . . . . . . . . . . . . . . . . . . . . . . . . 41

3.3. Zellbiologische Methoden . . . . . . . . . . . . . . . . . . . . . . 41

3.3.1. Kultivierung von eukaryontischen Zellen . . . . . . . . . . . . . 41

3.3.2. Transiente Transfektion von HeLa/HEK 293 Zellen . . . . . . . . . . . 42

3.3.3. Stabile Transfektion von HeLa/HEK 293 Zellen . . . . . . . . . . . . . 43

3.3.4. Immunfluoreszenz . . . . . . . . . . . . . . . . . . . . . . . . . . . . 44

3.3.5. Expression in Xenopus-Oozyten . . . . . . . . . . . . . . 45

3.3.5.1. Operative Entnahme und Präparation der Oozyten . . . . . . 45

3.3.5.2. Mikroinjektion . . . . . . . . . . . . 46

3.3.5.3. Zwei-Elektroden Spannungsklemme . . . . . . . . . . . . 46

3.3.5.4. Gefrierschnitte von Oozyten . . . . . . . . . . . . . . 48

3.4. Proteinbiochemische Methoden und Immunzytochemie . . . . . . . . . . . . 48

3.4.1. Proteinextraktion aus Gewebe und Zellen . . . . . . . . . . . . . . . . 48

3.4.2. Quantitative Proteinbestimmung mit Bicinchoninsäure (BCA) . . . . . 49

3.4.3. Deglykosylierung mit PNGaseF . . . . . . . . . . . . . . . . . . . 49 
3.4.4. Denaturierende Polyacrylamid-Gelelektrophorese . . . . . . . . . . . . 50

3.4.5. Western Blot . . . . . . . . . . . . . . . . . 50

3.4.6. Methoden zur Expression und Isolierung rekombinanter Proteine . . . . 52

3.4.6.1. Expression und Aufreinigung von GST-Fusionsproteinen . . . 52

3.4.6.2. Expression und Aufreinigung von His-Fusionsproteinen . . . . 52

3.4.6.3. Antikörperproduktion .............. 53

3.4.7. GST-pulldown . . . . . . . . . . . . . . . . 53

4. Ergebnisse $\quad 55$

4.1. Pathogenese der GJA12-assoziierten PMLD . . . . . . . . . . . . 55

4.1.1. Mutationsanalyse der PMLD-Patienten . . . . . . . . . . . . 55

4.1.2. Untersuchungen zur Funktionalität der Cx46.6-Mutanten . . . . . . . 59

4.1.2.1. Lokalisation und Expression von Cx46.6-WT-GFP in Oozyten 62

4.1.3. Erzeugung eines Anti-Cx46.6 Antiserums . . . . . . . . . . . . . 63

4.1.4. Expressionsanalyse der Cx46.6-WT- und -mt-Proteine . . . . . . . . . 65

4.1.5. Subzelluläre Lokalisation der Cx46.6-WT- und -mt-Proteine . . . . . . 66

4.2. Pathogenese der RNASET2 defizienten zystischen Leukoenzephalopathie . . 70

4.2.1. Analyse des RNASET2-Expressionsniveaus mittels RealTime-PCR . . 70

4.2.2. RNASET2-Mutationsanalyse . . . . . . . . . . . . . 73

4.2.3. Auswirkungen der Mutationen in Spleißkonsensussequenzen . . . . . . . 74

4.2.3.1. Analyse der Spleißvarianten mittels TA-Klonierung . . . . . . 75

4.2.3.2. Spleißdefekt-Analyse mittels Minigenkonstrukt . . . . . . 76

4.2.4. RNASET2-Expressionsanalyse in verschiedenen Geweben . . . . . . . 78

4.2.5. Expression und Sekretion von RNASET2 . . . . . . . . . . . . . 79

4.2.6. Herstellung eines Anti-RNASET2-Antiserums . . . . . . . . . . . . 81

4.2.7. Generierung von stabilen Zellinien . . . . . . . . . . . . . 83

4.2.7.1. Subzelluläre Lokalisation von RNASET2 . . . . . . . . . . . . 83

4.2.8. RNASET2 in lymphoblastoiden Patienten-Zellen . . . . . . . . . . . . 85

4.2.8.1. Expressions- und Glykosylierungsanalyse von RNASET2 . . . 85

4.2.8.2. Sekretionsanalyse von RNASET2 . . . . . . . . . . . 87

4.2.8.3. Subzelluläre Lokalisation von RNASET2 . . . . . . . . . . . . 88

4.2.9. Prozessierung der RNASET2 . . . . . . . . . . . . . . . . 91

4.2.10. RNASET2-Interaktionsstudien . . . . . . . . . . . . . . . . 92

5. Diskussion $\quad 95$

5.1. Pathogenese der GJA12-assoziierten PMLD . . . . . . . . . . . . . 95

5.1.1. Mutationsanalyse der PMLD-Patienten . . . . . . . . . . . . . 95

5.1.2. Untersuchungen zur Funktionalität der Cx46.6-Mutanten . . . . . . . . 96 
5.1.3. Charakterisierung des PMLD-Pathomechanismus . . . . . . . . . 98

5.2. Pathogenese der RNASET2 defizienten zystischen Leukoenzephalopathie . . . 102

5.2.1. Charakterisierung der RNASET2-Mutationen . . . . . . . . . . . 103

5.2.2. Charakterisierung der RNASET2 . . . . . . . . . . . . 106

5.2.3. Pathomechanismus der RNASET2 defizienten zystischen Leukoenzephalopathie . . . . . . . . . . . . . . . . . . 108

5.2.4. RNASET2-Interaktionsstudien . . . . . . . . . . . . . . . 110

5.3. Fazit . . . . . . . . . . . . . . . . . . . . 112

$\begin{array}{ll}\text { 6. Zusammenfassung } & 113\end{array}$

$\begin{array}{ll}\text { Literaturverzeichnis } & 115\end{array}$

$\begin{array}{ll}\text { Abbildungsverzeichnis } & 131\end{array}$

$\begin{array}{ll}\text { Tabellenverzeichnis } & 132\end{array}$

$\begin{array}{lll}\text { Anhang } & \text { A }\end{array}$

A.1. Sequenzen der Oligonukleotide . . . . . . . . . . . . . . . . . . A

$\begin{array}{lll}\text { Publikationen } & \text { E }\end{array}$

$\begin{array}{ll}\text { Danksagung } & \text { G }\end{array}$

Wissenschaftlicher Werdegang I 


\section{Verzeichnis der Abkürzungen}

\begin{tabular}{|c|c|}
\hline $\mathrm{A}$ & Adenin \\
\hline $\mathrm{A}$ & Ampere \\
\hline$\alpha$ & anti \\
\hline Amp & Ampicillin \\
\hline ANOVA & Analysis of Variance \\
\hline APS & Ammoniumpersulfat \\
\hline AS & Aminosäure \\
\hline asCx38 & Antisense Oligonukleotide gegen Connexin 38 \\
\hline ATCC & American Type Culture Collection \\
\hline ATP & Adenosintriphosphat \\
\hline $\mathrm{H}_{2} \mathrm{O}$ bidest. & doppelt destilliertes Wasser \\
\hline $\mathrm{bp}$ & Basenpaare \\
\hline BSA & Bovine Serum Albumine \\
\hline bzw. & beziehungsweise \\
\hline $\mathrm{C}$ & Cytosin \\
\hline${ }^{\circ} \mathrm{C}$ & Grad Celsius \\
\hline ca. & circa \\
\hline cDNA & aus Ribonukleinsäure umgeschriebene Desoxyribonukleinsäure \\
\hline CLminusM & Cystic Leukoencephalopathy without Megalencephaly \\
\hline CMV & Cyto-Megalie-Virus \\
\hline cRNA & aus Desoxyribonukleinsäure synthetisierte Ribonukleinsäure (in vitro) \\
\hline $\mathrm{Cx}$ & Connexin \\
\hline DAPI & $4^{\prime}, 6$-Diamidino-2-phenylindol, Fluoreszenzfarbstoff zur DNA Detektion \\
\hline dATP & Desoxyadenosintriphosphat \\
\hline $\mathrm{dCTP}$ & Desoxycytosintriphosphat \\
\hline DEPC & Diethylpyrocarbonat \\
\hline DMEM & Dulbecco's Modified Eagle Medium \\
\hline DMSO & Dimethylsulfoxid \\
\hline DNA & Desoxyribonukleinsäure \\
\hline $\mathrm{dNTP}$ & Desoxyribonukleosidtriphosphat \\
\hline
\end{tabular}


DSMZ

DTT

dTTP

dUTP

EBV

E.coli

ECL

EDTA

EGFP

ER

etc.

$\mathrm{EtOH}$

FKS

G

g

$\times \mathrm{g}$

GAPDH

GJA12

GST

HEK

HeLa

HEPES

His

HRP

$\mathrm{IgG}$

Ind.

IPTG

$\mathrm{kb}$

$\mathrm{kDa}$

1

LAMP-1

$\mathrm{LB}$

$\mathrm{M}$

MAG

MBP

$\min$

MOG
Deutsche Sammlung von Mikroorganismen und Zellkulturen

Dithiothreitol

Desoxythymidintriphosphat

Desoxyuridyltriphosphat

Epstein-Barr-Virus

Escherichia coli

Enhanced Chemiluminescence

Ethylendiamintetraacetat

Enhanced Green Fluorescent Protein

Endoplasmatisches Retikulum

et cetera

Ethanol

fetales Kälberserum

Guanin

Gramm

Vielfaches der Erdbeschleunigung

Glycerinaldehyd-3-Phosphat-Dehydrogenase

Gap Junction Protein $\alpha 12$

Glutathion-S-Transferase

Human Embryonic Kidney

humane Zervixkarzinom-Epithelzellen (von Henrietta Lacks)

2-(4-[2-Hydroxyethyl]-1-piperazinyl)-ethansulfonsäure

Histidin

Horseradish Peroxidase

Immunglobulin G

Individuum

Isopropyl-D-Galctopyranosid

Kilobasenpaar

Kilodalton

Liter

Lysosomal-Associated Membrane Protein 1

Luria Broth

Molar, Mol/Liter

Myelin-assoziiertes Glykoprotein

basisches Myelin Protein

Minuten

Myelin-Oligodendrozyten Glykoprotein 


\begin{tabular}{|c|c|}
\hline MOPS & 3-Morpholinopropansulfonsäure \\
\hline mRNA & Boten(messenger)-Ribonukleinsäure \\
\hline $\mathrm{mt}$ & Mutante \\
\hline MW & Molekulargewicht \\
\hline $\mathrm{N}_{2}$ & Stickstoff \\
\hline $\mathrm{nm}$ & Nanometer \\
\hline nt & Nukleotide \\
\hline $\mathrm{OD}_{600}$ & Optische Dichte bei $600 \mathrm{~nm}$ \\
\hline PAGE & Polyacrylamid Gelelektrophorese \\
\hline PBS & Phosphat-gepufferte Kochsalzlösung \\
\hline PCR & Polymerasekettenreaktion \\
\hline PDI & Protein-Disulfid-Isomerase \\
\hline PFA & Paraformaldehyd \\
\hline Pfu & Pyrococcus furiosus \\
\hline $\mathrm{pH}$ & negativer dekadischer Logarithmus der Protonenkonzentration \\
\hline PLP1 & Proteolipidprotein 1 \\
\hline PMD & Pelizaeus-Merzbacher Disease \\
\hline PMLD & Pelizaeus-Merzbacher Like Disease \\
\hline PNS & peripheres Nervensystem \\
\hline RNA & Ribonukleinsäure \\
\hline RNase & Ribonuklease \\
\hline RNASET2 & humane Ribonuklease T2 \\
\hline$R T$ & reverse Transkriptase \\
\hline S & Svedbergeinheit \\
\hline SDS & Natriumlaurylsulfat/Natriumdodecylsulfat \\
\hline sec & Sekunden \\
\hline S.E.M. & standard error of the mean \\
\hline $\mathrm{T}$ & Thymin \\
\hline Taq & Thermophilus aquaticus \\
\hline TBS & Tris-gepufferte Kochsalzlösung \\
\hline $\mathrm{TE}$ & Tris-EDTA \\
\hline TEMED & Tetramethylethylendiamin \\
\hline TEVC & Two Electrode Voltage Clamp \\
\hline Tris & Tris(Hydroxymethyl)-aminoacetat \\
\hline $\mathrm{U}$ & Enzymeinheiten (Unit) \\
\hline UPR & Unfolded Protein Response \\
\hline UV & Ultraviolett \\
\hline
\end{tabular}


V

vgl.

$\mathrm{v} / \mathrm{v}$

WT

$\mathrm{w} / \mathrm{v}$

z.B.

X-Gal

z.B.

ZNS

$\%$

Volt

vergleiche

Volumenverhältnis

Wildtyp

Gewicht- zu Volumenverhältnis

zum Beispiel

5-Brom-4-Chlor-3-Indolyl-b-D-galactosid

zum Beispiel

Zentralnervensystem

Prozent

An einigen Stellen war die Verwendung englischer Fachtermini nötig, da eine Übersetzung ins Deutsche unzureichend ist. Die Abkürzung der chemischen Elemente erfolgte gemäß dem Periodensystem.

\section{Verwendete Vorsilben für Potenzen der Zahl Zehn}

$$
\begin{aligned}
& \mathrm{p}=\text { pico }=1 \times 10^{-12} \\
& \mathrm{n}=\text { nano }=1 \times 10^{-9} \\
& \mathrm{\mu}=\text { mikro }=1 \times 10^{-6} \\
& \mathrm{~m}=\text { milli }=1 \times 10^{-3} \\
& \mathrm{k}=\text { kilo }=1 \times 10^{3}
\end{aligned}
$$

\section{Ein- und Dreibuchstabencode für Aminosäuren}
A, Ala
Alanin
M, Met
Methionin
C, Cys
Cystein
$\mathrm{N}$, Asn
Asparagin
D, Asp
Asparaginsäure
P, Pro
Prolin
E, Glu
Glutaminsäure
Q, Gln
Glutamin
F, Phe
Phenylalanin
$\mathrm{R}, \operatorname{Arg}$
Arginin
G, Gly
Glycin
$\mathrm{S}$, Ser
Serin
$\mathrm{H}$, His
Histidin
$\mathrm{T}$, Thr
Threonin
I, Ile
Isoleucin
$\mathrm{V}, \mathrm{Va}$
Valin
K, Lys Lysin
W, Trp
Tryptophan
L, Leu
Leucin
Y, Tyr
Tyrosin 


\section{Einleitung}

\subsection{Leukoenzephalopathien}

Der Begriff Leukoenzephalopathie, häufig auch als Leukodystrophie bezeichnet, leitet sich aus dem Griechischen ab und bedeutet "schlechte Ernährung der weißen Hirnsubstanz". Als Leukoenzephalopathien im weitesten Sinne werden unabhängig von ihrer Ursache alle Erkrankungen oder Schädigungen der weißen Hirnsubstanz bezeichnet.

Leukoenzephalopathien im engeren Sinne bilden eine Gruppe von genetisch determinierten Erkrankungen, bei denen Fehler im Aufbau oder in der Erhaltung der weißen Substanz in Gehirn und Rückenmark vorliegen. Das Myelin ist der Hauptbestandteil der weißen Substanz. Es gibt drei Varianten von Myelinmetabolismusstörungen, die wie folgt bezeichnet werden: Hypo-, Dys- und Demyelinisierung. Liegt eine Hypomyelinisierung vor, bezeichnet dies ein vermindertes Vorhandensein von Myelin. Bei der Dysmyelinisierung wird fehlerhaftes Myelin gebildet und bei einer Demyelinisierung werden die zuvor gebildeten Myelinscheiden ganz oder in Teilen wieder abgebaut.

Leukoenzephalopathien sind angeborene Erkrankungen und manifestieren sich meist in der frühen Kindheit, können aber auch erst im Erwachsenenalter symptomatisch werden. Klinische Leitsymptome sind oft eine primäre psychomotorische Entwicklungsverzögerung oder in anderen Fällen zunächst der Verlust erworbener motorischer Fähigkeiten mit progredienter Bewegungsstörung und später im Verlauf auch der Verlust kognitiver Funktionen.

Schon während des 19. Jahrhunderts wurden die ersten Patienten mit Leukoenzephalopathien beschrieben. Die Möglichkeiten der Darstellung des menschlichen Myelins in vivo mittels Magnetresonanztomographie (MRT) und die Messung einzelner Stoffwechselprodukte mittels lokalisierter Protonenspektroskopie (MRS) des Gehirns haben den Prozess der Diagnosestellung entscheidend beeinflusst. Die erste Einteilung dieser Erkrankungen erfolgte durch Bielschowsky und Henneberg (1928). Inzwischen werden die Myelinationsstörungen in der Regel in zwei Gruppen eingeteilt. Etwa zwei Drittel der kernspintomographisch erfassten Leukoenzephalopathien lassen sich definierten Krankheitsbildern mit bekannter genetischer Ursache zuordnen. Gekennzeichnet sind diese im Allgemeinen durch Einlagerungen abnormer toxischer 
Stoffwechselprodukte in die weiße Substanz, die zu einem fortschreitenden Abbau des Myelins führen, oder durch primär genetisch veränderte myelinbildende Zellen (Oligodendrozyten oder Schwann-Zellen). Diese angeborenen, meist neurometabolischen Erkrankungen bilden die Gruppe der sogenannten "klassischen Leukoenzephalopathien" und werden nach den subzellulären Strukturen bzw. Organellen, in denen die defekten Stoffwechselwege lokalisiert sind, eingeteilt:

- lysosomale Erkrankungen wie z.B. die metachromatische Leukoenzephalopathie, die Globoidzellleukodystrophie (Morbus Krabbe) oder die Mukopolysaccharidosen,

- mitochondriale Erkrankungen wie z.B. der Pyruvatcarboxylase-Mangel oder Defekte in der Atmungskette,

- peroxisomale Erkrankungen wie z.B. die X-chromosomale Adrenoleukodystrophie oder das Zellweger Syndrom,

- Erkrankungen mit Defekten im Zytoplasma wie z.B. Morbus Canavan oder Abbaustörungen von Aminosäuren,

- Erkrankungen der Myelinogenese wie z.B. die klassische Pelizaeus-Merzbacher Erkrankung (Pelizaeus-Merzbacher Disease: PMD).

Bei etwa einem Drittel der erfassten Leukoenzephalopathien kann jedoch keine primäre Krankheitsursache erkannt werden. Sie lassen sich derzeit nicht durch biochemische oder molekulargenetische Laboruntersuchungen klassifizieren und werden somit als unklare Leukoenzephalopathien bezeichnet. Unter den unklaren Leukoenzephalopathien befinden sich jedoch auch Fälle, die anhand klinischer und kernspintomographischer Daten als Krankheitsentität mit einer wahrscheinlich gemeinsamen Ursache zusammengefasst werden können.

Die vorliegende Arbeit behandelt ausschließlich die zwei folgenden Leukoenzephalopathien: die GJA12-assoziierte Pelizaeus-Merzbacher ähnliche Erkrankung (Pelizaeus-Merzbacher Like Disease: PMLD) und die zystische Leukoenzephalopathie ohne Megalenzephalie (Cystic Leukoencephalopathy without Megalencephaly: CLminusM). Beide Erkrankungen gehörten lange Zeit zu den unklaren Leukoenzephalopathien, die jeweils als eine Krankheitsentität definiert wurden. Für die GJA12-assoziierte PMLD, der eine primäre Hypomyelinisierung zugrunde liegt, konnte das krankheitsverursachende Gen, das Connexin 46.6, von Uhlenberg et al. (2004) identifiziert werden. Den bislang unklaren genetischen Defekt der CLminusM, die durch eine Dysmyelinisierung gekennzeichnet ist, konnten wir in unserer Arbeitsgruppe ebenfalls kürzlich identifizieren und charakterisieren. 


\subsection{Myelin und Myelinisierung im Zentralnervensystem}

Die graue Substanz des Zentralnervensystems (ZNS) besteht überwiegend aus den Nervenzellkörpern, im Gegensatz zur weißen Substanz, die aus markhaltigen Nervenfasern und den Neurogliazellen gebildet wird (van der Knaap et al., 1995). Zu den Neurogliazellen gehören Astrozyten und Oligodendrozyten. Die Oligodendrozyten, die zuerst von Virchow (1846) beschrieben und als Nervenkitt bezeichnet wurden, ummanteln mit ihren zahlreichen Fortsätzen als Bestandteil ihrer Membran die Nervenfasern. Dabei ist eine Oligodendrozytenzelle in der Lage, bis zu 50 Axone zu umhüllen. Die Gesamtheit der lamellenartig angeordneten Membranen wird als Myelin bezeichnet, welches den Hauptbestandteil der weißen Substanz des zentralen Nervensystems bildet. Im peripheren Nervensystem (PNS) wird das Myelin von Schwann-Zellen gebildet. Astrozyten haben zahlreiche Fortsätze mit denen sie mit Oligodendrozyten, anderen Astrozyten, Neuronen und Endothelzellen über Kanäle (Gap Junctions) in Verbindung stehen. Auf diese Weise bilden die Astrozyten und Oligodendrozyten ein ausgedehntes Netzwerk, das panglial syncytium (Mugnaini, 1986; Rash et al., 1997).

Das Besondere der Myelinmembranen besteht darin, dass sie im Gegensatz zu anderen Zelloberflächen oder intrazellulären Membranen lipidreich und proteinarm sind. Isoliertes Myelin besteht je nach Herkunft zu 70-85\% aus Lipiden und zu 15-30\% aus Proteinen, bezogen auf das Trockengewicht (Norton und Cammer, 1984). Des Weiteren hat es einen extrem niedrigen Wasseranteil von ca. 40\%, was durch die kompakte, wenig Zytoplasma enthaltende Struktur bedingt ist. Die Funktion der einzelnen, größtenteils myelinspezifischen Lipide und Proteine im Aufbau und in der Erhaltung des Myelins ist weitestgehend unbekannt. Aufgrund des hohen Lipidgehalts erscheint das Myelin in der makroskopischen Sicht weiß, weshalb stark myelinisierte Regionen im Zentralnervensystem als weiße Substanz bezeichnet werden, im Gegensatz zur gering myelinisierten grauen Substanz.

Bei den Lipiden ist der Unterschied zwischen ZNS und PNS sehr gering. Zwischen den Proteinen des PNS-Myelins und des ZNS-Myelins gibt es jedoch spezifische Unterschiede. Die Proteine des ZNS-Myelins, welches 40-50\% der weißen Gehirnmasse ausmacht, setzen sich zu 80\% aus dem basischen Myelin Protein (MBP) und dem Proteolipidprotein 1 (PLP1) zusammen (Baumann und Pham-Dinh, 2001). Das PLP1 spielt eine große Rolle bei interzellulärer Signalübertragung, oligodendroglialer Entwicklung, Ionenkanal-Aufbau und Ausbildung von axoglialen Übergängen (Gow und Lazzarini, 1996; Gudz et al., 2002; Mar und Noetzel, 2008). Das MBP ist wahrscheinlich mitverantwortlich für die Stabilisierung von kompaktiertem Myelin, indem es mit seinen positiven Ladungen gegenüberliegende zytoplasmatische Myelinmembranen verbindet (Kursula, 2001). 
Vier Prozent der Myelin-Proteine werden durch die 2', 3'-zyklische Nukleotid 3'-Phosphohydrolase (CNP) repräsentiert. CNP ist mit der Plasmamembran der Oligodendrozyten assoziiert (Braun et al., 1991). Zwei wichtige Glykoproteine des Myelins sind das Myelin-assoziierte Glykoprotein (MAG) und das Myelin-Oligodendrozyten Glykoprotein (MOG; Baumann und Pham-Dinh, 2001). MAG hat nur einen Anteil von $1 \%$ an den Proteinen des Myelins, sowohl im ZNS als auch im PNS. Es findet sich im periaxonalen Bereich in der Myelinmembran und spielt eine wichtige Rolle bei der Glia-Axon Wechselwirkung (Poltorak et al., 1987). MOG ist auf der extrazellulären Seite der äußersten Myelinmembran und in der Oligodendrozyten Plasmamembran lokalisiert (Brunner et al., 1989; Lebar et al., 1986) und macht ungefähr 0,05\% der gesamten Myelinproteine aus (Amiguet et al., 1992).

Die Myelinisierung im menschlichen ZNS setzt bereits im 6. Schwangerschaftsmonat ein und endet größtenteils in den ersten Lebensjahren. Die Myelinisierung der einzelnen Strukturelemente des ZNS erfolgt nach einem genetisch festgelegten und sehr genauen Zeitplan, in dem sich die folgenden Gesetzmäßigkeiten erkennen lassen (Yakovlev und Lecours, 1967):

- Die Myelinisierung erfolgt zum Zeitpunkt der Funktionsaufnahme von Strukturelementen des Nervensystems.

- Die Myelinisierung erfolgt zuerst im PNS und anschließend im ZNS; innerhalb des ZNS schreitet die Myelinisierung von kaudal (Rückenmark) nach rostral (Gehirn) und von zentralen zu peripheren Hirnregionen fort.

- Die Myelinisierung erfolgt zunächst an afferenten (sensorischen) Neuronen, dann an efferenten (motorischen) Neuronen und abschließend an Assoziationsneuronen.

Die Myelinisierung bewirkt eine Konzentration der für die Nervenleitung wichtigen Ionenkanäle in den Myelin-freien Bereichen, ermöglicht die saltatorische Reizweiterleitung entlang der Ranvier-Schnürringe und gewährleistet so eine schnelle und zuverlässige Fortleitung von Impulsen (Kaplan et al., 1997).

\subsection{GJA12-assoziierte PMLD}

Die GJA12-assoziierte Pelizaeus-Merzbacher ähnliche Erkrankung (PMLD) zählte lange Zeit zu den unklaren, einer Krankheitsentität zugeordneten Leukoenzephalopathien. Der klinische Phänotyp ist nicht vom Erscheinungsbild der klassischen Pelizaeus-Merzbacher-Erkrankung (PMD) zu unterscheiden; genotypisch lassen sich jedoch keine Übereinstimmungen finden (Garbern et al., 1999). Klinische Leitsymptome sind ein meist in den ersten Lebensmonaten auftretender Nystagmus (unkontrollierbare, rhythmische Bewegungen der Augen) und eine 
primäre psychomotorische Entwicklungsverzögerung, gefolgt von Ataxie (Störungen der Bewegungskoordination), muskulärer Hypotonie, Dysarthrie (Sprachstörungen) und progredienter Spastizität (Schiffmann und Boespflug-Tanguy, 2001). Die PMD, der Prototyp einer Leukoenzephalopathie mit primär generalisierter Hypomyelinisierung, wird X-chromosomal vererbt und beruht auf Deletionen, Duplikationen oder Punktmutationen des PLP1-Gens (Schiffmann und Boespflug-Tanguy, 2001). PMLD dagegen weist einen autosomal rezessiven Erbgang auf.

Bei 20\% aller Patienten mit einem klinischen und radiologischen PMD-Phänotyp kann kein Defekt im PLP1-Gen nachgewiesen werden (Schiffmann und Boespflug-Tanguy, 2001). Bei diesen Patienten wird die Erkrankung als PMD-ähnlich (PMLD) bezeichnet. Von Uhlenberg et al. konnte 2004 für einen Teil der Patienten mit PMLD das Connexin 46.6 (Cx46.6), auch als Gap Junction Protein $\alpha$ 12 (GJA12) bezeichnet, als neues Krankheitsgen identifiziert werden. Alle bisher bei PMLD-Patienten beschriebenen Sequenzveränderungen des Cx46.6-Gens sind in Tabelle 1.1 zusammengefasst. Die Mutationen sind entsprechend der Internationalen Mutationsnomenklatur bezeichnet (Nukleotid +1 entspricht dem A des Startcodons; den Dunnen und Antonarakis, 2000; den Dunnen und Paalman, 2003).

Tabelle 1.1.: Bisher beschriebene Mutationen der GJA12-assoziierten PMLD

\begin{tabular}{|c|c|c|}
\hline Mutationsbezeichnung & & Autor \\
\hline auf DNA-Ebene & auf Proteinebene & \\
\hline c. $[875 \mathrm{~T}>\mathrm{C}][875 \mathrm{~T}>\mathrm{C}]$ & p.[M286T][M286T] & Uhlenberg et al. (2004) \\
\hline c. $[268 \mathrm{C}>\mathrm{T}][989 \mathrm{delC}]$ & p.[P90S][P330RfsX141] & \\
\hline c. $[718 \mathrm{C}>\mathrm{T}][814 \mathrm{~T}>\mathrm{G}]$ & p. $[\mathrm{R} 240 \mathrm{X}][\mathrm{Y} 272 \mathrm{D}]$ & \\
\hline c. $[706 \mathrm{G}>\mathrm{A}][706 \mathrm{G}>\mathrm{A}]$ & p. $[\mathrm{G} 236 \mathrm{~S}][\mathrm{G} 236 \mathrm{~S}]$ & Bugiani et al. (2006) \\
\hline c. $[841 \mathrm{insG}][841 \mathrm{insG}]$ & p.[L281AfsX5][L281AfsX5] & \\
\hline c.[371dup22][371dup22] & p.[H132PfsX13][H132PfsX13] & \\
\hline c. $\left[913 \_946 \mathrm{del}\right]\left[913 \_946 \mathrm{del}\right]$ & p.[P305RfsX155][P305RfsX155] & $\begin{array}{l}\text { Salviati et al. (2006) und } \\
\text { Wolf et al. (2006) }\end{array}$ \\
\hline
\end{tabular}

Eine weitere Cx46.6-Mutation (p.Ile36Met) in der ersten Transmembrandomäne wurde von Orthmann-Murphy et al. (2009) in drei Mitgliedern einer Familie beschrieben. Der mildere Phänotyp scheint von dem bisher bekannten PMLD-Phänotyp abzuweichen. Die drei Patienten zeigten einen sehr späten Krankheitsbeginn, die Erkrankung ist langsam progredient, die Patienten haben eine spastische Paraplegie mit normaler oder fast normaler psychomotorischer Entwicklung und keinen Nystagmus.

Nicht bei allen untersuchten PMLD-Patienten konnten Cx46.6-Mutationen nachgewiesen werden. Dies zeigt, dass es sich bei dieser Krankheitsentität um eine genetisch heterogene Gruppe 
von Patienten handelt und neben $C x 46.6$ noch weitere diesen klinischen Phänotyp verursachende Krankheitsgene existieren müssen. Von Magen et al. wurde 2008 das HSPD1-Gen, welches das Hitzeschockprotein 60 (HSP60) kodiert, als ein weiteres Krankheitsgen für die PMLD identifiziert.

\subsubsection{Gap Junction Proteine/Connexine}

Gap Junction Proteine bilden interzelluläre Kanäle zwischen unmittelbar benachbarten Plasmamembranen nahezu aller eukaryontischer Zellen mit Ausnahme von Skelettmuskelzellen und isolierten Zellen (z.B. Erythrozyten). Durch so genannte Gap Junctions, Verbindungen über den Interzellularspalt hinweg, wird eine direkte Zellkommunikation benachbarter Zellen ermöglicht. Gap Junctions befinden sich oft in höherer Dichte (zehn bis mehrere Tausend interzelluläre Kanäle) im Bereich sogenannter Gap Junction Plaques. (Cascio et al., 1995; Falk et al., 1997; Musil und Goodenough, 1993; Unger et al., 1999)

Durch passive Diffusion über die Gap Junctions wird der Austausch sowohl von geladenen als auch von ungeladenen Substanzen wie organischen und anorganischen Ionen, Nukleotiden (z.B. cAMP, ATP), Aminosäuren, Wasser, Glukose, etc. ermöglicht. Die Porengröße lässt eine Diffusion von Molekülen bis zu einer Masse von 1000 Dalton zu (Bruzzone et al., 1996). Das Öffnen und Schließen der Gap Junction Kanäle kann durch physiologische Parameter, wie dem zellulären pH-Wert oder der $\mathrm{Ca}^{2+}$-Konzentration, aber auch durch pharmakologische Agenzien modifiziert werden (Liu et al., 1993; Morley et al., 1996). Die Kanalöffnung wird durch externe divalente Kationen (z.B. $\mathrm{Ca}^{2+}$ ) und meist auch durch hyperpolarisierende Membranpotentiale blockiert. Diese beiden Effekte scheinen synergistisch zu wirken, um die Öffnung der Halbkanäle unter physiologischen Bedingungen zu verhindern (Ebihara, 2003).

Die beiden an einer Gap Junction beteiligten Kanäle werden als Halbkanäle oder Connexone bezeichnet (Abbildung 1.1 a). Ein Connexon besteht aus sechs Connexinen, hoch konservierte integrale Membranproteine, die aufgrund ihrer prognostizierten molekularen Masse benannt werden (Willecke et al., 2002). Connexine (Cx gefolgt von der Molekularmasse in Kilodalton) werden durch eine Multigenfamilie kodiert, die für das humane Genom insgesamt 21 und für das murine Genom insgesamt 20 Gene umfasst. Für die meisten humanen Connexin-Gene existiert jeweils ein orthologes Mausgen (Söhl und Willecke, 2003).

Connexin-Gene weisen eine sehr ähnliche Grundstruktur auf. Sie bestehen aus einem kleinen und einem größeren Exon, wobei der gesamte kodierende Bereich auf Exon 2 lokalisiert ist. Zwei Ausnahmen von dieser Struktur sind bekannt, das Cx36-Gen, bei dem Exon 1 einen Teil der kodierenden Sequenz enthält und das Cx45-Gen, das aus drei Exons besteht (Willecke et al., 2002). Viele Connexine werden gewebespezifisch exprimiert, wobei die meisten Connexine in 
verschiedenen Geweben gleichzeitig synthetisiert werden. Es können aber auch verschiedene Connexine in einem Gewebe gebildet werden (Nicholson et al., 1987; Traub et al., 1989). Über die Hälfte der Connexine werden auch im Nervensystem exprimiert (Nagy et al., 2004). Anhand von Experimenten an transgenen Mäusen, bei denen einzelne Connexingene gezielt ausgeschaltet wurden, wird vermutet, dass der Verlust eines Connexins durch andere Connexine kompensiert werden kann (Menichella et al., 2003).

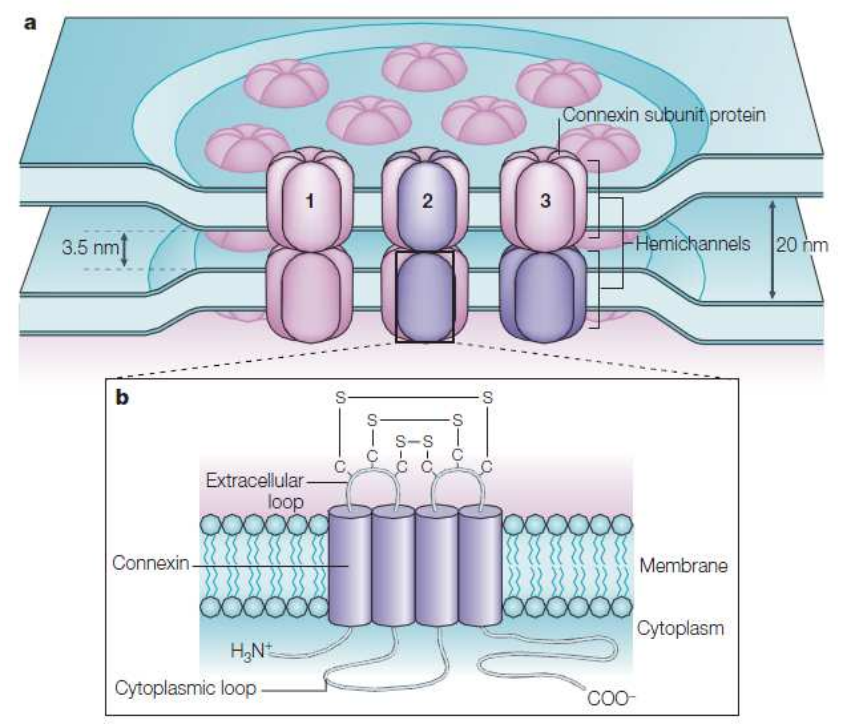

Abbildung 1.1.: Strukturmodell von Gap Junction-Kanälen (a) und Connexinen (b). (Söhl et al., 2005).

Aufgrund von Sequenzanalysen und Antikörperbindungsstudien wird für die Connexin-Membrantopologie generell eine Tetra-Helix-Struktur angenommen. Die schematische Darstellung der Membrantopologie eines Connexins zeigt Abbildung 1.1 b. Die vier $\alpha$-helikalen Transmembrandomänen werden durch zwei extrazelluläre Schleifen und eine intrazelluläre Schleife verbunden, wobei der Amino-Terminus (N-Terminus) und der Carboxy-Terminus (C-Terminus) auf der zytoplasmatischen Seite lokalisiert sind (Evans et al., 2000; Goodenough et al., 1996; Kumar, 1996; Yeager et al., 1998). Die Aminosäuresequenzen der vier Transmembranbereiche und der extrazellulären Schleifen sind unter den verschiedenen Connexinen hoch konserviert. Dagegen stellen die intrazelluläre Schleife und der C-Terminus die variablen Regionen der Proteine dar.

In der dritten Transmembrandomäne weist jede vierte Aminosäure einen Aminosäurerest mit polarer Seitenkette auf, was ihr einen amphipathischen Charakter verleiht. Dies ist ein Hinweis darauf, dass die dritte Transmembrandomäne an der Bildung der hydrophilen Kanalpore beteiligt sein könnte. Bei allen Connexinen finden sich in beiden extrazellulären Schleifen jeweils drei Cysteinreste, die miteinander Disulfidbrücken bilden. Die dadurch erreichte Stabilisierung 
der Tertiärstruktur ermöglicht das Aneinanderdocken zweier Connexine (Foote et al., 1998; Rahman und Evans, 1991).

Posttranslationale Modifikationen, wie die Ubiquitinierung oder die Phosphorylierung der Connexin-Proteine, stellen mögliche Regulationsmechanismen für die Zell-Zell-Kommunikation über Gap Junction Kanäle dar. Die häufigste posttranslationale Modifikation der Connexine ist die Phosphorylierung von Serin-, Tyrosin- und Threoninresten durch verschiedene Proteinkinasen (Moreno und Lau, 2007). Nahezu alle Connexine werden durch Kinasen modifiziert, wobei sie hauptsächlich an ihrem zytoplasmatischen C-Terminus phosphoryliert werden. Es wird postuliert, dass die verschiedenen Phosphorylierungen zu einer Feinjustierung der Regulation von Gap Junction Kanälen beitragen, um damit eine Anpassung der Zelle an sich verändernde Bedingungen zu gewährleisten. Betroffen sind davon der Transport der Connexone an die Plasmamembran, die Degradation der Connexin-Proteine, der Auf- und Abbau sowie das Öffnen und Schließen der Gap Junction Kanäle (Lampe und Lau, 2004). Eine mangelnde Phosphorylierung führt dazu, dass die Connexine im Golgi-Apparat oder im Endoplasmatischen Retikulum (ER) verbleiben (Laird et al., 1995).

\subsubsection{Bildung und Abbau von Gap Junction Kanälen}

Die Gap Junction Biosynthese und der Einbau in die Membran sind strikt geregelte Prozesse. Die meisten Connexine werden im ER synthetisiert und cotranslational in die Membran des ER integriert. Die Oligomerisierung von sechs Connexinen zu einem Halbkanal beginnt sehr wahrscheinlich im ER und endet im trans-Golgi-Netzwerk (Das Sarma et al., 2002; Musil und Goodenough, 1993). Im trans-Golgi-Kompartiment werden die Connexone in Transportvesikel verpackt und entlang der Mikrotubuli zur Plasmamembran transportiert (Lauf et al., 2002). Über Vesikelfusion werden die Connexone in die Plasmamembran eingebracht und bilden einen Pool von frei diffundierenden Halbkanälen. Diese Halbkanäle können entweder in Bereichen der Membran lokalisiert sein, die keinen Kontakt zu benachbarten Zellen haben oder sie diffundieren zu Regionen mit Zellkontakt, um mit gegenüberliegenden Halbkanälen zu interagieren und interzelluläre Kanäle zu bilden (Harris, 2001).

Die Connexone und Gap Junction Kanäle können unterschiedlich zusammengesetzt sein (Abbildung 1.2). Homomere Connexone bestehen aus sechs gleichen Connexin-Proteinen und heteromere Connexone aus sechs unterschiedlichen Connexin-Proteinen. Genauso können sich zwei gleichartige Connexone (homotypisch) oder zwei verschiedene Connexone (heterotypisch) zu einem Gap Junction Kanal zusammenlagern. Die Interaktion der gegenüberliegenden Connexone wird dabei von den extrazellulären Schleifen gewährleistet (Perkins et al., 1998; Unger et al., 1999). Die extrazellulären Schleifen verschiedener Connexin-Moleküle sind, obwohl ebenfalls 
hoch konserviert, nicht immer kompatibel zueinander, so dass nicht jede Form heterotypischer Gap Junction möglich ist (Bruzzone et al., 1993).

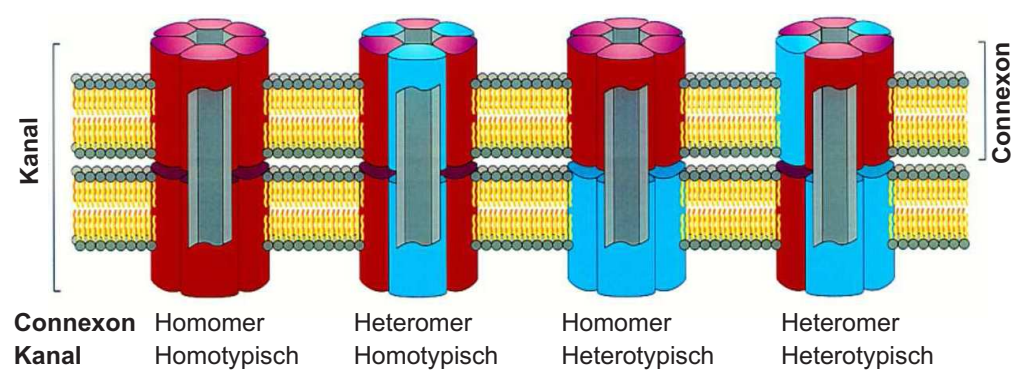

Abbildung 1.2.: Zusammensetzung von homotypischen und heterotypischen Gap Junction Kanälen aus homomeren oder heteromeren Connexonen. (modifiziert nach Kumar, 1996)

Einzelne Kanäle aggregieren schließlich zu Gap Junction Plaques, die bis zu einige tausend Gap Junction Kanäle beinhalten können (Forge et al., 2003; McNutt und Weinstein, 1970). Gap Junction Plaques sind sehr dynamische Strukturen, die einem ständigen Umbau unterliegen, wobei die Kanäle und Connexine über Vesikel aus den Plaques entnommen und dem Abbau zugeführt werden (Laird et al., 1995). Die Halbwertszeit von interzellulären Gap Junctions beträgt einige Stunden $\left(\mathrm{t}_{(1 / 2)}=1,5-5\right.$ Stunden; Musil et al., 2000).

Der Abbau der Gap Junction Plaques erfolgt über sogenannte Annular Gap Junctions. Man geht davon aus, dass sich die Gap Junction-enthaltenden Membranen in eine der beiden Zellen einstülpen und dadurch Vesikel mit einer Doppelmembran ins Zytoplasma abgeschnürt werden, um entweder wiederverwendet oder abgebaut zu werden (Gaietta et al., 2002; Jordan et al., 2001). Die vesikulären Strukturen fusionieren entweder mit Lysosomen und die Connexine werden dort von lysosomalen Enzymen degradiert, oder sie werden über das UbiquitinProteasom-System abgebaut (Laing und Beyer, 1995; Musil et al., 2000; Qin et al., 2003). Die Phosphorylierung von Connexinen scheint eine große Rolle bei der Degradation zu spielen. Es wurde festgestellt, dass Mutanten von Cx45 und Cx31, bei denen gezielt phosphorylierbare Serinreste ausgetauscht worden waren, schneller abgebaut wurden als das Wildtyp-Protein (Diestel et al., 2004; Hertlein et al., 1998).

\subsubsection{Connexin 46.6/Gap Junction Protein $\alpha 12$ (GJA12)}

Das humane Connexin 46.6/GJA12-Gen ist auf dem Chromosom 1q41-q42 lokalisiert und wird in der Literatur auch als Cx47 und GJC2 bezeichnet. In dieser Arbeit wird hauptsächlich die Bezeichnung Connexin 46.6 (Cx46.6) verwendet. Das Cx46.6-Gen besteht aus zwei Exons, wobei das zweite Exon den kodierenden Bereich beinhaltet und eine Größe von 1320 bp besitzt. Das 
Protein besteht dementsprechend aus 439 Aminosäuren. Die Expression von Cx46.6-mRNA in Mäusen erreicht ein hohes Niveau im Rückenmark und Gehirn. In der Retina, in Herzund in Lungengewebe wurden keine Cx46.6-Transkripte nachgewiesen (Teubner et al., 2001). In humanen Gehirnbereichen und im Rückenmark wird das Cx46.6 hoch exprimiert. Deutlich geringere Mengen an Cx46.6-mRNA Transkripten wurden im PNS (Nervus ischiadicus und Nervus suralis) quantifiziert (Uhlenberg et al., 2004). Im ZNS von Primaten wird das Cx46.6 in Oligodendrozyten exprimiert (Orthmann-Murphy et al., 2007b).

Anatomische und funktionelle Studien des Säugetier-ZNS haben gezeigt, dass Astrozyten und Oligodendrozyten durch Gap Junctions verbunden sind und so das panglial syncytium bilden (Mugnaini, 1986; Orthmann-Murphy et al., 2008). Über die Hälfte der 20 in Säugetieren exprimierten Connexine werden im Nervensystem in Astrozyten, Oligodendrozyten, Schwannzellen und Neuronen gebildet (Nagy et al., 2004). Zahlreiche Gap Junctions bilden sich zwischen Astrozyten (A/A) aus, einige zwischen Astrozyten und Oligodendrozyten (A/O) und sehr wenige oder fast keine zwischen Oligodendrozyten (O/O; Orthmann-Murphy et al., 2007b).

Humane Oligodendrozyten Connexine wie Cx46.6 (GJA12) oder Cx32 (GJB1) scheinen essentiell für die Erhaltung von Myelin zu sein, da Mutationen im Cx46.6 oder auch im Cx32 Myelinerkrankungen, wie PMLD (Uhlenberg et al., 2004) oder die Charcot-Marie-Tooth Erkrankung (CMTX1; Scherer und Kleopa, 2005), verursachen. Kanäle zwischen Astrozyten werden durch homotypische Cx43/Cx43 und Cx30/Cx30 Verbindungen gebildet. Heterotypische Kanäle zwischen Astrozyten und Oligodendrozyten entstehen überwiegend aus Cx43/Cx46.6 und Cx30/Cx32 und eventuell auch aus Cx26/Cx32 Gap Junctions (Altevogt und Paul, 2004; Li et al., 2004; Nagy et al., 2003; Orthmann-Murphy et al., 2007b; Rash et al., 2001).

Eine transgene GJA12/Cx46.6-knockout Maus zeigt, dass das Fehlen des Connexin 46.6 nur eine minimale Beeinträchtigung der ZNS-Myelinisierung zur Folge hat. Die Maus weist keinen mit der menschlichen PMLD vergleichbaren Phänotyp auf (Menichella et al., 2003; Odermatt et al., 2003). Eine Cx32/Cx46.6-doppelt-defiziente Maus zeigt dagegen eine stark beeinträchtigte Myelinisierung im ZNS. Die Myelinisierung der peripheren Nerven scheint nicht betroffen zu sein (Odermatt et al., 2003). Werden diese beiden Connexine der Oligodendrozyten ausgeschaltet, kommt es in der Maus zu einem Myelinisierungsdefekt. Der Verlust des Cx46.6 kann offenbar im Mausmodell durch das Cx32 kompensiert werden (Menichella et al., 2003). 


\subsection{CLminusM/RNASET2 defiziente zystische Leukoenzephalopathie}

Die zystische Leukoenzephalopathie ohne Megalenzephalie (CLminusM; Henneke et al., 2005), im späteren Verlauf dieser Arbeit auch als RNASET2 defiziente zystische Leukoenzephalopathie bezeichnet, gehörte lange zu den in ihrer Ursache unklaren, als Krankheitsentität definierten, zystischen Leukoenzephalopathien. Die Patienten sind bei Geburt zunächst asymptomatisch, fallen aber in der Regel in den ersten 12 Lebensmonaten durch eine verzögerte psychomotorische Entwicklung und eine Bewegungsstörung auf. Die Erkrankung ist nicht progredient im Sinne eines raschen Verlusts bereits erlernter Fähigkeiten. Familien mit mehr als einem betroffenen Kind konsanguiner Eltern führten zu der Annahme, dass die Erkrankung autosomal rezessiv vererbt wird (Henneke et al., 2005).

Die Patienten weisen ein spezifisches kernspintomographisches Muster auf mit bilateralen anterioren Temporalzysten, sowie periventrikulär und unmittelbar an die Zysten angrenzenden leukodystrophischen Veränderungen. Computertomographie-Analysen (CT) zeigen bei einigen Patienten intrakraniale Kalkablagerungen. Andere bekannte Ursachen für bilaterale Temporalzysten mit oder ohne Leukoenzephalopathie wie z.B. congenitale Rubella Infektionen (Rötelvirus; Stadlan und Sung, 1967) oder CMV Infektionen (Cytomegalievirus; Steinlin et al., 1996) konnten als Krankheitsursache ausgeschlossen werden.

Zur Untersuchung der Ursache der CLminusM wurde in Vorarbeiten unserer Arbeitsgruppe eine genomweite Kopplungsanalyse an zwei konsanguinen türkischen Familien mit jeweils zwei betroffenen Kindern durchgeführt. Dies führte zunächst zur Identifikation eines Krankheitslokus auf Chromosom 6q26-27 und schließlich innerhalb dieses Lokus zur Identifikation des RNASET2-Gens als Krankheitsgen. Im Rahmen dieser Arbeit wurde der genetische Defekt der CLminusM weiter charakterisiert.

\subsubsection{Ribonukleasen}

Ribonukleinsäuren sind essentielle Bestandteile aller lebenden Zellen. Ribosomale, Boten (messenger)- und Transfer-RNAs sind die primären Produkte der Genexpression und haben eine zentrale Rolle in der Proteinbiosynthese. Kleine RNA-Moleküle (small nuclear und nucleolar RNA), die RNA-Komponente der Telomerase und si(small interfering)-RNAs sind an der RNAProzessierung, der DNA-Replikation, der endogenen Regulation der Genexpression und an der Pathogenabwehr beteiligt. 
Im zellulären RNA-Metabolismus übernehmen ribonukleolytische Enzyme, die Ribonukleasen (RNasen), wesentliche Funktionen. Sie sind ubiquitär vorkommende Enzyme, die die Spaltung von Phosphodiesterbindungen im Ribose-Phosphat-Rückgrat der RNA-Moleküle katalysieren. RNasen spielen eine Schlüsselrolle bei vielen zellulären Funktionen, wie zum Beispiel bei der DNA-Replikation, der Transkription, der RNA-Prozessierung, dem Splicing, dem RNA-Editing oder der Translationskontrolle (Deutscher, 1988). Sie können Einzelstrang-RNA, DoppelstrangRNA und RNA-DNA-Hybride hydrolysieren (Irie, 1999).

Die meisten der klassischen einzelstrangspezifischen RNasen können in drei Familien eingeteilt werden: RNase A-, RNase T1- und RNase T2- Familie (Deshpande und Shankar, 2002; Raines, 1998; Yoshida, 2001). Ribonukleasen der RNase A-Familie sind pyrimidinspezifische, basische, überwiegend in Vertebraten gefundene Hydrolasen, während die basischen Enzyme der T1Familie mikrobieller Herkunft und hauptsächlich guanosinspezifisch sind. Die RNase T2-Familie bildet eine relativ heterogene Gruppe unspezifischer, saurer RNasen mit sowohl mikrobiellen Vertretern, als auch Vertretern in höheren Organismen, wie Pflanzen oder Tieren (Irie, 1999). Das einzige humane Mitglied dieser Proteinfamilie von sauren Hydrolasen ist die RNASET2 (Trubia et al., 1997).

\subsubsection{Familie der T2-Typ RNasen}

Die RNasen der T2-Familie sind saure Endoribonukleasen mit Spezifität für EinzelstrangRNA, die 3'-phosphorylierte Nukleotide freisetzen. Ein Kennzeichen der Enzymkatalyse ist die Unspezifität in Bezug auf die zu spaltenden Basen. Das katalytische pH-Optimum liegt bei vier bis fünf. Die molekulare Masse der T2-Typ RNasen liegt im Bereich von etwa 20 bis $40 \mathrm{kDa}$ (Deshpande und Shankar, 2002).

Die meisten RNasen der T2-Familie sind Glykoproteine und zeigen eine große Variation der Glykosylierungsanzahl. Nur die RNaseRh (Komiyama und Irie, 1971), die RNaseLE2 (Kobayashi et al., 1998; Shimada et al., 1991) und die RNaseLE (Jost et al., 1991) werden nicht glykosyliert. Im Allgemeinen sind die RNasen der T2-Familie N-glykosyliert. Die Konsensussequenz einer N-Glykosylierung lautet Asn-X-Thr/Ser. Eine O-Glykosylierung wurde bisher nur bei der RNaseLE37 und LE45 in Lentinus edodes nachgewiesen (Inokuchi et al., 2000).

Die für die Familie namensgebende RNaseT2 wurde ursprünglich aus Aspergillus oryzae isoliert (Kawata et al., 1988). Es folgte die Charakterisierung der homologen Enzyme RNaseRh aus Rhizopus niveus (Horiuchi et al., 1998) und RNaseM aus Aspergillus saitoi (Watanabe et al., 1990). Gemeinsames Kennzeichen der Primärstrukturen aller T2-Typ RNasen sind zwei hoch konservierte Peptidsequenzen (Conserved Active site $\mathbf{S}$ egments, CASI und CAS II), in denen die katalytisch wichtigen Aminosäuren enthalten sind (Irie, 1997). Die Aminosäuren des aktiven 
Zentrums sind His-46, His-104, Glu-105, Lys-108 und His-109, während Trp-49, Asp-51 und Tyr-57 an der Bindung der Base beteiligt sind (Irie, 1999).

Die T2-Typ RNasen gehören zum $\alpha+\beta$ Strukturtyp (Aravind und Koonin, 2001). Zwei in allen RNasen konservierte Disulfidbrücken (8C-9C und 11C-14C) sind von grundlegender Bedeutung für den Erhalt der aktiven Konformation. Hinsichtlich der Zahl und Lage weiterer S-S-Bindungen bestehen deutliche Unterschiede zwischen den RNasen aus Pilzen, Tieren und Pflanzen. RNasen aus Pilzen haben im Allgemeinen zehn, bakterielle RNasen sechs und tierische sowie pflanzliche RNasen acht Cystein-Reste (Irie, 1999).

Die subzelluläre Lokalisation der T2-Typ RNasen ist sehr verschieden. Sie umfasst sekretorische, lysosomale, nukleare und zytoplasmatische Enzyme (Deshpande und Shankar, 2002; Irie, 1999). Aufgrund der verschiedenen, zum Teil unerwarteten Lokalisationen der RNasen wird davon ausgegangen, dass sie neben der Ribonuklease-Aktivität noch andere Funktionen haben (Campomenosi et al., 2006). Obwohl die biologische Funktion vieler extrazellulär lokalisierter RNasen anhand der Lokalisation und des Genexpressionsverhaltens postuliert wurde, ist die zelluläre Rolle dieser Enzyme im Allgemeinen ungeklärt (MacIntosh et al., 2001). Ihnen wird eine Metabolisierung externer RNA-Quellen zugeschrieben wie z.B. den sekretierten Enzymen aus Pilzen und der periplasmatischen RNase I aus E. coli (Deshpande und Shankar, 2002). Diese Genfunktion ist für E.coli nicht essentiell, da RNase I- Stämme mit deletiertem rna-Gen lebensfähig sind und auch die Überexpression nicht toxisch ist (Nicholson, 1997). Für die RNY1, die einzige T2-Typ RNase von Saccharomyces cerevisiae, wird eine Beteiligung an der Regulation der Membranpermeabilität oder -stabilität vermutet. Die Genexpression wird durch Hitzeschock und Osmotischen Stress kontrolliert (MacIntosh et al., 2001).

\subsubsection{Die humane RNASET2}

Das RNASET2-Gen kodiert das Glykoprotein RNASET2, das einzige humane Mitglied der Typ-2 Familie der RNasen (Trubia et al., 1997). Drei mutmaßliche Glykosylierungspositionen sind vorhanden (AS 76, 106, 212). Das RNASET2-Gen ist auf dem Chromosom 6q27 lokalisiert und besteht aus neun Exons, die einen kodierenden Bereich von 771 Nukleotiden und 256 Aminosäuren umfassen. Die RNASET2-cDNA-Sequenz kodiert wie z.B. die RNaseLE für Nterminale 24 Aminosäuren umfassende Signalsequenzen zum kotranslationalen Transport in das Endoplasmatische Retikulum (Campomenosi et al., 2006; Köck et al., 1995).

Die physiologische Funktion der humanen RNASET2 ist weitestgehend unklar. Eine lysosomale (saure Ribonuklease) und eine sekretorische Aktivität wird angenommen. Eine Lokalisation des RNASET2-Proteins im Lysosom wurde von Campomenosi et al. (2006) durch subzelluläre Fraktionierung und Markerenzym-Untersuchungen gezeigt. Die Autoren vermu- 
ten, dass die RNASET2 während des Transports zum Lysosom oder nach dem Transport ins Lysosom proteolytisch prozessiert wird und somit das "Volle-Länge Protein" nur im sekretorischen Weg entsteht. Für das sekretierte Glykoprotein sind eine T2-Typ-RNase-Aktivität, eine Tumor- und Metastasen-suppremierende Wirkung und ein Antiangiogenese-Effekt beschrieben (Acquati et al., 2005; Smirnoff et al., 2006). In primären Ovarialkarzinom-Zellen wurde eine signifikante Reduktion der RNASET2-Expression beobachtet, Mutationen wurden nicht nachgewiesen (Acquati et al., 2001; Liu et al., 2002).

\subsection{Zielsetzung}

Im Rahmen der vorliegenden Arbeit sollte ein Beitrag zur Aufklärung der Pathomechanismen von zwei humanen Leukoenzephalopathien, der GJA12-assoziierten PMLD und der CLminusM/RNASET2 defizienten zystischen Leukoenzephalopathie geleistet werden.

Von Uhlenberg et al. wurde 2004 das Connexin 46.6/GJA12 als neues Krankheitsgen einer PMLD identifiziert. Eine große Kohorte von Patienten mit unklaren Leukoenzephalopathien, die anhand der klinischen und radiologischen Kriterien der PMLD zugeordnet wurden, sollte in dieser Arbeit auf mögliche Connexin 46.6-Mutationen untersucht werden. Des Weiteren sollten funktionelle Auswirkungen bestimmter Mutationen auf die Gap Junction vermittelte Kommunikation näher charakterisiert werden, um Aussagen zum Pathomechanismus der GJA12-assoziierten PMLD zu treffen.

Der genetische Defekt der CLminusM sollte basierend auf Ergebnissen aus Vorarbeiten unserer Arbeitsgruppe genauer charakterisiert werden. In diesen Vorarbeiten wurde ein die Erkrankung verursachendes Gen, das RNASET2-Gen, in vier Patienten aus zwei Familien identifiziert. Weitere Patienten, die die Kriterien zur Diagnose der CLminusM erfüllten, waren im Rahmen dieser Arbeit auf RNASET2-Mutationen zu untersuchen. Weiterhin sollte das RNASET2 WildtypProtein sowie die neu identifizierten RNASET2-Mutanten in Patientenzellen und im Zellmodell näher charakterisiert werden. Hierdurch sollte die Rolle der RNASET2 in der Pathogenese der CLminusM/RNASET2 defizienten zystischen Leukoenzephalopathie sowie in der Gehirnentwicklung allgemein einschließlich der Myelinisierungsprozesse besser verstanden werden. 


\section{Material}

\subsection{Geräte}

Analysewaage Typ L2200P

Binokular Stemi CV8

BioPhotometer

Brutschrank, Typ 400 HY

Elektrodenhalter (Spannung) ESW-F15V

Elektrodenhalter (Strom) E45W

Faraday-Käfig

Fastblot B 43

Heizblock Thermomixer Compact

iQ 5 Cycler

Kaltlichtlampe KL 1500 electronic

Kapillarziehgerät PE-2

Luminescent Image Analyzer, Typ LAS-4000 mini

Mikrobiologische Sicherheitswerkbank HERA safe

Mikroinjektor Nanoliter 2000

Mikromanipulatoren Modell M

Mikropipetten (20, 100, 200, $1000 \mu \mathrm{l})$

Mikroskop, Nikon, Typ Eclipse TS100

Mikroskop, Typ Axio Imager M.1

Mikrowellenherd

Mikrozentrifuge, Typ 5415 D

Mikrozentrifuge, Typ MIKRO 200 R

Mini-Protean Tetra Elektrophorese System

Oozyten Voltage Clamp Verstärker OC-725C

pH-Meter Typ InoLab

RC-5 Superspeed Kühl-Zentrifuge
Sartorius, Göttingen

Zeiss, Göttingen

Eppendorf, Hamburg

Bachofer, Reutlingen

Warner, Hambden CT, USA

Warner, Hambden CT, USA

Eigenbau der Institutswerkstatt

Biometra, Göttingen

Eppendorf, Hamburg

BioRad, San Jose, USA

Schott, Mainz

Narishige, Japan

Fujifilm, Düsseldorf

Thermo Fisher Scientific, Schwerte

WPI, Sarasota, FL, USA

Leitz, Wetzlar

Gilson, Middelton, USA

Nikon GmbH, Düsseldorf

Carl Zeiss, Göttingen

Siemens, München

Eppendorf, Hamburg

Hettich Zentrifugen, Tuttlingen

Bio-Rad, San Jose, USA

Warner, Hambden CT, USA

WTW, Weilheim

Thermo Fisher Scientific, Schwerte 
Röntgenfilmentwickler Optimax, Typ TR

Schüttelinkubator, Typ Ecotron

Spannungsgerät 2301 Macrodrive

SS-34/GSA-Rotoren für Sorvall-Zentrifuge

T300 Thermocycler

Tischkühlzentrifuge, Typ ROTANTA/R

Tischzentrifuge, Typ UNIVERSAL 320

Ultra pure water system, Typ Milli Q Plus

Ultraschallprozessor

Vortex Genie 2

Zellkulturinkubator HERAcell 150

Zweikanalschreiber BD 112
MS Laborgeräte, Wiesloch

Infors HAT, Bottmingen, Schweiz

LKB, Gräflingen

Thermo Fisher Scientific, Schwerte

Biometra, Göttingen

Hettich Zentrifugen, Tuttlingen

Hettich Zentrifugen, Tuttlingen

Millipore, Schwalbach

Hielscher Ultrasonics GmbH, Teltow

Bender \& Hobbein, Zürich, Schweiz

Thermo Fisher Scientific, Schwerte

Kipp und Zonen, Delft, Niederlande

\subsection{Chemikalien}

Die Chemikalien wurden von den Firmen Braun (Melsungen), Bio-Rad (San Jose, USA), Merck (Darmstadt), Roth (Karlsruhe) und Sigma (Deisenburg) im Reinheitsgrad pro analysis bezogen.

\subsection{Restriktionsendonukleasen und Standards}

\section{Material}

Ampicillin

dNTP-Set

Gene Ruler ${ }^{\mathrm{TM}}$ DNA Ladder Mix

Kanamycin

Pfu DNA Polymerase, $3 \mathrm{U} / \mu \mathrm{l}$

Prestained ProSieve Protein Marker

Protease-Inhibitor Cocktail Tabletten

Restriktionsendonukleasen

RNase A, $10 \mathrm{mg} / \mathrm{ml}$

Taq-DNA Polymerase, $5 \mathrm{U} / \mathrm{\mu l}$

\section{Hersteller}

Sigma, Deisenburg

Peqlab, Erlangen

Fermentas, St. Leon-Rot

Invitrogen, Karlsruhe

Promega, Mannheim

Lonza, Köln

Roche, Mannheim

New England Biolabs, Frankfurt

Calbiochem, Frankfurt

Qiagen, Hilden 


\subsection{Kits zur Bearbeitung von DNA/RNA}

Kit

BigDye Terminator v3.1 Cycle Sequencing Kit

DNeasy ${ }^{\circledR}$ Blood\&Tissue Kit

Effectene Transfection Reagent

FlipFlop Site-Directed Mutagenesis Kit

High Pure PCR Purification Kit

iScript cDNA Synthesis Kit

iQ SYBR Green Supermix

Ligate-IT ${ }^{\mathrm{TM}}$ Rapid Ligation Kit

mMESSAGE mMACHINE ${ }^{\circledR}$ SP6 Kit

NucleoBond ${ }^{\circledR}$ Plasmid Kit

NucleoBond ${ }^{\circledR}$ Xtra Midi Kit

NucleoSpin ${ }^{\circledR}$ Extract II

pGEM ${ }^{\circledR}$ T-Easy Vector System I

SuperScript ${ }^{\circledR}$ III First-Strand Synthesis Kit
Hersteller

Applied Biosytems, Forster City, USA

Qiagen, Hilden

Qiagen, Hilden

Bioline, Luckenwalde

Roche, Mannheim

BioRad, Hercules, USA

BioRad, Hercules, USA

Usb, Cleveland Ohio, USA

Ambion, Austin, TX, USA

Macherey-Nagel, Düren

Macherey-Nagel, Düren

Macherey-Nagel, Düren

Promega, Mannheim

Invitrogen, Karlsruhe

\subsection{Antikörper und Immunreagenzien}

Die folgenden primären und sekundären Antikörper sowie Immunreagenzien wurden in dieser Arbeit verwendet. In der Tabelle sind die Bezeichnung der Antikörper, die Herkunft und der Verwendungszweck, einschließlich der eingesetzten Verdünnung, aufgeführt. Die Kleinbuchstaben vor den Antikörpernamen geben das jeweilige Tier an, aus dem die Antikörper gewonnen wurden oder gegen welches sie gerichtet sind ( $d=$ Esel; $g=$ Ziege; $m=$ Maus; $r=$ Kaninchen).

Tabelle 2.1.: Übersicht der eingesetzten Antikörper mit ihrer jeweiligen Verdünnung

\begin{tabular}{llll}
\hline Antikörper & \multicolumn{3}{c}{ Verdünnung } \\
\hline Primärantikörper & Hersteller/Quelle & Western Blot & Zytochemie \\
\hline m- $\alpha$ COXIV & Abcam & - & $1: 200$ \\
m- $\alpha$ GAPDH & Abcam & $1: 5000$ & - \\
m- $\alpha$ 58K Golgi Protein & Abcam & - & $1: 250$ \\
m- $\alpha$ LAMP-1 (CD107a) & BD Biosciences & - & $1: 1000$ \\
m- $\alpha$ Myc-Tag & CellSignaling & $1: 1000$ & $1: 200$ \\
\hline
\end{tabular}




\begin{tabular}{llll}
\hline Antikörper & & Verdünnung & \\
\hline Primärantikörper & Hersteller/Quelle & Western Blot & Zytochemie \\
\hline r- $\alpha$ Myc-Tag & SantaCruz & - & $1: 200$ \\
m- $\alpha$ Pan-Cadherin & Abcam & - & $1: 1000$ \\
m- $\alpha$ PDI (RL90) & Abcam & - & $1: 200$ \\
m- $\alpha$ Tubulin & Sigma & $1: 50000$ & - \\
r- $\alpha$ Connexin 46.6 & Seramun & $1: 10000$ & $1: 2000$ \\
r- $\alpha$ RNASET2 & Seramun & $1: 20000$ & $1: 2000$ \\
\hline Sekundärantikörper & Hersteller/Quelle & Western Blot & Zytochemie \\
\hline HRP-d- $\alpha$ mIgG & Jackson Immuno & $1: 50000$ & - \\
& Research & & \\
HRP-g- $\alpha$ rIgG & Jackson Immuno & $1: 5000$ & - \\
& Research & & $1: 1000$ \\
Alexa Fluor ${ }^{\circledR} 488-g-\alpha$ mIgG & Molecular Probes & - & $1: 1000$ \\
Alexa Fluor ${ }^{\circledR} 488-d-\alpha$ rIgG & Molecular Probes & - & $1: 1000$ \\
Cy ${ }^{\text {TM }} 3$-g- $\alpha$ rIgG & Jackson Immuno & - & \\
Cy ${ }^{\text {TM } 3-g-~} \alpha$ mIgG & Research & & $1: 1000$ \\
\hline Immunreagenzien & Jackson Immuno & - & \\
\hline Glutathion Sepharose ${ }^{\text {TM }} 4 \mathrm{~B}$ & GE Healthcare & $80 \%$ ige Suspensionslösung \\
\hline
\end{tabular}

\subsection{Bakterienstämme, Zelllinien und Tiere}

Tabelle 2.2.: Übersicht der verwendeten Bakterienstämme, Zelllinien und Tiere

\begin{tabular}{|c|c|c|}
\hline & Name & Herkunft \\
\hline \multirow[t]{4}{*}{ Bakterienstamm } & E.coli BIOblue & Bioline \\
\hline & E.coli BL21 & Bioline \\
\hline & E.coli BL21 codon plus & Stratagene \\
\hline & E.coli XL10-Gold ${ }^{\mathrm{TM}}$ & Stratagene \\
\hline \multirow[t]{4}{*}{ Zelllinien } & HEK 293 & DSMZ Nr.: ACC 305 \\
\hline & (human embryonic kidney) & \\
\hline & HeLa & DSMZ Nr.:ACC 57 \\
\hline & (humane Zervix-Karzinom-Zellen) & \\
\hline
\end{tabular}




\begin{tabular}{ll}
\hline Name & Herkunft \\
\hline JK-10 & EBV-immortalisierte \\
& Kontroll-Lymphozyten
\end{tabular}

\section{Familie 1}

JL-09

JL-11

JL-22

JL-15

JL-19

JL-21

Familie 3

Familie 2

JL-13
EBV-immortalisierte

Patienten-Lymphozyten

(Ind. 326)

EBV-immortalisierte

Patienten-Lymphozyten

(Ind. 327)

EBV-immortalisierte

Patienten-Lymphozyten

(Ind. 330)

EBV-immortalisierte

Patienten-Lymphozyten

(Ind. 37)

EBV-immortalisierte

Patienten-Lymphozyten

(Ind. 28)

EBV-immortalisierte

Patienten-Lymphozyten

(Ind. 36)

EBV-immortalisierte

Patienten-Lymphozyten

(Ind. 35)

EBV-immortalisierte

Patienten-Lymphozyten

(Ind. 4483)

Tiere

Xenopus laevis Weibchen
Nasco (Fort Atkinson in

Wisconsin, USA)

Die lymphoblastoiden Zelllinien wurden mittels Standardmethoden der EBV (Epstein-Barr-Virus) Transfektion freundlicherweise vom Institut für Humangenetik in Bonn hergestellt.

Ind=Individuum 


\subsection{Puffer und Nährmedien}

\subsubsection{Häufig verwendete Puffer und Stammlösungen}

5x DNA-Ladepuffer (Orange G): 15\% Ficoll 400; 200 mM EDTA; 0,1\% Orange G

PBS: $140 \mathrm{mM} \mathrm{NaCl} ; 2,5 \mathrm{mM} \mathrm{KCl} ; 6,5 \mathrm{mM} \mathrm{Na}_{2} \mathrm{HPO}_{4} ; 1,5 \mathrm{mM} \mathrm{K}_{2} \mathrm{HPO}_{4} ; \mathrm{pH} 7,4$

PBST: PBS + 0,1\%(v/v) Tween-20

TAE-Puffer: 40 mM Tris-HCl pH 8,0; 0,1\% (v/v) Eisessig; 1 mM EDTA pH 8,0

TBE: 89 mM Tris-Base; 89 mM Borsäure; 0,2 M EDTA pH 8,0

TBS: $20 \mathrm{mM}$ Tris-HCl pH 7,5; $150 \mathrm{mM} \mathrm{NaCl}$

TBST: TBS + 0,1\% (v/v) Tween-20

TE: 10 mM Tris-HCl pH 8,0; 1 mM EDTA

\subsubsection{Denaturierendes RNA-Gel}

10x Laufpuffer: $200 \mathrm{mM}$ MOPS

$50 \mathrm{mM}$ Natrium-Acetat

$10 \mathrm{mM}$ EDTA

pH 7,0; Lagerung lichtgeschützt

Ladepuffer: $\quad$ 0,025\% Bromphenolblau

1,75 ml DEPC-Wasser

$4 \mathrm{ml}$ Formamid (40\%)

$2 \mathrm{ml}$ Formaldehyd (20\%)

$2 \mathrm{ml}$ 10x Laufpuffer (20\%) 


\subsubsection{SDS-Polyacrylamid-Gelelektrophorese}

\section{Herstellung von Trenn- und Sammelgel}

Es wurden je nach Experiment kleine $(10 \mathrm{~cm} \times 7 \mathrm{~cm})$ und große SDS-Gele $(16 \mathrm{~cm} \mathrm{x} 15 \mathrm{~cm})$ mit unterschiedlichen Polyacrylamid-Konzentrationen (8-15\%) verwendet. Die Angaben in Tabelle 2.3 und 2.4 beziehen sich auf ein Gesamtvolumen von $10 \mathrm{ml}$. Die Sammelgele wurden mit einem Anteil von 5\% Polyacrylamid hergestellt.

Tabelle 2.3.: Übersicht der Lösungen zur Herstellung verschiedener Trenngele

\begin{tabular}{lcccc}
\hline & \multicolumn{4}{c}{ Polyacrylamid-Konzentration } \\
\hline Trenngelbestandteile & $8 \%$ & $10 \%$ & $12 \%$ & $15 \%$ \\
\hline $\mathrm{H}_{2} \mathrm{O}$ & $4,6 \mathrm{ml}$ & $4,0 \mathrm{ml}$ & $3,3 \mathrm{ml}$ & $2,3 \mathrm{ml}$ \\
$30 \%$ Acrylamidlösung $(37,5: 1)$ & $2,7 \mathrm{ml}$ & $3,3 \mathrm{ml}$ & $4,0 \mathrm{ml}$ & $5,0 \mathrm{ml}$ \\
$1,5 \mathrm{M}$ Tris- $\mathrm{HCl}(\mathrm{pH} 8,8)$ & $2,5 \mathrm{ml}$ & $2,5 \mathrm{ml}$ & $2,5 \mathrm{ml}$ & $2,5 \mathrm{ml}$ \\
$10 \%$ SDS & $100 \mu \mathrm{l}$ & $100 \mu \mathrm{l}$ & $100 \mu \mathrm{l}$ & $100 \mu \mathrm{l}$ \\
$10 \%$ Ammoniumpersulfat & $100 \mu \mathrm{l}$ & $100 \mu \mathrm{l}$ & $100 \mu \mathrm{l}$ & $100 \mu \mathrm{l}$ \\
TEMED & $6 \mu \mathrm{l}$ & $4 \mu \mathrm{l}$ & $4 \mu \mathrm{l}$ & $4 \mu \mathrm{l}$ \\
\hline
\end{tabular}

Tabelle 2.4.: Übersicht der Lösungen zur Herstellung des Sammelgels

\begin{tabular}{lc}
\hline Sammelgelbestandteile & \\
\hline $\mathrm{H}_{2} \mathrm{O}$ & $6,8 \mathrm{ml}$ \\
$30 \%$ Acrylamidlösung $(37,5: 1)$ & $1,7 \mathrm{ml}$ \\
$1,0 \mathrm{M}$ Tris- $\mathrm{HCl}(\mathrm{pH} 6,8)$ & $1,25 \mathrm{ml}$ \\
$10 \%$ SDS & $100 \mu \mathrm{l}$ \\
$10 \%$ Ammoniumpersulfat & $100 \mu \mathrm{l}$ \\
TEMED & $10 \mu \mathrm{l}$ \\
\hline
\end{tabular}

\section{Lösungen und Puffer}

Coomassie-Färbe-Lösung: 0,2\% Brilliant Blue G-250; 10\% Essigsäure; 30\% Isopropanol

Coomassie-Entfärbe-Lösung: 10\% Essigsäure; 20\% Isopropanol; $70 \% \mathrm{H}_{2} \mathrm{O}$

Ponceau S-Färbelösung: 15\% (v/v) Essigsäure; 30\% (v/v) Methanol; 0,25\% (w/v) Ponceau S 
SDS-Laufpuffer: 25 mM Tris-Base; 190 mM Glycin; 0,1\% (w/v) SDS

4x SDS-Probenpuffer (Laemmli): 160 mM Tris-HCl pH 6,8; 140 mM SDS; 20\% (v/v) Glycerin; 1 Spatelspitze Bromphenolblau; $40 \mathrm{mg} / \mathrm{ml}$ DTT

Semidry Transferpuffer: $150 \mathrm{mM}$ Glycin; $25 \mathrm{mM}$ Tris-Base; 0,04\% (w/v) SDS; 20\% (v/v) Methanol

\subsubsection{Medien für Bakterienkulturen}

LB-Medium: 1\% (w/v) Trypton, 0,5\% (w/v) Hefeextrakt, 1\% (w/v) NaCl

LB-Platten: LB-Medium + 1,5\% (w/v) Agar (bei Bedarf mit Zusatz von 100 pg/ml Ampicillin oder $25 \mu \mathrm{g} / \mathrm{ml}$ Kanamycin)

\subsubsection{Medien für Zellkulturen}

Dulbecco's Modified Eagle Medium (DMEM): 10\% (v/v) FKS, 1 mM Natrium-Pyruvat, $2 \mathrm{mM}$ L-Glutamin, $100 \mathrm{U} / \mathrm{ml}$ Penicillin, $100 \mu \mathrm{g} / \mathrm{ml}$ Streptomycin

Einfriermedium: 70\% (v/v) DMEM , 20\% (v/v) FKS, 10\% (v/v) DMSO

RPMI-1640: 25\% FKS, 2 mM L-glutamine, 1\% Phytahemagglutinin-L, 100 U/ml Penicillin, $100 \mu \mathrm{g} / \mathrm{ml}$ Streptomycin

Dulbecco's PBS, DMEM, RPMI-1640, die Medium-Zusätze und die Trypsin-EDTA-Lösung wurden von der Firma PAA Laboratories GmbH (Pasching, Österreich) bezogen. Das FKS wurde von der Biochrom $A G$ (Berlin) geliefert.

\subsubsection{Medien für Xenopus laevis Oozyten}

Oozyten-Ringer (ORI): $110 \mathrm{mM} \mathrm{NaCl}, 3 \mathrm{mM} \mathrm{KCl,} 2 \mathrm{mM} \mathrm{CaCl} 2,5 \mathrm{mM}$ Hepes, pH-Wert 7,5 (mit Tris eingestellt)

Aufbewahrungsmedium: Oozyten-Ringer mit 0,55 mg/ml Na ${ }^{+}$-Pyruvat, $50 \mu \mathrm{g} / \mathrm{ml}$ Gentamycin 


\subsection{Plasmide und Oligonukleotide}

In der folgenden Tabelle sind die kommerziell erhältlichen Ausgangsvektoren und die im Rahmen dieser Arbeit konstruierten Plasmide aufgelistet. Angegeben sind die Bezeichnungen der Vektoren, die Herkunft bzw. der klonierte Sequenzbereich sowie die GenBank-Zugriffsnummer der inserierten Sequenzen (Biotechnologie Server NCBI; www.ncbi.nlm.nih.gov). Weiterhin aufgelistet ist der Verwendungszweck bzw. die eventuelle Mutationsbezeichnung. Durch Restriktionsverdau (3.1.9) und Sequenzanalyse (3.1.14) wurde die Identität der konstruierten Plasmide verifiziert. Die zur Klonierung verwendeten Oligonukleotide wurden von der Firma Metabion (Martinsried) bezogen und sind im Anhang (Tabelle A.1 und A.2) aufgelistet.

Tabelle 2.5.: Übersicht der verwendeten Ausgangsvektoren und konstruierten Plasmide

\begin{tabular}{|c|c|c|}
\hline Ausgangsvektoren & Herkunft & Verwendungszweck \\
\hline pcDNA3.1 $(+)$ & Invitrogen & $\begin{array}{l}\text { eukaryontischer Expressions- } \\
\text { vektor }\end{array}$ \\
\hline pcDNA3.1/myc-His $(-) B$ & Invitrogen & $\begin{array}{l}\text { eukaryontischer Expressions- } \\
\text { vektor }\end{array}$ \\
\hline $\mathrm{pCS} 2+$ & $\begin{array}{l}\text { zur Verfügung gestellt } \\
\text { vom Adolf-Butenand } \\
\text { Institut, Prof. Rupp }\end{array}$ & $\begin{array}{l}\text { eukaryontischer Expressions- } \\
\text { vektor }\end{array}$ \\
\hline pEGFP-N1 & Clontech & $\begin{array}{l}\text { eukaryontischer Expressions- } \\
\text { vektor für EGFP-Fusionspro- } \\
\text { teine (EGFP N-terminal) }\end{array}$ \\
\hline pGEM ${ }^{\circledR} \mathrm{T}$-Easy & Promega & $\begin{array}{l}\text { Klonierung von PCR-Produk- } \\
\text { ten }\end{array}$ \\
\hline pGEX-KG & ATCC & $\begin{array}{l}\text { prokaryontischer Expressions- } \\
\text { vektor für GST-Fusionspro- } \\
\text { teine (GST N-terminal) }\end{array}$ \\
\hline pSPL3 & Gibco (BRL) & $\begin{array}{l}\text { Minigen-Konstrukt zur Ana- } \\
\text { lyse von Spleißdefekten }\end{array}$ \\
\hline
\end{tabular}




\begin{tabular}{|c|c|c|}
\hline konstruierte Plasmide & $\begin{array}{l}\text { cDNA-Bereich, } \\
\text { GenBank-Nummer }\end{array}$ & Mutationsbezeichnung \\
\hline pcDNA3.1(+)-Cx46.6 (1.ATG) & nt1-1320, NM_020435 & \\
\hline pcDNA3.1(+)-Cx46.6-2.ATG & nt10-1320, NM_020435 & \\
\hline pcDNA3.1(+)-Cx46.6P90S & nt1-1320, NM_020435 & Pro90Ser \\
\hline pcDNA3.1(+)-Cx46.6T398I & nt1-1320, NM_020435 & Thr398Ile \\
\hline pcDNA3.1(+)-Cx46.6G149S & nt1-1320, NM_020435 & Gly149Ser \\
\hline pcDNA3.1(+)- & nt1-1320, NM_020435 & Ala98Gly_Val99insThr \\
\hline \multicolumn{3}{|l|}{ Cx46.6A98G_V99insT } \\
\hline pcDNA3.1(+)-Cx46.6G236R & nt1-1320, NM_020435 & Gly236Arg \\
\hline pcDNA3.1(+)-Cx46.6T265A & nt1-1320, NM_020435 & Thr265Ala \\
\hline $\mathrm{pCS} 2(+)-\mathrm{Cx} 46.6$ & nt1-1320, NM_020435 & \\
\hline $\mathrm{pCS} 2(+)-\mathrm{Cx} 46.6 \mathrm{P} 90 \mathrm{~S}$ & nt1-1320, NM_020435 & Pro90Ser \\
\hline pCS2(+)-Cx46.6T398I & nt1-1320, NM_020435 & Thr398Ile \\
\hline pCS2(+)-Cx46.6G149S & nt1-1320, NM_020435 & Gly149Ser \\
\hline $\mathrm{pCS} 2(+)-$ & nt1-1320, NM_020435 & Ala98Gly_Val99insThr \\
\hline \multicolumn{3}{|l|}{ Cx46.6A98G_V99insT } \\
\hline $\mathrm{pCS} 2(+)-\mathrm{Cx} 46.6 \mathrm{G} 236 \mathrm{R}$ & nt1-1320, NM_020435 & Gly236Arg \\
\hline $\mathrm{pCS} 2(+)-\mathrm{Cx} 46.6 \mathrm{~T} 265 \mathrm{~A}$ & nt1-1320, NM_020435 & Thr265Ala \\
\hline pEGFP-N1-Cx46.6 & nt1-1320, NM_020435 & \\
\hline pGEX-KG-Cx46.6-15 & nt310-591, NM_020435 & \\
\hline
\end{tabular}




\begin{tabular}{lll}
\hline konstruierte Plasmide & $\begin{array}{l}\text { cDNA-Bereich, } \\
\text { GenBank-Nummer }\end{array}$ & Mutationsbezeichnung \\
\hline pGEX-KG-RNASET2-19 & nt328-771, NM_003730 & \\
pcDNA3.1/myc(-)B- & nt1-771, NM_003730 \\
RNASET2WT & & \\
pcDNA3.1/His(-)B- & nt1-771, NM_003730 & \\
RNASET2WT & & \\
pcDNA3.1/myc(-)B- & nt1-771, NM_003730 & Cys184Arg \\
RNASET2C184R & & Cys184Arg \\
pcDNA3.1/His(-)B- & nt1-771, NM_003730 & \\
RNASET2C184R & & \\
\hline
\end{tabular}





\section{Methoden}

\subsection{DNA: Molekularbiologische Methoden}

\subsubsection{Konzentrationsbestimmung von Nukleinsäuren}

Die Konzentrationsbestimmung von Nukleinsäuren in wässrigen Lösungen wurde photometrisch (NanoDrop ND-1000, Thermo Scientific) durchgeführt. Dazu wurde die Absorption bei einer Wellenlänge von $260 \mathrm{~nm}\left(\mathrm{OD}_{260}\right)$ gemessen, wobei für die $\mathrm{OD}_{260}$ von 1,0 folgende ReferenzKonzentrationen zugrunde gelegt wurden:

- $50 \mu \mathrm{g} / \mathrm{ml}$ für Doppelstrang-DNA

- $20 \mu \mathrm{g} / \mathrm{ml}$ für Einzelstrang-Oligonukleotide

- $40 \mu \mathrm{g} / \mathrm{ml}$ für RNA

Zusätzlich konnte die Reinheit einer DNA-Lösung durch Bestimmung der optischen Dichte bei einer Wellenlänge von $280 \mathrm{~nm}$ überprüft werden. Für reine DNA gilt:

- $\mathrm{OD}_{260} / \mathrm{OD}_{280}>1,8$ (Sambrook et al., 1989).

Verunreinigungen der DNA durch Proteine oder Phenol sind an einer deutlichen Steigerung der Absorption bei $280 \mathrm{~nm}$ erkennbar.

\subsubsection{Phenol-Chloroform-Isoamylalkohol-Extraktion}

Durch Extraktion einer DNA/RNA-Lösung mit Phenol/Chloroform/Isoamylalkohol (25:24:1; v/v/v) wurden Proteine, Ethidiumbromid oder Reste anderer hydrophober Kontaminationen entfernt. Zur Entfernung des Phenols aus der wässrigen Phase und zur weiteren Denaturierung von Proteinen wurde eine zusätzliche Extraktion mit Chloroform angeschlossen.

Die DNA/RNA-Lösung wurde mit einem Volumen Phenol/Chloroform/Isoamylalkohol bzw. Chloroform versetzt und gründlich gemischt. Anschließend wurde der Ansatz zur Beschleuni- 
gung der Phasentrennung zentrifugiert (fünf Minuten, Raumtemperatur, 16100×g). Die obere, wässrige Phase wurde in ein neues Reaktionsgefäß überführt. Durch eine Ethanol-Präzipitation (3.1.3) wurde die DNA/RNA konzentriert und so von eventuellen Resten der organischen Lösungsmittel befreit.

\subsubsection{Ethanol-Präzipitation}

Die Ethanol-Präzipitation dient zur Überführung von Nukleinsäuren in neue Puffer, zum Ankonzentrieren der Proben oder zur Reinigung.

Die Präzipitation der DNA/RNA-Fragmente erfolgte unter Zugabe von drei Volumen 98\%igem Ethanol und 1/10 Volumen $3 \mathrm{M}$ Na-Acetat-Lösung ( $\mathrm{pH} 4,8)$. Nach gründlicher Durchmischung wurde der Ansatz 20 Minuten bei Raumtemperatur präzipitiert und anschließend 20 Minuten bei $4^{\circ} \mathrm{C}$ und $18620 \times \mathrm{g}$ zentrifugiert. Zur Entfernung von Salzresten wurde das Sediment mit $70 \%$ igem (v/v) Ethanol gewaschen und erneut zentrifugiert (fünf Minuten, Raumtemperatur, $18620 \times \mathrm{g})$. Das DNA-Sediment wurde fünf Minuten luftgetrocknet und anschließend in dem gewünschten Volumen Wasser oder entsprechendem Puffer resuspendiert.

\subsubsection{Polymerase-Kettenreaktion}

Die Polymerase-Kettenreaktion (PCR=Polymerase Chain Reaction) ermöglicht durch selektive Amplifikation die Vervielfältigung kleinster Mengen DNA für analytische bzw. präparative Zwecke in vitro. Dabei wird doppelsträngige DNA hitzedenaturiert, so dass zwei kurze Oligonukleotide bei einer spezifischen Temperatur anlagern können (Annealing), die dann von einer thermostabilen DNA-Polymerase bei $72^{\circ} \mathrm{C}$ verlängert werden (Extension). Die neu synthetisierten Stränge stehen in der nächsten Amplifikationsrunde ebenfalls als Matrize zur Verfügung. So wird die von den Oligonukleotiden eingerahmte Sequenz idealerweise exponentiell vermehrt.

Polymerase-Kettenreaktionen wurden mit thermostabiler Taq- oder Pfu-Polymerase durchgeführt. Für einen Standardansatz von 50 ll wurden jeweils 20 pmol der Oligonukleotide, 10200 ng der Matrizen-DNA, je 20 pmol der dNTPs und 2,5 Units (U) der entsprechenden Polymerase im Reaktionspuffer nach Herstellerangaben verwendet. Für eine Standard-PCR wurde dem PCR-Ansatz zur Amplifikation des GJA12-Gens Betain mit einer Endkonzentration von 1,5 M zugefügt. Dieses Additiv erhöht die PCR-Spezifität und -Effektivität, besonders bei GCreichen Regionen.

Die PCR wurde in einem Thermocycler von Biometra durchgeführt. Auf eine initiale zweiminütige Denaturierung bei $94^{\circ} \mathrm{C}$ folgten 25 bis 30 Zyklen mit jeweils einer Minute Denaturierung 
bei $94^{\circ} \mathrm{C}$, einer Minute Hybridisierung bei der für das Primerpaar spezifischen Temperatur und anschließender Elongation bei $72^{\circ} \mathrm{C}$ mit einer Minute pro Kilobasenpaar für die Taq-Polymerase oder zwei Minuten pro Kilobasenpaar für die Pfu-Polymerase. Die PCR-Zyklen wurden durch einen finalen Syntheseschritt von zehn Minuten bei $72^{\circ} \mathrm{C}$ abgeschlossen und die Reaktion wurde durch Abkühlen auf $4^{\circ} \mathrm{C}$ gestoppt. Die PCR-Produkte wurden in einem Agarosegel analysiert (3.1.6).

\subsubsection{Aufreinigung von PCR-Produkten}

Die Aufreinigung von PCR-Produkten erfolgte mittels High Pure PCR Purification Kit der Firma Roche nach Herstellerangaben. In Anwesenheit eines chaotropen Salzes bindet die DNA selektiv an eine Glasfaser- oder Silica-Matrix. Anschließend wird die gebundene DNA durch eine Reihe von Wasch- und Zentrifugationsschritten von noch vorhandenen Primern, Nukleotiden und Salzen gereinigt. Durch Zugabe eines Puffers mit niedriger Salzkonzentration kann die DNA anschließend wieder eluiert werden (Vogelstein und Gillespie, 1979).

\subsubsection{Mutagenese-PCR}

Für das Setzen von Punktmutationen wurde eine Mutagenese-PCR mit dem FlipFlop SiteDirected Mutagenesis Kit (Bioline) durchgeführt. Das Prinzip dieser PCR basiert auf der Amplifikation des gesamten Plasmids mit einer high fidelity-DNA-Polymerase (Accuzyme), die eine hohe Korrekturleseaktivität aufweist, und dem Einsatz von speziellen Nukleotiden. Die dCTPs der Nukleotide wurden durch hydroxymethylierte-dCTPs ersetzt. Das bei der MutagenesePCR entstehende Plasmid wird daher teilweise hydroxymethyliert. Nach den ersten zehn Zyklen werden durch Zugabe von spezifischen, thermostabilen Restriktionsenzymen die nichthydroxymethylierten Formen des Plasmids gespalten und stehen zur weiteren Amplifikation nicht mehr zur Verfügung. Die Beseitigung der Matrizen-DNA erfolgt während fünf weiterer Zyklen der Amplifikation. Es bleibt nur das hydroxymethylierte Mutations-Plasmid erhalten. Dieses wird dann direkt zur Transformation weiterverwendet. Die kompetenten Zellen müssen einen $m c r A^{-}$, $m c r B C^{-}$, $m r r^{-}$Genotyp aufweisen (z.B.: XL10-Gold, Stratagene), damit das hydroxymethylierte Plasmid nicht abgebaut wird.

Für jede Mutations-PCR wurden zwei zueinander komplementäre Primer entworfen. Sie wurden so gewählt, dass die einzufügende Mutation in der Mitte der Primer lag, so dass zu beiden Seiten der Mutation etwa 12-20 korrekt hybridisierende Basen lagen. Die zur Mutagenese verwendeten Primer sind im Anhang (Tabelle A.1 und A.2) aufgelistet. Für einen Standardansatz von $50 \mathrm{\mu l}$ wurden jeweils 25-100 ng der Matrizen-DNA, 25 pmol der Mutagenese- 
Oligonukleotide, 60 pmol der hydroxymethylierten-dNTPs, $5 \mu l$ Reaktionspuffer und $5 \mathrm{U}$ der Polymerase verwendet. Amplifikationsbedingungen wurden nach Angaben des Herstellers (Tabelle 3.1) gewählt.

Tabelle 3.1.: Amplifikationsbedingungen der FlipFlop Site-Directed-Mutagenese

\begin{tabular}{|c|c|c|}
\hline Zyklen & Temperatur & Mutagenese Reaktionszeit \\
\hline \multirow{2}{*}{1} & $94^{\circ} \mathrm{C}$ & $2 \mathrm{~min}$ \\
\hline \multirow{3}{*}{10} & $94^{\circ} \mathrm{C}$ & $1 \mathrm{~min}$ \\
\cline { 2 - 3 } & primerabhängige Temperatur & $1 \mathrm{~min}$ \\
\cline { 2 - 3 } & $72^{\circ} \mathrm{C}$ & $1,5 \mathrm{~min} / \mathrm{kb}$ (Größe des Plasmids) \\
\hline \multirow{3}{*}{1} & $4^{\circ} \mathrm{C}$ & 2 min \\
\hline \multirow{3}{*}{5} & Zugabe von $2 \mu \mathrm{l}$ thermostabilen Restriktions-Enzymen \\
\hline \multirow{3}{*}{5} & $94^{\circ} \mathrm{C}$ & 1 min \\
\cline { 2 - 3 } & $94^{\circ} \mathrm{C}$ & 1 min \\
\cline { 2 - 3 } & primerabhängige Temperatur & 1,5 min $/ \mathrm{kb}$ (Größe des Plasmids) \\
\hline \multirow{2}{*}{} & $72^{\circ} \mathrm{C}$ & \\
\hline
\end{tabular}

\subsubsection{Agarose-Gelelektrophorese}

Durch PCR oder Restriktionsverdau erhaltene DNA-Fragmente können zu analytischen oder präparativen Zwecken durch Elektrophorese in horizontalen Agarosegelen aufgetrennt werden. Dabei wird die unterschiedliche Mobilität der negativ geladenen DNA ausgenutzt, die abhängig von der Molekülgröße, der Molekülform und der Agarosekonzentration des Gels ist. Für lineare doppelsträngige DNA-Fragmente besteht im elektrischen Feld über einen weiten Größenbereich der DNA eine lineare Abhängigkeit zwischen dem dekadischen Logarithmus der Fragmentlänge (in Basenpaaren) und der relativen Wanderungsdistanz (in cm, bezogen auf die gesamte Wanderungsstrecke). Zirkuläre Plasmid-DNA hingegen wandert aufgrund ihrer superhelikalen Molekülform schneller als lineare DNA gleicher Größe. Der direkt in die Gellösung gegebene Fluoreszenzfarbstoff Ethidiumbromid interkaliert zwischen den Basen von Nukleinsäuren; in ausreichender Menge akkumuliert, können diese somit im UV-Licht indirekt nachgewiesen werden.

Die DNA wurde für analytische und präparative Zwecke in Agarosegelen mit 0,8-1,5 \% (w/v) Agarose, 0,5 $\mathrm{fg} / \mathrm{ml}$ Ethidiumbromid und entsprechendem Volumen an TBE als Laufpuffer aufgetrennt. Die DNA-Proben wurden mit 5x DNA-Ladepuffer (2.7.1) versetzt und bei einer konstanten Spannung von 50-100 V elektrophoretisch aufgetrennt. Nach Abschluss der Elektropho- 
rese wurden die DNA-Fragmente unter UV-Licht mit einer Wellenlänge von $366 \mathrm{~nm}$ sichtbar gemacht und fotografiert (BioDoc Analyze, Biometra).

\subsubsection{Isolierung von DNA-Fragmenten aus Agarosegelen}

Die Isolierung von DNA-Restriktionsfragmenten aus Agarosegelen zur Reinigung der DNA von Enzymen, Salzen oder Nukleotiden erfolgte mit Hilfe des NucleoSpin ${ }^{\circledR}$ Extract II Kits (MachereyNagel). Diese Methode beruht auf dem von Vogelstein und Gillespie (1979) beschriebenen Prinzip der reversiblen Bindung von Nukleinsäuren an Partikel einer Anionenaustauschersilikat-Suspension (Glasmilch), abhängig von der Ionenstärke des Lösungsmittels. Die gewünschte DNA-Bande wurde nach gelelektrophoretischer Auftrennung unter UV-Licht (366 nm) aus dem Agarosegel ausgeschnitten und die DNA den Herstellerangaben folgend extrahiert.

\subsubsection{Klonierung von PCR-Fragmenten}

Die direkte Klonierung von PCR-Fragmenten nach dem Prinzip der TA-Klonierung erfolgte mit dem $p$ GEM $^{\circledR}$ T-Easy Vector System I (Promega). Der linearisierte Vektor (pGEM ${ }^{\circledR}$ T-Easy) dieses Kits trägt ein einzelnes 3'-Deoxythymidin. Die Taq-Polymerase besitzt eine Matrizenunabhängige Aktivität, einzelne Deoxyadenosine an das 3'-Ende des PCR-Produkts anzufügen. Diese Tatsache ermöglicht die TA-Klonierung.

Das PCR-Produkt kann direkt nach der PCR ohne vorherigen Restriktionsverdau in den pGEM ${ }^{\circledR}$ T-Easy Vektor ligiert werden. Die Ligation wird von dem Enzym T4-DNA-Ligase katalysiert, wobei unter ATP-Verbrauch die Bindung zwischen einer 5'-Phosphatgruppe und einer 3'-Hydroxylgruppe zweier DNA-Fragmente gebildet wird. Nach Ligation des PCR-Produkts in den Vektor erfolgte die Transformation in chemisch kompetente Zellen.

Der Ligationsansatz setzte sich wie folgt zusammen:

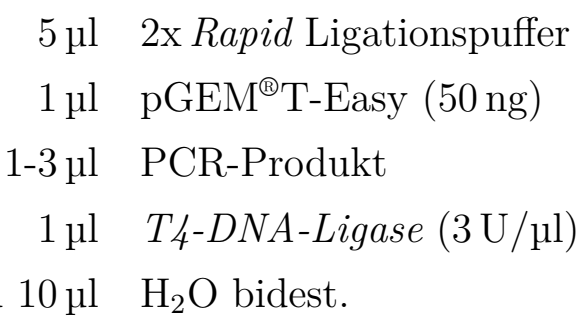

Nach einer einstündigen Inkubation bei Raumtemperatur oder über Nacht bei $4^{\circ} \mathrm{C}$ wurden $2 \mu l$ des Ligationsansatzes in chemisch kompetente Zellen transformiert (3.1.12). 


\subsubsection{Spaltung von DNA mit Restriktionsendonukleasen}

Zur Spaltung doppelsträngiger DNA werden Restriktionsendonukleasen verwendet, die das Phosphat-Zucker-Gerüst der DNA im Bereich spezifischer Palindrom-Sequenzen spalten. Bei den verwendeten Enzymen entstehen kurze überhängende Einzelstrangabschnitte, so genannte sticky ends. Die sequenzspezifische Spaltung von DNA dient zur Überprüfung der Reinheit und Identität von Plasmiden und wird zur Klonierung von DNA-Fragmenten verwendet.

In einem Standardansatz wurde der Verdau zwei Stunden bei $37^{\circ} \mathrm{C}$ inkubiert, wobei pro $\mu g$ DNA $2 \mathrm{U}$ des jeweiligen Enzyms eingesetzt wurden. Die Restriktion erfolgte in den vom Hersteller der Restriktionsenzyme (NEB) mitgelieferten Puffersystemen und einer BSA-Stocklösung bei den empfohlenen Temperaturen. Für den simultanen Verdau mit zwei Restriktionsendonukleasen wurde ein Puffer eingesetzt, der beiden Enzymen eine ausreichende Aktivität erlaubt. Für die Erfordernis einer Inaktivierung der Restriktionsenzyme, wurde der Verdauansatz 15 Minuten bei $65^{\circ} \mathrm{C}$ inkubiert. Die Vollständigkeit der Spaltung wurde mittels Agarose-Gelelektrophorese überprüft (3.1.6).

\subsubsection{Ligation von DNA-Fragmenten}

Bei der Ligation werden DNA-Fragmente, die identische Einzelstrangüberhänge haben, durch das Enzym T4-DNA-Ligase (Amersham Biosciences) verknüpft. Dabei katalysiert die Ligase unter ATP-Verbrauch die Bindung zwischen einer 5'-Phosphatgruppe und einer 3'-Hydroxylgruppe zweier doppelsträngiger DNA-Fragmente. Auf diese Weise können z.B. enzymatisch gespaltene cDNA-Fragmente in Vektoren eingebracht werden. In der Regel wird das DNAFragment (Insert) im molekularen Überschuss zur Vektor-DNA gegeben. Dabei werden 50$100 \mathrm{ng}$ Vektor verwendet und die benötigte Insert-Menge über folgende Formel berechnet:

$$
\frac{\mathrm{ng} \text { Vektor } * \mathrm{~kb} \text { Insert }}{\mathrm{kb} \text { Vektor }} * \text { molares Verhältnis } \frac{\text { Insert }}{\text { Vektor }}=\mathrm{ng} \text { Insert }
$$

Die Ligation erfolgte in dem vom Hersteller mitgelieferten Puffersystem in einem 15 l Ansatz:

$$
\begin{array}{rl}
50-100 \mathrm{ng} & \text { Vektor-DNA } \\
\mathrm{x} n \mathrm{~g} & \text { Insert-DNA } \\
4 \mu \mathrm{l} & 5 \mathrm{x} \text { Ligate-IT Ligase-Puffer } \\
1 \mu \mathrm{l} & \text { Ligate-IT T4-DNA Ligase } \\
\text { ad } 15 \mu \mathrm{l} & \mathrm{H}_{2} \mathrm{O} \text { bidest. }
\end{array}
$$


Die Inkubation des Ansatzes erfolgte 5-10 Minuten bei Raumtemperatur. Für die anschließende Transformation wurden 2-5 $\mathrm{\mu l}$ des Ligations-Ansatzes verwendet (3.1.12).

\subsubsection{Herstellung kompetenter Bakterien}

Die spontane Aufnahme von in Lösung befindlicher Fremd-DNA durch Bakterien wird als Kompetenz bezeichnet. Durch die Behandlung von Bakterien mit $\mathrm{CaCl}_{2} / \mathrm{MgCl}_{2}$ und die damit einhergehende Modifikation der Zelloberfläche kann dieser Zustand induziert und die Kompetenz erhöht werden.

$90 \mathrm{ml}$ LB-Medium (2.7.4) wurden mit $10 \mathrm{ml}$ einer Übernachtkultur des jeweiligen E.coli-Stammes inokuliert und bei $37^{\circ} \mathrm{C}$ schüttelnd bis zu einer optischen Dichte von $\mathrm{OD}_{600}=0,6$ inkubiert. Die Bakterien wurden anschließend 15 Minuten bei $4^{\circ} \mathrm{C}$ und $1500 \times$ g zentrifugiert. Der Überstand wurde dekantiert und das Zellsediment mit 1/4 Volumen eiskalter, sterilfiltrierter $100 \mathrm{mM} \mathrm{MgCl}_{2}$-Lösung vorsichtig resuspendiert und fünf Minuten auf Eis inkubiert. Nach erneuter Zentrifugation (zehn Minuten, $4^{\circ} \mathrm{C}, 1500 \times \mathrm{g}$ ) wurde das Sediment in 1/20 Volumen eiskalter $100 \mathrm{mM} \mathrm{CaCl}_{2}$-Lösung resuspendiert und 20 Minuten auf Eis inkubiert. Nach einer letzten Zentrifugation (zehn Minuten, $4^{\circ} \mathrm{C}, 1500 \times \mathrm{g}$ ) wurde das Sediment in 1/100 Volumen einer eiskalten $100 \mathrm{mM} \mathrm{CaCl}_{2}$-Lösung mit 15\% (v/v) Glycerol aufgenommen. Die Suspension wurde aliquotiert und in flüssigem Stickstoff schockgefroren. Bis zum Gebrauch wurden die Aliquots bei $-80^{\circ} \mathrm{C}$ gelagert.

\subsubsection{Transformation kompetenter Bakterien}

Durch Transformation werden Plasmide in kompetente Bakterien übertragen. Bei der chemischen Transformation wird das DNA-Bakterien-Gemisch zunächst auf Eis inkubiert, was zur Anlagerung der DNA an die kompetenten Bakterien führt. Durch einen anschließenden Hitzeschock wird die DNA von den Bakterien aufgenommen. Während einer darauf folgenden Inkubation bei $37^{\circ} \mathrm{C}$ in antibiotika-freiem LB-Medium beginnt die Expression des auf dem aufgenommenen Plasmid kodierten Resistenzgens. Zur Selektion werden die transformierten Zellen auf entsprechenden LB-Selektionsplatten ausplattiert.

Ein Aliquot mit $20 \mu \mathrm{l}$ chemisch kompetenten Zellen wurde auf Eis aufgetaut, mit 2-5 $\mathrm{ll}$ DNA vermischt und 15-30 Minuten auf Eis inkubiert. Der Hitzeschock erfolgte 45-90 Sekunden bei $42^{\circ} \mathrm{C}$. Nach einer zehnminütigen Inkubation auf Eis wurde dem Transformationsansatz $500 \mu \mathrm{l}$ LB-Medium (ohne Antibiotikum) zugesetzt und 45-60 Minuten bei $37^{\circ} \mathrm{C}$ schüttelnd inkubiert. Die transformierten Zellen wurden auf entsprechenden LB-Selektionsplatten (mit Antibioti- 
kum) ausplattiert und über Nacht bei $37^{\circ} \mathrm{C}$ inkubiert. Im Fall einer Farbselektion wurden vor dem Ausplattieren auf der Platte $100 \mu \mathrm{g} / \mathrm{ml}$ X-Gal und $40 \mu \mathrm{g} / \mathrm{ml}$ IPTG ausgestrichen.

\subsubsection{Isolierung von DNA}

\section{Isolierung von Plasmid-DNA}

Die Gewinnung von Plasmid-DNA aus Bakterien im Kleinmaßstab erfolgte durch alkalische Zelllyse und alkoholische Präzipitation (Sambrook et al., 1989). Zunächst wurden $300 \mu l$ einer E.coli-Übernachtkultur bei $3300 \times \mathrm{g}$ drei Minuten zentrifugiert und das Sediment in $250 \mu \mathrm{l}$ Lösung P1 (50 mM Tris-HCl pH 8,0; 10 mM EDTA) resuspendiert. Zum Abbau bakterieller RNA wurden dem Puffer P1 $100 \mu \mathrm{g} / \mathrm{ml}$ RNase A zugesetzt. Die Lyse der Zellen erfolgte anschlieBend durch Zugabe von $250 \mu \mathrm{l}$ Lysepuffer P2 (200 mM NaOH, 1\% [w/v] SDS). Der Ansatz wurde vorsichtig gemischt und fünf Minuten bei Raumtemperatur inkubiert. Die Einhaltung der Inkubationszeit war wichtig, um eine maximale Zelllyse zu gewährleisten und gleichzeitig eine irreversible Denaturierung der Plasmid-DNA zu vermeiden. Nach Zugabe von $350 \mu l$ der Lösung P3 (3 M Kaliumacetat pH 5,5) erfolgte während einer zehnminütigen Inkubation bei Raumtemperatur die Fällung der genomischen DNA und der Proteine. Nach Abtrennung von Zelltrümmern, genomischer DNA und Proteinen durch Zentrifugation (zehn Minuten, $4^{\circ} \mathrm{C}$, $16100 \times \mathrm{g}$ ), wurde die im Überstand enthaltene Plasmid-DNA mit 0,9 Volumen Isopropanol gefällt. Die DNA wurde durch Zentrifugation $\left(20\right.$ Minuten, $\left.4^{\circ} \mathrm{C}, 16100 \times \mathrm{g}\right)$ sedimentiert, mit 70\%igem Ethanol gewaschen und erneut durch Zentrifugation sedimentiert. Danach wurde die DNA kurz bei Raumtemperatur getrocknet und in 15,4 $\mathrm{\mu l}$ Wasser resuspendiert.

Dem DNA-Wasser-Gemisch wurden die zur Analyse benötigten Restriktionsenzyme sowie der entsprechende 10x Puffer und eine BSA-Stocklösung (Endkonzentration 0,1 mg/ml) zugesetzt. Nach einstündiger Inkubation bei $37^{\circ} \mathrm{C}$ wurden die so gewonnenen DNA-Fragmente im Agarosegel analysiert.

Zur Isolierung reiner Plasmid-DNA oder größerer Mengen, die für die Sequenzierung von Konstrukten, für die Transformation von Bakterien oder für die Transfektion von eukaryontischen Zellen eingesetzt werden sollten, wurden die NucleoBond ${ }^{\circledR}$ Plasmid oder NucleoBond $d^{\circledR}$ XtraMidi Kits von Macherey-Nagel nach Herstellerangaben verwendet.

\section{Isolierung von genomischer DNA}

Die Isolierung von genomischer DNA aus Patienten-Blut oder -Gewebe erfolgte mittels DNeasy ${ }^{\circledR}$ Blood\&Tissue Kit nach Herstellerangaben. Diese Methode beruht auf dem von Vogelstein und 
Gillespie (1979) beschriebenen Prinzip der reversiblen Bindung von Nukleinsäuren an Partikel einer Anionenaustauschersilikat-Suspension (Glasmilch), abhängig von der Ionenstärke des Lösungsmittels.

\subsubsection{DNA-Sequenzierung und Sequenzanalyse}

Die DNA-Sequenzierung wurde für alle im Rahmen dieser Arbeit hergestellten und verwendeten Konstrukte durchgeführt, um Klonierungen bzw. das Einfügen von Mutationen zu überprüfen. Des Weiteren wurde Patienten-DNA sequenziert, um eventuelle Sequenzveränderungen zu analysieren.

Die DNA-Sequenzierung wurde nach dem Kettenabbruchverfahren (Sanger et al., 1977) mit Fluoreszenzfarbstoff-markierten Didesoxynukleotiden (ddATP, ddGTP, ddCTP und ddTTP) mit Hilfe des Sequenzierungskits BigDye Terminator v3.1 Cycle Sequencing und sequenzspezifischen Oligonukleotiden durchgeführt. Hierbei kommt es nach einer statistischen Häufigkeit zum Abbruch der DNA-Synthese sobald ein ddNTP eingebaut wird. Dies führt zur Erzeugung unterschiedlich langer Fragmente. Die Nukleotide zum Kettenabbruch werden in einem Verhältnis mit den Synthesebausteinen gemischt, so dass alle möglichen Fragmentgrößen in Folge des Kettenabbruchs nach einer statistischen Häufigkeit auftreten.

Ein Sequenzierungs-PCR-Ansatz setzte sich wie folgt zusammen:

$$
\begin{array}{rl}
\text { ca. 500 ng } & \text { DNA } \\
2 \mu \mathrm{l} & 5 \mathrm{x} \text { Cycle Sequencing Puffer } \\
0,5 \mu \mathrm{l} & \text { Oligonukleotid }(10 \mathrm{pmol} / \mathrm{\mu l}) \\
1 \mu \mathrm{l} & \text { BigDye } \\
\text { ad } 10 \mu \mathrm{l} & \mathrm{H}_{2} \mathrm{O} \text { bidest. }
\end{array}
$$

Die PCR-Reaktion wurde im Thermocycler mit 24 Wiederholungen des folgenden Programms durchgeführt:

\section{Schritt 1: $\quad 96^{\circ} \mathrm{C} \quad 10 \mathrm{sec}$}

Schritt 2: $60^{\circ} \mathrm{C} \quad 4 \mathrm{~min}$

Nach Abschluss der Sequenzierreaktion wurde der Sequenzieransatz mit $114 \mu$ l Wasser aufgefüllt und die DNA gereinigt. Die Fällung der DNA-Fragmente erfolgte mittels Ethanol-Präzipitation (3.1.3). Das Sediment wurde anschließend in $10 \mu l$ Formamid resuspendiert.

Zur Analyse der DNA-Fragmente wurden sie über ein Gelkapillarsystem elektrophoretisch der Größe nach aufgetrennt. Die vier unterschiedlichen Fluoreszenz-Farbstoffgruppen, die jeweils an ein bestimmtes Nukleotid gekoppelt waren, wurden durch einen Laser angeregt. Die verschiedenen Fluoreszenzsignale wurden durch ein Detektorsystem des DNA-Sequenzers (ABI 
PRISM, 3100 Genetic Analyzer) anhand ihrer unterschiedlichen Emissionswellenlängen identifiziert und quantifiziert. Die Auswertung der DNA-Sequenzen erfolgte mittels Data Collection Software 2.0 und der Sequencing Analysis Software Version 5.1. Die Sequenzierergebnisse wurden dann mit Referenzsequenzen mit Hilfe des Programms DNA Star verglichen.

\subsection{RNA: Molekularbiologische Methoden}

\subsubsection{Präparation von RNA aus Gewebe und Zellen}

Das peqGOLD TriFast - eine monophasische Lösung von Phenol und Guanidinisothiocyanat ist eine Weiterentwicklung der single step-RNA-Isolationsmethode von Chomczynski und Sacchi (1987). Während der Homogenisation bzw. Lyse erhält peqGOLD TriFast die Integrität der RNA. Die Zellen werden lysiert und Zellbestandteile aufgelöst. Durch die Zugabe von Chloroform und die folgende Zentrifugation wird die Lösung in drei Phasen separiert:

- eine wässrige, die RNA enthaltende Phase,

- eine Interphase (DNA)

- und eine organische Phenol/Chloroform-Phase (Proteine).

Die RNA wird aus der wässrigen Phase durch Zugabe von Isopropanol und erneuter Zentrifugation isoliert. Bei Bedarf kann durch Präzipitation mit Ethanol die DNA aus der Interphase isoliert oder durch die Zugabe von Isopropylalkohol das Protein aus der organischen Phase präzipitiert werden (Chomczynski, 1993).

\section{Homogenisation:}

Zur Lyse der Zellen wurden diese trypsinisiert und durch Zentrifugation sedimentiert. Das Zellsediment wurde in peqGOLD TriFast ( $1 \mathrm{ml}$ peqGOLD TriFast pro 5-10 x $10^{6}$ Zellen bzw. pro $10 \mathrm{~cm}^{2}$-Schale) durch repetitives Pipettieren lysiert. Zur Extraktion der RNA aus Gewebe wurden 50-100 mg Gewebe mit $1 \mathrm{ml}$ peqGOLD TriFast homogenisiert.

\section{Phasen-Trennung:}

Die Proben wurden fünf Minuten bei Raumtemperatur inkubiert (komplette Dissoziation der Nukleoproteinkomplexe). Pro $1 \mathrm{ml}$ eingesetztem peqGOLD TriFast wurden 0,2 ml Chloroform zugegeben. Die Suspension wurde etwa 15 Sekunden kräftig geschüttelt und drei bis zehn Minuten bei Raumtemperatur inkubiert. Zur Phasenseparation folgte eine 15-minütige Zentrifugation bei $4^{\circ} \mathrm{C}$ und $12000 \times \mathrm{g}$. Die RNA befand sich aussschließlich in der wässrigen oberen 
Phase, die weiße Interphase und die organische, rote untere Phase beinhalteten DNA und Proteine.

\section{RNA-Präzipitation:}

Aus der wässrigen Phase wurde in einem neuen Reaktionsgefäß durch Zugabe von 0,5 ml Isopropanol pro $1 \mathrm{ml}$ eingesetztem peqGOLD TriFast die RNA präzipitiert. Eine Inkubation von 20 Minuten bei $-80^{\circ} \mathrm{C}$ sollte diesen Effekt noch verstärken. Anschließend wurde die präzipitierte RNA zehn Minuten bei $12000 \times g$ abzentrifugiert.

\section{RNA Wasch-Schritt:}

Das gelartige Sediment wurde zweimal mit $1 \mathrm{ml}$ 75\%igem Ethanol pro $1 \mathrm{ml}$ peqGOLD TriFast gewaschen und zehn Minuten bei $4^{\circ} \mathrm{C}$ und $12000 \times \mathrm{g}$ zentrifugiert. Der Überstand wurde verworfen.

Lösen $\operatorname{der} R N A$ :

Anschließend wurde die RNA luftgetrocknet, ohne sie dabei vollständig auszutrockenen, da dies die Löslichkeit stark beeinträchtigen würde. Die RNA wurde in 100-150 pl RNase-freiem Wasser zehn Minuten bei $55-60^{\circ} \mathrm{C}$ gelöst. Kontaminationen mit DNA wurden durch einen DNaseVerdau mit folgendem Standard-Ansatz entfernt.

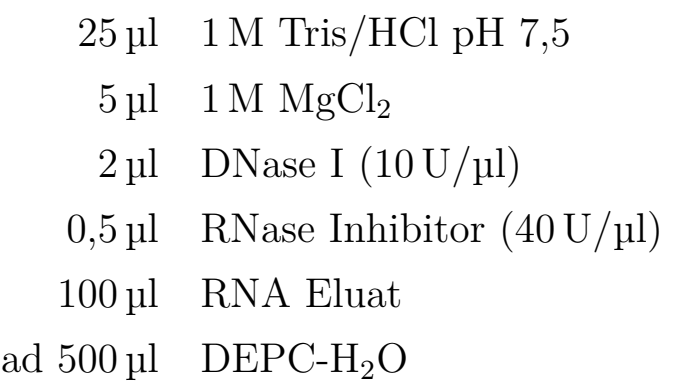

Der Ansatz wurde dann 20 Minuten bei $37^{\circ} \mathrm{C}$ im Thermoblock inkubiert und anschließend mittels Phenol/Chloroform-Extraktion aufgereinigt (3.1.2). Die Qualität der RNA wurde über ein 1\%iges denaturierendes Agarose-Gel überprüft (3.2.2) und die RNA-Menge photometrisch quantifiziert (3.1.1). Die RNA wurde dann bei $-80^{\circ} \mathrm{C}$ gelagert.

\subsubsection{Denaturierendes RNA-Agarose-Gel}

Zur Qualitätsüberprüfung von isolierter RNA wurden denaturierende Agarose-Gele verwendet. Zunächst wurde die RNA-Elektrophoresekammer sorgfältig mit RNase-Zap und DEPC-Wasser gereinigt. Je nach gewünschter Agarose-Konzentration (z.B. 1\% w/v) wurde Agarose (0,6g) dem entsprechenden Gelvolumen (53 ml) DEPC-Wasser zugesetzt, gemischt und in der Mikrowelle kurz aufgekocht. Nach Abkühlung im Wasserbad auf ca. $60^{\circ} \mathrm{C}$ wurden der Agaroselösung 
unter Rühren $6 \mathrm{ml}$ 10x MOPS-Puffer (2.7.2), 2-3\% Formaldehyd (37\%ig; 1,5 ml) und 0,5 $\mu \mathrm{l}$ Ethidiumbromid-Lösung $(10 \mathrm{mg} / \mathrm{ml})$ hinzugefügt. Die Gelflüssigkeit wurde luftblasenfrei in die dekontaminierte Gelkammer gegossen und abgekühlt.

Nach Überführung des Gels in die Elektrophoresekammer wurde die Kammer mit 1x MOPSPuffer gefüllt und mit den RNA Proben, die mit Ladepuffer (2.7.2) versetzt und drei Minuten auf $95^{\circ} \mathrm{C}$ erhitzt wurden, beladen. Die Elektrophorese wurde ca. 60 Minuten bei 50-60 V und $300 \mathrm{~mA}$ ausgeführt. Die mit Ethidiumbromid assoziierten Nukleinsäuren wurden durch UVLicht visualisiert. Bei intakter Säuger Gesamt-RNA sollten deutlich zwei Banden zu erkennen sein, die die 28S- und 18S-rRNA repräsentieren. Das Verhältnis der Intensitäten von 28S- und 18S-rRNA sollte bei 1,5 bis 2,5 zu 1 liegen. Niedrigere Werte deuten auf eine RNA-Degradation hin.

\subsubsection{Reverse Transkriptase-PCR}

Die Reverse Transkriptase-PCR (RT-PCR) ist eine Methode zum Nachweis der Genexpression von spezifischen Genen in Zellmaterial, Gewebe oder Blutserum. Die aus den genannten Materialien isolierte mRNA (3.1.2) wird dafür in cDNA umgeschrieben.

Bei der Erststrang-Synthese benötigt die katalysierende, virale Reverse Transkriptase (RT) als Startsequenz einen Oligo $\left(\mathrm{dT}_{15}\right)$-Primer, der bei eukaryontischen mRNAs an den typischen Poly-(A)-Schwanz (3'-Ende) bindet und somit den Initiationspunkt für die $R T$ bildet. Die Zweitstrang-Synthese erfolgt am DNA/RNA-Hybrid.

Durch eine milde Behandlung mit RNase H werden Teile der RNA entfernt und 3'OH-Oligonukleotide für die DNA-Polymerase produziert. Die 5' $\rightarrow$ 3'-Exonuklease-Aktivität der DNAPolymerase entfernt die in Syntheserichtung liegenden Primer sukzessiv und die PolymeraseAktivität ersetzt diese durch neue Nukleotide aus dem vorliegenden Desoxynukleotid-Vorrat. Der Vorteil dieser Methode liegt darin, dass sich das Intermediärprodukt für die ZweitstrangSynthese in meist doppelsträngiger Form befindet, so dass ein Zurückfalten von einzelsträngiger DNA unterbunden und somit der Verlust an 5'-terminalen Sequenzen bei der Klonierung reduziert wird.

\section{Erststrang-cDNA Synthese}

Für die Erststrang-Synthese mittels SuperScript ${ }^{T M} I I I$ First-Strand Synthesis System for RTPCR (Invitrogen) wurden 1-2 $\mu$ g gesamt-RNA eingesetzt. Der Reaktionsansatz und die Reaktionsbedingungen wurden wie folgt gewählt: 


$\begin{array}{ll}1 \mu \mathrm{l} & 50 \mu \mathrm{M} \text { Oligo }\left(\mathrm{dT}_{15}\right) \text {-Primer } \\ 1 \mu \mathrm{l} & 10 \mathrm{mM} \text { dNTP } \\ \mathrm{x} \mu \mathrm{l} & \text { RNA }(1-2 \mu \mathrm{g}) \\ \mathrm{x} \mu \mathrm{l} & \mathrm{H}_{2} \mathrm{O} \text { bidest. ad } 10 \mu \mathrm{l}\end{array}$

- Denaturierung der RNA, Primer und dNTPs fünf Minuten bei $65^{\circ} \mathrm{C}$

- Inkubation des Ansatzes eine Minute auf Eis

Folgende Reagenzien wurden zugefügt:

$2 \mu \mathrm{ll} \quad$ 10x $R T$-Puffer

$4 \mathrm{ul} \quad 25 \mathrm{mM} \mathrm{MgCl}_{2}$

$2 \mu \mathrm{l} \quad 0,1 \mathrm{M} \mathrm{DTT}$

1 ul RNase Inhibitor

$1 \mu \mathrm{l} \quad$ SuperScript ${ }^{\mathrm{TM}}$ III $R T$

- cDNA-Synthese 50 Minuten bei $50^{\circ} \mathrm{C}$

- Terminale Reaktion fünf Minuten bei $85^{\circ} \mathrm{C}$

- Teil-RNA-Entfernung durch Zugabe von $1 \mu$ l RNase H und Inkubation 20 Minuten bei $37^{\circ} \mathrm{C}$

Die synthetisierte cDNA wurde anschließend z.B. zur RealTime-PCR eingesetzt (3.2.4).

\subsubsection{Expressionsanalyse mittels RealTime-PCR}

Bei der RealTime-PCR wird die Akkumulation eines PCR-Produkts während der PCR-Reaktion detektiert, wodurch eine absolute oder relative Abschätzung der Menge der AusgangscDNA und daher der Transkriptmenge eines bestimmten Gens möglich ist. Die Quantifizierung wird mit Hilfe von Fluoreszenz-Messungen durchgeführt, die während eines PCR-Zyklus erfasst werden. Die Fluoreszenz nimmt proportional mit der Menge der PCR-Produkte zu. Am Ende eines Laufs (der aus mehreren Zyklen besteht) wird anhand von erhaltenen Fluoreszenzsignalen die Quantifizierung in der exponentiellen Phase der PCR vorgenommen. Nur in der exponentiellen Phase der PCR (die wenige Zyklen in einem Lauf dauert) ist die korrekte Quantifizierung möglich, da während dieser Phase die optimalen Reaktionsbedingungen herrschen.

Als Amplikon für die RealTime-PCR wird zunächst eine Region des Gens von 150-250 bp ausgewählt, die keine Homologien zu anderen Genen aufweist. Der zu amplifizierende Bereich soll Intron-Exon-Übergange mit einschließen, um sicher zu stellen, dass keine Verunreinigungen 
mit genomischer DNA vorliegen. Des Weiteren sollen die spezifischen Oligonukleotide eine Schmelztemperatur von $58-62^{\circ} \mathrm{C}$ und einen GC-Gehalt von 40-60\% aufweisen.

Die Spezifität der zur RealTime-PCR verwendeten Oligonukleotide wurde überprüft, indem sie zunächst mit der zu untersuchenden cDNA in einer Standard-PCR (3.1.4) getestet wurden. Die RealTime-PCR wurde dann mit dem iQSYBR Green Supermix Kit (BioRad) im Transkriptomanalyselabor der Humanmedizin in Göttingen durchgeführt. Die Ausgangs-cDNA der verschiedenen Hirnregionen, der Leber, der Niere und des Skelettmuskels wurde von der Firma Bio Chain (Hayward, USA) geliefert. Die verwendete Patienten-cDNA wurde aus Lymphozytenoder Blut-RNA (3.2.1) mittels RT-PCR (3.2.3) synthetisiert. Für die Amplifikation, die für die jeweilige Bedingung in Triplikaten durchgeführt wurde, wurde folgender Reaktionsansatz gewählt.

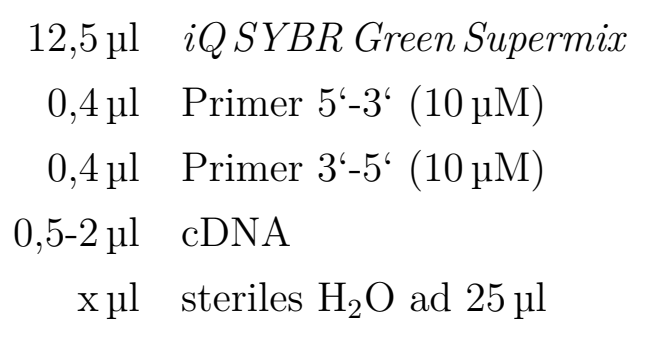

Folgende Programmeinstellungen wurden für den $i Q 5$ Cycler (BioRad) verwendet. Die Schmelztemperatur wurde je nach Struktur der Primer-Paare angepasst.

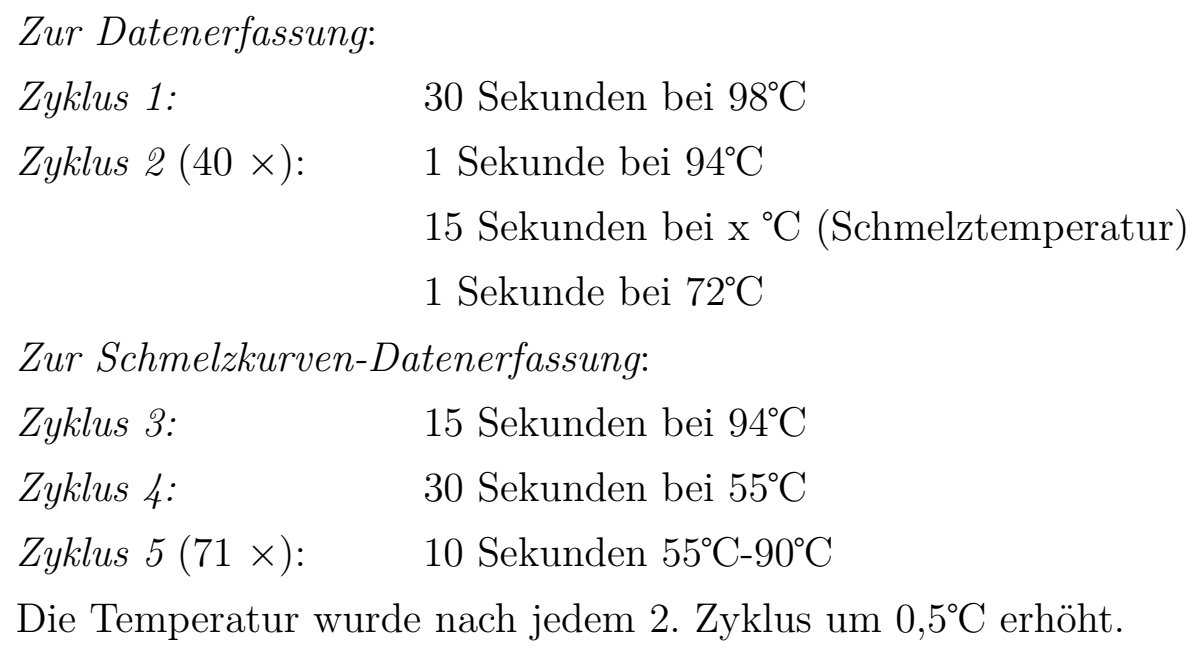

Bei der Datenanalyse wurde darauf geachtet, dass der Korrelationskoeffizient der Eichgeraden über 0,99 lag und die PCR im Messbereich über eine Effizienz von etwa 100\% (Produktverdopplung) verfügte. Des Weiteren wurde die Reaktionsspezifität anhand der Schmelzkurve kontrolliert. Die RealTime-PCR Daten wurden entweder mit Hilfe eines ungepaarten Student's T-Test oder mit einer einfaktoriellen ANOVA statistisch analysiert. 


\subsubsection{In vitro Transkription}

Synthetische mRNA für Mikroinjektionen in Xenopus laevis Oozyten wurde unter Verwendung eines mMESSAGE mMACHINE Kits der Firma Ambion hergestellt. Bei der in vitro Synthese mit einer Sp6-Polymerase wird am 5'-Ende der Transkripte eine 7-Methylguanosin Cap-Struktur angefügt, die für einen effizienten Export der injizierten Transkripte aus dem Zellkern sowie zur Translationsinitiation benötigt wird. Am 3'-Ende der Transkripte wird ein Poly-A-Schwanz angehängt, der durch den spezifischen Expressionsvektor kodiert wird. Diese Modifikation der RNA führt zu einer Erhöhung der Stabilität durch Schutz vor Abbau sowie zu einer Erhöhung der Translatierbarkeit.

Zur Synthese der komplementären RNA (cRNA) wurde der das Fragment enthaltene pCS2+Vektor durch die Restriktionsenzyme KpnI bzw. NsiI linearisiert (3.1.9). Die RNA-Synthese wurde nach folgendem Reaktionsprotokoll durchgeführt.

$10 \mu \mathrm{l} \quad 2 \mathrm{xNTP} / \mathrm{CAP}$

$2 \mu \mathrm{l} \quad$ 10x Reaktionspuffer

$1 \mu \mathrm{g}$ linearisierte DNA

$2 \mu \mathrm{l} \quad$ Enzym-Mix

ad $20 \mathrm{\mu l}$ Nuklease-freies $\mathrm{H}_{2} \mathrm{O}$

Der Ansatz wurde 2-3 Stunden bei $37^{\circ} \mathrm{C}$ inkubiert und anschließend mit $1 \mu \mathrm{l}$ TURBO DNase versetzt und weitere 15 Minuten bei $37^{\circ} \mathrm{C}$ inkubiert, um die Matrizen-DNA aus dem Transkriptionsansatz zu entfernen. Die RNA wurde durch LiCl-Präzipitation gereinigt.

Die LiCl-Präzipitation ist eine effektive Methode, um Nukleotide und Proteine aus dem RNAReaktionsansatz zu entfernen. Die RNA wird durch Zugabe von $30 \mu \mathrm{LiCl-Präzipitationslösung}$ (Ambion) mindestens 30 Minuten bei $-20^{\circ} \mathrm{C}$ präzipitiert. Um die gefällte RNA zu sedimentieren wird sie 15 Minuten bei $4^{\circ} \mathrm{C}$ und $18620 \times$ g zentrifugiert. Das Sediment wird mit $70 \%$ igem Ethanol gewaschen, in Nuklease-freiem Wasser resuspendiert und bei $-80^{\circ} \mathrm{C}$ gelagert.

\subsection{Zellbiologische Methoden}

\subsubsection{Kultivierung von eukaryontischen Zellen}

Die Kultivierung der HeLa bzw. HEK 293 Zellen erfolgte mit DMEM-Medium low glucose und folgenden Zusätzen: 10\% (v/v) FKS, $2 \mathrm{mM}$ L-Glutamin, $100 \mathrm{U} / \mathrm{ml}$ Penicillin und $100 \mu \mathrm{g} / \mathrm{ml}$ Streptomycin. Die Lymphozyten-Zelllinien wurden in RPMI-1640 Medium kultiviert, supplementiert mit 25\% FKS, 2 mM L-Glutamin, 1 mM Natrium-Pyruvat, 1\% (v/v) Phytahemagglu- 
tinin-L, $100 \mathrm{U} / \mathrm{ml}$ Penicillin und $100 \mathrm{\mu g} / \mathrm{ml}$ Streptomycin. Alle Zellen wurden unter 5\% $\mathrm{CO}_{2}$ bei $37^{\circ} \mathrm{C}$ kultiviert. Medien und Lösungen (2.7.5) wurden auf $37^{\circ} \mathrm{C}$ vorgewärmt.

Das Ablösen der adhärenten Zellen (HeLa/HEK 293) erfolgte routinemäßig nach Erreichen der Konfluenz des Zellrasens. Dazu wurde das Medium abgesaugt und die Zellen mit PBS gewaschen. Die Zellen wurden anschließend etwa drei Minuten mit Trypsin/EDTA bei $37^{\circ} \mathrm{C}$ bis zur Loslösung vom Kulturflaschenboden behandelt. Die gelösten Zellen wurden in serumhaltigem DMEM-Medium aufgenommen und durch mehrmaliges Auf- und Abpipettieren vereinzelt. Suspensionszellen (Lymphozyten) wurden zur Teilung durch Zentrifugation (fünf Minuten, 61×g) sedimentiert, das verbrauchte Medium abgesaugt, das Zellsediment in entsprechendem Volumen frischem Kulturmedium resuspendiert und auf die gewünschte Anzahl an Kulturflaschen aufgeteilt.

\section{Zellzahlbestimmung}

Alle Zellzahlbestimmungen in einer Zellsuspension wurden mittels einer mit einem Deckglas verschlossenen Neubauer-Zählkammer $\left(0,0225 \mathrm{~mm}^{2}\right.$ Fläche bei einer Tiefe von 0,1 mM) durchgeführt. Die gezählte Zellzahl in einem 16 Gruppenquadrate umfassenden Großquadrat entsprach x mal $10^{4}$ Zellen pro ml.

\section{Gefrierkonservierung von eukaryontischen Zellen}

Zur langfristigen Lagerung von eukaryontischen Kulturzellen wurden Gefrierstocks angelegt. Die Zellen wurden nach Ablösen von der Kulturflasche zentrifugiert $(61 \times \mathrm{g})$ und in DMSOhaltigem Kulturmedium (2.7.5) aufgenommen, in Kryoröhrchen (Nalgene) zu je $1 \mathrm{ml}$ aliquotiert und 24 Stunden bei $-80^{\circ} \mathrm{C}$ in einem Styroporbehälter gelagert. Anschließend wurden sie zur langfristigen Lagerung in flüssigen Stickstoff oder in eine $-150^{\circ} \mathrm{C}$ Truhe (Sanyo) überführt. Der Zusatz von DMSO dient den Zellen beim Einfriervorgang als Schutz gegen Eiskristalle.

\subsubsection{Transiente Transfektion von HeLa/HEK 293 Zellen}

Eukaryontische Zellen sind in der Lage, unverpackte exogene DNA aufzunehmen und zu exprimieren. Die Expression transfizierter DNA kann allerdings nur bis zu 72 Stunden nach der Transfektion nachgewiesen werden, da die Zellen die exogene DNA nach einer Kinetik erster Ordnung wieder abbauen. Versuche dieser Art werden daher als „transiente Transfektion“ bezeichnet. 
Die Transfektion von eukaryontischen Zellen erfolgte mittels Effectene Transfection Reagent Kit von Qiagen nach Herstellerangaben. Das Prinzip der Effectene-Transfektion beruht auf der Kondensation der zu transfizierenden DNA mit Hilfe eines Verstärkers (Enhancer) und definierten Pufferbedingungen (EC-Puffer). Das zugefügte Effectene-Reagenz assoziiert mit der kondensierten DNA und formt auf diese Weise spontan Mizellen gleicher Größe und Struktur, was zu einer besonders hohen und reproduzierbaren Transfektionseffizienz führen soll. Die mit DNA beladenen Phospholipidpartikel verschmelzen mit der Zellmembran und setzen die DNA ins Zellinnere frei. Von dort aus gelangt sie in den Zellkern, wo sie transkribiert wird. Anschließend kann, ausgehend von der transkribierten RNA, eine Proteinexpression erfolgen.

Je nach Verwendungszweck wurden die Zellen in $10 \mathrm{~cm}^{2}$-Schalen (für Proteinextraktion) oder in 12-Loch-Platten (für Immunfluoreszenzen) transfiziert. Dazu wurden am Vortag für $10 \mathrm{~cm}^{2}$ Schalen 0,6 $\times 10^{6}$ Zellen pro Schale oder für 12-Loch-Platten 0,8 x $10^{5}$ Zellen pro Loch ausgesät. Für Immunfluoreszenzanalysen wurden die 12-Loch-Platten zuvor mit Deckgläschen bestückt. Bei zu transfizierenden HEK 293 Zellen wurden die Deckgläschen mindestens 30 Minuten mit $0,1 \mathrm{mg} / \mathrm{ml}$ Poly-D-Lysin beschichtet. Um eine optimale Transfektionseffizienz der Zellen zu erzielen, sollten die Zellen zum Zeitpunkt der Transfektion bis zu einer Konfluenz von ca. 70\% gewachsen sein. Eine Präparation von Zellextrakten (3.4.1) oder eine Immunfluoreszenz-Analyse (3.3.4) wurde in den meisten Fällen 24 bis 48 Stunden nach der Transfektion durchgeführt.

\subsubsection{Stabile Transfektion von HeLa/HEK 293 Zellen}

Die stabile Transfektion erfolgte nach dem Protokoll der transienten Transfektion (3.3.2). Der Unterschied bestand jedoch darin, dass linearisierte DNA zur Transfektion verwendet wurde, da diese effizienter in das Wirtszell-Genom eingebaut wird. Des Weiteren wurden die Zellen nach der Transfektion durch Inkubation mit dem Antibiotikum Geneticin (G418) einem Selektionsdruck ausgesetzt. Das Aminoglykosid G418 bindet irreversibel an die 80S Ribosomenuntereinheit und blockiert die Proteinsynthese der Zellen. Der in die Zellen stabil transfizierte Vektor (z.B. pcDNA3.1) enthält ein Antibiotikaresistenzgen (z.B. Geneticin) und schützt die Zellen vor einer Selektion.

Die transient transfizierten Zellen wurden zunächst 2-3 Tage unter Standardbedingungen kultiviert. Anschließend wurden sie in Selektionsmedium (DMEM mit $800 \mu \mathrm{g} / \mathrm{ml}$ G418) weiterkultiviert, wobei das Medium regelmäßig (alle 2-3 Tage) erneuert wurde. Nur Zellen mit stabil integriertem Plasmid überlebten die Selektion. Als Negativ-Kontrolle wurden nicht transfizierte Zellen mitbehandelt. Nach 4-5 Tagen waren diese Zellen ausnahmslos abgestorben. Nach ungefähr 14-20 Tagen wuchsen auf der stabil transfizierten Zellkulturschale sichtbare Kolonien. 
Diese wurden mittels kleiner Glaszylinder isoliert und passagiert. Die separate Kultivierung der Zellklone erfolgte in 6-Loch-Platten unter weiter anhaltendem Selektionsdruck.

\subsubsection{Immunfluoreszenz}

Zum Nachweis spezifischer endogener Proteine wurden HeLa oder HEK 293 Zellen auf Deckgläschen (Durchmesser: 20mm) ausgesät und gegebenenfalls transfiziert (3.3.2). Die mehrmals mit PBS gewaschenen Zellen wurden mit 4\% Paraformaldehyd (PFA) und 4\% (w/v) Sucrose in PBS 20-30 Minuten fixiert. Die Zellen wurden erneut mit PBS gewaschen und zehn Minuten mit 50 mM Glycin in PBS zur Absättigung freier Aldehydgruppen des PFA inkubiert. Es folgte eine Blockierung unspezifischer Bindungsstellen und Permeabilisierung der Membran mit 5\% Ziegenserum und 0,1\% Triton X-100 in PBS eine Stunde bei Raumtemperatur. Die Inkubation mit dem spezifischen Primärantikörper, verdünnt in Blockierlösung (Tabelle 2.1), erfolgte eine Stunde bei Raumtemperatur oder über Nacht bei $4^{\circ} \mathrm{C}$ in einer feuchten Kammer. Die Deckgläser wurden drei- bis fünfmal mit PBS gewaschen, um nicht-gebundene Primärantikörper zu entfernen, und mit entsprechenden Fluoreszenz-Farbstoff markierten Sekundärantikörpern (verdünnt in Blockierlösung, siehe Tabelle 2.1) eine Stunde bei Raumtemperatur in einer feuchten Kammer inkubiert. Zuletzt wurden die Zellen drei- bis fünfmal mit PBS gewaschen und auf einem Objektträger in ca. $8 \mu$ ProLong-Gold (Invitrogen) eingebettet.

Zur Immunfärbung spezifischer Proteine in Lymphozyten-Zellen wurde ein entsprechendes Volumen Suspensionszellen $(1 \mathrm{ml})$ bei $95 \times \mathrm{g}$ sedimentiert und einmal mit RPMI-Medium gewaschen. Das Zellsediment wurde in fünffachem Sedimentvolumen FKS (50 pl) resuspendiert. Ein Tropfen dieser Suspension wurde auf einem Objektträger ausgestrichen und luftgetrocknet. Die Fixierung wurde 30 Minuten in 4\% Paraformaldehyd, 0,1 M Cacodylat in PBS (pH 7,4) durchgeführt. Die in PBS gewaschenen Objektträger wurden zur Permeabilisierung der Lymphozyten vier Minuten in 0,1\% Triton X-100 in PBS inkubiert. Es folgten zwei Waschschritte in PBS und eine Blockierung unspezifischer Bindungsstellen 15 Minuten mit 1\% BSA in PBS. Anschließend wurden die Zellen zweimal in PBS gewaschen und die Inkubation des Primärantikörpers angeschlossen. Diese Inkubation erfolgte in entsprechender Verdünnung (in PBS, Tabelle 2.1) in einer feuchten Kammer eine Stunde bei Raumtemperatur. Die Objektträger wurden fünfmal mit PBS gewaschen, um nicht gebundene Primärantikörper zu entfernen, und mit entsprechenden Fluoreszenz-Farbstoff markierten Sekundärantikörpern (verdünnt in PBS, Tabelle 2.1) eine Stunde bei Raumtemperatur in einer feuchten Kammer inkubiert. Abschließend wurden die Zellen drei- bis fünfmal mit PBS gewaschen und mit ca. $8 \mu$ ProLong-Gold (Invitrogen) eingebettet. 
Fluoreszenzsignale wurden mit dem Fluoreszenzmikroskop Axio Imager M.1 in Kombination mit einer CCD Digitalkamera (Axio Cam HRm) und der Axio Vision LE4.5 Software von Zeiss analysiert.

\subsubsection{Expression in Xenopus-Oozyten}

Für die Expression heterologer Proteine und die funktionelle Charakterisierung von Membranproteinen werden Oozyten des südafrikanischen Krallenfrosches Xenopus laevis verwendet. Heterologe cRNA kann sehr einfach injiziert und die Proteinexpression durch elektrophysiologische Messungen untersucht werden (Wagner et al., 2000). Für die elektrophysiologischen Experimente werden Oozyten der Reifestadien V und VI verwendet, da sie sich aufgrund ihrer Größe leicht handhaben lassen und außerdem eine gute Expression der injizierten cRNA festzustellen ist. Da die Oogenese bei Xenopus laevis Weibchen asynchron verläuft, befinden sich im Ovar alle Stadien (I bis VI) der Entwicklung zur selben Zeit. Unter idealen Voraussetzungen enthalten Ovarien von reifen Weibchen zahlreiche Oozyten des Stadiums V und VI. $\mathrm{Zu}$ erkennen sind die Reifestadien der Oozyten sowohl am Durchmesser (1,1-1,3 mM) als auch an der charakteristischen Pigmentierung beider Zellpole (klare Abgrenzung des animalischen, schwarzen Pol vom vegetativen, weißen Pol). (Dumont, 1972)

Die Oozyten und der Messaufbau für elektrophysiologische Experimente im Rahmen dieser Arbeit wurden freundlicherweise von Frau Prof. Dr. B.C. Burckhardt in der Abteilung Vegetative Physiologie und Pathophysiologie, Universitätsmedizin Göttingen, zur Verfügung gestellt.

\subsubsection{Operative Entnahme und Präparation der Oozyten}

Zur operativen Entnahme der Oozyten wurden die Xenopus laevis Weibchen auf Eis gelegt, welches eine 0,3\%ige 3-Aminobenzoesäure-Äthylester-Lösung (Tricain, Novartis) für eine anästhesierende Wirkung enthielt. Durch einen kleinen abdominalen Schnitt von 1-2 cm Länge wurden einzelne Ovarsäckchen entnommen. Die Öffnung wurde mit zwei Nähten (Muskel- und Hautnaht) wieder verschlossen. Die Entnahme erfolgte durch eine Mitarbeiterin der Abteilung Vegetative Physiologie und Pathophysiologie (Ausnahmegenehmigung nach $§ 9$ Abs. 1 Satz 4 Tierschutzgesetz lag vor).

Zur Vereinzelung der Oozyten wurde das Ovarsäckchen mittels zweier Pipetten aufgerissen und zur enzymatischen Entfernung des die Oozyten umgebenden Follikelepithels über Nacht in ORI mit Kollagenase (Typ CLS II, Biochrom) bei $16-18^{\circ} \mathrm{C}$ inkubiert. Die nun größtenteils defollikulierten Oozyten wurden zehn Minuten in calciumfreiem ORI inkubiert und anschließend mehrere Male mit calciumhaltigem ORI gewaschen, um Follikelzellreste zu entfernen. Unter 
einem Binokular wurden intakte Oozyten der Stadien V und VI nach Dumont für die Versuche ausgesucht.

\subsubsection{Mikroinjektion}

Für die Injektion wurden Glaskapillaren mit dem Pipettenzieher hergestellt und die Spitze manuell unter dem Mikroskop gekappt. Um die Kapillaren aus Sodaklarglas gegen Luft abzudichten, wurden sie mit Paraffin-Öl gefüllt. Anschließend wurde die zu injizierende Substanz in die Kapillare aufgezogen und mit dem Mikroinjektor das entsprechende Volumen (23 nl) in die Grenze zwischen vegetativem und animalischem Pol der Oozyte injiziert, um den Kern der Oozyte nicht zu verletzen.

Antisense Oligonukleotide sind kurze DNA-Fragmente, die komplementär zur mRNA sind und spezifisch die Biosynthese bestimmter Proteine inhibieren. Die Expression des endogenen $X e$ nopus Connexin 38 (Cx38) wurde durch eine zusätzliche Injektion mit Antisense Oligonukleotiden (asCx38) blockiert, um spezifische Cx46.6-Ströme messen zu können (Barrio et al., 1991; Bruzzone et al., 1993; Hennemann et al., 1992). $23 \mathrm{nl}$ (5 ng/Oozyte) der synthetisierten cRNA (3.2.5) und $23 \mathrm{nl}$ ( $23 \mathrm{ng} /$ Oozyte) der asCx38 wurden also zusammen in eine Oozyte injiziert. Als Kontrolle wurden Oozyten verwendet, die nur mit asCx38 injiziert wurden. Bis zur weiteren Analyse wurden die Oozyten in täglich ersetztem Aufbewahrungs-ORI (2.7.6) bei 16-18 ${ }^{\circ} \mathrm{C}$ gelagert.

\subsubsection{Zwei-Elektroden Spannungsklemme}

Die Charakterisierung der elektrophysiologischen Eigenschaften von injizierten Oozyten erfolgte mittels der Zwei-Elektroden Spannungsklemme ( Two Electrode Voltage Clamp, TEVC). Ein negativ gekoppelter feed-back-Regelkreis stellte die Hauptkomponente der TEVC-Anordnung dar (Abbildung 3.1). Er ermöglichte die Einstellung des Membranpotentials auf einen definierten Wert. Neben einem Oozyten-Spannungsklemmen-Verstärker wurden für das Messbad eine Referenz- und eine Erdungselektrode sowie eine Strom- und Spannungselektrode für die Oozyte benötigt. Die Erdungs- und Referenzelektroden bestanden aus chloriertem Silberdraht. Die Referenzelektrode war an den Vorverstärker der Spannungselektrode angeschlossen. Da die chlorierten Silberdrahtelektroden nicht direkt in die Oozyte eingestochen werden konnten, wurde jede Silberdrahtelektrode mit einer mit drei molarer KCl-gefüllten Glaskapillare verlängert, die dann wie in Abbildung 3.1 in die Oozyte eingestochen wurden.

In eine spülbare Badkammer wurde eine Oozyte platziert und mit Hilfe von Mikromanipulatoren zuerst die Spannungs- und dann die Stromelektrode eingestochen. Das Ruhemembranpo- 


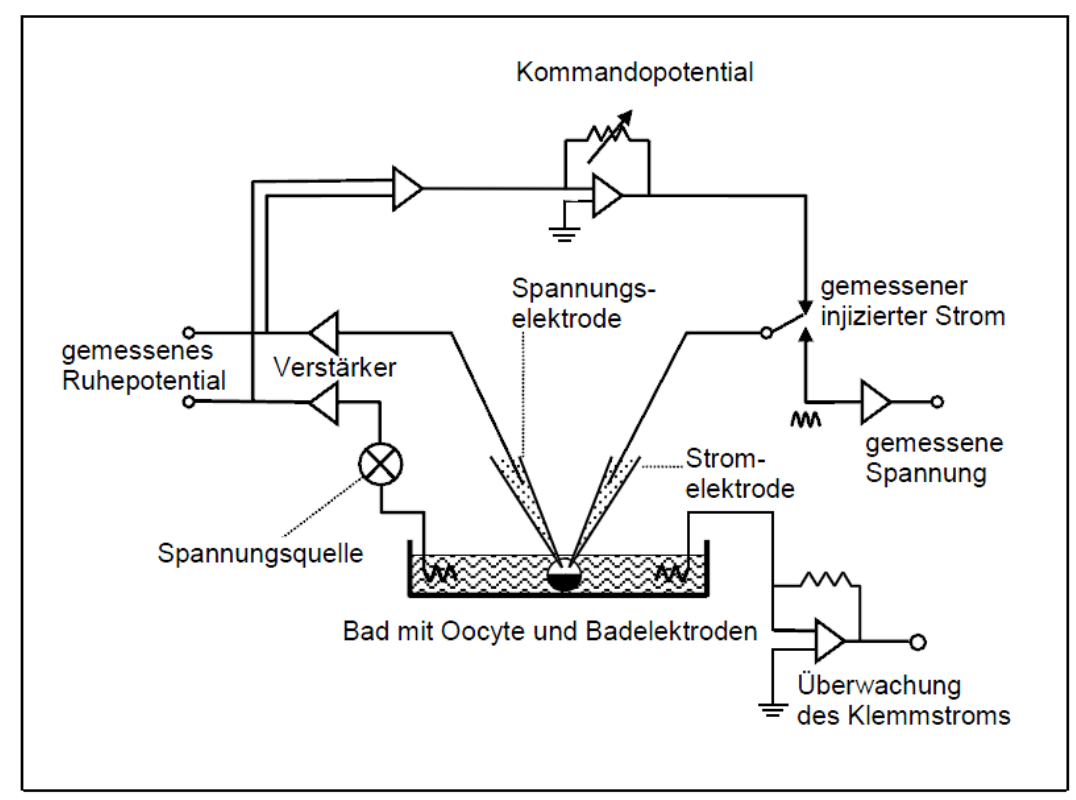

Abbildung 3.1.: Schematische Darstellung des TEVC-Aufbaus. (Schwarzer, 2000)

tential wurde als Potentialdifferenz zwischen dem Intrazellularraum und einer extrazellulären Referenzelektrode über die Spannungselektrode gemessen. Zu diesem Zeitpunkt kam es vom Betrag her zu keinem Ionenfluss über die Membran, d.h. der transmembranöse Strom war konstant null. Dieser Modus wird auch als Current-Clamp-Modus bezeichnet.

Die Messung der Ionenströme wurde bei konstant gehaltenem Membranpotential durchgeführt (Voltage-Clamp-Modus), um eine wechselseitige Beeinflussung von Membranpotential und transmembranösen Ionenströmen zu vermeiden. Das Membranpotential wird konstant gehalten, indem durch die Stromelektrode ein entgegengesetzter Strom eingespeist wird, sobald das Membranpotential vom Sollwert abweicht. Der einzuspeisende Strom entspricht dabei immer den Ladungsverschiebungen über die Membran der Oozyte. Beim Umschalten in den Voltage-Clamp-Modus wurde über die Stromelektrode so viel Strom in die Zelle injiziert, dass diese konstant auf einem gewählten Membranpotential von $-40 \mathrm{mV}$ bzw. $0 \mathrm{mV}$ gehalten werden konnte. Der Betrag an Strom, der zur Aufrechterhaltung des vorgegebenen Potentials in die Zelle injiziert werden musste, wurde als Parameter, der dem transmembranösen Ionenfluss entsprach, vom Zweikanalschreiber aufgezeichnet. Die Richtung des Stroms wird konventionell als Bewegung positiv geladener Ionen bezeichnet. Ein Nettoeinstrom kann sich also sowohl auf den Einstrom positiv geladener Teilchen, als auch auf den Ausstrom negativer Ladungen beziehen.

Nach dem Einstechen der Spannungs- und Stromelektroden in die Oozyte wurde die Perfusion mit ORI gestartet und ca. fünf Minuten gewartet bis sich ein stabiles Membranpotential eingestellt hatte. Die Oozyte konnte nun auf ein Potential von $-40 \mathrm{mV}$ geklemmt werden. Nach einer Zeitspanne von 200 Sekunden wurde die Perfusion auf ORI ohne Calcium umgestellt. Der 
transmembranöse Strom wurde nach fünf Minuten gemessen. Nach Depolarisation der Oozyte durch ein Klemmpotential von $0 \mathrm{mV}$ wurde der transmembranöse Strom nach 100 Sekunden abgelesen.

\subsubsection{Gefrierschnitte von Oozyten}

Zur Anfertigung von Gefrierschnitten wurden die Oozyten drei Tage nach Injektion der cRNA viermal mit ORI gewaschen und zur Fixierung 30 Minuten in 4\% Paraformaldehyd (PFA) inkubiert. Nach zweimaligem Waschen mit ORI wurde die Oozyte mit Einbettmedium für Gefrierschnitte (Tissue Freezing Medium, Jung) auf einem Stück Kork eingedeckt und direkt in 2-Methylbutan, das in einem Metallbecher mit flüssigem Stickstoff gekühlt wurde, gehalten. Sobald das Einbettmedium fest war, wurden die eingebetteten Oozyten entweder bei $-80^{\circ} \mathrm{C}$ zwischengelagert oder es wurden direkt im Kryotom (Jung CM 3000) 8 um dünne Schnitte angefertigt. Die Schnitte wurden auf Objektträgern in ProLong-Gold (Invitrogen) eingedeckelt. Die Fluoreszenzanalyse erfolgte mit dem Fluoreszenzmikroskop Axio Imager M.1 und der Axio Vision LE4.5 Software von Zeiss.

\subsection{Proteinbiochemische Methoden und Immunzytochemie}

\subsubsection{Proteinextraktion aus Gewebe und Zellen}

Zur Herstellung von Proteinextrakten aus Gewebe oder Zellen wurde RIPA-Puffer verwendet, der wie folgt zusammengesetzt ist.

$$
\begin{array}{rl}
150 \mathrm{mM} & \mathrm{NaCl} \\
50 \mathrm{mM} & \text { Tris-HCl pH 8,0 } \\
5 \mathrm{mM} & \text { EDTA pH } 8,0 \\
0,5 \%(\mathrm{w} / \mathrm{v}) & \text { Na-Deoxycholat } \\
1 \%(\mathrm{v} / \mathrm{v}) & \text { Nonidet P-40 } \\
0,1 \%(\mathrm{w} / \mathrm{v}) & \text { SDS }
\end{array}
$$

Um endogene Proteasen zu hemmen, wurde der Protease-Inhibitor Cocktail frisch nach Herstellerangaben (Roche) zugegeben.

Zunächst wurden die Zellen zur Proteinextraktion zweimal mit kaltem PBS gewaschen. Zellen einer $10 \mathrm{~cm}^{2}$-Schale wurden in $600 \mathrm{\mu l}$ RIPA-Puffer mit Hilfe eines Zellschabers in ein Reagiergefäß überführt und durch repetitives Pipettieren homogenisiert. Um Proteine aus Gewebe zu extrahieren, wurde ein entsprechendes Volumen RIPA-Puffer zur Homogenisation mit Hilfe 
eines Douncers verwendet. Zur Proteinextraktion aus Suspensionszellen (z.B. Lymphozyten) wurden die Zellen einer $75 \mathrm{~cm}^{2}$-Zellkultur-Flasche zehn Minuten bei $95 \times$ g sedimentiert und in $100 \mu \mathrm{l}$ PBS resuspendiert. Zu dieser Suspension wurden dann $500 \mu \mathrm{l}$ RIPA-Puffer zugegeben.

Nach einer 15-minütigen Inkubation der Zellen in RIPA-Puffer bei $4^{\circ} \mathrm{C}$ wurden die unlöslichen Bestandteile durch einen Zentrifugationsschritt $\left(18620 \times \mathrm{g}, 4^{\circ} \mathrm{C}, 15\right.$ Minuten $)$ abgetrennt und der Überstand in ein neues Gefäß überführt. Die Proteinkonzentration wurde mit dem BC Assay for Protein quantitation-Kit bestimmt. Zur weiteren Aufbewahrung wurden die Proteinextrakte in flüssigem Stickstoff schockgefroren und bei $-80^{\circ} \mathrm{C}$ gelagert.

\subsubsection{Quantitative Proteinbestimmung mit Bicinchoninsäure (BCA)}

Alkalisches Kupfer (Cu II) wird von Proteinen proportional zu ihrer Konzentration zu Cu I reduziert. Dieses reduzierte Kupfer kann mit Hilfe der Bicinchoninsäure gemessen werden, da die beiden einen dunklen Farbkomplex mit einem Absorptionsmaximum von $562 \mathrm{~nm}$ bilden, wobei die Extinktionszunahme einem Anstieg der Proteinkonzentration direkt proportional ist. Die Kupferreduktion wird durch Cystein, Cystin, Tyrosin, Tryptophan und die Peptidbindungen hervorgerufen. Die BCA-Proteinbestimmung zeichnet sich vor allem durch ihre Toleranz gegenüber Detergenzien aus.

Die quantitative Proteinbestimmung wurde mit dem Kit BC Assay for Protein quantitation (Uptima) nach Herstellerangaben durchgeführt. Als repräsentativer Standard diente das im Kit enthaltene Serum Albumin mit einer Ausgangskonzentration von $2 \mathrm{mg} / \mathrm{ml}$. Für die Proteinquantifizierung wurde eine BSA-Standardreihe von 0 bis $30 \mu \mathrm{g}$ angesetzt. Die Konzentrationsbestimmung der Proben erfolgte in einem Spektralphotometer über Extinktionsmessung bei $562 \mathrm{~nm}$.

\subsubsection{Deglykosylierung mit PNGase F}

Die Peptid-N-Glykosidase F (PNGase F) spaltet spezifisch N-Glykane vom Asparaginrest des Peptids ab. Zur Deglykosylierung wurde eine definierte Menge (30-50 ug) Proteinextrakt (3.4.1) in 10x Denaturierungspuffer zehn Minuten bei $95^{\circ} \mathrm{C}$ denaturiert. 1/10 Volumen G7-Puffer und 1/10 Volumen 10\% Nonidet P-40 wurden zum Ansatz hinzugegeben. Der DeglykosylierungsAnsatz wurde nach Zugabe von 1-5 $\mathrm{ll}$ PNGase F ein bis zwei Stunden bei $37^{\circ} \mathrm{C}$ inkubiert. Die deglykosylierten Proteinextrakte wurden direkt in 4x SDS-Probenpuffer (2.7.3) aufgenommen und mittels SDS-Gelelektrophorese (3.4.4) analysiert. 


\subsubsection{Denaturierende Polyacrylamid-Gelelektrophorese}

Mit der denaturierenden Polyacrylamid-Gelelektrophorese (SDS-PAGE) werden Proteine gelelektrophoretisch in einem diskontinuierlichen System unter denaturierenden Bedingungen in SDS-haltigen Polyacrylamidgelen größenabhängig (Molekulargewicht) aufgetrennt (Laemmli, 1970). Durch Einsatz des anionischen Detergenz SDS werden die Eigenladungen der Proteine überdeckt, so dass sie schließlich alle eine negative Ladung tragen. Außerdem werden die Proteine denaturiert und durch Zugabe reduzierender Substanzen (DTT, $\beta$-Mercaptoethanol) vollständig entfaltet und in ihre Untereinheiten zerlegt. Die Auftrennung erfolgt in einer Gelmatrix aus Acrylamidpolymeren, die über N'N'-Methylen-bisacrylamid quervernetzt werden. Die Durchlässigkeit der Matrix ist abhängig von der Konzentration der Polyacrylamid-Monomeren und dem Grad der Quervernetzung, d.h. der Konzentration der bifunktionellen Gruppen. Die Polymerisation erfolgt durch eine Radikalkettenreaktion, die von dem Radikalstarter APS gestartet wird und daraufhin den Polymerisierungskatalysator TEMED aktiviert.

Bei der diskontinuierlichen Gelelektrophorese wird dem eigentlichen Trenngel noch ein Sammelgel von ca. 1/10 Länge der Trenngelstrecke vorgeschaltet, dessen pH-Wert um zwei Einheiten tiefer liegt als der des Trenngels. Dies führt zu einer Verdichtung der Proteinprobe vor dem Eintritt in das Trenngel und somit zu einer schärferen Trennung der jeweiligen Proteinbanden. Es wurden überwiegend Minigele in einer Gelelektrophorese-Kammer der Firma BioRad verwendet. Hierbei betrug die Laufstrecke im Sammelgel 0,5-1 cm und die des Trenngels ca. $6 \mathrm{~cm}$. Die Zusammensetzung der Trenn- bzw. Sammelgele ist in den Tabellen 2.3 und 2.4 aufgelistet.

Die zu analysierenden Proteinproben wurden vor Auftrag auf das Gel mit 4x SDS-Probenpuffer (2.7.3) versetzt und fünf Minuten bei $95^{\circ} \mathrm{C}$ denaturiert. Die Elektrodenkammer wurde mit 1x SDS-Laufpuffer (2.7.3) gefüllt und die Proteinproben wurden nach ihrer Denaturierung in die Geltaschen pipettiert. Die elektrophoretische Auftrennung der Proteine erfolgte bei einer konstanten Stromstärke von 25 mA/Gel und konnte durch mitlaufende Protein-Molekulargewichtsstandards (2.3) verfolgt werden. Die Gele wurden anschließend entweder mit CoomassieblauLösung angefärbt (2.7.3) oder im Western Blot (3.4.5) eingesetzt.

\subsubsection{Western Blot}

Durch das Western Blot Verfahren werden Proteine, die zuvor gelelektrophoretisch aufgetrennt wurden, durch Anlegen eines elektrischen Feldes aus dem Gel auf eine Nitrozellulosemembran transferiert. Da die Proteine auf dieser Membran aufgrund hydrophober Wechselwirkungen immobilisiert vorliegen, sind sie für weitere Analysen ohne den störenden Einfluss der Gelmatrix zugänglich. 
Bei der Immunologischen Detektion können anschließend einzelne Proteine eines Proteingemisches mittels spezifischer Antikörper auf der Membran nachgewiesen werden. Dafür wird zunächst ein Antikörper an das entsprechende Protein gebunden, an den dann wiederum ein Sekundärantikörper bindet. Da der Sekundärantikörper Enzym-gekoppelt ist (Horseradish Peroxidase: HRP), kann durch anschließende Zugabe eines geeigneten Substrats eine Farbreaktion oder ein Chemilumineszenzsignal hervorgerufen werden. Dieses wird dort sichtbar, wo sich das Protein auf der Membran befindet.

\section{Proteintransfer}

Beim eingesetzten Semidry-Blotting-Verfahren wurden Whatman-Filterpapiere und eine Nitrozellulosemembran mit Transferpuffer (2.7.3) getränkt und in einer Blotapparatur so geschichtet, dass die Proteine aus dem Gel zur Anode wandern konnten und dabei auf der Membran haften blieben. Die Wanderung zur Anode kommt durch das SDS zustande, das nach der Gelelektrophorese noch an die Proteine gebunden ist und ihnen so eine negative Ladung verleiht. Der Proteintransfer wurde in einer Semidry-Blot-Apparatur (Biometra) nach Anweisung des Herstellers durchgeführt und erfolgte eine Stunde mit $2 \mathrm{~mA}$ pro $\mathrm{cm}^{2}$-Gelfläche. Der Proteintransfer konnte im Anschluss durch eine reversible Färbung mit Ponceau S-Lösung (2.7.3) überprüft werden.

\section{Immunologische Detektion von Proteinen}

Nach dem Proteintransfer wurde die Nitrozellulosemembran eine Stunde bei Raumtemperatur oder über Nacht bei $4^{\circ} \mathrm{C}$ in Blockierlösung (5\% [w/v] Magermilchpulver in TBST) inkubiert, um unspezifische Bindungsstellen abzusättigen. Danach wurden die Primärantikörper in geeigneter Verdünnung (Tabelle 2.1) in Blockierlösung ein bis zwei Stunden bei Raumtemperatur auf die Membran gegeben. Vor Zugabe der Sekundärantikörper wurde die Membran drei- bis fünfmal jeweils fünf Minuten mit TBST gewaschen, um nicht gebundene Primärantikörper zu entfernen. Der geeignete Sekundärantikörper wurde ebenfalls in Blockierlösung verdünnt (Tabelle 2.1) und eine Stunde bei Raumtemperatur auf die Membran gegeben. Danach wurde nochmals drei- bis fünfmal jeweils fünf Minuten mit TBST gewaschen.

Durch Verwendung eines HRP-gekoppelten Sekundärantikörpers wurden die immunologisch markierten Proteine detektiert. Dazu wurde die Membran fünf Minuten bei Raumtemperatur mit Lumi-Light Western Blotting Substrate (Roche) inkubiert, wobei das daraus entstandene Chemilumineszenzsignal mittels Luminescent Image Analyzer und der Software MultiGaugeVer3.X-(Fujifilm) analysiert oder auf Röntgenfilmen detektiert wurde. 


\subsubsection{Methoden zur Expression und Isolierung rekombinanter Proteine}

\subsubsection{Expression und Aufreinigung von GST-Fusionsproteinen}

Für die Aufreinigung von GST-Fusionsproteinen wurde Glutathion Sepharose $4 B$ (GE Healthcare) verwendet. Mit entsprechendem prokaryontischem Expressionsvektor (pGEX-KG) transformierte E.coli BL21-Zellen (Bioline) wurden in $20 \mathrm{ml}$ Selektionsmedium über Nacht schüttelnd bei $37^{\circ} \mathrm{C}$ inkubiert. Mit dieser Vorkultur wurden am nächsten Morgen $400 \mathrm{ml}$ desselben Mediums inokuliert und bis zu einer $\mathrm{OD}_{600}$ von 0,6 bei $37^{\circ} \mathrm{C}$ unter Schütteln weiter kultiviert.

Die Expression der Fusionsproteine wurde durch Zugabe von 1 mM IPTG (Isopropyl $\beta$-D-Thiogalactopyranosid, Roth) induziert. Nach dreistündiger Inkubation bei $25^{\circ} \mathrm{C}$ wurden die Bakterien sedimentiert $\left(5000 \times \mathrm{g}\right.$, zehn Minuten, $\left.4^{\circ} \mathrm{C}\right)$ und in $20 \mathrm{ml}$ eiskaltem PBS-Puffer resuspendiert. Dem PBS-Puffer wurden zuvor 1\% Triton X-100 und Protease-Inhibitor Cocktail (Complete, Roche) zugefügt. Nach einer Ultraschallbehandlung (sechsmal jeweils zehn Sekunden auf Eis, 100\% Amplitude, 1 Zyklus, Ultraschallprozessor UP 50H) wurde das Lysat 30 Minuten schüttelnd auf Eis inkubiert und über Nacht bei $-20^{\circ} \mathrm{C}$ eingefroren. Das Bakterienlysat wurde am nächsten Tag auf Eis aufgetaut und 20 Minuten bei $4^{\circ} \mathrm{C}$ und $14460 \times$ g zentrifugiert. Der Überstand wurde in ein $15 \mathrm{ml}$ Falcon überführt und mit $900 \mu \mathrm{l}$ Glutathion Sepharose $4 B$ versetzt 45 Minuten bei Raumtemperatur auf einem Rotator inkubiert. Die Matrix mit dem gebundenen Protein wurde fünfmal mit PBS gewaschen und anschließend in einem Volumen PBS mit Protease-Inhibitor bei $4^{\circ} \mathrm{C}$ gelagert.

GST-Fusionsproteine, die der Herstellung von Antikörpern dienten, wurden nach Bindung an die Glutathion-Sepharose und anschließenden Waschschritten viermal mit $1 \mathrm{ml}$ Elutionspuffer (10 mM Glutathion, $50 \mathrm{mM}$ Tris- $\mathrm{HCl}$ pH 8,0) eluiert. Die Proteinlösung wurde über Nacht gegen fünf Liter 1xPBS dialysiert. Qualität und Quantität der Aufreinigung wurden durch SDS-PAGE (3.4.4), anschließender Coomassie-Färbung und Proteinbestimmung (3.4.2) überprüft.

\subsubsection{Expression und Aufreinigung von His-Fusionsproteinen}

Zur Expression des His-Fusionsproteins wurden stabil transfizierte HEK 293 Zellen (3.3.3) eingesetzt. Die Aufreinigung der rekombinanten Proteine erfolgte aus dem Zellkulturüberstand. Das Medium wurde durch Zentrifugation $\left(3000 \times \mathrm{g}, 4^{\circ} \mathrm{C}, 60\right.$ Minuten $)$ von Zellmaterial getrennt und anschließend mittels Minisartfilter mit einer Porengröße von 0,45 $\mu \mathrm{m}$ (Sartorius) filtriert. Nach Zugabe von $20 \mathrm{mM} \mathrm{K}_{2} \mathrm{HPO}_{4}(\mathrm{pH} 7,5)$; 0,5 M NaCl und $40 \mathrm{mM}$ Imidazol wurde die Lösung filtriert und entgast (0,22 $\mu \mathrm{m}$ Membranfilter, Corning) auf eine HisTrap FF crude Säule ( GE Healthcare) gegeben. Die Säule enthält immobilisierte Nickelchelate. Diese Komplexverbin- 
dungen weisen noch freie Koordinationsstellen auf und können deshalb Proteine komplexieren, die über geeignete Donor-Liganden verfügen. Als Donor dient in diesem Fall der 6-HistidinTag, der mit dem Nickelchelat einen stabilen Komplex bildet. Die Elution erfolgte durch einen Imidazol-Gradienten von 40-500 mM (Protein-Verdrängung durch Imidazol). Die Hauptfraktion des gebundenen His-Fusionsproteins wurde mit einer Imidazolkonzentration von $100 \mathrm{mM}$ eluiert.

\subsubsection{Antikörperproduktion}

Zur Antikörperproduktion wurde das jeweilige rekombinante Fusionsprotein an die Firma Seramun verschickt. Dort wurden dann je zwei Kaninchen immunisiert und das gewonnene Hyperimmunserum wurde zur Immunfluoreszenz oder Western Blot weiter verwendet.

\subsubsection{GST-pulldown}

Mittels GST-pulldown können Bindungspartner eines GST-Fusionsproteins ermittelt werden. Dazu wird das GST-Fusionsprotein über den GST-Anteil an Glutathion-Sepharose gekoppelt. Gibt man dann ein Proteingemisch hinzu, so interagieren die Bindungspartner mit dem GSTFusionsprotein. Nach Isolierung der Glutathion-Sepharose können etwaige Bindungspartner in SDS-PAGE (3.4.4) und Western Blot (3.4.5) analysiert werden.

Für die GST-pulldown Experimente wurde das GST-Fusionsprotein in Bakterien exprimiert und gereinigt (3.4.6.1). Die an Glutathion-Sepharose gebundenen GST-Fusionsproteine wurden mit humanem Gehirnextrakt (20 mg) oder Hela-Zellextrakt (8-10 konfluent gewachsene $10 \mathrm{~cm}^{2}$ Schalen) über Nacht bei $4^{\circ} \mathrm{C}$ inkubiert. Zuvor wurde von der GST-Fusionsprotein-Sepharose ein Drittel abgenommen und bis zur weiteren Verwendung bei $4^{\circ} \mathrm{C}$ gelagert. Diese Proben dienten bei der späteren Analyse mittels SDS-PAGE als Negativkontrolle. Am folgenden Tag wurde das Glutathion-Sepharose-GST-Fusionsprotein-Zellextrakt-Gemisch dreimal mit Lysepuffer (mit Protease-Inhibitor) zehn Minuten bei $4^{\circ} \mathrm{C}$ drehend gewaschen, um alle nichtgebundenen Proteine zu entfernen. Zwischen den Waschschritten wurde die Sepharose fünf Minuten bei $650 \times \mathrm{g}$ und $4^{\circ} \mathrm{C}$ zentrifugiert.

Abschließend wurde der Überstand vollständig abgenommen und die gebundenen Proteine durch Zugabe von $200 \mu \mathrm{l}$ 4xSD-Probenpuffer und fünfminütiger Inkubation bei $95^{\circ} \mathrm{C}$ von der Sepharose eluiert. Die Elution der Kontrollen (GST und GST-Fusionsprotein ohne Zelllysatinkubation) wurde entsprechend in $100 \mu \mathrm{l}$ 4x SDS-Probenpuffer durchgeführt. Die Proben wurden mittels SDS-Gelelektrophorese (3.4.4) analysiert. Nach kolloidaler Coomassie-Färbung wurden Banden putativer Bindungspartner aus dem Gel ausgeschnitten und massenspektro- 
metrisch analysiert. Die massenspektrometrische Untersuchung wurde freundlicherweise von dem Analytik-Labor des Instituts für Mikrobiologie und Genetik (Universität Göttingen, Dr. Oliver Valerius) durchgeführt. 


\section{Ergebnisse}

\subsection{Pathogenese der GJA12-assoziierten PMLD}

In einer informativen konsanguinen türkischen Familie mit mehreren PMLD Betroffenen konnte von Uhlenberg et al. nach einer genomweiten Kopplungsanalyse 2004 das Connexin 46.6 (Cx46.6) bzw. Gap Junction Protein $\alpha 12$ (GJA12) als neues Krankheitsgen identifiziert werden. In drei von fünf Familien mit PMLD Betroffenen wurden fünf verschiedene Cx46.6-Mutationen (Tabelle 1.1) gefunden. Von Bugiani et al. (2006), Salviati et al. (2006) und Wolf et al. (2006) wurden insgesamt vier weitere Mutationen (Tabelle 1.1) nachgewiesen.

\subsubsection{Mutationsanalyse der PMLD-Patienten}

Im Rahmen dieser Arbeit wurde ein Kollektiv von 195 Patienten aus 184 betroffenen Familien, die anhand der klinischen und kraniellen kernspintomographischen Parameter der Krankheitsentität der PMLD zugeordnet werden konnten, auf Mutationen im Cx46.6-Gen untersucht. Die genomische DNA wurde mittels Standardmethoden (3.1.13) direkt aus dem Blut der Patienten isoliert. Das Cx46.6-Gen wurde durch spezifische Oligonukleotide (Tabelle A.1) in einer PCR amplifiziert (3.1.4) und sequenziert (3.1.14). Die Sequenzierergebnisse wurden mit der Referenzsequenz NM_020435.2 abgeglichen und mit Hilfe des Programms DNA Star auf Mutationen untersucht.

In den 184 untersuchten PMLD Familien wurden bei 20 Patienten aus 16 Familien neue Mutationen identifiziert. Die Sequenzveränderungen sind in Tabelle 4.1 zusammengefasst. Angegeben ist das Geschlecht, eine eventuell vorhandene Konsanguinität der Eltern, die ethnische Herkunft der Patienten und die Mutationsbezeichnung auf Nukleotid- und Proteinebene. Des Weiteren ist aus den Tabellenangaben ersichtlich, ob die Mutation homozygot (beide Allele betreffend) oder heterozygot (ein Allel betreffend) vorliegt. 15 Patienten, von denen 13 aus Familien mit konsanguinen Eltern stammen, tragen homozygote Cx46.6-Mutationen. Heterozygote Mutationen des Cx46.6-Gens wurden bei fünf Individuen nachgewiesen. Alle Mutationen wurden durch eine zweite PCR und Sequenzanalyse verifiziert. 
Tabelle 4.1.: Daten der Patienten mit neu identifizierten $C x 46.6$-Mutationen

\begin{tabular}{|c|c|c|c|c|c|c|}
\hline $\begin{array}{l}\text { Fa- } \\
\text { milie }\end{array}$ & Patient & $\begin{array}{l}\text { Ge- } \\
\text { schlecht }\end{array}$ & $\begin{array}{l}\text { Konsan- } \\
\text { guinität }\end{array}$ & Herkunft & $\begin{array}{l}\text { Mutation auf } \mathrm{Nu} \text { - } \\
\text { kleotidebene }\end{array}$ & $\begin{array}{l}\text { Mutation auf } \\
\text { Proteinebene }\end{array}$ \\
\hline F1 & mt3436 & $\mathrm{w}$ & ja & Türkei & $\begin{array}{l}\text { c. }\left[69 \_82 \text { dup } 14\right]+ \\
{\left[69 \_82 \text { dup14] }\right.}\end{array}$ & $\begin{array}{l}\text { p.[L28RfsX16]+ } \\
{[\text { L28RfsX16] }}\end{array}$ \\
\hline & mt3437 & $\mathrm{m}$ & ja & Türkei & $\begin{array}{l}\text { с. }\left[69 \_82 \text { dup } 14\right]+ \\
{\left[69 \_82 \text { dup } 14\right]}\end{array}$ & $\begin{array}{l}\text { p.[L28RfsX16]+ } \\
{[\text { L28RfsX16] }}\end{array}$ \\
\hline $\mathrm{F} 2$ & mt3550 & $\mathrm{m}$ & nein & Italien & $\begin{array}{l}\text { c. }\left[292 \_293 i n s G T A\right] \\
+[-]\end{array}$ & $\begin{array}{l}\text { p.[A98G_V99 } \\
\text { insT]+[-] }\end{array}$ \\
\hline F3 & G47 & $\mathrm{m}$ & nein & Italien & $\begin{array}{l}\text { c. }[392 \mathrm{delC}]+ \\
{[392 \mathrm{delC}]}\end{array}$ & $\begin{array}{l}\text { p.[P131RfsX79]+ } \\
{[\text { P131RfsX79] }}\end{array}$ \\
\hline $\mathrm{F} 4$ & G588 & $\mathrm{w}$ & nein & Italien & c. $[392 \mathrm{delC}]+[-]$ & $\begin{array}{l}\text { p.[P131RfsX79]+ } \\
{[-]}\end{array}$ \\
\hline F5 & G344 & $\mathrm{m}$ & nein & $\begin{array}{l}\text { Reunion } \\
\text { Island }\end{array}$ & c. $[445 \mathrm{G}>\mathrm{A}]+[-]$ & p. $[\mathrm{G} 149 \mathrm{~S}]+[-]$ \\
\hline F6 & G1356 & $\mathrm{m}$ & ja & Lybien & $\begin{array}{l}\text { c. }[620 \mathrm{del} A]+ \\
{[620 \operatorname{del} A]}\end{array}$ & $\begin{array}{l}\text { p.[E207GfsX3]+ } \\
{[\mathrm{E} 207 \mathrm{GfsX} 3]}\end{array}$ \\
\hline F7 & G297 & $\mathrm{w}$ & ja & Algerien & $\begin{array}{l}\text { c. }[695 \mathrm{insG}]+ \\
{[695 \mathrm{insG}]}\end{array}$ & $\begin{array}{l}\text { p. }[\mathrm{Y} 232 \mathrm{X}]+ \\
{[\mathrm{Y} 232 \mathrm{X}]}\end{array}$ \\
\hline F8 & G680 & $\mathrm{w}$ & ja & Algerien & $\begin{array}{l}\text { c. }[695 \mathrm{insG}]+ \\
{[695 \mathrm{ins} \mathrm{G}]}\end{array}$ & $\begin{array}{l}\text { p. }[\mathrm{Y} 232 \mathrm{X}]+ \\
{[\mathrm{Y} 232 \mathrm{X}]}\end{array}$ \\
\hline F9 & mt1205 & $\mathrm{m}$ & ja & Türkei & $\begin{array}{l}\text { c. }\left[970 \_971 \text { dupGC }\right] \\
+\left[970 \_971 \text { dupGC }\right]\end{array}$ & $\begin{array}{l}\text { p.[A325PfsX147] } \\
+[\mathrm{A} 325 \mathrm{Pfs} 147]\end{array}$ \\
\hline F10 & G193 & $\mathrm{m}$ & ja & Türkei & $\begin{array}{l}\text { с. }[706 \mathrm{G}>\mathrm{C}]+ \\
{[706 \mathrm{G}>\mathrm{C}]}\end{array}$ & $\begin{array}{l}\mathrm{p} \cdot[\mathrm{G} 236 \mathrm{R}]+ \\
{[\mathrm{G} 236 \mathrm{R}]}\end{array}$ \\
\hline
\end{tabular}




\begin{tabular}{|c|c|c|c|c|c|c|}
\hline $\begin{array}{l}\text { Fa- } \\
\text { milie }\end{array}$ & Patient & $\begin{array}{l}\text { Ge- } \\
\text { schlecht }\end{array}$ & $\begin{array}{l}\text { Konsan- } \\
\text { guinität }\end{array}$ & Herkunft & $\begin{array}{l}\text { Mutation auf } \mathrm{Nu}- \\
\text { kleotidebene }\end{array}$ & $\begin{array}{l}\text { Mutation auf } \\
\text { Proteinebene }\end{array}$ \\
\hline F11 & G330 & $\mathrm{w}$ & nein & Ägypten & $\begin{array}{l}\text { c. }[793 \mathrm{~A}>\mathrm{G}]+ \\
{[793 \mathrm{~A}>\mathrm{G}]}\end{array}$ & $\begin{array}{l}\text { p. }[\mathrm{T} 265 \mathrm{~A}]+ \\
{[\mathrm{T} 265 \mathrm{~A}]}\end{array}$ \\
\hline F12 & mt4089 & $\mathrm{m}$ & ja & Türkei & $\begin{array}{l}\text { c. }\left[932 \_951 d u p 20\right] \\
+\left[932 \_951 d u p 20\right]\end{array}$ & $\begin{array}{l}\text { p. }[\mathrm{C} 318 \mathrm{Pf} X 160] \\
+[\mathrm{C} 318 \mathrm{Pf} X 160]\end{array}$ \\
\hline & mt4090 & $\mathrm{w}$ & ja & Türkei & $\begin{array}{l}\text { c. }\left[932 \_951 \mathrm{dup} 20\right] \\
+\left[932 \_951 \mathrm{dup} 20\right]\end{array}$ & $\begin{array}{l}\text { p. }[\text { C318PfsX160] } \\
+[\mathrm{C} 318 \mathrm{PfsX} 160]\end{array}$ \\
\hline F13 & $\mathrm{mt} 3548$ & $\mathrm{~m}$ & nein & Italien & c. $[1193 \mathrm{C}>\mathrm{T}]+[-]$ & p. $[\mathrm{T} 398 \mathrm{I}]+[-]$ \\
\hline F14 & G218 & $\mathrm{m}$ & nein & England & c. $[1193 \mathrm{C}>\mathrm{T}]+[-]$ & p. $[$ T398I $]+[-]$ \\
\hline \multirow[t]{3}{*}{ F15 } & mt5040 & $\mathrm{w}$ & ja & Brasilien & $\begin{array}{l}\text { c. }\left[369 \_370 \operatorname{delGC}\right]+ \\
{\left[369 \_370 \operatorname{delGC}\right]}\end{array}$ & $\begin{array}{l}\text { p. }[\mathrm{R} 125 \mathrm{SfsX} 12] \\
+[\mathrm{R} 125 \mathrm{SfsX} 12]\end{array}$ \\
\hline & mt5041 & $\mathrm{m}$ & ja & Brasilien & $\begin{array}{l}\text { c. }\left[369 \_370 \operatorname{delGC}\right]+ \\
{\left[369 \_370 \mathrm{delGC}\right]}\end{array}$ & $\begin{array}{l}\text { p. }[\text { R125SfsX12] } \\
+[R 125 \text { Sf X12] }\end{array}$ \\
\hline & mt5042 & $\mathrm{w}$ & ja & Brasilien & $\begin{array}{l}\text { c. }\left[369 \_370 \operatorname{delGC}\right]+ \\
{\left[369 \_370 \operatorname{delGC}\right]}\end{array}$ & $\begin{array}{l}\text { p. }\left[\mathrm{R} 125 \mathrm{SfsX}_{\mathrm{X}} 12\right] \\
+[\mathrm{R} 125 \mathrm{Sfs} 12]\end{array}$ \\
\hline F16 & mt5008 & $\mathrm{m}$ & ja & Türkei & $\begin{array}{l}\text { c. }[373 \mathrm{C}>\mathrm{T}]+ \\
{[373 \mathrm{C}>\mathrm{T}]}\end{array}$ & $\begin{array}{l}\mathrm{p} \cdot[\mathrm{R} 125 \mathrm{X}]+ \\
{[\mathrm{R} 125 \mathrm{X}]}\end{array}$ \\
\hline
\end{tabular}

Die Mutationsbezeichnung erfolgte entsprechend der Internationalen Mutationsnomenklatur (Nukleotid +1 entspricht dem A des Startcodons) (den Dunnen und Antonarakis, 2000; den Dunnen und Paalman, 2003). $\mathrm{m}=$ männlich; w=weiblich

Bei den Eltern der Patienten mt3436, mt3437, G47, G297, mt1205, mt5040-5042 und mt5008 konnten die homozygoten Mutationen heterozygot bestätigt werden. Die Mutationsanalyse der Eltern von Individuum G218 und G588 ergab, dass die Mütter Trägerinnen der jeweiligen Mutation sind. Die homozygote Mutation der Patienten mt4089 und mt4090 aus Familie 12 wurde bei dem Vater heterozygot nachgewiesen, während von der Mutter dieser Patienten kein Material für eine genetische Untersuchung zur Verfügung stand. Ebenso konnten die Eltern der 
Patienten G1356, G193 und G330 mit homozygoten Mutationen und der Patienten mt3548, mt3550 und G344 mit heterozygoten Mutationen, nicht genetisch untersucht werden.

Insgesamt wurden 13 neue Mutationen identifiziert (siehe auch Abbildung 4.1):

- sechs Frameshift Mutationen: p.Leu28ArgfsX16, p.Arg125SerfsX12, p.Pro131ArgfsX79, p.Glu207GlyfsX3, p.Cys318ProfsX160 und p.Ala325ProfsX147;

- vier Missense Mutationen: p.Gly149Ser, p.Gly236Arg, p.Thr265Ala und p.Thr398Ile;

- zwei Nonsense Mutationen: p.Arg125X und p.Tyr232X;

- eine komplexe Missense-Insertion Mutation: p.Ala98Gly_Val99insThr.

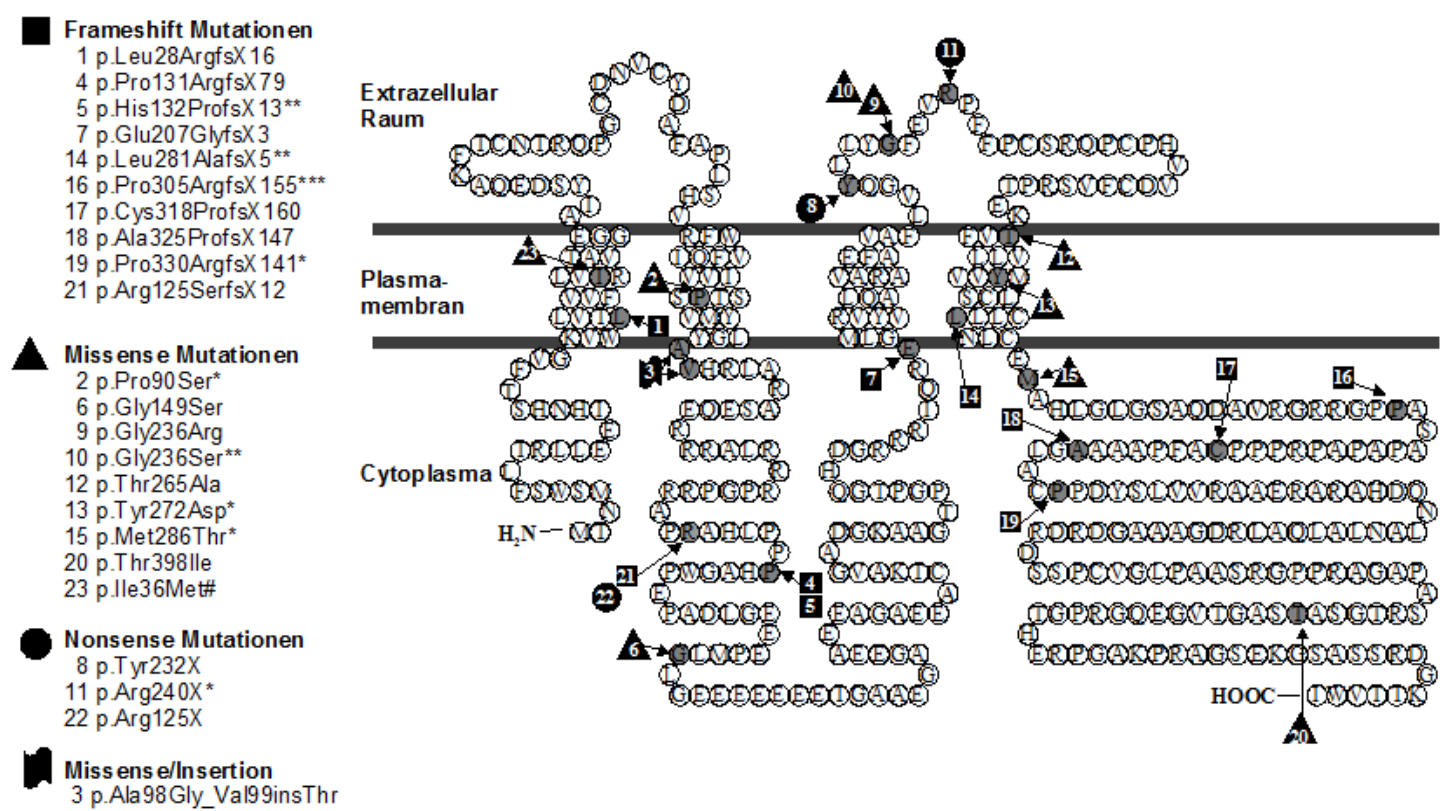

Abbildung 4.1.: Membrantopologie und Lokalisation aller Mutationen im Connexin 46.6. $*$ Mutationen beschrieben von Uhlenberg et al. (2004). ** Mutationen beschrieben von Bugiani et al. (2006). *** Mutation beschrieben von Salviati et al. (2006) und Wolf et al. (2006). \# Mutation beschrieben von Orthmann-Murphy et al. (2008) (angeborene spastische Paraplegie).

Frameshift Mutationen führen zur Verschiebung des DNA-Leserasters und haben auf Proteinebene große Auswirkungen. Die Aminosäuresequenz und somit auch die Proteinstruktur werden stark verändert. Bei Patient mt3437 kommt es durch die Duplikation von 14 bp zu einer Verschiebung des Leserasters. Das daraus resultierende hypothetische Protein besteht aus nur 44 Aminosäuren (p.Leu28ArgfsX16). Führt die Mutation auf DNA-Ebene direkt zu einem StopCodon spricht man von einer Nonsense Mutation, wie bei Patient mt5008. Die Translation des Proteins stoppt bei der Aminosäure Arginin 125 (p.Arg125X). Missense Mutationen führen zu einem Aminosäureaustausch, wie bei Patient G193 (p.Gly236Arg). Hier wird durch den 
Basenaustausch auf DNA Ebene (c.706G>C) die Aminosäure Glycin 236 durch ein Arginin ersetzt.

Die Membrantopologie und die Verteilung aller bisher bekannten Mutationen im Connexin 46.6 sind in Abbildung 4.1 dargestellt. Drei der neu identifizierten Mutationen sind in den Plasmamembrandomänen, fünf in der intrazellulären Schleife, zwei in der zweiten extrazellulären Schleife und drei im zytoplasmatischen C-Terminus lokalisiert.

Zur Bestätigung der Annahme, dass die identifizierten Mutationen im Cx46.6-Gen die Ursache der Erkrankung sind und es sich nicht um Polymorphismen handelt, wurden 160 gesunde Kontrollindividuen ebenfalls auf Cx46.6-Mutationen untersucht. Es wurde jedoch keine der neu lokalisierten Mutationen nachgewiesen. Die beschriebenen Mutationen wurden im Rahmen dieser Arbeit identifiziert und sind veröffentlicht (Henneke et al., 2008).

\subsubsection{Untersuchungen zur Funktionalität der Cx46.6-Mutanten}

Die funktionellen Auswirkungen folgender Missense Mutationen und einer Missense-Insertion Mutation sollten in der vorliegenden Arbeit näher charakterisiert werden:

$$
\begin{array}{ll}
\text { c. } 268 \mathrm{C}>\mathrm{T} & \text { p.Pro90Ser } \\
\text { c. } 1193 \mathrm{C}>\mathrm{T} & \text { p.Thr398Ile } \\
\text { c. } 445 \mathrm{G}>\mathrm{A} & \text { p.Gly149Ser } \\
\text { c.292_293insGTA } & \text { p.Ala98Gly_Val99insThr } \\
\text { c.706G }>\mathrm{C} & \text { p.Gly236Arg } \\
\text { c.793A }>\text { G } & \text { p.Thr265Ala }
\end{array}
$$

Die Untersuchung der Mutationen im Cx46.6-Protein wurde elektrophysiologisch mittels der Zwei-Elektroden Spannungsklemme (TEVC) an RNA injizierten Xenopus laevis Oozyten durchgeführt (3.3.5). Die Cx46.6-kodierende Wildtyp Sequenz und die durch Mutagenese (3.1.5) erzeugten Cx46.6-Mutanten wurden in einen Oozyten Expressionsvektor (pCS2+) subkloniert und in vitro transkribiert (3.2.5). Die Qualität der RNA wurde mittels denaturierendem RNAAgarose-Gel überprüft (3.2.2).

Die synthetische RNA (Wildtyp oder Mutante) wurde in eine Oozyte injiziert (3.3.5.2). Gleichzeitig wurde mittels Injektion eines Antisense Oligonukleotids (Sequenz siehe Tabelle A.1) das endogen in Oozyten exprimierte Connexin 38 blockiert (Barrio et al., 1991; Bruzzone et al., 1993; Hennemann et al., 1992). 48-72 Stunden nach RNA-Injektion wurde zunächst das Ruhemembranpotential der injizierten Oozyten bestimmt (3.3.5.3). Die zu untersuchenden, mit Antisense Oligonukleotiden (asCx38) allein, mit asCx38 und Wildtyp- bzw. mit asCx38 und 
Mutanten-Cx46.6-cRNA injizierten Oozyten wurden während der Messung mit calciumhaltiger Oozyten-Ringerlösung (ORI) perfundiert.

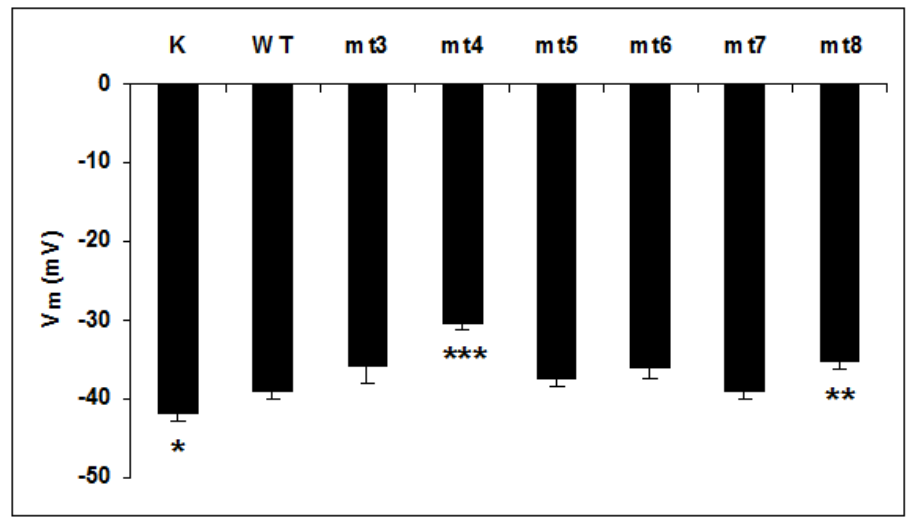

Abbildung 4.2.: Elektrophysiologische Untersuchung des Ruhemembranpotentials von Connexin 46.6 injizierten Oozyten. (a) Das Ruhemembranpotential $\left(\mathrm{V}_{\mathrm{m}}, \mathrm{mV}\right)$ wurde unter Perfusion der Oozyten mit ORI gemessen. $\mathrm{K}=$ asCx38+Wasser $(\mathrm{n}=81)$; WT=asCx38+WildtypCx46.6-RNA ( $\mathrm{n}=84) ; \mathrm{mt3}=\mathrm{asCx} 38+\mathrm{Cx} 46.6$-Pro90Ser-RNA $(\mathrm{n}=19) ; \mathrm{mt} 4=\mathrm{asCx} 38+\mathrm{Cx} 46.6-\mathrm{Thr}-$ 389Ile-RNA ( $\mathrm{n}=83) ; \mathrm{mt5}=$ asCx38+Cx46.6-Gly149Ser-RNA $(\mathrm{n}=37) ; \mathrm{mt6}=$ asCx38+Cx46.6-Ala98Gly_Val99insThr-RNA (n=34); mt7=asCx38+Cx46.6-Gly236Arg-RNA (n=40); mt8=asCx38+Cx46.6-Thr265Ala-RNA ( $\mathrm{n}=53)$. Abweichungen der Messwerte sind als Standardfehler des Mittelwertes (S.E.M.=standard error of the mean) angegeben. P-Werte wurden durch einen ungepaarten Student's T-Test in Bezug zu Cx46.6-Wildtyp injizierten Oozyten bestimmt und nach Bonferroni adjustiert. ${ }^{*} \mathrm{P} \leq 0,026 ;{ }^{* *} \mathrm{P} \leq 0,0032 ;{ }^{* * *} \mathrm{P}=0,0001$.

Die Mittelwerte der gemessenen Ruhemembranpotentiale der Oozyten (Cx46.6-Wildtyp, Pro90Ser, Gly149Ser, Gly236Arg, Ala98Gly_Val99insThr und Thr265Ala) liegen insgesamt zwischen

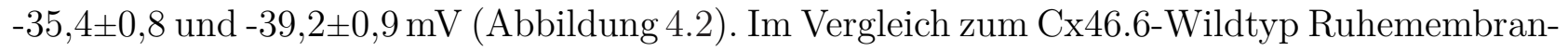
potential ist kein signifikanter Unterschied bei diesen Mutanten erkennbar. Auffällig ist jedoch ein hoch signifikanter Unterschied $(\mathrm{P}=0,0001)$ des Membranpotentials von $9 \mathrm{mV}$ der $\mathrm{Cx} 46.6$ Thr389Ile injizierten Oozyten $(-30,4 \pm 0,9 \mathrm{mV}$; mt4) im Vergleich zu Cx46.6-Wildtyp injizierten Oozyten $(-39,2 \pm 0,9 \mathrm{mV}$; WT). Das Membranpotential des Wildtyps zeigt eine leichte, signifikante Depolarisation im Vergleich zum Potential der asCx38 Oozyten von $3 \mathrm{mV}(-41,93 \pm 0,9 \mathrm{mV}$; $\mathrm{K} ; \mathrm{P}=0,025)$.

Zur Messung des transmembranösen Stroms wurde das Membranpotential der Oozyte auf einen definierten Wert von -40 mV (Klemmpotential) eingestellt, da die Calcium aktivierten Chloridkanäle, die einen großen Anteil am endogenen Ionenstrom der Oozyte haben, bei $-40 \mathrm{mV}$ überwiegend inaktiviert vorliegen (Barish, 1983). Die Connexon-Öffnung wird durch externe divalente Kationen (z.B. $\mathrm{Ca}^{2+}$ ) blockiert, um die Öffnung der Halbkanäle unter physiologischen Bedingungen zu verhindern (Ebihara, 2003). Zur Connexon-Deblockierung wurde somit nach einer Zeitspanne von 200 Sekunden die Perfusion der Oozyte mit ORI ohne Calcium gestartet. Der Connexin-spezifische transmembranöse Strom wurde nach fünf Minuten abgelesen (Versuchsverlauf siehe Abbildung 4.3). 


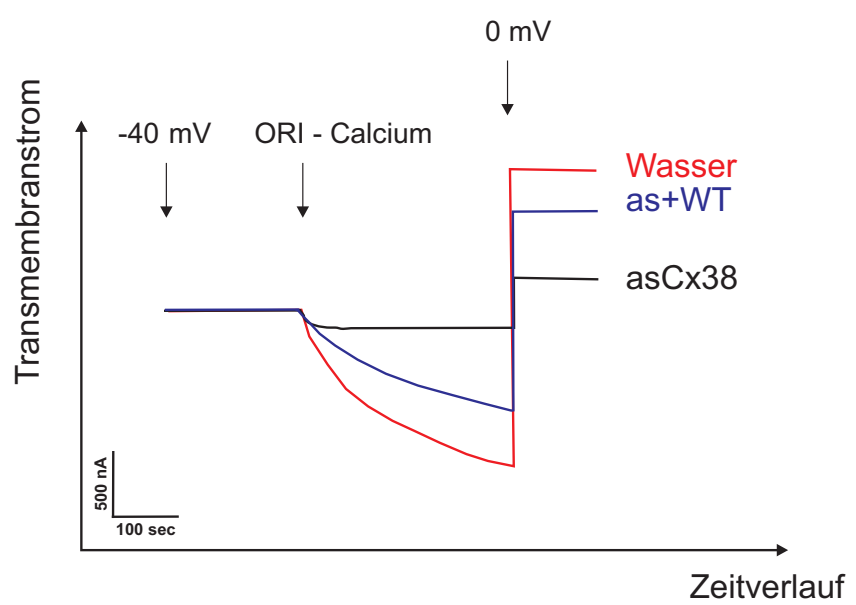

Abbildung 4.3.: Versuchsverlauf der elektrophysiologischen Messung. Der gemessene Transmembranstrom und der Zeitverlauf der Messung jeweils eines Beispiels für asCx38 injizierte Oozyten (asCx38), asCx38 und Cx46.6-Wildtyp coinjizierte Oozyten (as+WT) und Wasser injizierte Oozyten (Wasser) sind abgebildet. Der Transmembranstrom während der Klemmspannung von $-40 \mathrm{mV}$ und der Perfusion mit calciumhaltigem ORI $(-40 \mathrm{mV})$ liegt zunächst bei $0 \mathrm{nA}$. Durch Perfusion der Oozyten mit ORI ohne Calcium (ORI-Calcium) während des Klemmpotentials von $-40 \mathrm{mV}$ wird ein Transmembranstrom aktiviert. Der eingespeiste Strom, der benötigt wird, um das Klemmpotential von $-40 \mathrm{mV}$ aufrecht zu halten, beträgt im Beispiel für die asCx38 injizierte Oozyte -230 nA, für die asCx38 und Cx46.6-Wildtyp coinjizierte Oozyte -800 nA und für die Wasser injizierte Oozyte $-1350 \mathrm{nA}$. Während der Perfusion mit ORI ohne Calcium wurde nach fünf Minuten das Klemmpotential auf $0 \mathrm{mV}$ umgestellt $(0 \mathrm{mV})$. Der eingespeiste Strom beträgt für die asCx38 injizierte Oozyte $130 \mathrm{nA}$, für die asCx38 und Cx46.6-Wildtyp coinjizierte Oozyte $660 \mathrm{nA}$ und für die Wasser injizierte Ooyzte $940 \mathrm{nA}$.

Durch die Perfusion der Oozyte mit ORI ohne Calcium werden nicht nur die Connexone sondern auch bestimmte endogene Kanäle (z.B. Calcium-inaktivierte Chlorid-Kanäle) entblockiert bzw. aktiviert. Diese Connexon-unabhängigen Ströme werden bei der Messung der asCx38 injizierten Oozyten aufgezeichnet. Zur Analyse des Cx46.6-spezifischen transmembranösen Stroms wurde zunächst der Mittelwert der gemessenen Ströme der asCx38 injizierten Oozyten des jeweiligen Messtages ermittelt und zur Normalisierung der Messdaten subtrahiert. Ein Ausreißer-Test nach Nalimov wurde anschließend durchgeführt. Die statistische Signifikanz der Daten wurde mittels ungepaartem Student's T-Test analysiert.

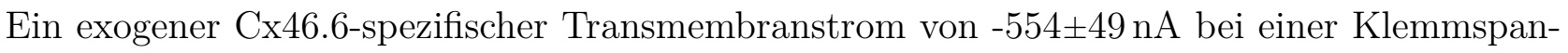
nung von -40 mV kann in den asCx38 plus Cx46.6-Wildtyp-RNA injizierten Oozyten (WT) nach der Normalisierung festgestellt werden (Abbildung 4.4 a). Ein Einwärtsstrom von $-693 \pm 58$ nA zeigt sich in den mit Cx46.6-Thr398Ile-RNA injizierten Oozyten (mt4). Signifikant reduzierte Transmembranströme konnten bei den Mutanten Pro90Ser (mt3), Gly149Ser (mt5), Ala98Gly_Val99insThr (mt6), Gly236Arg (mt7) und Thr265Ala (mt8) aufgezeichnet werden. Der normalisierte Halbkanal-Strom der Mutante Gly149Ser beträgt $-269 \pm 68$ nA. Dieser Strom ist 
im Vergleich zum Wildtyp-Strom um mehr als die Hälfte reduziert. Alle anderen MutantenStröme sind noch kleiner.

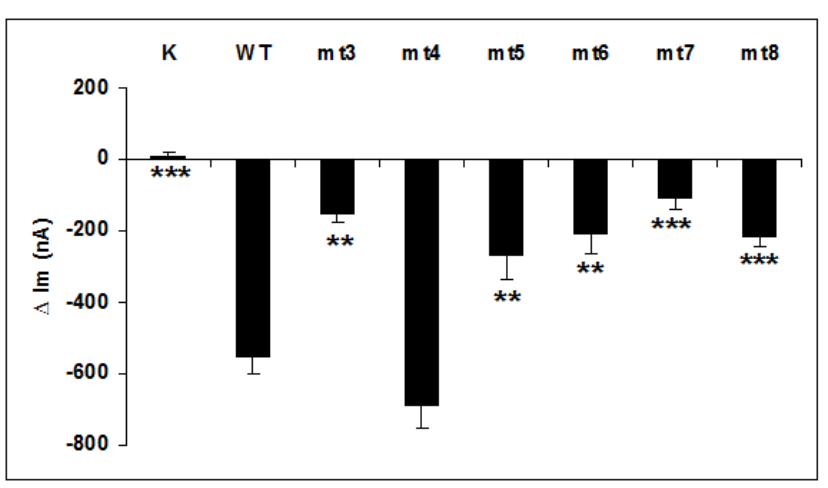

(a) Transmembranstrom bei $-40 \mathrm{mV}$ Klemmspannung

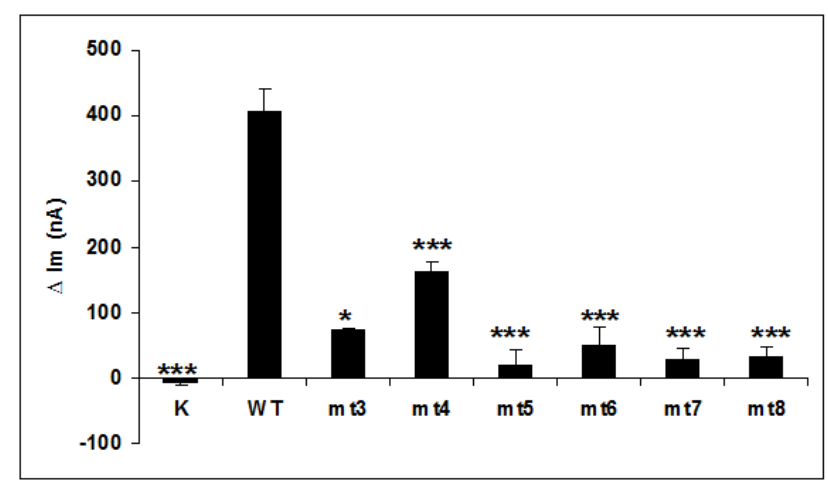

(b) Transmembranstrom bei $0 \mathrm{mV}$ Klemmspannung

Abbildung 4.4.: Elektrophysiologische Untersuchung des Transmembranstroms von Connexin 46.6 injizierten Oozyten. Dargestellt sind jeweils die mit dem Mittelwert der asCx38 injizierten Oozyten $(\mathrm{K})$ normalisierten Ströme $\left(\Delta \mathrm{I}_{\mathrm{m}}, \mathrm{nA}\right)$. Die Beschriftung entspricht den unter Abbildung 4.2 erklärten Abkürzungen. Abweichungen der Messwerte sind als Standardfehler des Mittelwertes (S.E.M.) angegeben. P-Werte wurden durch einen ungepaarten Student's T-Test in Bezug zu Cx46.6-Wildtyp injizierten Oozyten bestimmt und nach Bonferroni adjustiert. ${ }^{*} \mathrm{P} \leq 0,019 ;{ }^{* *} \mathrm{P} \leq 0,0012 ;{ }^{* * *} \mathrm{P}=0,0001$. (a) Der Transmembranstrom der mit asCx38 und RNA injizierten Oozyten wurde bei einer Klemmspannung von $-40 \mathrm{mV}$ während der Perfusion mit ORI ohne Calcium gemessen. (b) Der Transmembranstrom der mit asCx38 und RNA injizierten Oozyten wurde bei einer Klemmspannung von $0 \mathrm{mV}$ während der Perfusion mit ORI ohne Calcium gemessen.

Durch Depolarisation der Oozyten durch ein Klemmpotential von $0 \mathrm{mV}$ soll eine ConnexonÖffnung verstärkt werden. Der transmembranöse Strom wurde nach einer Stabilisationsphase von 100 Sekunden abgelesen und ebenfalls mit dem Wert der asCx38 injizierten Oozyten abgeglichen (Abbildung 4.4b). Der normalisierte Halbkanal-Strom der mit Cx46.6-WT-RNA inji-

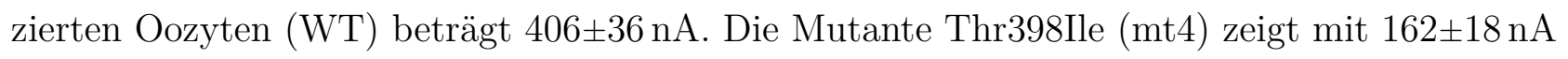
eine signifikante Verminderung des Transmembranstroms. Der normalisierte Halbkanal-Strom der anderen Mutanten (Pro90Ser, Gly149Ser, Ala98Gly_Val99insThr, Gly236Arg und Thr265Ala) zum Ausgleich der transmembranösen Ströme liegt unter 75 nA. Diese Mutanten zeigen also eine deutliche Verminderung des Transmembranstroms im Vergleich zum Cx46.6-Wildtyp.

\subsubsection{Lokalisation und Expression von Cx46.6-WT-GFP in Oozyten}

Die Expression und Lokalisation des Cx46.6-WT-Proteins sollte in den injizierten Oozyten untersucht werden. Da zu Beginn dieser Arbeit kein Cx46.6-Antikörper zur Verfügung stand, wurde die kodierende Region des Cx46.6-Gens mit einem GFP-Tag versehen und in den pCS2+-Vektor ligiert. Der GFP-Tag resultierte aus der Subklonierung von Connexin 46.6 in 
einen pEGFP-N1-Vektor. Das Cx46.6-WT-GFP Konstrukt wurde in vitro transkribiert (3.2.5) und in Oozyten injiziert (3.3.5.2). Drei Tage nach der Injektion wurden Gefrierschnitte von Cx46.6-WT-GFP-RNA und Wasser injizierten Oozyten angefertigt (3.3.5.4). Die Expression der Cx46.6-WT-GFP-Proteine wurde mittels Fluoreszenzmikroskop analysiert.

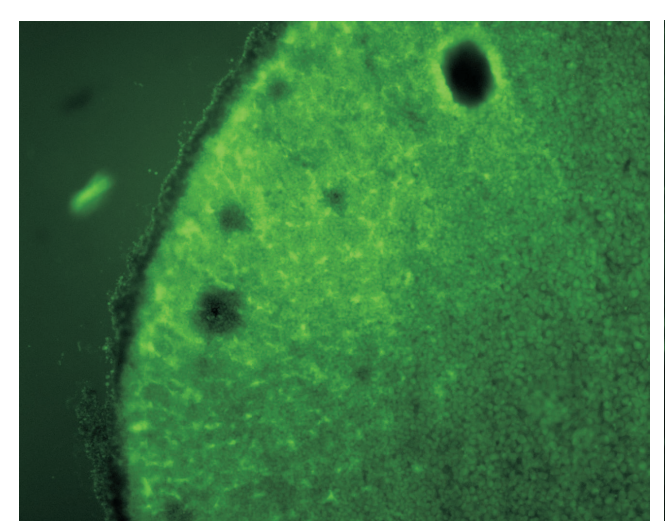

(a) Cx46.6-WT-GFP injizierte Oozyte

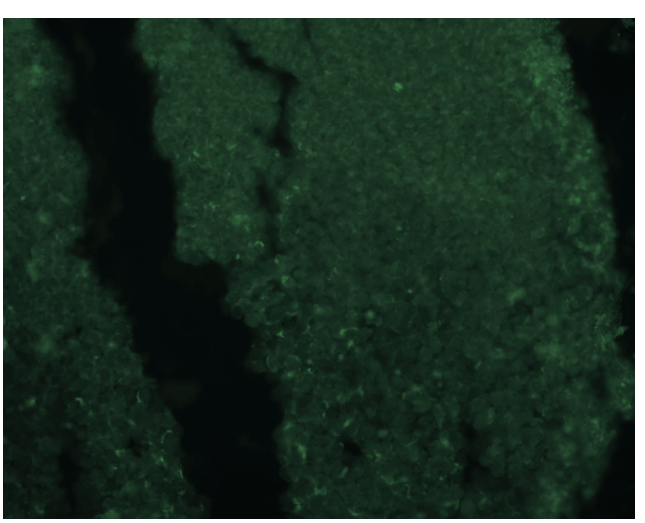

(b) Wasser injizierte Oozyte

Abbildung 4.5.: Lokalisation und Expressionsanalyse von Cx46.6-WT-GFP in Oozyten.

(a) Gefrierschnitt einer mit Cx46.6-WT-GFP-RNA injizierten Oozyte im Vergleich zur (b) Wasser injizierten Oozyte.

Anhand der GFP-Autofluoreszenz ist eine Expression des Cx46.6-WT-GFP-Proteins in der Oozyte deutlich erkennbar (Abbildung 4.5a). Im Vergleich dazu zeigt die Wasser injizierte Oozyte keine GFP-Autofluoreszenz (Abbildung 4.5 b). Ein Teil des Cx46.6-WT-GFP-Proteins lässt sich an der Plasmamembran detektieren, ein großer Teil verbleibt jedoch im Zytoplasma bzw. in einem Bereich kurz vor der Membran.

\subsubsection{Erzeugung eines Anti-Cx46.6 Antiserums}

Um Untersuchungen zur Expression und Lokalisation des Cx46.6-Proteins ohne möglicherweise störenden GFP-Tag durchführen zu können, wurde ein polyklonaler Antikörper hergestellt. Der die Aminosäuren 104-197 kodierende Bereich der Cx46.6-cDNA (Nukleotide 310-591) wurde mit einer humanen cDNA als Matrize amplifiziert, in den prokaryontischen Expressionsvektor pGEX-KG kloniert (Tabelle 2.5) und als GST-Cx46.6-Fusionsprotein (GST-15) in Bakterien exprimiert (3.4.6.1). Dieser intrazelluläre Bereich des Cx46.6-Proteins wurde für die Antikörperproduktion gewählt, da er keine Homologien zu anderen Proteinen, besonders nicht zu anderen Connexinen aufweist.

Zur Auswahl der zu immunisierenden Kaninchen wurden Präimmunseren von 6 Kaninchen im Western Blot getestet, um eine unspezifische Detektion des Proteins auszuschließen. Das 
gereinigte GST-Cx46.6-Fusionsprotein (ca. $2 \mathrm{mg}$ ) wurde von der Firma Seramun (Heidesee) zur Immunisierung von zwei ausgewählten Kaninchen (K112 und K113) eingesetzt.

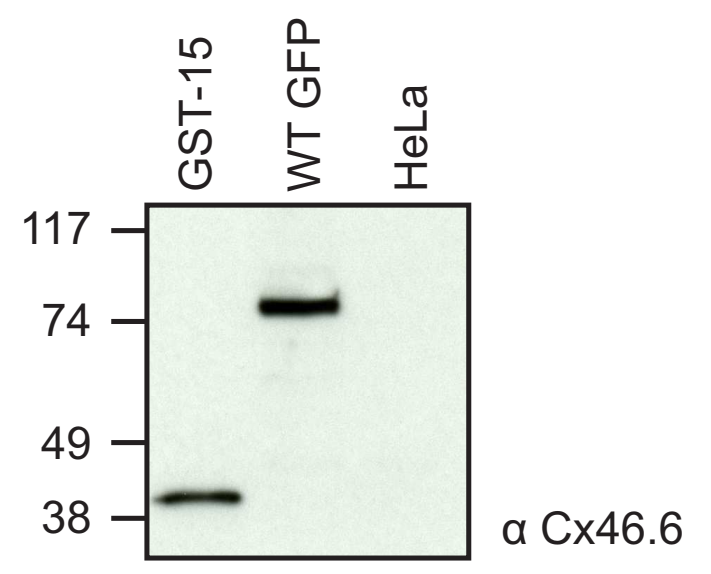

Abbildung 4.6.: Charakterisierung des Cx46.6-Antiserums im Western Blot. Für die Analyse des polyklonalen Cx46.6-Antiserums im Western Blot wurden $10 \mathrm{ng}$ des in Bakterien exprimierten GST-Cx46.6-Fusionsproteins (AS 104-197, GST-15), $30 \mu \mathrm{g}$ Proteinextrakt transient transfizierter HeLa Zellen (Cx46.6-Wildtyp-GFP-Protein, WT GFP) und $30 \mathrm{\mu g}$ untransfizierter HeLa Zellextrakt (Negativkontrolle, HeLa) eingesetzt. Die Detektion der rekombinant exprimierten Proteine erfolgte mit dem ungereinigten Antiserum in einer Verdünnung von 1:10000. Der Größenstandard wurde in kDa angegeben.

Nach Erhalt der Cx46.6-Immunseren wurde die Spezifität im Western Blot (3.4.4 und 3.4.5) überprüft. Dazu wurde das rekombinante GST-Cx46.6-Fusionsprotein (GST-15), Proteinextrakte von transient transfizierten Cx46.6-WT-GFP (WT GFP) und von untransfizierten HeLa Zellen (HeLa) eingesetzt. Nach Ermittlung der optimalen Antikörper Konzentration in verschiedenen nicht gezeigten Western Blot-Analysen wurde das Cx46.6-Antiserum in einer Verdünnung von 1:10000 verwendet. Das GST-Cx46.6-Fusionsprotein wird in entsprechender Größe von etwa $39 \mathrm{kDa}$ spezifisch vom Antiserum des Kaninchens 112 detektiert (Abbildung 4.6). Auch das Cx46.6-WT-GFP-Protein wird im HeLa-Gesamtproteinextrakt spezifisch vom Antikörper als Bande auf einer Höhe von ungefähr 75 kDa nachgewiesen. Im untransfizierten HeLaProteinextrakt bindet das Antiserum nicht unspezifisch. Die Spezifität des Cx46.6-Antiserums konnte somit im Immunoblot bestätigt werden.

Um die Spezifität des Cx46.6-Antiserums in der Immunfluoreszenz zu testen, wurden HeLa Zellen mit dem Cx46.6-WT-GFP-Konstrukt transient transfiziert (3.3.2). Durch Immunfärbung (3.3.4) der Zellen mit dem Cx46.6-Antiserum und einem sekundären Cy3-gekoppelten $\alpha$ Kaninchen-IgG Antikörper (rot) konnte eine Kolokalisation der roten und grünen Fluoreszenzsignale in der Überlagerung anhand der Gelbfärbung gezeigt werden (Abbildung 4.7). Das Cx46.6-Antiserum kann spezifisch zur Detektion von Cx46.6 in der Immunfluoreszenz verwendet werden. 

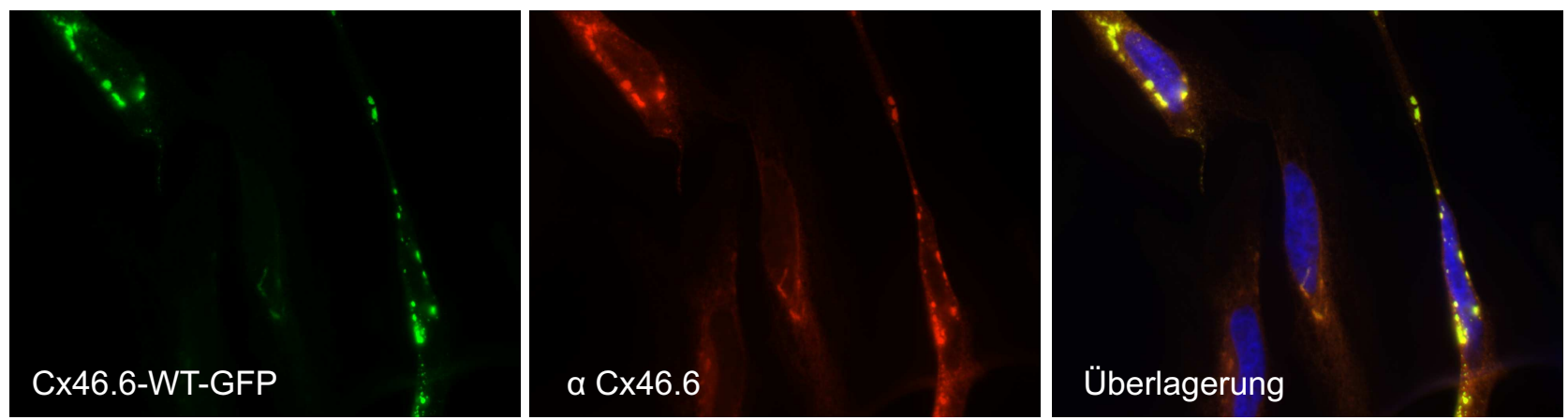

Abbildung 4.7.: Charakterisierung des Cx46.6-Antiserums in der Immunfluoreszenz. Zur Untersuchung des Cx46.6-Antiserums in der Immunfluoreszenz wurden HeLa Zellen transient mit einem Cx46.6-WT-GFP-Konstrukt transfiziert. Zur Detektion der Proteine wurde das polyklonale Cx46.6-Antiserum ( $\alpha$ Cx46.6) in einer Verdünnung von 1:2000 eingesetzt. Als sekundärer Antikörper wurde ein Cy3-gekoppelter $\alpha$ Kaninchen-IgG-Antikörper (rot) verwendet. Die Kernfärbung erfolgte durch DAPI im ProLongGold-Eindeckelmedium. Fluoreszenzsignale wurden mit dem Fluoreszenzmikroskop Axio Imager M.1 und der Axio Vision LE4.5 Software von Zeiss analysiert.

\subsubsection{Expressionsanalyse der Cx46.6-WT- und -mt-Proteine}

Zunächst wurde untersucht, ob ein Unterschied der Cx46.6-Proteinexpression zwischen Wildtyp (WT)- und Mutanten (mt)-Proteinen besteht. Zur Expressionsanalyse wurden HeLa Zellen transient mit den verschiedenen WT- und mt-Konstrukten (Tabelle 2.5) transfiziert (3.3.2) und anschließend im Immunoblot analysiert (3.4.4 und 3.4.5).

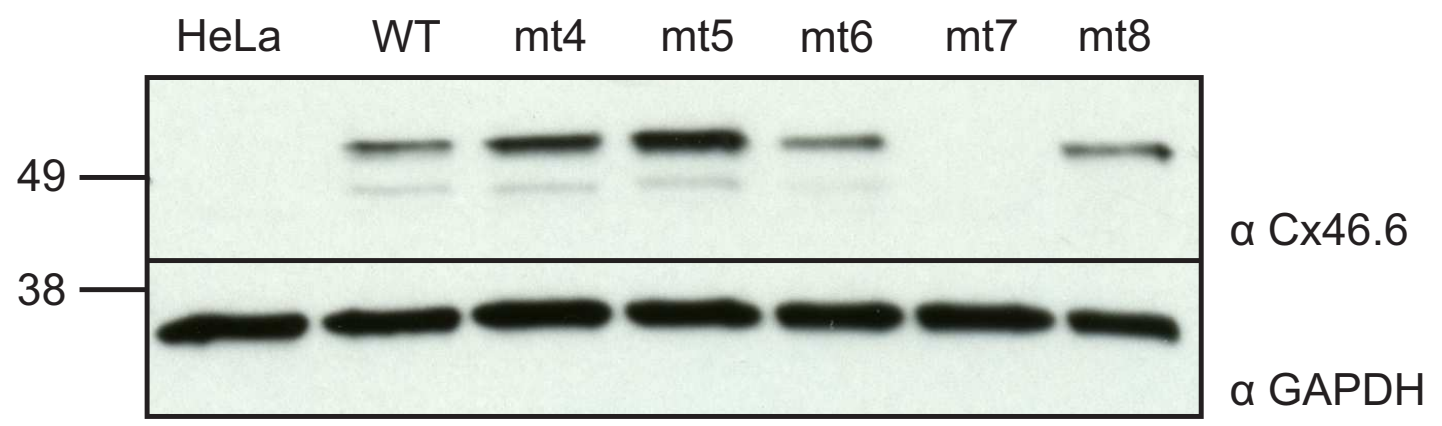

Abbildung 4.8.: Immundetektion der Expression von Cx46.6 in transient transfizierten HeLa Zellen. Zur Expressionskontrolle des Cx46.6-Wildtyp-Proteins (WT) und der verschiedenen Cx46.6 Mutanten (mt4=Thr398Ile; mt5=Gly149Ser; mt6=Ala98Gly_Val99insThr; mt7=Gly236Arg; mt8=Thr265Ala) wurden $30 \mu \mathrm{g}$ des jeweiligen Proteinextrakts eingesetzt. Als Negativkontrolle wurden $30 \mu \mathrm{g}$ Proteinextrakt untransfizierter HeLa Zellen (HeLa) verwendet. Die Detektion des Cx46.6-Proteins erfolgte mittels Cx46.6-Antiserums in einer Verdünnung von 1:10000. Als Ladekontrolle diente das GAPDH-Protein, welches durch einen GAPDH-Antikörper (Verdünnung 1:5000) detektiert wurde. Der Größenstandard wurde in kDa angegeben. 
Abbildung 4.8 zeigt einen Western Blot dieser Wildtyp- und Mutanten-Proteinextrakte. Es ist zu sehen, dass das Cx46.6-WT-Protein (WT) so wie die Mutanten Thr398Ile (mt4), Gly149Ser (mt5), Ala98Gly_Val99insThr (mt6) und Thr265Ala (mt8) exprimiert und vom Antiserum detektiert werden. Die mitgeführte GAPDH-Kontrolle zeigt in allen Spuren die gleiche Bandenstärke, dies lässt schließen, dass überall die gleiche Menge Proteinextrakt aufgetragen wurde. Auffällig ist, dass die Mutanten Thr398Ile (mt4) und Gly149Ser (mt5) stärker exprimiert werden als das Wildtyp-Protein, und dass die Mutante Gly236Arg (mt7) nicht exprimiert wird. Als Negativkontrolle diente ein Proteinextrakt aus untransfizierten HeLa Zellen.

\subsubsection{Subzelluläre Lokalisation der Cx46.6-WT- und -mt-Proteine}

Anhand der Bestimmung der subzellulären Lokalisation der in HeLa Zellen exprimierten Proteine wurde untersucht, ob die Mutationen im Cx46.6-Protein Auswirkungen auf den Transport zur Plasmamembran haben. Dazu wurden HeLa Zellen mit den verschiedenen Konstrukten (Wildtyp und Mutanten) transient transfiziert (3.3.2). In der Immunfluoreszenz (3.3.4) wurde das Cx46.6-Protein 48 Stunden nach der Transfektion mit dem Cx46.6-Antiserum und einem Alexa488-gekoppelten $\alpha$ Kaninchen-IgG-Antikörper (grün) detektiert. Zur Membranlokalisation wurde das Transmembranprotein Pan-Cadherin mit einem monoklonalen Pan-CadherinAntikörper und einem sekundären Cy3-gekoppelten $\alpha$ Maus-IgG-Antikörper nachgewiesen.

Die Lokalisation des Cx46.6-WT-Proteins konnte an der Plasmamembran detektiert werden (Kolokalisation mit Pan-Cadherin; Abbildung 4.9A). Stärker grün gefärbte Bereiche in der Membran deuten daraufhin, dass sich die Connexone zu Gap Junction Plaques zusammenlagern. Verbindungen zur Nachbarzelle sind deutlich sichtbar an den filamentösen grün gefärbten Membranausläufern der Zelle. Von Orthmann-Murphy et al. (2007a) wurde ein alternatives Startcodon neun Basenpaare nach dem ersten ATG als Translationsinitiationscodon beschrieben. Die bislang in dieser Arbeit verwendeten Konstrukte wurden vom ersten Startcodon aus synthetisiert. Um zu untersuchen, ob diese beiden Startcodons zu Unterschieden in der Lokalisation der Proteine führen, wurde ein Cx46.6-Wildtyp Konstrukt mit dem zweiten alternativen Startcodon kloniert und mittels Immunfluoreszenz analysiert. In der Lokalisation der beiden Wildtyp Konstrukte zeigten sich keine Unterschiede (Abbildung 4.9 A und B). Das vom ersten Startcodon aus translatierte Protein sowie das um drei Aminosäuren verkürzte Protein konnten an der Plasmamembran durch Kolokalisation mit Pan-Cadherin nachgewiesen werden. 

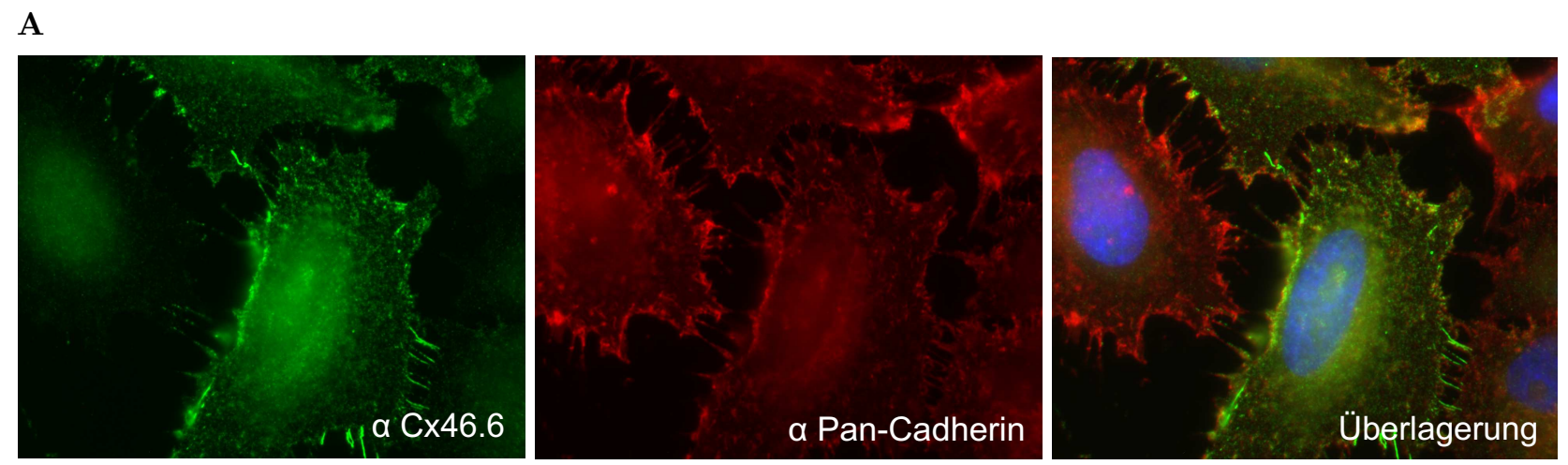

B
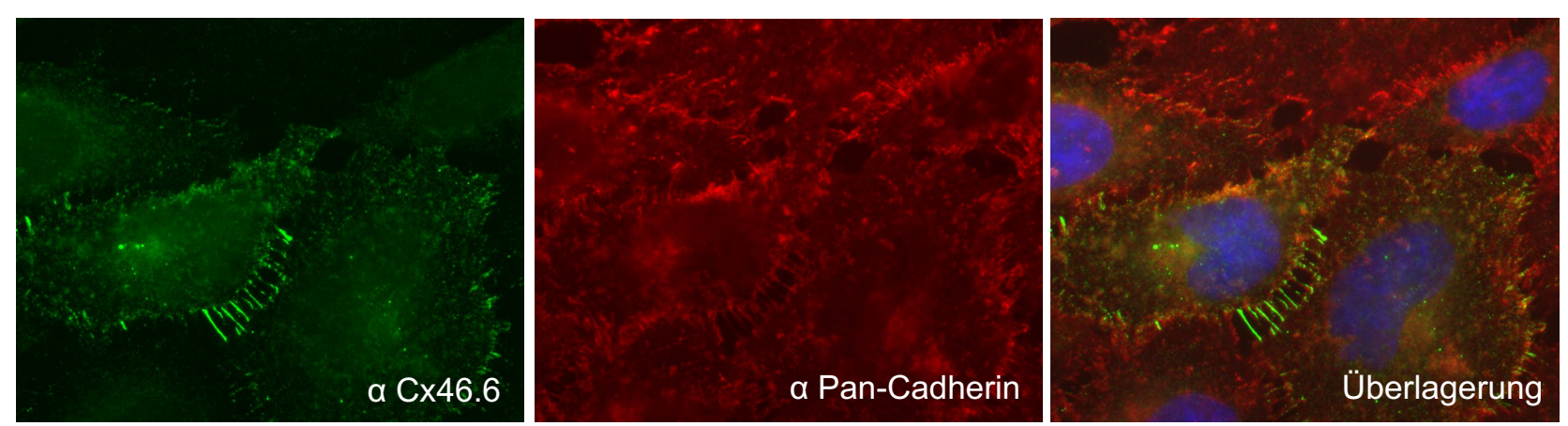

Abbildung 4.9.: Subzelluläre Lokalisation von Cx46.6-WT in transient transfizierten HeLa Zellen. Die subzelluläre Lokalisation in den Cx46.6-WT transfizierten HeLa Zellen wurde mit Hilfe des Cx46.6-Antiserums ( $\alpha$ Cx46.6, grün) und dem Pan-Cadherin Antikörper ( $\alpha$ Pan-Cadherin, rot) nachgewiesen. Die Kernfärbung erfolgte mittels DAPI im ProLongGoldEindeckelmedium. (A) Lokalisation des Cx46.6-WT-1.ATG-Proteins. (B) Lokalisation des Cx46.6-WT-2.ATG-Proteins.

In Abbildung 4.10 ist die subzelluläre Lokalisation der Mutanten Connexine dargestellt. Die Bilder auf der linken Seite zeigen die Färbung des Cx46.6, die mittleren Bilder die Färbung des Endoplasmatischen Retikulums und auf den Bildern rechts ist die Überlagerung der Einzelfärbungen mit einer Zellkernfärbung zu sehen. Die Mutante Pro90Ser zeigt eine Kolokalisation mit dem ER-Marker (PDI, Abbildung 4.10 A). Das Connexin gelangt nicht an die Plasmamembran. Das gleiche Bild zeigt sich auch für die Mutante Ala98Gly_Val99insThr und Thr265Ala (Abbildung 4.10 B und C). Beide Proteine sind im ER lokalisiert, was durch eine gelbliche Färbung in der Überlagerung der beiden Einzelfärbungen deutlich wird. Das Cx46.6-Thr398Ile wird größtenteils in die Membran eingebaut und bildet Verbindungen zu Nachbarzellen. Eine partielle Kolokalisation mit dem ER konnte nachgewiesen werden (Abbildung 4.10 D). Cx46.6Proteine mit der Mutation Gly149Ser wurden teilweise in der Membran detektiert, ein großer Teil ist aber mit dem ER-Marker kolokalisiert (Abbildung 4.10E). Die Mutante Gly236Arg wurde mittels Cx46.6-Antikörper in der Immunfluoreszenz, wie auch im Western Blot, nicht nachgewiesen (Abbildung 4.10 F) und wird offensichtlich nicht exprimiert. 

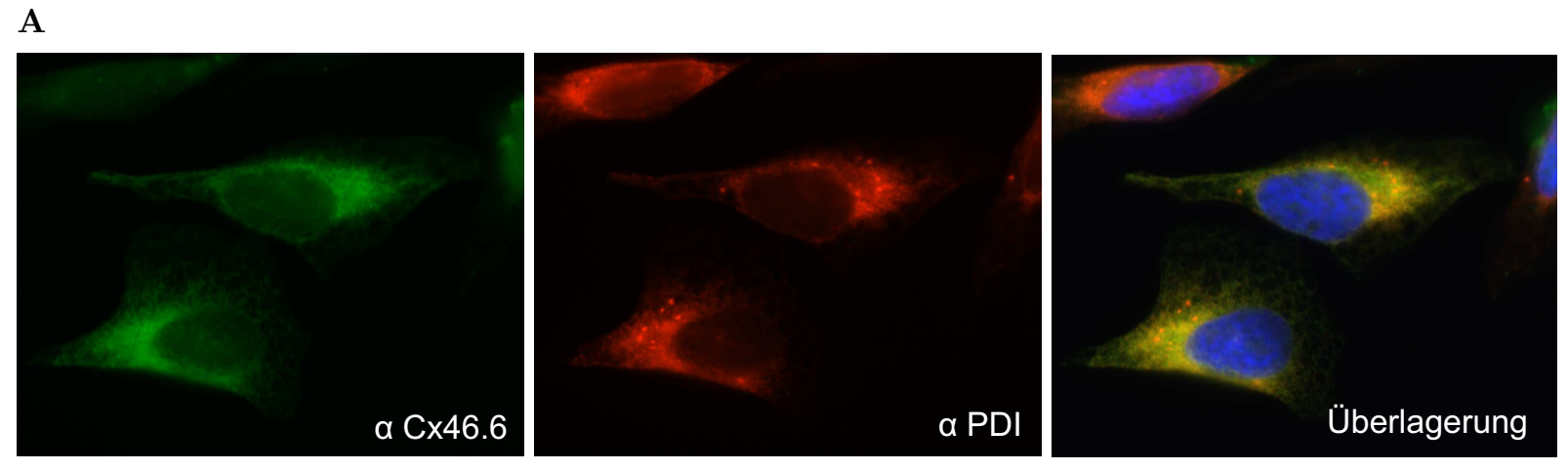

B
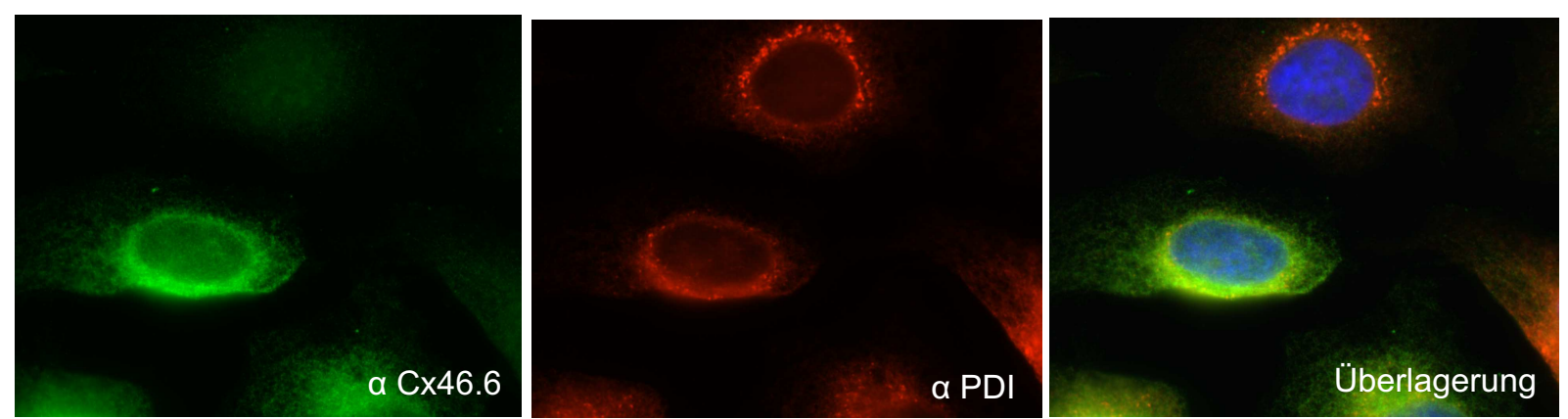

C
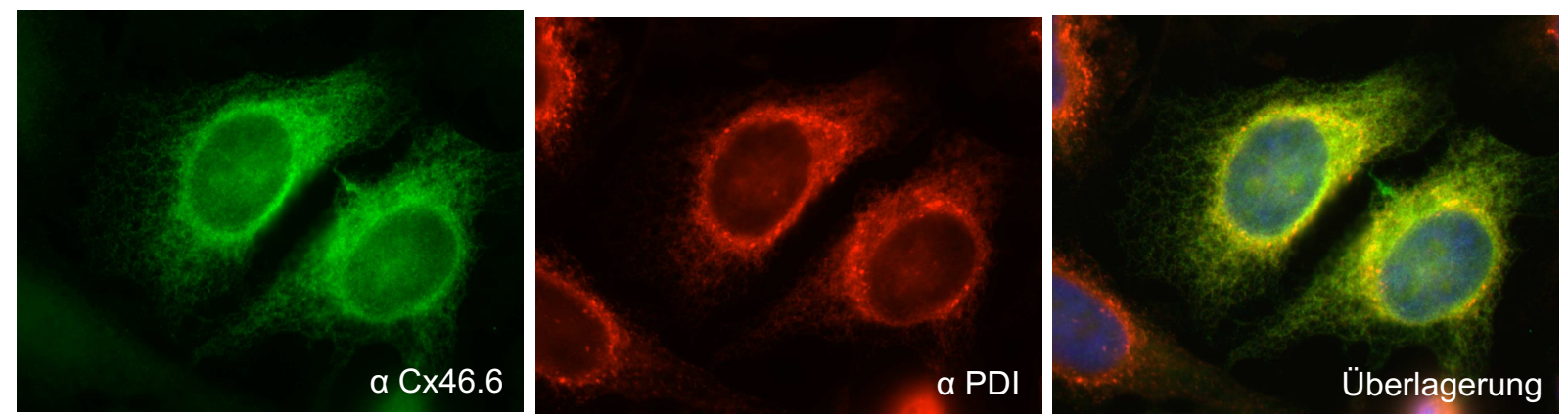

D
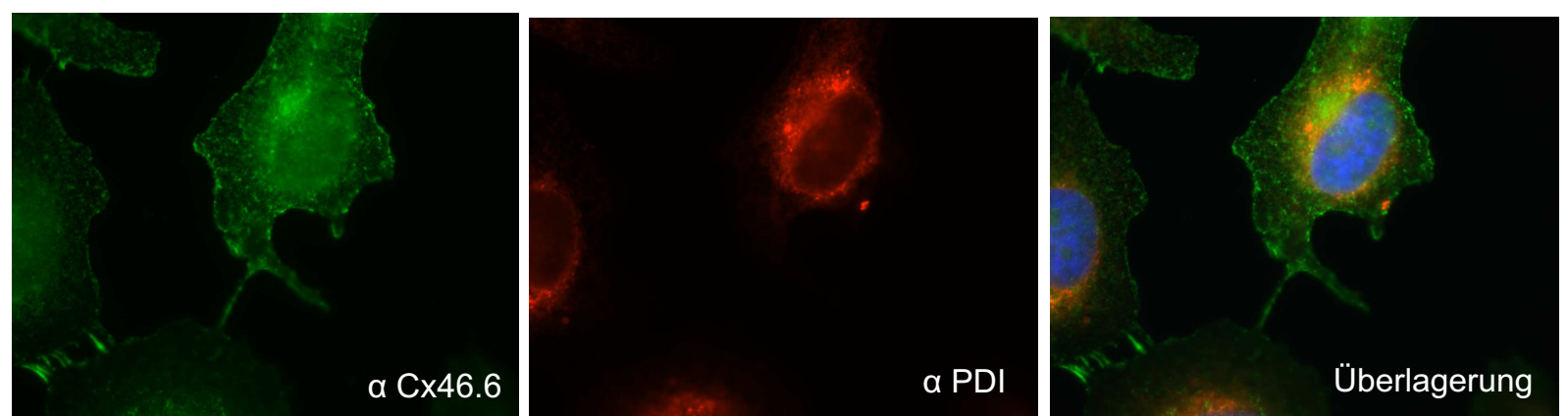

E
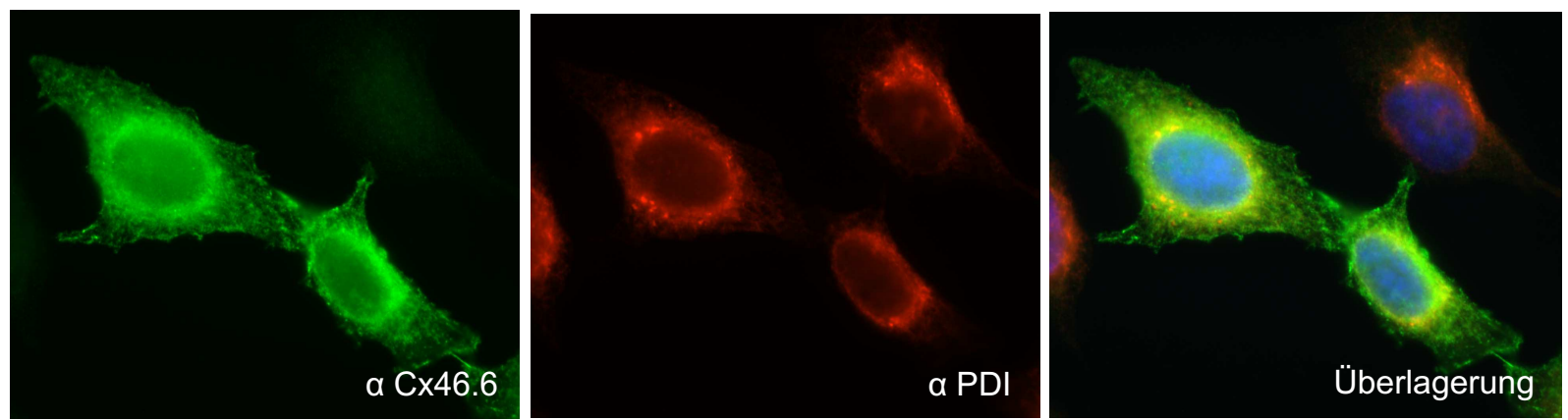
$\mathbf{F}$
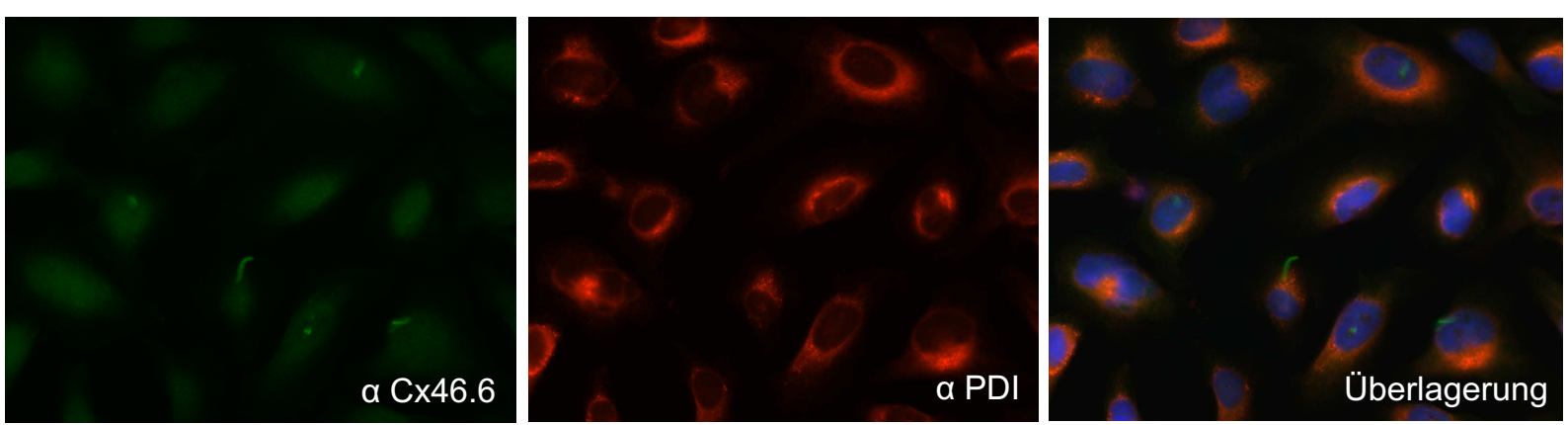

Abbildung 4.10.: Subzelluläre Lokalisation von Cx46.6-mt in transient transfizierten HeLa Zellen. Die subzelluläre Lokalisation in den mit Cx46.6-Mutanten transfizierten HeLa Zellen wurde mit Hilfe des Cx46.6-Antiserums ( $\alpha$ Cx46.6, grün) nachgewiesen. Als ER-Marker wurde ein Protein-Disulfid-Isomerase Antikörper ( $\alpha$ PDI) gewählt. Die Kernfärbung erfolgte mittels DAPI im ProLongGold-Eindeckelmedium. (A) Lokalisation des Cx46.6-Pro90Ser-Proteins. (B) Lokalisation des Cx46.6-Ala98Gly_Val99insThr-Proteins. (C) Lokalisation des Cx46.6Thr265Ala-Proteins. (D) Lokalisation des Cx46.6-Thr398Ile-Proteins. (E) Lokalisation des Cx46.6-Gly149Ser-Proteins. (F) Lokalisation des Cx46.6-Gly236Arg-Proteins. 


\subsection{Pathogenese der RNASET2 defizienten zystischen Leukoenzephalopathie}

Um den genetischen Defekt der CLminusM zu klären, wurde in Vorarbeiten unserer Arbeitsgruppe eine genomweite Kopplungsanalyse an zwei konsanguinen türkischen Familien mit jeweils zwei betroffenen Kindern durchgeführt. Es konnten homozygote Segmente auf Chromosom 6q26-q27 in beiden Familien identifiziert werden. Nach genauerer Eingrenzung durch polymorphe Mikrosatelliten wurden Haplotypen konstruiert und der Lokus der genetischen Ursache auf 46 trankriptionelle Einheiten eingegrenzt. In einer Transkriptomanalyse konnte eine signifikant erniedrigte Expression des RNASET2-Gens bei den Betroffenen beider Familien im Vergleich zu gesunden Familienmitgliedern detektiert werden. Daraufhin erfolgten Sequenzierungen dieses Kandidatengens bei den vier Betroffenen beider Indexfamilien. Mutationen konnten nachgewiesen und damit RNASET2 als erkrankungsverursachendes Gen identifiziert werden.

Diese Analysen zur Identifikation des genetischen Defekts der CLminusM, im Folgenden als RNASET2 defiziente zystische Leukoenzephalopathie bezeichnet, wurden vor Beginn der vorliegenden Arbeit durchgeführt. Die molekulare Charakterisierung des Krankheitsgens und Untersuchungen zur der Pathogenese der Erkrankung sind im Rahmen dieser Arbeit erfolgt.

\subsubsection{Analyse des RNASET2-Expressionsniveaus mittels RealTime-PCR}

Die Microarray-Daten zum Expressionsniveau des RNASET2-Gens der beiden Familien sollten mittels RealTime-PCR bestätigt und das Expressionsniveau relativ quantifiziert werden. Die Oligonukleotide und der zu amplifizierende Bereich für die RealTime-PCR wurden wie in 3.2.4 beschrieben gewählt. Es wurden drei verschiedene Primerpaare (Tabelle A.2) eingesetzt, um mit den jeweils amplifizierten Fragmenten die im Microarray verwendeten Oligonukleotide zu erfassen. Amplikon 1 beinhaltet mit einer Größe von 336 bp die Exons 2, 3, 4, 5 und 6; Amplikon 2 (231 bp) amplifiziert Exon 4, 5 und 6; Amplikon 3 (235 bp) schließt Exon 6, 7, 8 und 9 mit ein. Die für die RealTime-PCR eingesetzte cDNA wurde aus RNA von lymphoblastoiden Patienten- bzw. Kontroll-Zellen synthetisiert.

Bei der relativen Quantifizierung wird die Genexpression eines Zielgens auf ein weiteres nicht reguliertes Referenzgen bezogen. Dieser Vorgang wird als Normalisierung der Expressionsergebnisse bezeichnet (Rasmussen, 2001), wobei mögliche unterschiedliche RNA-Anfangskonzentrationen berücksichtigt werden. Als Referenzgen wurde die Glycerinaldehyd-3-Phosphat-Dehydrogenase (GAPDH, housekeeping gene) gewählt, da es sich um ein konstitutiv exprimiertes 
Protein handelt. Durch spezifische Oligonukleotide (Tabelle A.2) wurde in der PCR ein Fragment von 185 bp vervielfältigt.

Die Reaktionsspezifität der RealTime-PCR wurde durch die Schmelztemperaturanalyse anhand der Schmelzkurve belegt. Das spezifische Produkt wurde durch seine Schmelztemperatur erfasst, da bei der Variation der Schmelztemperatur pro Genprodukt nur ein Temperaturbereich existiert, indem die DNA-Doppelstrang Konformation maximal ist und somit auch eine maximale SYBR Green Inkorporation vorliegt. Des Weiteren konnte die Produktspezifität der RealTime PCR-Produkte mittels Agarose-Gelelektrophorese bestätigt werden.

Die relative Expression der RNASET2-Transkripte wurde anhand der delta-delta CT-Methode berechnet (Livak und Schmittgen, 2001).

$$
\begin{array}{ll}
\Delta \mathrm{CT} & =\mathrm{CT} \text { Zielgen }(\text { RNASET2 })-\mathrm{CT} \text { Referenzgen }(\text { GAPDH }) \\
\Delta \Delta \mathrm{CT} & =\Delta \mathrm{CT} \text { Patient }-\Delta \mathrm{CT} \text { Kontrolle } \\
\text { Relative Expression } & =2^{-\Delta \Delta C T}
\end{array}
$$

Dieses Berechnungsschema setzt eine Verdopplung der DNA Menge in jedem Zyklus voraus. Man geht von einer optimalen RealTime-PCR Effizienz (Effizienz=2) in allen Proben aus. Die Effizienz wurde mit Hilfe der Steigung einer Standardkurve aus unterschiedlichen Verdünnungsstufen (1:1, 1:10, 1:100, 1:1000) berechnet (Rasmussen, 2001). Sie betrug in der RealTime-PCR für Amplikon 1 und 2 99,6\% (1,99) und für Amplikon 3 90,1\% (1,8). Diese Werte entsprechen nahezu der optimalen PCR-Effizienz.

Der CT-Wert (Cycle Threshold = Schwellenwert-Zyklus) entspricht der Anzahl der PCR Zyklen die nötig sind, um ein konstant definiertes Fluoreszenzniveau zu erreichen, an dem die Fluoreszenz erstmalig signifikant über die Hintergrund-Fluoreszenz ansteigt. Zu diesem Zeitpunkt befindet sich in allen Reaktionsgefäßen die gleiche Menge an neu synthetisierter DNA. Nach einer Normalisierung der CT-Werte wurde die relative Expression $\left(2^{-\Delta \Delta C T}\right)$ des RNASET2-Gens, bezogen auf den $\Delta$ CT-Wert eines unabhängigen, gesunden Kontroll-Patienten, bestimmt. Für Amplikon 3 wurde die relative RNASET2-Expression bezogen auf den $\Delta$ CT-Wert der Mutter (Individuum 326) von Patient 330 berechnet.

Die Ergebnisse der Expressionsanalyse der Mitglieder aus Familie 1 und 2 sind in Abbildung 4.11 dargestellt. Zu Familie 1 gehören die erkrankten Individuen 330 und 327 sowie die gesunde Mutter 326. Zu Familie 2 gehören die erkrankten Geschwister 28 und 37 sowie die gesunden Eltern 35 und 36. Die relative Expression von Individuum 330 für die verschiedenen Fragmente ist mit 0,13 bis 0,3 (Abbildung 4.11 a-c) in Bezug zur Kontrolle signifikant herabgesetzt $(\mathrm{P} \leq 0,0008)$. Bei Individuum 327 ist ein nicht so deutlicher Unterschied des RNASET2Expressionsniveaus erkennbar. Die relative Expression der RNASET2 für Amplikon 1 liegt 
bei $0,5(\mathrm{P}=0,0056)$. Für Amplikon 3 weist Individuum 327 eine Transkriptexpression von $80 \%$ $(\mathrm{P}=0,045)$ im Vergleich zur Kontrolle auf. Für Amplikon 2 hingegen besteht keine signifikante Differenz zur Kontrolle, das Expressionsniveau liegt bei 1. Die relative RNASET2-Expression der Mutter von Familie 1 (Individuum 326) zeigt für Amplikon 1 und 2 ebenfalls keinen signifikanten Unterschied zur Kontrolle.

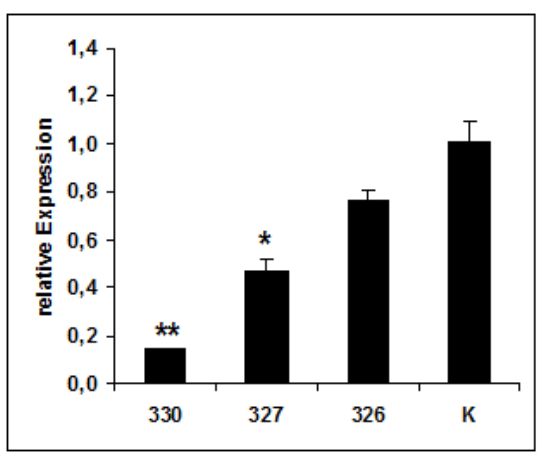

(a) Familie 1: Amplikon 1

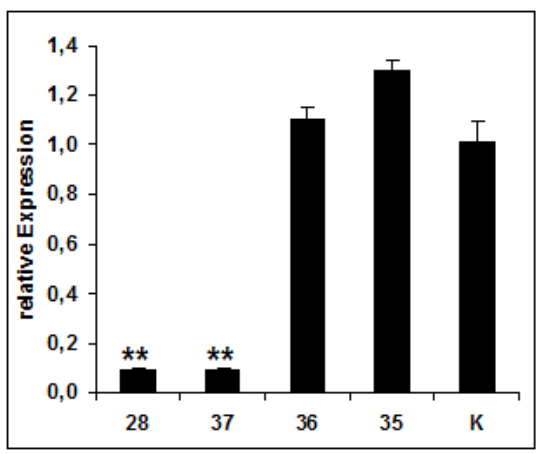

(d) Familie 2: Amplikon 1

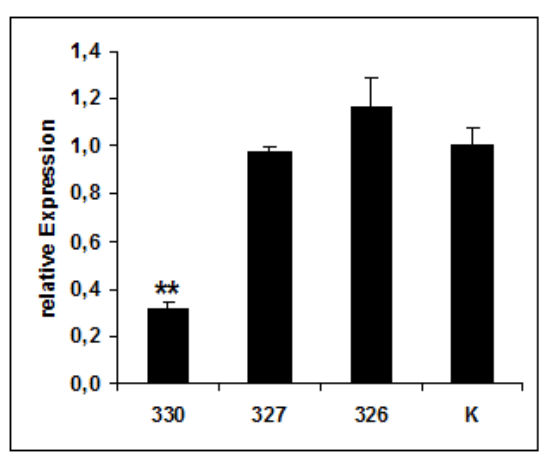

(b) Familie 1: Amplikon 2

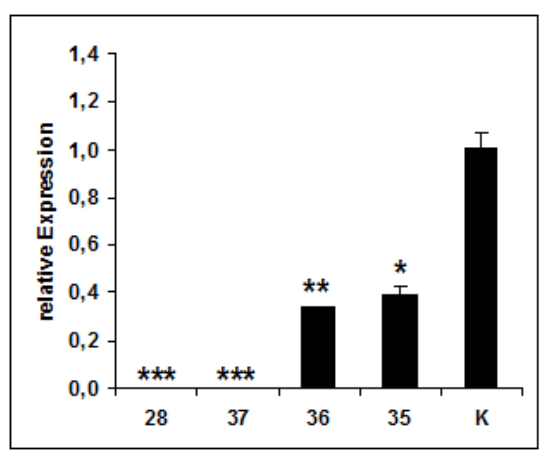

(e) Familie 2: Amplikon 2

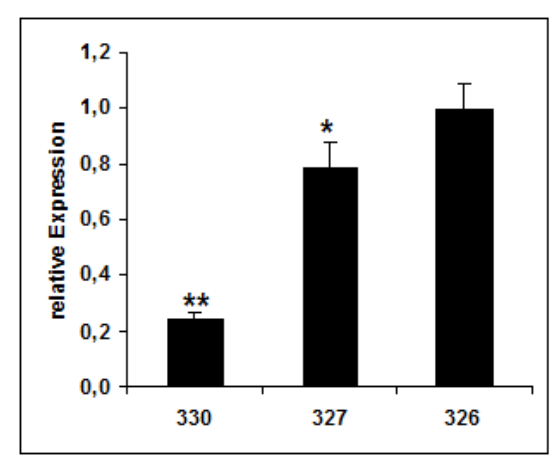

(c) Familie 1: Amplikon 3

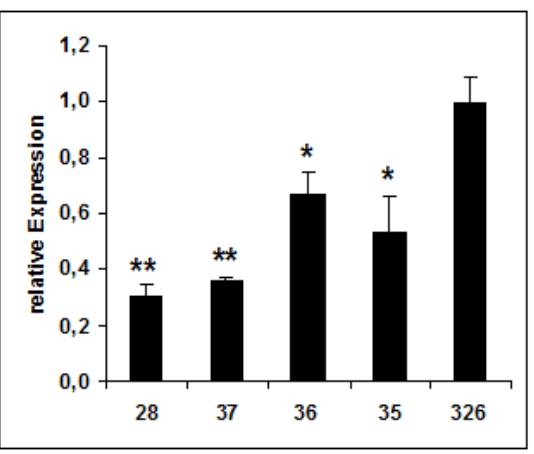

(f) Familie 2: Amplikon 3

Abbildung 4.11.: RNASET2-Expressionsanalyse der Familien 1 und 2 mittels RealTimePCR. Amplikon 1 beinhaltet mit einer Größe von 336 bp die Exons 2, 3, 4, 5 und 6; Amplikon 2 (231 bp) amplifiziert Exon 4, 5 und 6; Amplikon 3 (235 bp) schließt Exon 6, 7, 8 und 9 mit ein. Die relative Expression wurde mittels RealTime-PCR untersucht und anhand der Formel: $2^{-\triangle \Delta C T}$ bestimmt. Abweichungen der Messwerte sind als Standardfehler des Mittelwertes (S.E.M.) angegeben. P-Werte wurden durch einen ungepaarten Student's T-Test bestimmt und nach Bonferroni adjustiert. ${ }^{*} \mathrm{P} \leq 0,045 ;{ }^{* *} \mathrm{P} \leq 0,0008 ;{ }^{* * *} \mathrm{P}=0,0001$. (a-c) Die relative Expression (Ordinate) der Geschwister aus Familie 1 (Individuum 330 und 327) und der Mutter (Individuum 326) wurde im Vergleich zu einer gesunden Kontrolle (K) bzw. bei Amplikon 3 im Vergleich zu Individuum 326 untersucht. (d-f) Die relative Expression (Ordinate) der Geschwister aus Familie 2 (Individuum 28 und 37) und der Eltern (36 und 35) wurde im Vergleich zu einer gesunden Kontrolle (K) bzw. bei Amplikon 3 im Vergleich zu Individuum 326 untersucht.

Die RNASET2-Expressionsanalyse mittels RealTime-PCR der Familie 2 zeigt eine deutliche Expressionsniveau-Absenkung vor allem für die erkrankten Familienmitglieder. Für Amplikon 1 liegt die relative Expression der Individuen 28 und 37 bei 0,094 ( $\mathrm{P}=0,0004)$, die der Eltern jedoch bei 1,1 bzw. 1,3 (Abbildung 4.11d). Transkripte zur Amplifikation von Fragment 2 kön- 
nen bei den erkrankten Geschwistern 28 und 37 nicht nachgewiesen werden $(\mathrm{P}=0,0001$; Abbildung 4.11e). Das Expressionsniveau der Eltern (Individuum 36 und 35) ist deutlich geringer als in der Kontrolle (etwa $70 \%$ weniger Expression; $\mathrm{P}=0,0007$ und $\mathrm{P}=0,0017$ ). Die relative Expression von Amplikon 3 der Patienten 28 und 37 ist mit 30\% bzw. $36 \%$ ebenfalls sehr niedrig ( $\mathrm{P}=0,0003)$. Die Transkriptmenge der Eltern liegt bei $67 \%$ bzw. $53 \%$ im Vergleich zur gesunden Mutter der Familie 1 (Individuum 326; $\mathrm{P}=0,0089$ bzw. $\mathrm{P}=0,0065$ ).

Ein niedriges RNASET2-Expressionsniveau in den Patienten der Familien 1 und 2 konnte gezeigt und somit die Microarray-Daten bestätigt werden. In Familie 2 zeigt sich jedoch ein viel deutlicherer Expressionsunterschied als in Familie 1. Die statistische Analyse des RNASET2Expressionsniveaus von Kontrolle (bzw. Individuum 326) und erkrankten Individuen wurde mittels ungepaartem Student's T-Test durchgeführt.

\subsubsection{RNASET2-Mutationsanalyse}

19 weitere Patienten mit CLminusM sollten auf Mutationen im RNASET2-Gen, welches neun Exons umfasst, mittels Sequenzanalyse auf mögliche krankheitsauslösende Sequenzveränderungen untersucht werden. Hierfür wurde die genomische DNA aus Blut oder lymphoblastoiden Zellen der Patienten isoliert (3.1.13), die neun Exons mittels PCR (3.1.4) amplifiziert und mit den spezifischen Oligonukleotiden der jeweiligen PCR-Reaktion sequenziert (3.1.14). Die Sequenzierergebnisse wurden mit der Referenzsequenz NM_003730.4 abgeglichen und mit Hilfe des Programms DNA Star auf Mutationen untersucht.

Bei der genetischen Untersuchung dieser 19 Patienten mit CLminusM wurden zwei homozygote Spleißregionen betreffende Mutationen identifiziert. Die Mutation c.262-2A $>$ G bei einem Mädchen (Patient 4483) mit konsanguinen türkischen Eltern führt zu einem Basenaustausch von Adenin zu Guanin in Intron 4. Eine heterozygote Mutation konnte jeweils bei den Eltern nachgewiesen werden. Eine Deletion des ersten Guanins in Intron 6 (c.332+1delG) wurde bei einem Jungen (Patient 4853) mit nicht konsanguinen spanischen Eltern detektiert, wobei für die Mutter des Patienten die Mutation heterozygot bestätigt wurde. Vom Vater stand kein Material für eine genetische Analyse zur Verfügung. Zwei weitere compound heterozygote Mutationen - eine 15 bp große Deletion (c.50_64del) und eine Substitution von G>A an der Stelle des letzten Nukleotids von Exon 8 (c.567G>A) - wurde bei einem Mädchen (Patient 3306) mit deutsch/türkischer Abstammung nachgewiesen. Auch von den Eltern dieses Patienten konnte keine Gen-Analyse durchgeführt werden, da kein DNA-Material vorhanden war.

Die identifizierten Sequenzveränderungen sind in Tabelle 4.2 unter Angabe des Geschlechts, einer eventuell vorhandenen Konsanguinität, der Herkunft und der Mutationsbezeichnung auf Nukleotidebene zusammengefasst. Mit aufgelistet sind auch die Mutationen der Familien 1 und 
2, die in Vorarbeiten unserer Arbeitsgruppe identifiziert, aber im Rahmen dieser Arbeit näher charakterisiert wurden. Bei den beiden betroffenen Individuen (330 und 327) der Familie 1 wurde ein homozygoter Basenaustausch in Exon 8 an Position 550 identifiziert (c.550T $>$ C). In Familie 2 wurde bei den erkrankten Geschwistern (28 und 37) die 2,5 kb große Deletion c.871341_147+1181del2583 identifiziert. Beide Mutationen konnten bei den Eltern der Patienten jeweils heterozygot nachgewiesen werden.

Tabelle 4.2.: Daten der Patienten mit neu identifizierten RNASET2-Mutationen

\begin{tabular}{|c|c|c|c|c|c|}
\hline $\begin{array}{l}\text { Fa- } \\
\text { milie }\end{array}$ & Patient & $\begin{array}{l}\text { Ge- } \\
\text { schlecht }\end{array}$ & $\begin{array}{l}\text { ver- } \\
\text { wandt }\end{array}$ & Herkunft & Mutation auf Nukleotidebene \\
\hline 1 & $327 / 330$ & $\mathrm{w} / \mathrm{m}$ & ja & türkisch & c. $.550 \mathrm{~T}>\mathrm{C}$, hom \\
\hline 2 & $28 / 37$ & $\mathrm{~m} / \mathrm{m}$ & ja & türkisch & c.87-1341_147+1181del2583, hom \\
\hline 3 & 4483 & $\mathrm{w}$ & ja & türkisch & c. $262-2 \mathrm{~A}>\mathrm{G}$, hom \\
\hline 4 & 4853 & $\mathrm{~m}$ & nein & spanisch & c. $332+1$ delG, hom \\
\hline 5 & 3306 & $\mathrm{w}$ & nein & deutsch/türkisch & c. $\left[50 \_64 \mathrm{del}\right]+[567 \mathrm{G}>\mathrm{A}]$, het \\
\hline
\end{tabular}

$\mathrm{m}=$ männlich; $\mathrm{w}=$ weiblich; del=Deletion; hom=homozygot; het=heterozygot

Alle Mutationen wurden durch eine zweite PCR und Sequenzanalyse verifiziert. Mindestens 59 gesunde Kontrollindividuen wurden ebenfalls auf das Vorhandensein der identifizierten RNASETQ-Mutationen untersucht, um ausschließen zu können, dass es sich bei den gefundenen Sequenzveränderungen um Polymorphismen handelt. Es wurde jedoch keine der beschriebenen RNASET2-Mutationen nachgewiesen.

\subsubsection{Auswirkungen der Mutationen in Spleißkonsensussequenzen}

Spleißen findet an so genannten splice sites oder auch Spleißkonsensussequenzen statt, die konservierte Nukleotid-Sequenzen tragen. Die Basensequenz eines Introns beginnt mit dem Spleiß-Donor am 5'-Ende GU und endet mit dem Spleiß-Akzeptor am 3'-Ende AG. Einige andere wichtige Nukleotid-Sequenzen in der Nähe der Spleißstellen sind weniger gut konserviert. Die Verzweigungsstelle (branch site) liegt etwa 20 bis 50 Nukleotide stromaufwärts der Akzeptorstelle und hat die Konsensussequenz CU(A/G)A(C/U). Sind diese Spleißkonsensussequenzen durch Mutationen verändert, kann es zu fehlerhaftem Spleißen kommen. Da die direkte Sequenzierung der cDNA PCR-Produkte kein eindeutiges Sequenz-Ergebnis zur Spleißvariantenanalyse ergab, wurden die Auswirkungen der Spleißkonsensussequenzen betreffenden Mutationen c.87-1341_147+1181del2583 (Individuen 28 und 37), c.262-2A>G (Individuum 4483), c.332+1delG (Individuum 4853) und c.567G>A (Individuum 3306), mittels einer TAKlonierung bzw. eines Minigenkonstruktes näher analysiert. 


\subsubsection{Analyse der Spleißvarianten mittels TA-Klonierung}

Den Geschwistern (Patient 28 und 37) mit der Deletions-Mutation c.87-1341_147+1181del2583 aus Familie 2 fehlt in genomischer DNA das gesamte Exon 2 und Bereiche von Intron 1 und 2. Der Spleiß-Akzeptor von Intron 1 sowie der Spleiß-Donor von Intron 2 sind deletiert. Bei Individuum 4483 ist die Spleißakzeptorkonsensussequenz von Intron 4 durch die Mutation c.262$2 \mathrm{~A}>\mathrm{G}$ direkt betroffen. Weiterhin wird bei Individuum 4853 durch die homozygote Mutation c.332+1delG der Spleißdonor von Intron 5 deletiert.

Zur Untersuchung der Auswirkung dieser Mutationen auf die Genexpression wurde cDNA aus RNA von lymphoblastoiden Patienten-Zellen synthetisiert (3.2.3) und mittels 5'UTR und 3'UTR Oligonukleotiden (Tabelle A.2) das RNASET2-Genprodukt amplifiziert (3.1.4). Nach einer TA-Klonierung (3.1.8) und Transformation (3.1.12), wurde aus 15 bzw. 10 Klonen PlasmidDNA isoliert (3.1.13) und mit den zur PCR eingesetzten 5'UTR und 3'UTR Oligonukleotiden sequenziert (3.1.14). Die Sequenzierergebnisse wurden mit Hilfe des Programms DNA Star ausgewertet. Kontroll-cDNA aus Lymphozyten und Fibroblasten wurde ebenfalls untersucht, es wurden jedoch keine alternativen Spleißprodukte zur RNASET2-Wildtyp-Sequenz nachgewiesen.

Bei den Geschwistern 28 und 37 zeigte sich folgende Häufigkeitsverteilung der Deletionen auf RNA-Ebene:

$\begin{array}{llll}9 \times & \text { Deletion von Exon 2-5 } & \text { r.87_332del } & \text { p.Asp30_Trp111del } \\ 4 \times & \text { Deletion von Exon 2+3 } & \text { r.87_203del } & \text { p.Asp30_Trp68del } \\ 1 \times & \text { Deletion von Exon 1+2 } & \text { r.-56_147del } & \text { Protein ? } \\ 1 \times & \text { Deletion von Exon 1-3 } & \text { r.-56_203del } & \text { Protein? }\end{array}$

Die Deletionsmutation c.87-1341_147+1181del2583 bedingt nicht nur einen Verlust von Exon 2, sondern auch einen Spleißdefekt. Die prä-mRNA wird in mindestens vier verschiedene Genprodukte gespleißt. Ob alle daraus resultierenden Proteine auch exprimiert werden, ist unklar.

Die Analyse der Spleißvarianten auf RNA-Ebene von Patient 4483 (c.262-2A>G) führte zu folgendem Ergebnis:

$\begin{array}{llll}4 \times & \text { Deletion von Exon 2-5 } & \text { r.87_332del } & \text { p.Asp30_Trp111del } \\ 3 \times & \text { Deletion von Exon } 5 & \text { r.262_332del } & \text { p.Asp88GlufsX3 } \\ 3 \times & 13 \text { bp Deletion in Exon } 5 & \text { r.262_274del } & \text { p.Asp88LysfsX2 }\end{array}$

Ein durch die Spleißakzeptormutation c.262-2A $>$ G bedingter Spleißdefekt konnte bestätigt werden. Es entstehen mindestens 3 alternative Spleißprodukte, wobei auch hier nicht sicher ist, ob die Proteine exprimiert werden. 
Die Spleißvariantenanalyse der homozygoten Mutation c.332+1delG (Individuum 4853) ergab zwei verschiedene Spleißprodukte, deren eventuelle Protein-Expression zu untersuchen wäre:

$\begin{array}{llll}5 \times & \text { Deletion von Exon 2-5 } & \text { r.87_332del } & \text { p.Asp30_Trp111del } \\ 2 \times & \text { Deletion von Exon 4+5 } & \text { r.204_332del } & \text { p.Pro69_Trp111del }\end{array}$

\subsubsection{Spleißdefekt-Analyse mittels Minigenkonstrukt (Exon-trapping)}

Die Auswirkung der heterozygoten Mutation c.567G>A in Exon 8 von Individuum 3306 sollte ebenfalls auf mRNA-Ebene analysiert werden. Die kodierte Aminosäure Glutamin 189 wird durch die Mutation nicht ausgetauscht. Das letzte Nukleotid von Exon 8 wird durch die Mutation jedoch so verändert, dass es in Verbindung mit dem ersten Nukleotid des Introns 8 einen möglichen Spleißakzeptor bildet (Abbildung 4.12). Dieser zusätzliche Spleißakzeptor könnte das Spleißosom beeinflussen.

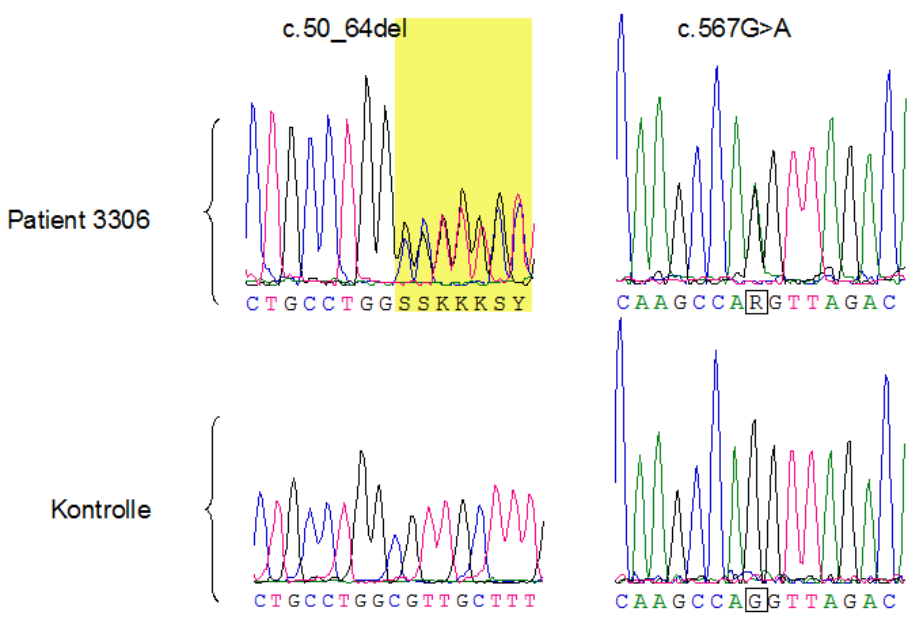

Abbildung 4.12.: Chromatogramm der genomischen Sequenzanalyse von Patient 3306. Die compound heterozygote Mutation c.[50_64del][567G>A] und die Wildtypsequenz des RNASETD-Gens einer Kontrolle sind im Vergleich abgebildet.

Zur Untersuchung des Spleißvorgangs stand in diesem Fall kein Patientenmaterial zur Verfügung. Aufgrund dessen wurde die Spleißeffizienzanalyse mittels Konstruktion eines Minigens durchgeführt. Minigenkonstrukte werden zur Identifikation und Analyse (in vivo) von Faktoren eingesetzt, die alternatives Spleißen verursachen. Zur Klonierung von Minigenen werden spezielle exon-trapping Proteinexpressions-Vektoren (pSPL3) verwendet, die eine funktionelle Spleißdonor- und Spleißakzeptorsequenz (Abbildung 4.13) enthalten. Das zu untersuchende Gen bzw. Exon wird mit flankierenden Intronbereichen und den primären regulatorischen Ele- 
menten, sowie den genomischen Spleißdonor- und Spleißakzeptorsequenzen kloniert (Church et al., 1994). Die das Spleißen regulierenden Bereiche liegen innerhalb von 200-300 Nukleotiden stromaufwärts bzw. stromabwärts vom regulierten Exon.

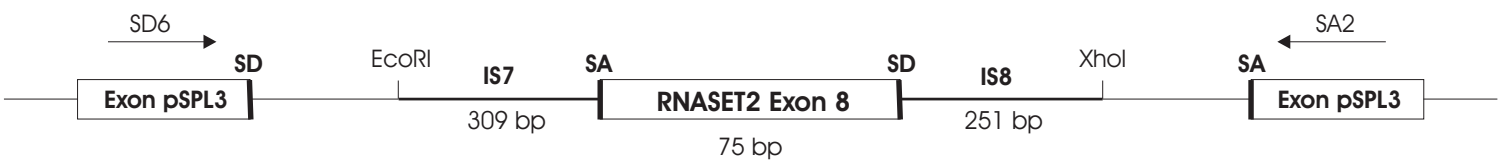

Abbildung 4.13.: Minigenkonstrukt (RNASET2-Exon 8) zur Spleißeffizienz-Analyse der heterozygoten Mutation c.567G $>$ A von Individuum 3306. Das Minigenkonstrukt vom Wildtyp oder mtG567A RNASET2 Exon 8 mit 309 bp von Intron 7 (IS7) und 251 bp von Intron 8 (IS8) wurde über die EcoRI und XhoI Schnittstellen in den pSPL3-Vektor subkloniert. Funktionelle Spleißdonor(SD)- und Spleißakzeptor(SA)-Sequenzen im Vektor und in der genomischen DNA sind vorhanden. Vektorspezifische Oligonukleotide SD6 $(\rightarrow)$ und SA2 $(\leftarrow)$ wurden zur Analyse der Spleißprodukte mittels $R T-P C R$ und DNA Sequenzanalyse verwendet.

Zur Konstruktion des RNASETQ-Minigenplasmids wurde Exon 8 (75 bp) mit 309 bp der 5'und $251 \mathrm{bp}$ der 3 '-flankierenden Intronsequenz in den pSPL3-Vektor (Gibco) kloniert. Durch spezifische Oligonukleotide (Tabelle A.2) mit EcoR1 bzw. Xho1-Schnittstellen und einer high fidelity Polymerase wurde das Wildtyp Fragment amplifiziert und in den pSPL3-Vektor subkloniert (Abbildung 4.13). Durch Mutagenese (3.1.5) wurde die Mutation c.567G >A eingefügt. Das Wildtyp- und das mtG567A-Minigenkonstrukt wurden mittels Sequenzierung verifiziert.

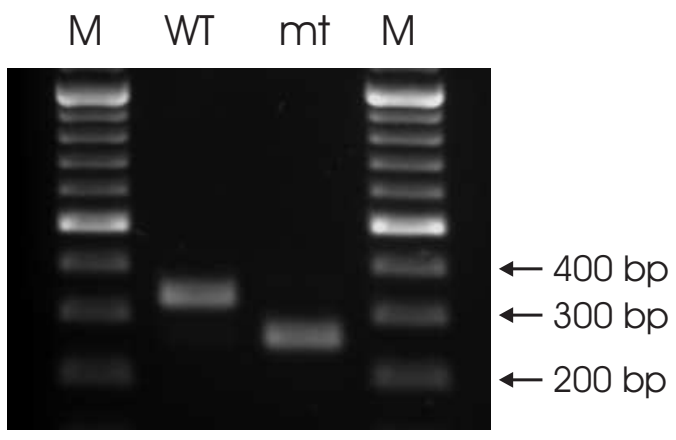

Abbildung 4.14.: Agarose-Gelelektrophorese zur Spleißeffizienz-Analyse der heterozygoten Mutation c.567G $>$ A von Individuum 3306. Eine Agarose-Gelelektrophorese nach der reversen Transkription und anschließender PCR von Gesamt-RNA der mit Wildtyp- oder mtG567A-Minigenkonstrukt transfizierten HeLa Zellen zeigt, dass das Spleißprodukt des $R N A$ SET2-Exon 8 Wildtyp Minigenkonstrukts (WT) etwa 70 bp höher läuft als das mtG567A Spleißprodukt (mt). Ein 1 kb DNA-Größenstandard (M) wurde verwendet.

Zur Spleißvorgangsanalyse in vivo wurde das Minigenkonstrukt in HeLa Zellen transfiziert und das Genprodukt auf RNA-Ebene analysiert (Cooper, 2005). Die extrahierte RNA wurde zur Analyse revers transkribiert (3.2.3) und mit vektorspezifischen Oligonukleotiden (SD6 und SA2, Tabelle A.2) amplifiziert (3.1.4) und sequenziert (3.1.14). Anhand des Größenunterschieds der beiden PCR-Produkte im Agarosegel (Abbildung 4.14) kann gezeigt werden, dass 
ein alternatives Spleißprodukt entsteht. Das Produkt des RNASET2-Exon 8 Wildtyp Minigens ist etwa 70 bp größer als das Spleißprodukt des mtG567A Minigens. Durch die Mutation c.567G > A kommt es zu einem alternativen Spleißvorgang, der dazu führt, dass das gesamte Exon 8 (Größe 75 bp) nicht in das Genprodukt integriert wird. Durch eine Sequenzanalyse der Spleißprodukte des Minigens konnte dieses Ergebnis bestätigt werden.

\subsubsection{RNASET2-Expressionsanalyse in verschiedenen Geweben}

Um das Expressionsniveau von RNASET2 in verschiedenen humanen Hirnregionen (Capsula interna, Temporallappen, Corpus callosum, Amygdala, Großhirnrinde, Hippocampus), fetalem Gehirn, der Leber, der Niere und des Skelettmuskels zu bestimmen, wurde cDNA (BioChain) mittels RealTime-PCR (3.2.4) analysiert.

Zur Amplifikation von Amplikon 2 (Exon 4, 5 und 6; 231 bp) wurden spezifische Oligonukleotide (Tabelle A.2) verwendet. Für die RealTime-PCR (3.2.4) wurde $1 \mu \mathrm{l}$ der cDNA eingesetzt, das entspricht einer definierten Menge von 0,25ng. Die Reaktionsspezifität der RealTime-PCR wurde durch die Schmelztemperaturanalyse anhand der Schmelzkurve belegt (vgl. 4.2.1). Des Weiteren konnte die Produktspezifität mittels Agarose-Gelelektrophorese der RealTime PCRProdukte bestätigt werden.

Die relative Expression der RNASET2-Transkripte in verschiedenen Geweben wurde anhand folgender Formel berechnet (Pfaffl, 2001).

$$
\begin{array}{ll}
\Delta \mathrm{CT} & =\mathrm{CT} \text { Kontrolle (Capsula interna)-CT Probe (Gewebe) } \\
\text { relative Expression } & =2^{\Delta C T}
\end{array}
$$

Eine Normalisierung der CT-Werte konnte vernachlässigt werden, da durch Einsatz definierter cDNA-Mengen eine unterschiedliche RNA-Anfangskonzentration nicht berücksichtigt werden musste. Die RNASET2-Expression wurde relativ zur Transkriptmenge der Capsula interna berechnet. Abbildung 4.15 zeigt die RNASET2-Expression in den verschiedenen Hirnregionen und Geweben. Das Expressionsniveau der Transkripte zeigt eine 1,5-fache Erhöhung auf 2,61 im Temporallappen. In der Amygdala können nur sehr wenig RNASET2-Transkripte nachgewiesen werden (relative Expression=0,067). Eine erhöhte Expressionsrate von 1,73 zeigt sich im fetalen Gehirn. In Leber, Niere und Skelettmuskel ist das Transkriptionsniveau der RNASET2 relativ zur Capsula interna um 0,2 leicht erhöht. Die Signifikanz der RNASET2-ExpressionsniveauUnterschiede wurde durch eine einfaktorielle Varianzanalyse (ANOVA) mit $\mathrm{P}<0,0001$ bestätigt. 


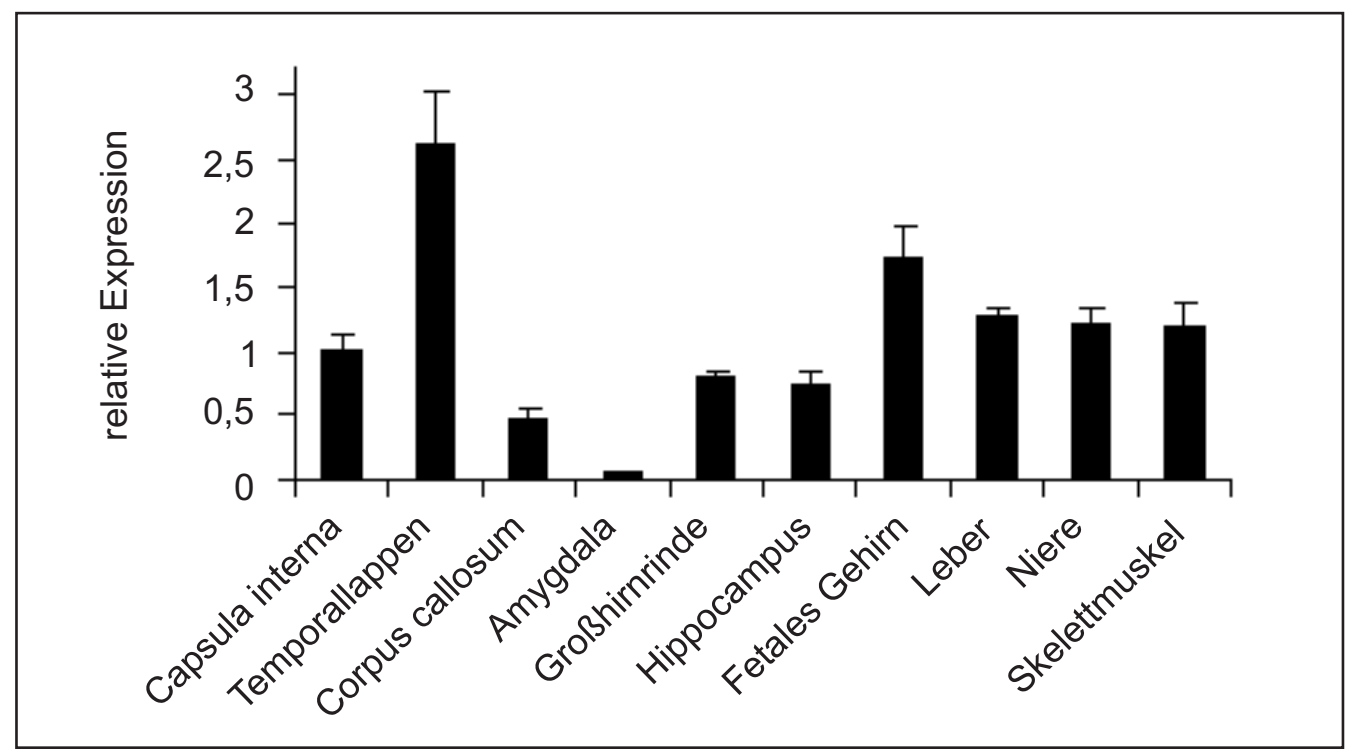

Abbildung 4.15.: Ergebnisse der RNASET2-Expressionsanalyse in verschiedenen Geweben. Zur Expressionsanalyse der verschiedenen humanen Hirnregionen (Capsula interna, Temporallappen, Corpus callosum, Amygdala, Großhirnrinde, Hippocampus), fetalem Gehirn, der Leber, der Niere und des Skelettmuskels wurde cDNA mittels RealTime-PCR analysiert. Die relative Expression (Ordinate) wurde im Vergleich zur Capsula interna anhand der Formel $2^{\triangle C T}$ bestimmt. Abweichungen der Messwerte sind als Standardfehler des Mittelwertes (S.E.M.) angegeben. Der P-Wert $(\mathrm{P}<0,0001)$ wurde durch eine einfaktorielle Varianzanalyse (ANOVA) bestimmt.

\subsubsection{Expression und Sekretion von RNASET2}

Die RNASET2-Wildtyp-Sequenz und die Missense Mutante c.550C > T (p.Cys184Arg) sollten hinsichtlich der Funktionalität und Lokalisation der daraus resultierenden Proteine näher charakterisiert werden. Die Wildtyp-Sequenz wurde mittels spezifischer Oligonukleotide (Tabelle A.2) amplifiziert und in die multiple Klonierungsstelle eines Myc-Tag kodierenden Vektors kloniert. Die Mutante wurde durch Einsatz von Mutagenese-Primern (Tabelle A.2) in einer Mutagenese-PCR (3.1.5) erzeugt. Da zu Beginn dieser Arbeit kein RNASET2-spezifischer Antikörper zur Verfügung stand, wurde eine Untersuchung der Expression und Sekretion des Wildtyp- und Mutanten-RNASET2-Proteins mit Hilfe eines $\alpha$ Myc-Antikörpers (Tabelle 2.1) durchgeführt. Die klonierten Myc-Konstrukte (Tabelle 2.5) wurden in HEK 293 Zellen transient transfiziert (3.3.2). Zellkulturüberstand und Proteinextrakt wurden zur Analyse im Western Blot (3.4.5) eingesetzt.

Abbildung 4.16 a zeigt, dass sowohl das Wildtyp- als auch das mtC184R-Protein in den HEK 293 Zellen exprimiert wird, da es mittels $\alpha$ Myc-Antikörper nachgewiesen werden kann (WT und mt). Die Negativkontrolle (Vektor-transfizierte Zellen, VK) zeigt kein Signal. Um sicher zu stellen, dass in allen Spuren gleiche Proteinmengen geladen wurden, konnte Tubulin als Ladekontrolle in allen drei Spuren durch gleichmäßige Signale quantifiziert werden. Im Zellkultur- 
überstand konnte das mtC184R-Protein im Gegensatz zum Wildtyp-Protein nicht detektiert werden (Abbildung 4.16 b). Die Mutation Cys184Arg der RNASET2 bedingt demnach einen Sekretionsdefekt des Proteins.

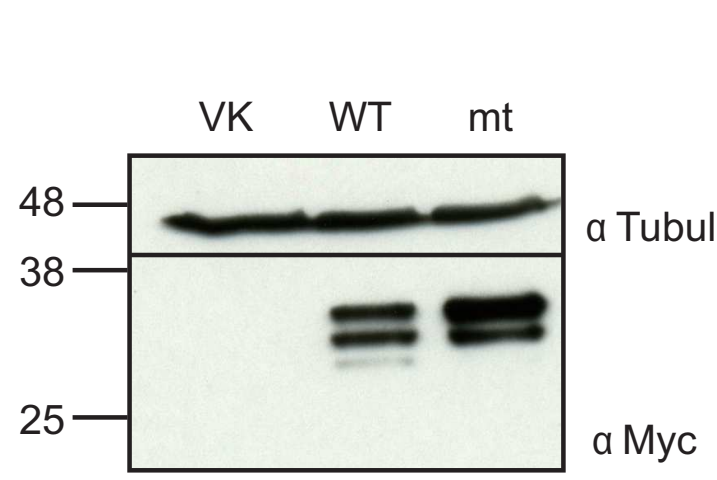

(a) Expressionsanalyse

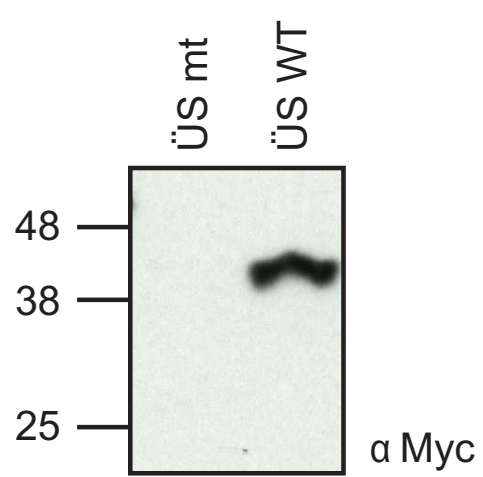

(b) Sekretionsanalyse

Abbildung 4.16.: Immundetektion der Expression und Sekretion von RNASET2-WT und RNASET2-mtC184R im Western Blot. (a) Zur Expressionsanalyse von RNASET2Wildtyp (WT) und RNASET2-mtC184R (mt) wurden jeweils $30 \mu \mathrm{g}$ Proteinextrakt aus transient transfizierten HEK 293 Zellen eingesetzt. Als Vektorkontrolle dienten $30 \mu g$ Proteinextrakt aus HEK 293 Zellen, transient transfiziert mit Vektor ohne Insert (VK). Die Detektion erfolgte durch einen monoklonalen Myc-Antikörper (Verdünnung 1:1000). Als Ladekontrolle wurde mit einem Tubulin-Antikörper (Verdünnung 1:50000) das Tubulin-Protein in allen drei Spuren nachgewiesen. (b) Die Sekretionsanalyse wurde mit $20 \mu \mathrm{l}$ Zellkulturüberstand (ÜS) der transient transfizierten HEK 293 Zellen (RNASET2-Wildtyp [WT] und RNASET2-mtC184R [mt]) durchgeführt, die nach einer Kultivierung der Zellen von 48 Stunden entnommen wurden. Die Detektion der sekretierten Proteine erfolgte durch einen monoklonalen Myc-Antikörper (Verdünnung 1:1000). Der Größenstandard wurde in $\mathrm{kDa}$ angegeben.

Der $\alpha$ Myc-Antikörper erkennt im Wildtyp und Mutanten Proteinextrakt drei Banden in einer Höhe von etwa $38 \mathrm{kDa}, 36 \mathrm{kDa}$ und $34 \mathrm{kDa}$. Um zu klären, ob es sich um unterschiedlich stark glykosylierte Formen der RNASET2 handelt, wurden definierte Mengen Proteinextrakt durch PNGase F Behandlung (3.4.3) deglykosyliert (Abspaltung der N-Glykane). Der deglykosylierte RNASET2-Wildtyp Proteinextrakt zeigt ein Signal in Höhe von etwa $32 \mathrm{kDa}$ und bestätigt die Annahme der dreifachen Glykosylierung von RNASET2 (Abbildung 4.17). Die Mutation Cys184Arg bedingt keine Veränderung des Glykosylierungsverhaltens des Proteins. Durch die PNGase F-Behandlung zeigt sich im Western Blot ebenfalls ein entsprechender Größenunterschied (Masse eines N-Glykans: ungefähr 2 kDa) der deglykosylierten Form im Vergleich zu den glykosylierten Ausgangsproteinen. 


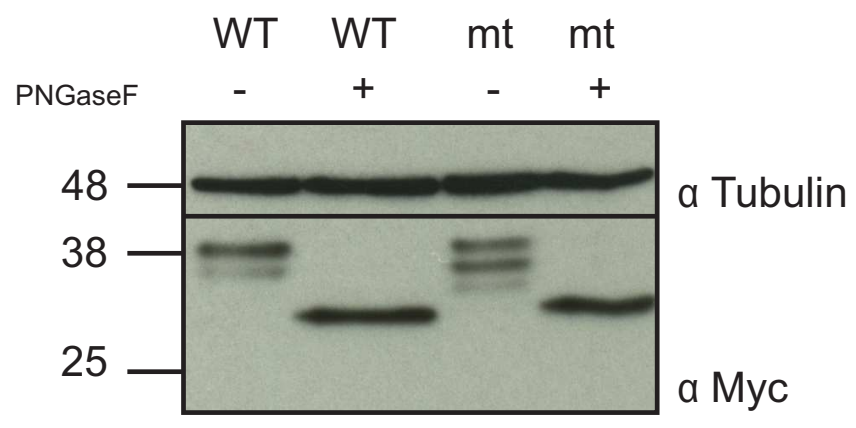

Abbildung 4.17.: Immunoblot zur Untersuchung der Glykosylierung von RNASET2-WT und RNASET2-mtC184R. Für die Glykosylierungsanalyse von RNASET2-Wildtyp (WT) und RNASET2-mtC184R (mt) wurden $30 \mu \mathrm{g}$ der glykosylierten (-) und der mit PNGase F behandelten HEK 293 Zellproteinextrakte $(+)$ eingesetzt. Die Detektion der Signale erfolgte durch das RNASET2-Antiserum (Verdünnung 1:20000). Als Ladekontrolle wurde mit einem TubulinAntikörper (Verdünnung 1:50000) das Tubulin-Protein in allen vier Spuren nachgewiesen. Der Größenstandard wurde in kDa angegeben.

\subsubsection{Herstellung eines Anti-RNASET2-Antiserums}

Das RNASET2-Gen wurde zur Herstellung eines polyklonalen Antiserums in voller Länge (Nukleotide 1-771) mit einer humanen cDNA als Matrize amplifiziert, in die multiple Klonierungsstelle eines eukaryontischen Expressionsvektors mit $6 \times$ His-Tag kloniert und als HisFusionsprotein exprimiert (3.4.6.2). Zur Auswahl der zu immunisierenden Kaninchen wurden Präimmunseren von 6 Kaninchen im Western Blot getestet, um eine unspezifische Detektion des Proteins auszuschließen. $4 \mathrm{mg}$ des über eine His Trap FF crude Säule aufgereinigten HisRNASET2-Fusionsproteins wurden von der Firma Seramun (Heidesee) zur Immunisierung von zwei ausgewählten Kaninchen (K37 und K38) eingesetzt.

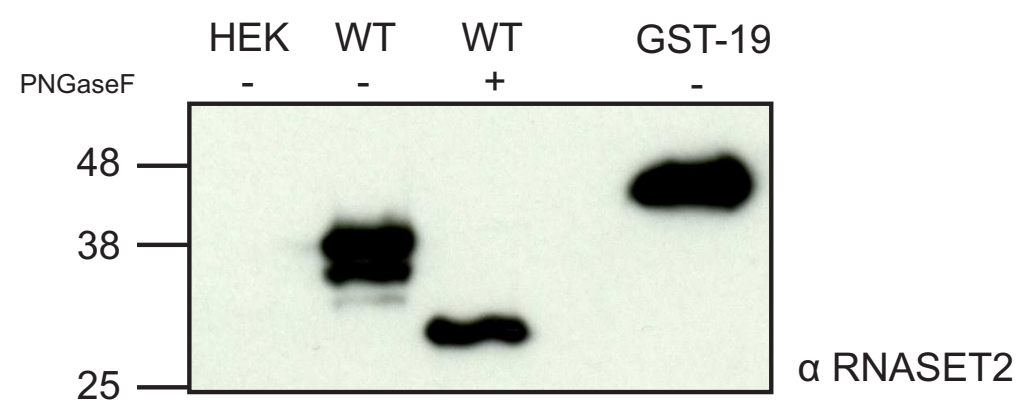

Abbildung 4.18.: Charakterisierung des RNASET2-Antiserums im Western Blot. Für die Analyse des polyklonalen RNASET2-Antiserums im Western Blot wurden jeweils $30 \mu \mathrm{g}$ Proteinextrakt aus transient transfizierten HEK 293 Zellen (RNASET2-Wildtyp, WT-), aus deglykosylierten transient transfizierten HEK 293 Zellen (RNASET2-Wildtyp, WT +) und aus untransfizierten HEK 293 Zellen (HEK, Negativkontrolle) eingesetzt. Des Weiteren wurden 50 ng des rekombinant in Bakterien exprimierten RNASET2-GST-19-Fusionsproteins (GST-19) eingesetzt. Die Detektion der rekombinant exprimierten Proteine erfolgte mit dem ungereinigten Antiserum in einer Verdünnung von 1:20000. Der Größenstandard wurde in kDa angegeben. 
Zum Nachweis der Spezifität des RNASET2-Antiserums wurden Proteinextrakte von untransfizierten HEK 293 Zellen als Negativkontrolle und Zellextrakte von RNASET2-WT transfizierten HEK 293 Zellen und ein rekombinantes GST-RNASET2-Fusionsprotein im Western Blot eingesetzt (Abbildung 4.18). In den untransfizierten HEK 293 Zellen (HEK) wird kein RNASET2-Protein nachgewiesen. Das RNASET2-Antiserum detektiert spezifisch die drei glykosylierten Banden der RNASET2-WT (WT-, vgl. Abbildung 4.16). Auch das deglykosylierte Protein $(\mathrm{WT}+)$ wird spezifisch erkannt. Ein rekombinantes GST-RNASET2-Fusionsprotein (GST-19) wurde ebenfalls geladen und entsprechend seiner Größe von 42 kDa detektiert. Die Spezifität des RNASET2-Antiserums konnte im Western Blot bestätigt werden.

Das RNASET2-Antiserum wurde in der Immunfluoreszenz untersucht, indem RNASET2-WTMyc transient transfizierte HeLa Zellen (3.3.2) mit einem monoklonalen $\alpha$ Myc-Antikörper (SantaCruz) und dem $\alpha$ RNASET2-Antiserum kogefärbt (3.3.4) wurden. Zur Detektion der primären Antikörper wurden Cy3-gekoppelte $\alpha$ Maus-IgG-Antikörper und Alexa488-gekoppelte $\alpha$ Kaninchen-IgG-Antikörper (Tabelle 2.1) verwendet.
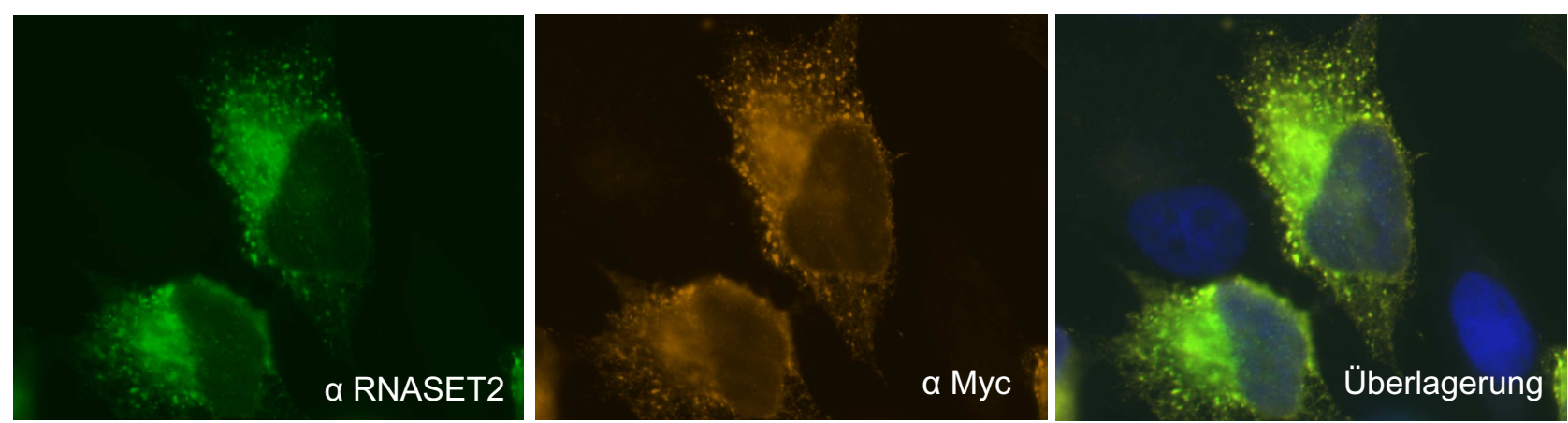

Abbildung 4.19.: Charakterisierung des RNASET2-Antiserums in der Immunfluoreszenz. Zur Untersuchung des RNASET2-Antiserums in der Immunfluoreszenz wurden HeLa Zellen transient mit einem RNASET2-WT-Myc-Konstrukt transfiziert. Zur Detektion der Proteine wurde das polyklonale RNASET2-Antiserum ( $\alpha$ RNASET2, Verdünnung 1:2000) und ein monoklonaler Myc-Antikörper ( $\alpha$ Myc, Verdünnung 1:200) eingesetzt. Als sekundäre Antikörper wurden Cy3-gekoppelte $\alpha$ Maus-IgG-Antikörper (rot) und Alexa488-gekoppelte $\alpha$ Kaninchen-IgGAntikörper (grün) verwendet. Die Kernfärbung erfolgte mittels ProLongGold-Eindeckelmedium mit DAPI. Fluoreszenzsignale wurden mit dem Fluoreszenzmikroskop Axio Imager M.1 und der Axio Vision LE4.5 Software von Zeiss analysiert.

Abbildung 4.19 zeigt anhand der gelben Färbung in der Überlagerung, dass es zu einer Kolokalisation der beiden primären Antikörper kommt. Das RNASET2-Antiserum kann somit spezifisch zur Erkennung von RNASET2-Proteinen in der Immunfluoreszenz verwendet werden. 


\subsubsection{Generierung von stabilen Zelllinien}

Um die subzelluläre Lokalisation von RNASET2-WT und RNASET2-mtC184R zu untersuchen, wurde jeweils eine stabile Zellinie generiert. Dazu wurde das mit PvuI linearisierte Plasmid in HEK 293 Zellen mittels Effectene Transfektions Reagenz transfiziert. Die transfizierten Zellen wurden nach zwei bis drei Tagen durch Zugabe des Antibiotikums Geneticin einem Selektionsdruck ausgesetzt (3.3.3). Zellen mit stabil integriertem Plasmid überlebten diese Selektion. Als Negativ-Kontrolle wurden untransfizierte Zellen mitbehandelt, die nach einigen Tagen vollständig abgestorben waren. Für weitere Experimente wurden stabile Mischklone verwendet.

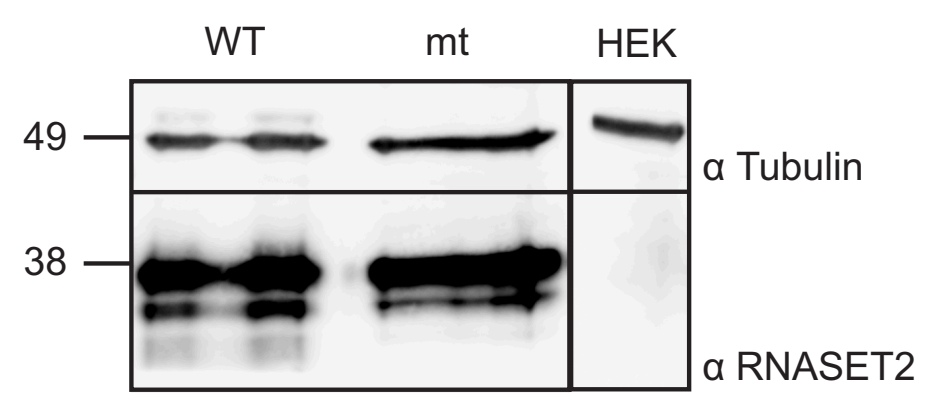

Abbildung 4.20.: Immundetektion der Expression von RNASET2-WT und RNASET2mtC184R in stabil transfizierten HEK 293 Zellen mittels Western Blot. HEK 293 Zellen wurden mit den RNASET2-Wildtyp (WT) und RNASET2-mtC184R (mt) Konstrukten stabil transfiziert und die Expression der rekombinanten Proteine im Western Blot analysiert. $30 \mu \mathrm{g}$ der stabilen Zellproteinextrakte und $30 \mu \mathrm{g}$ Proteinextrakt untransfizierter HEK 293 Zellen (HEK, Negativkontrolle) wurden im Immunoblot eingesetzt. Als Ladekontrolle wurde das Tubulin-Protein mit einem $\alpha$ Tubulin-Antikörper nachgewiesen. Der Größenstandard wurde in $\mathrm{kDa}$ angegeben.

Die Expression des RNASET2-WT- und des RNASET2-mtC184R-Proteins in den stabilen HEK 293 Zellen wurde mittels Immunoblot bestätigt (Abbildung 4.20). Das RNASET2-Antiserum detektiert keine Bande in untransfizierten HEK 293 Zellen. Als Ladekontrolle wurde das Tubulin-Protein mit einem $\alpha$ Tubulin-Antikörper nachgewiesen, welcher in allen Spuren gleich starke Banden erzeugte.

\subsubsection{Subzelluläre Lokalisation von RNASET2}

Zur Ermittlung der subzellulären Lokalisation wurden stabil transfizierte HEK 293 Zellen (WT und mtC184R) auf mit Poly-D-Lysin beschichteten Deckgläschen (20 mm) ausgesät. Nach Erreichen einer Konfluenz von etwa 70\% wurden RNASET2-Proteine mittels RNASET2Antiserum in der Immunfluoreszenz (3.3.4) detektiert. 
A.1
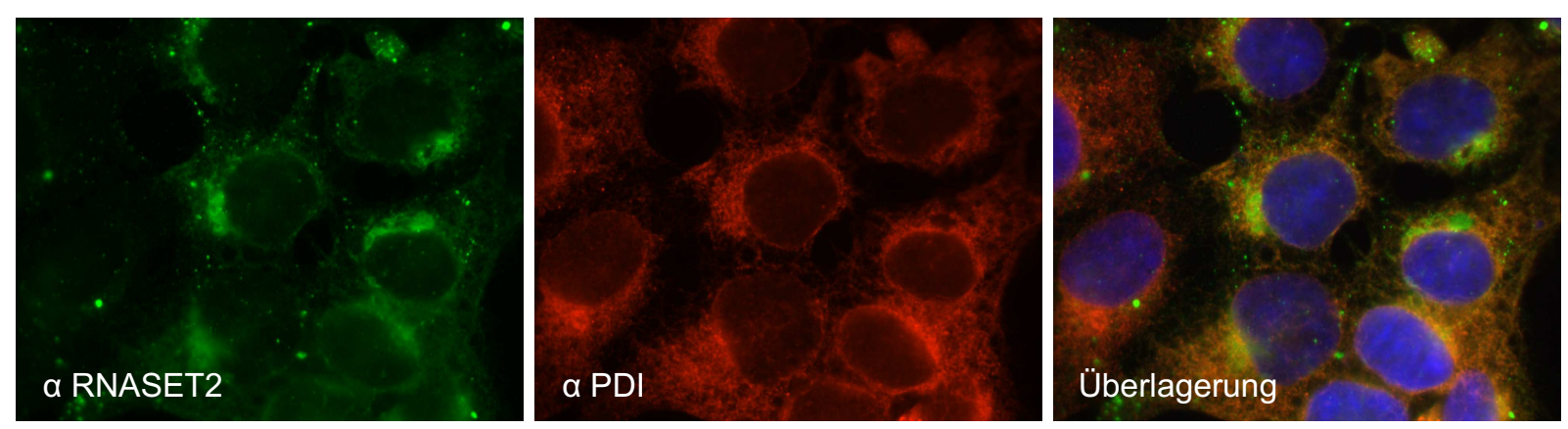

A. 2
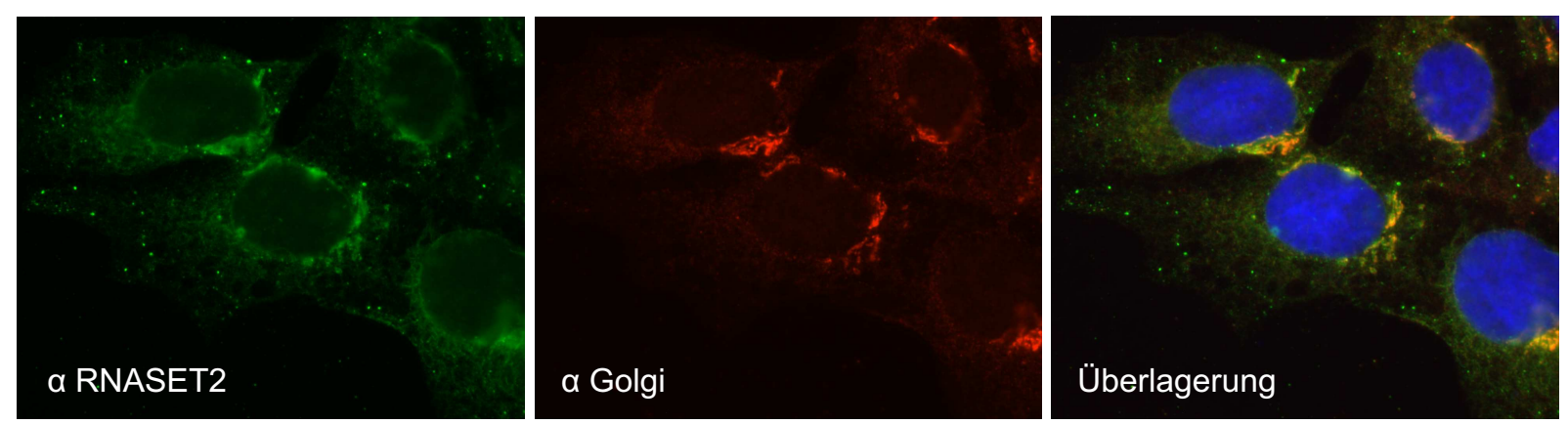

A.3
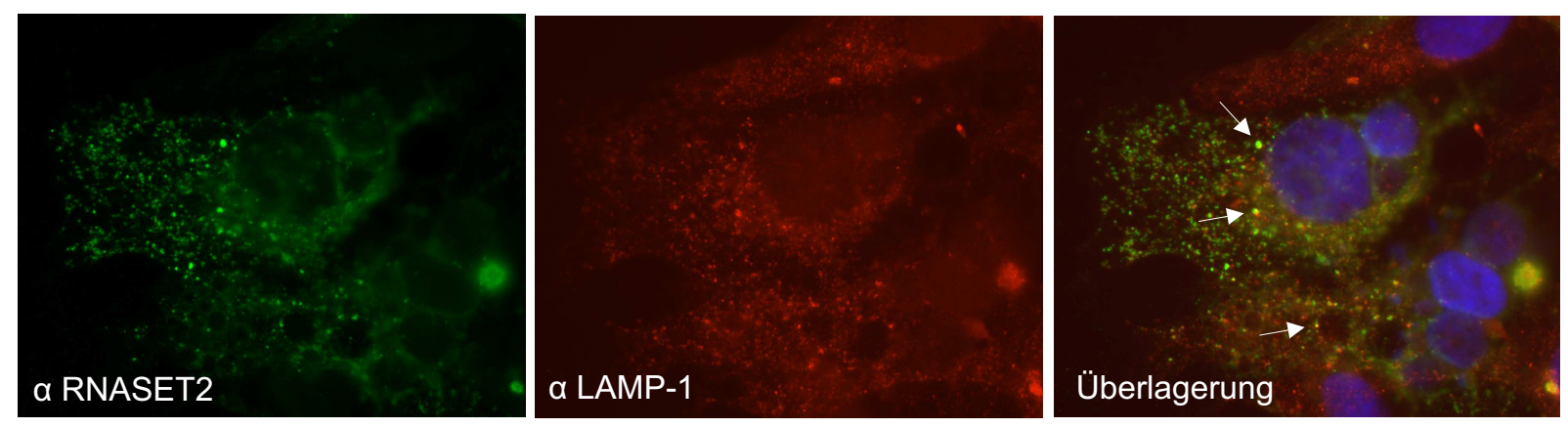

B
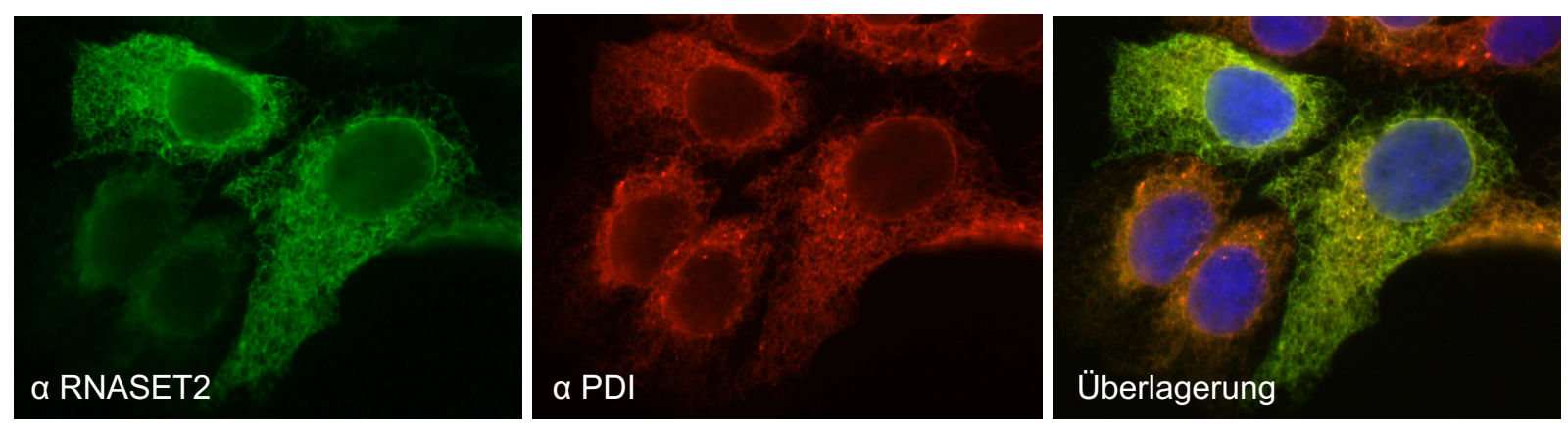

Abbildung 4.21.: Subzelluläre Lokalisation von RNASET2-WT und -mtC184R in stabilen HEK 293 Zellen. RNASET2-WT und RNASET2-mtC184R wurden mittels RNASET2-Antiserum ( $\alpha$ RNASET2, grün) und dem jeweiligen Zellkompartimentmarker (rot) nachgewiesen. Protein-DisulfidIsomerase ( $\alpha$ PDI, ER-Marker), 58K-Golgi-Protein ( $\alpha$ Golgi, Golgi-Apparat-Marker) und lysosomale Membranprotein 1 ( $\alpha$ LAMP 1, Lysosomen-Marker) Antikörper wurden zur Detektion der jeweiligen Zellkompartimente gewählt. Als sekundäre Antikörper wurden Cy3-gekoppelte $\alpha$ Maus-IgG-Antikörper (rot) und Alexa488-gekoppelte $\alpha$ Kaninchen-IgG-Antikörper (grün) verwendet. Die Kernfärbung erfolgte mittels DAPI im ProLongGold-Eindeckelmedium. (A.1-A.3) Subzelluläre Lokalisation des RNASET2Wildtyp-Proteins. Die weißen Pfeile markieren Kolokalisationen von RNASET2-WT mit Lysosomen. (B) Subzelluläre Lokalisation des RNASET2-mtC184R-Proteins. 
Mit Hilfe von primären Antikörpern, die für verschiedene Zellkompartimente (ER, Golgi, Lysosom) als Marker dienen, wurde die intrazelluläre Lokalisation von RNASET2 analysiert. In Abbildung 4.21 ist die subzelluläre Lokalisation der RNASET2 in stabil transfizierten HEK 293 Zellen dargestellt. Die Bilder auf der linken Seite zeigen die Färbung der RNASET2, die mittleren Bilder stellen das jeweils angefärbte Kompartiment dar und auf den Bildern rechts ist die Überlagerung der Einzelfärbungen zu sehen. Aus Abbildung 4.21 A.1 ist ersichtlich, dass die Wildtyp-RNASET2 teilweise mit der Protein-Disulfid-Isomerase (PDI), einem Marker für das Endoplasmatische Retikulum, kolokalisiert. Das 58K-Golgi-Protein (Marker für den GolgiApparat) zeigt ebenfalls eine partielle Kofärbung mit der RNASET2 (Abbildung 4.21 A.2), die an der gelblichen Färbung in der Überlagerung der Einzelfärbungen zu erkennen ist.

In den stabil transfizierten HEK 293 Zellen werden außerdem durch das RNASET2-Antiserum punktförmige Strukturen detektiert. Die Verteilung dieser Strukturen ist nicht in allen Zellen gleich. Um zu analysieren, ob es sich bei diesen punktförmigen Anfärbungen in den stabil transfizierten Zellen um Lysosomen handelt, wurden die Zellen mit dem lysosomalen Marker LAMP-1 kogefärbt. Einzelne Kolokalisationen des RNASET2-Proteins mit Lysosomen in Zellen mit besonders starker Punktierung sind in Abbildung 4.21 A.3 zu sehen. Ein Großteil des punktierten Musters scheint aber andere vesikuläre Strukturen zu repräsentieren.

Die mit RNASET2-mtC184R stabil transfizierten Zellen zeigen eine andere Lokalisation des RNASET2-mtC184R-Proteins (Abbildung 4.21 B). Die Kolokalisation bezieht sich ausschließlich auf das Endoplasmatische Retikulum. Färbungen mit den Zellkompartimentmarkern des Golgi-Apparats oder der Lysosomen weisen keine Kolokalisation auf. Das Protein bleibt im ER und wird von dort nicht in den sekretorischen Weg eingeschleust.

\subsubsection{RNASET2 in lymphoblastoiden Patienten-Zellen}

\subsubsection{Expressions- und Glykosylierungsanalyse von RNASET2}

Die Expression endogener RNASET2 in Patienten-Lymphozyten wurde im Western Blot analysiert. Proteinextrakte wurden wie in 3.4.1 beschrieben hergestellt und im Immunoblot (3.4.4 und 3.4.5) detektiert. Das endogene RNASET2-Protein der Kontroll-Lymphozyten (JK-10) ist in Höhe von ca. $36 \mathrm{kDa}$ detektierbar (Abbildung 4.22). Eine weitere sehr schwache Proteinbande ist etwa zwei bis drei Kilodalton darunter sichtbar. Diese zweite schwache Bande repräsentiert möglicherweise eine weniger stark glykosylierte Form des Proteins. Bei den Lymphozyten von Patient 327 (JL-11) zeigen sich Banden der gleichen Größe wie in der Kontrolle. Die kleinere schwächere Bande wird in der Kontrolle deutlicher sichtbar als im Patienten-Proteinextrakt (siehe auch Abbildung 4.23). 


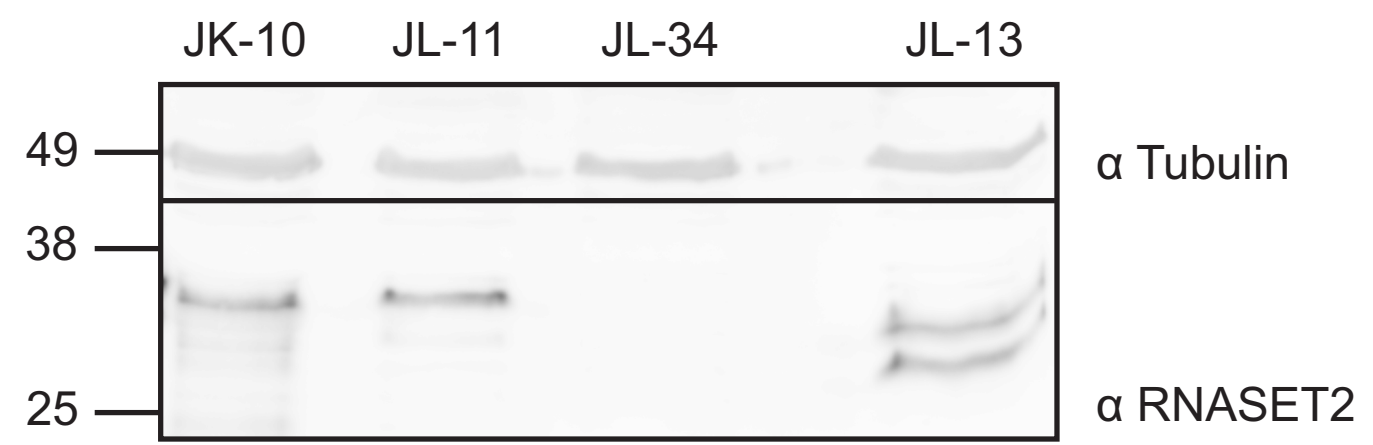

Abbildung 4.22.: Immundetektion der RNASET2-Expression in Patienten-Lymphozyten mittels Western Blot. Zur Analyse der RNASET2-Expression in lymphoblastoiden Zellen wurden jeweils $50 \mu \mathrm{g}$ Proteinextrakt von Kontroll-Lymphozyten (JK-10) und den PatientenZellen JL-11, JL-34 und JL-13 eingesetzt. Die Detektion der Signale erfolgte mittels RNASET2Antiserum (Verdünnung 1:20000). Als Ladekontrolle wurde das Tubulin-Protein mit einem $\alpha$ Tubulin-Antikörper nachgewiesen (Verdünnung 1:50000). Der Größenstandard wurde in kDa angegeben.

Endogenes Protein kann bei Patient 4483 mit der Spleißmutation c.262-2A>G mittels RNASET2-Antiserum nicht nachgewiesen werden (JL-34). Entweder werden die durch das alternative Spleißen bedingten Proteinprodukte nicht gebildet, gleich wieder abgebaut oder sie werden so schwach exprimiert, dass sie im Western Blot nicht detektiert werden können. Das RNASET2Protein des Patienten 37 mit der Mutation c.87-1341_147+1181del2583 (Deletion von Exon 2 und Bereiche von Intron 1 und 2) wird vom Antikörper in Höhe von ca. 32 kDa detektiert (JL13). Diese Proteinbande entspricht in etwa dem Spleißprodukt, welches durch Deletion von Exon zwei und drei entsteht (r.86_203del; p.Asp30_Trp68del). Eine zweite ca. 2 kDa kleinere Bande wird ebenfalls vom Antiserum detektiert.

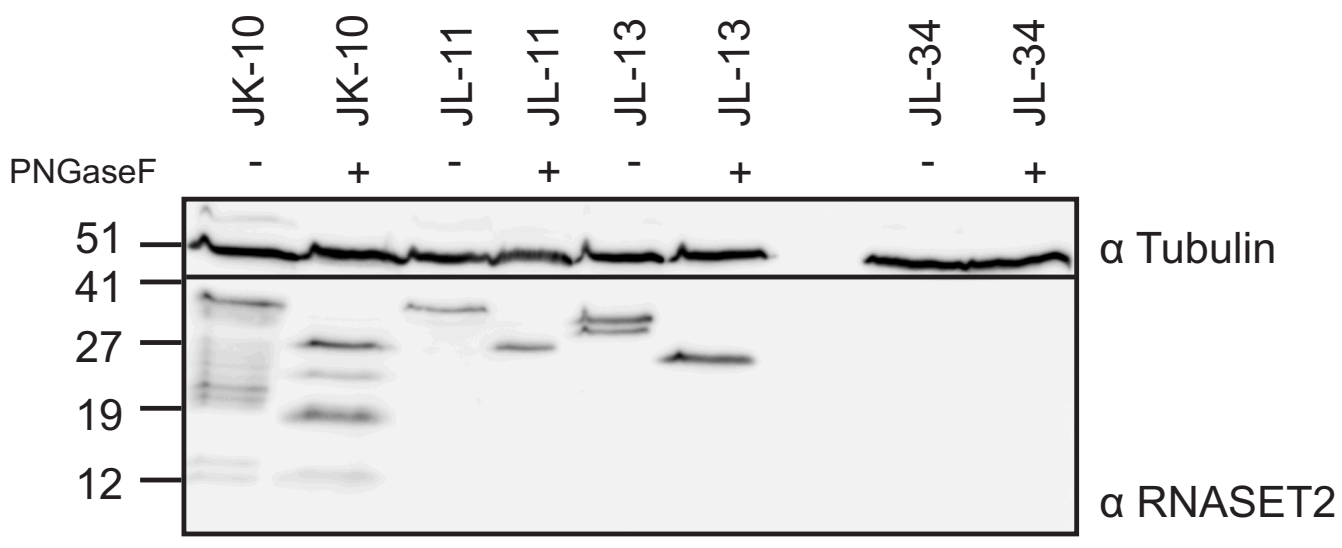

Abbildung 4.23.: Immundetektion der RNASET2-Glykosylierung in Patienten-Lymphozyten mittels Western Blot. Zur Analyse der RNASET2-Glykosylierung in Patienten-Lymphozyten wurden jeweils $50 \mu \mathrm{g}$ Proteinextrakt einer Kontroll-Lymphozyten-Zelllinie (JK-10) und der Patienten-Zelllinien JL-11, JL-13 und JL-34 eingesetzt. Die Detektion der glykosylierten und deglykosylierten (- und + PNGase F) Proteine erfolgte mittels RNASET2-Antiserum (Verdünnung 1:20000). Als Ladekontrolle wurde das Tubulin-Protein mit einem $\alpha$ Tubulin-Antikörper nachgewiesen (Verdünnung 1:50000). Der Größenstandard wurde in kDa angegeben. 
Um zu untersuchen, ob die Patientenzellen ebenfalls unterschiedlich glykosylierte Formen der RNASET2 exprimieren, wurde Zellproteinextrakt zur Deglykosylierung verwendet (3.4.3). Des Weiteren wurde untersucht, ob die beiden detektierten RNASET2-Banden unterschiedlich große oder unterschiedlich stark glykosylierte Proteine des Patienten 37 (JL-13) repräsentieren. In Abbildung 4.23 ist der Western Blot zur Untersuchung der Deglykosylierung von KontrollLymphozyten- und Patienten-Lymphozyten-Proteinextrakten dargestellt. Der Kontroll-Proteinextrakt (JK-10 -) und auch der Proteinextrakt der Patientenzellen JL-11 (JL-11 -) zeigen eine glykosylierte Bande in Höhe von ca. $36 \mathrm{kDa}$ und eine zweite sehr schwache Bande zwei bis drei Kilodalton kleiner. Die deglykosylierte Bande wird in beiden Spuren in Höhe von 27 kDa detektiert. In dem Kontrollproteinextrakt lassen sich noch weitere Banden detektieren. Ob es sich dabei um Abbauprodukte oder prozessierte Formen der RNASET2 handelt, ist unklar. Durch die Deglykosylierung werden z.B. die Banden in Höhe von 22-23 kDa auf 19 kDa verkleinert.

Die zwei Banden der Patientenzellen JL-13 werden durch PNGase F-Behandlung zu einem Signal auf Höhe von $24 \mathrm{kDa}$. Dies zeigt, dass es sich nicht um zwei unterschiedlich große Proteine handelt, sondern um unterschiedlich stark glykosylierte Formen der RNASET2-Mutante. Im Proteinextrakt der Patientenzellen JL-34 lässt sich kein Protein und somit auch keine Deglykosylierung nachweisen.

\subsubsection{Sekretionsanalyse von RNASET2}

Die Sekretion von RNASET2 in lymphoblastoiden Patienten-Zellen wurde in serumfreiem Zellkulturüberstand untersucht. In zuvor durchgeführten Western Blot-Analysen von Zellkulturüberstand mit Serum wurden die großen Mengen an Serumalbumin unspezifisch vom Antikörper detektiert und überlagerten fast vollständig das spezifische Signal. Die Lymphozyten wurden in gleicher Zellzahl $\left(100 \times 10^{4}\right.$ Zellen $)$ in $1 \mathrm{ml}$ Medium ausgesät. Nach 48 Stunden in serumfreiem RPMI-1640 wurden die Zellbestandteile des Zellkulturüberstandes sedimentiert und im Western Blot analysiert (Abbildung 4.24).

Das RNASET2-Antiserum erzeugt im Zellkulturüberstand der Kontrolle (JK-10) in Höhe von etwa 39 kDa ein (schwaches) spezifisches Signal. Somit wird nachgewiesen, dass das RNASET2Wildtyp-Protein ins Medium sezerniert wird. In allen anderen Spuren (ÜS JL-11, ÜS JL-13, ÜS JL-34) wird auf gleicher Höhe kein Signal erzeugt. Offensichtlich werden die RNASET2-mtProteine der Patienten-Zellen nicht sezerniert, sondern verbleiben intrazellulär. Bei JL-34 war im Medium kein Protein zu erwarten, da vorausgegangene Experimente zeigten, dass dieses Protein nicht gebildet wird oder nicht stabil ist (vgl. Abbildung 4.22). 


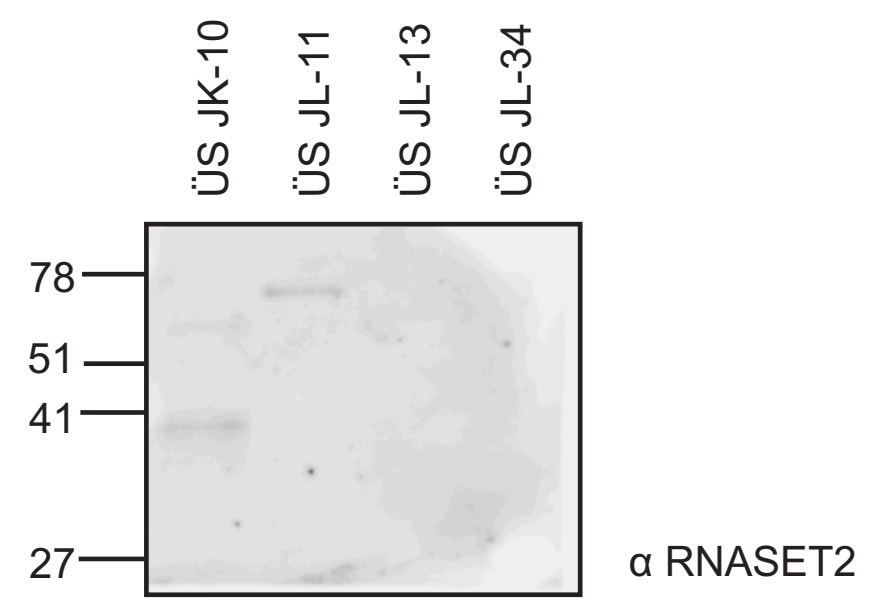

Abbildung 4.24.: Immundetektion der RNASET2-Sekretion von Patienten-Lymphozyten im Western Blot. Zellkulturüberstände (ÜS) von 48 Stunden serumfrei kultivierten lymphoblastoiden Patienten-Zellen (JL-11, JL-13, JL-34) und lymphoblastoiden Kontroll-Zellen (JK-10) wurden im Western Blot mit Hilfe des RNASET2-Antiserums (Verdünnung 1:20000) analysiert. $25 \mathrm{\mu l}$ des Überstandes wurden jeweils eingesetzt. Der Größenstandard wurde in kDa angegeben.

\subsubsection{Subzelluläre Lokalisation von RNASET2}

Die subzelluläre Lokalisation der endogenen RNASET2 in den Patienten-Lymphozyten und Lymphozyten einer gesunden Kontrolle wurde in der Immunfluoreszenz untersucht. Je $1 \mathrm{ml}$ einer Zellsuspension wurde zentrifugiert, das Zellsediment in entsprechendem Volumen FKS resuspendiert und auf Objektträgern ausgestrichen. Die Immunfärbung erfolgte wie in 3.3.4 beschrieben durch das RNASET2-Antiserum und den ensprechenden Zellkompartiment-Antikörpern.

In Abbildung 4.25 ist die subzelluläre Lokalisation der RNASET2 in lymphoblastoiden KontrollZellen dargestellt. Die linken Bilder zeigen die Färbung der RNASET2, die mittleren Bilder stellen das jeweilige Zellkompartiment dar und auf der rechten Seite ist die Überlagerung der RNASET2- und Zellkompartiment-Färbung zu sehen. Der Abbildung 4.25 A kann entnommen werden, dass die RNASET2 in Kontroll-Lymphozyten zum großen Teil im ER lokalisiert ist, erkennbar an der gelben Färbung in der Überlagerung der Einzelfärbungen. Ein geringerer Anteil der RNASET2 ist auch im Golgi-Apparat zu finden (Abbildung 4.25 B). Es kommt aber auch zu vereinzelten Kolokalisationen mit Lysosomen (Abbildung 4.25 C). Es zeigt sich eine ähnliche subzelluläre Verteilung der RNASET2 wie in den stabil transfizierten HEK 293 Zellen (Abbildung 4.21). 
A
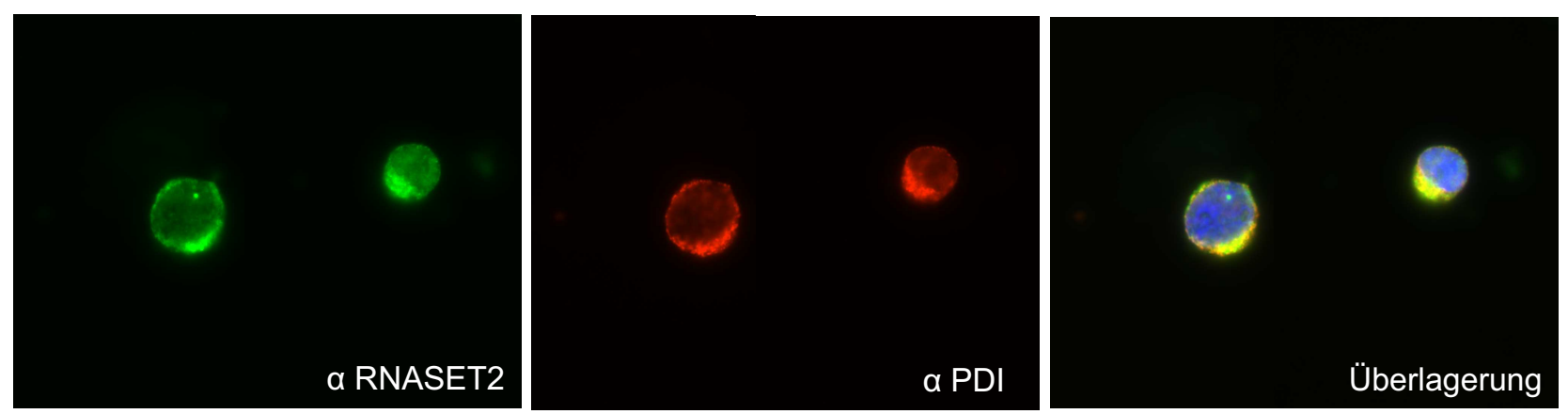

B
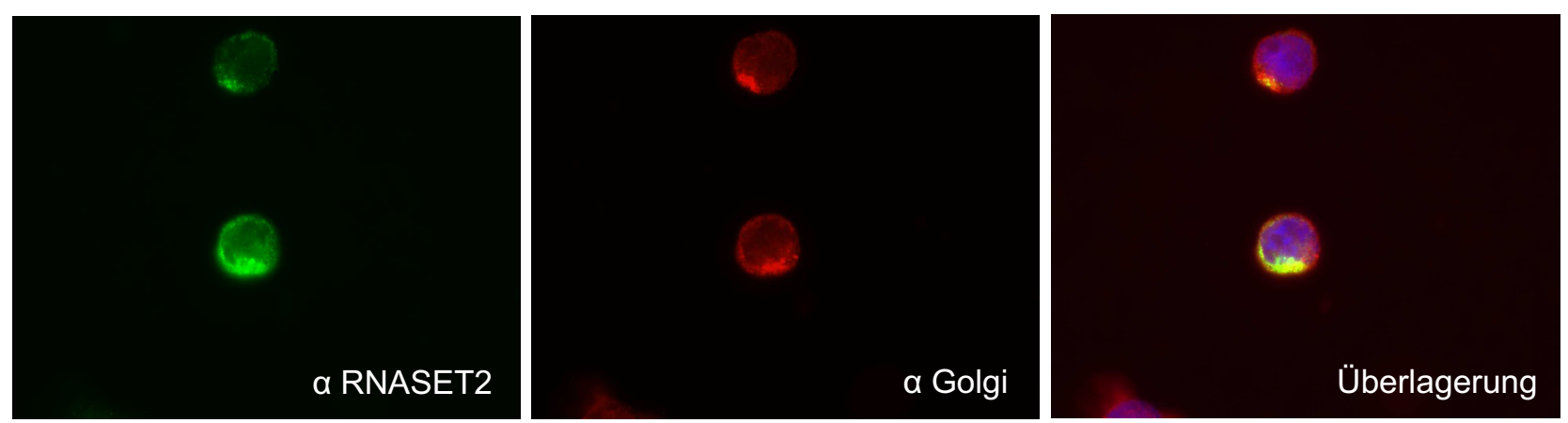

C
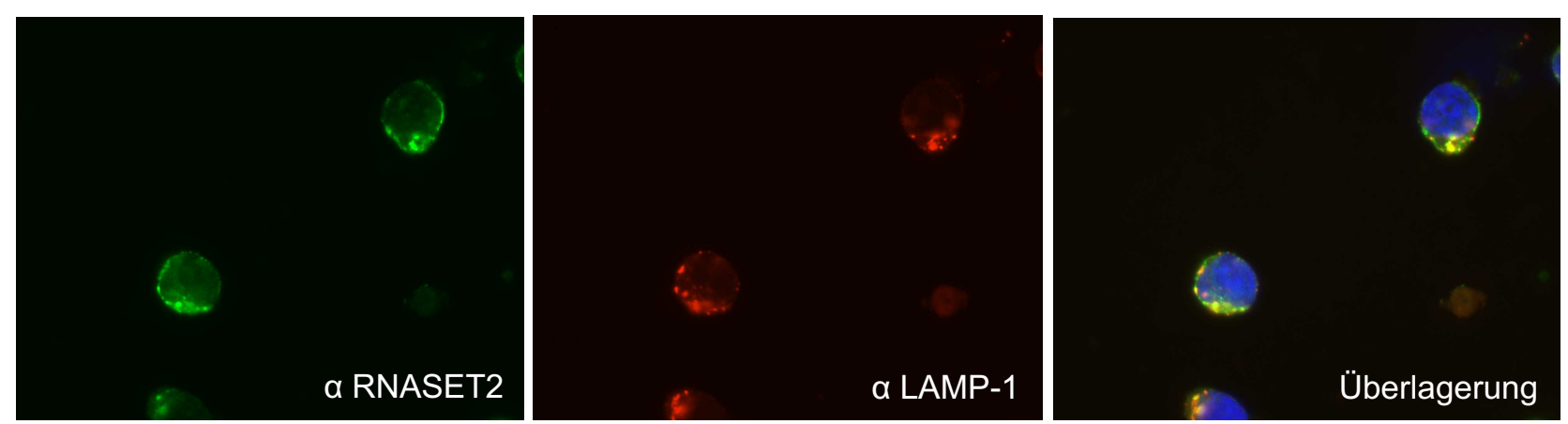

Abbildung 4.25.: Subzelluläre Lokalisation von RNASET2 in lymphoblastoiden Kontroll-Zellen. (A-C) Die subzelluläre Lokalisation von RNASET2 in lymphoblastoiden KontrollZellen (JK-10) wurde mit Hilfe des RNASET2-Antiserums ( $\alpha$ RNASET2, grün) und dem jeweiligen Zellkompartimentmarker (rot) nachgewiesen. Als ER-Marker wurde ein Protein-DisulfidIsomerase Antikörper ( $\alpha$ PDI) gewählt (A). Der Golgi-Apparat wurde durch einen Antikörper gegen das 58K-Golgi-Protein ( $\alpha$ Golgi) detektiert (B). Lysosomen wurden durch einen Antikörper gegen das lysosomale Membranprotein 1 ( $\alpha$ LAMP-1) nachgewiesen $(\mathrm{C})$. Als sekundäre Antikörper wurden Cy3-gekoppelte $\alpha$ Maus-IgG-Antikörper (rot) und Alexa488-gekoppelte $\alpha$ KaninchenIgG-Antikörper (grün) verwendet. Die Kernfärbung erfolgte mittels DAPI im ProLongGoldEindeckelmedium (blau).

Abbildung 4.26 zeigt die subzelluläre Lokalisation der RNASET2 in lymphoblastoiden Patienten-Zellen. Die Aufteilung der einzelnen Bilder erfolgte wie in Abbildung 4.25 zur subzellulären Lokalisation der lymphoblastoiden Kontroll-Zellen. Das RNASET2-mtC184R-Protein der Patienten-Zellen JL-11 ist im ER lokalisiert, erkennbar an der gelben Färbung der Überlagerung der Einzelfärbungen (Abbildung 4.26 A). 
A
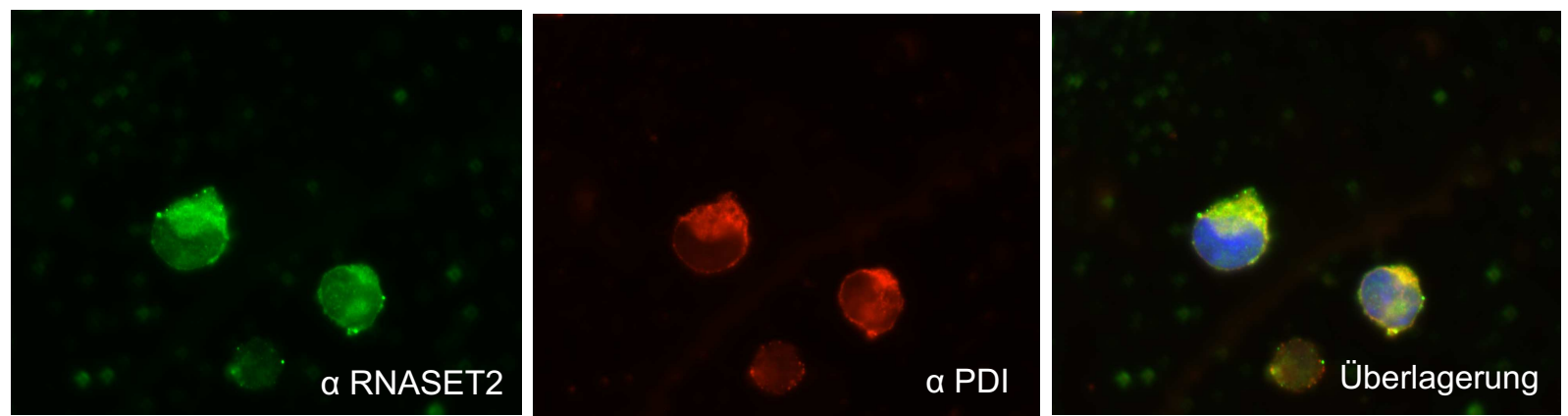

B.1
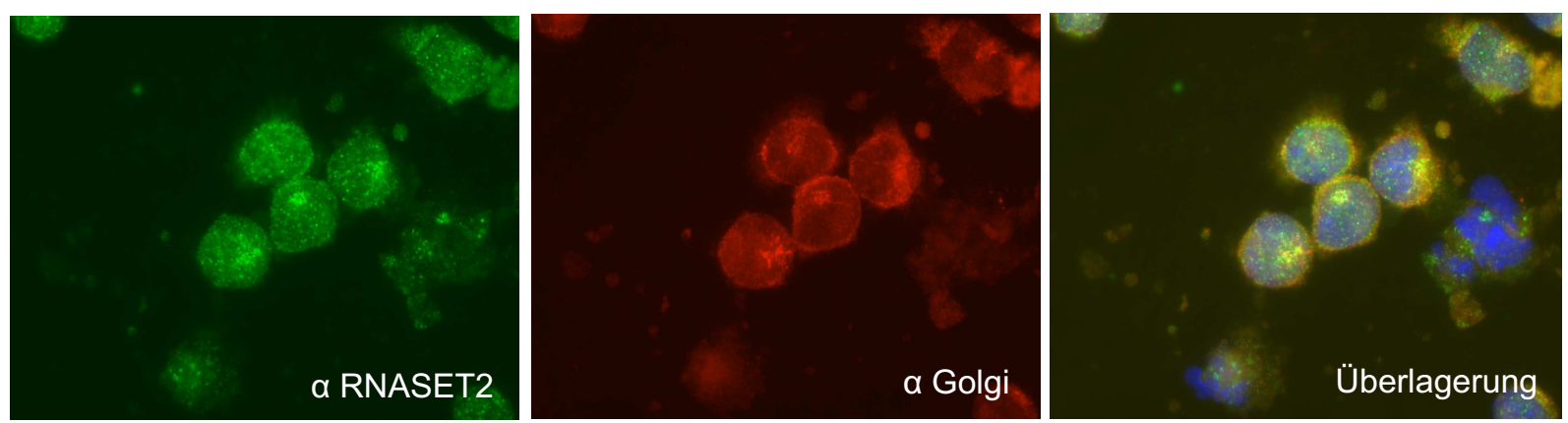

B.2
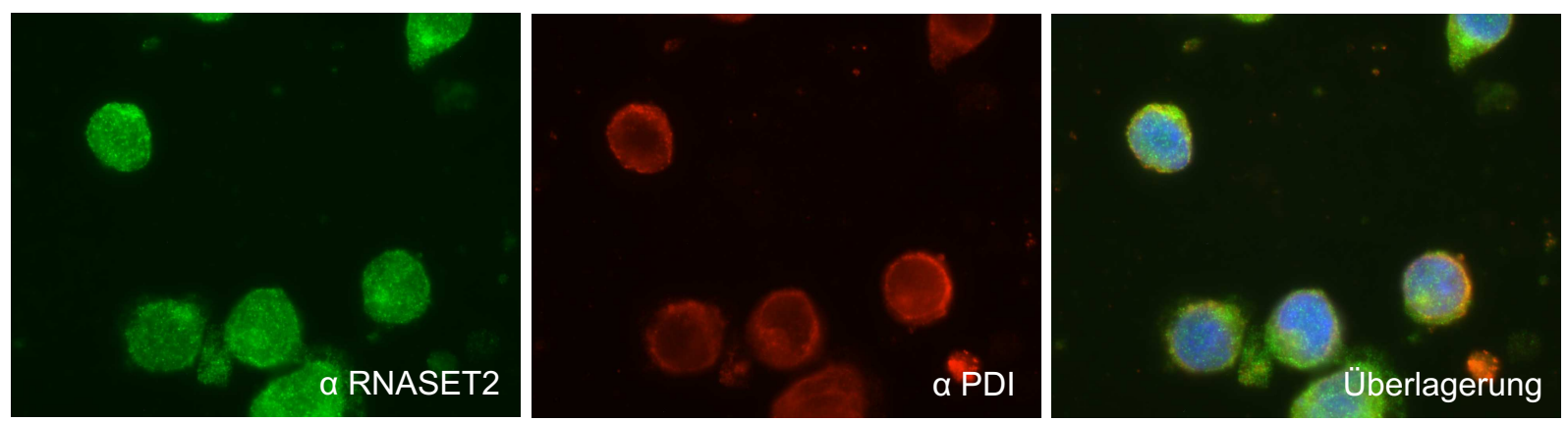

C
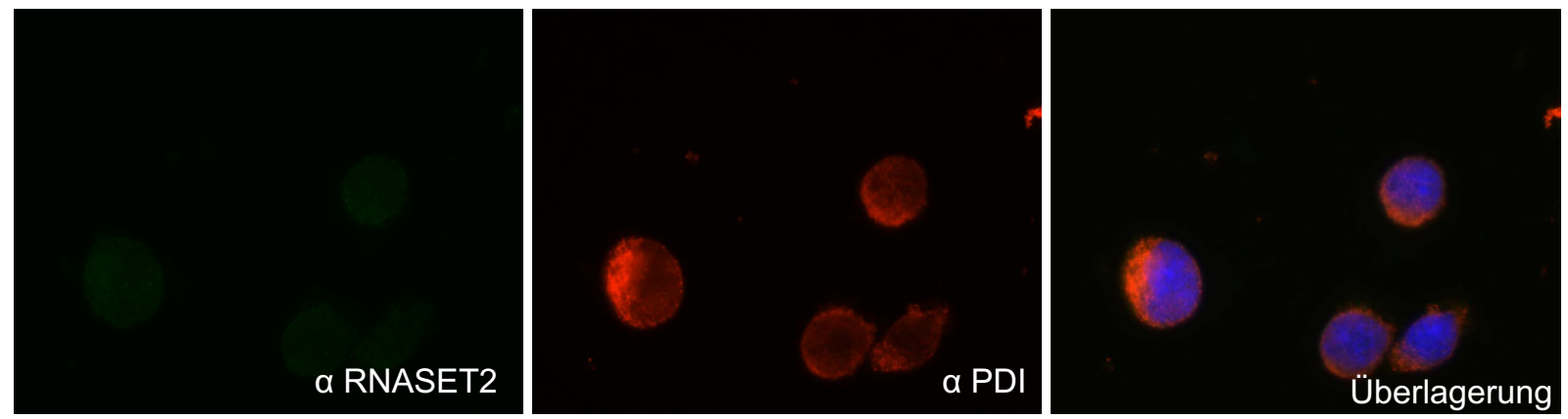

Abbildung 4.26.: Subzelluläre Lokalisation von RNASET2 in lymphoblastoiden Patienten-Zellen. (A-C) Die subzelluläre Lokalisation von RNASET2 wurde mit Hilfe des RNASET2Antiserums ( $\alpha$ RNASET2, grün) und dem jeweiligen Zellkompartimentmarker (rot) in den lymphoblastoiden Patienten-Zellen JL-11 (A), JL-13 (B.1 und B.2), JL-34 (C) nachgewiesen. Als ERMarker wurde ein Protein-Disulfid-Isomerase Antikörper ( $\alpha$ PDI) gewählt. Der Golgi-Apparat wurde durch einen Antikörper gegen das 58K-Golgi-Protein ( $\alpha$ Golgi) detektiert. Als sekundäre Antikörper wurden Cy3-gekoppelte $\alpha$ Maus-IgG-Antikörper (rot) und Alexa488-gekoppelte $\alpha$ Kaninchen-IgG-Antikörper (grün) verwendet. Die Kernfärbung erfolgte mittels DAPI im ProLongGold-Eindeckelmedium (blau). 
Dieses Ergebnis bestätigt die ER-Kolokalisation in den mit RNASET2-mtC184R stabil transfizierten HEK 293 Zellen (Abbildung 4.21).

In den lymphoblastoiden Patienten-Zellen JL-13 kommt es zu einer überwiegenden Kolokalisation mit dem Golgi-Apparat und dem ER (Abbildung 4.26 B.1 und B.2). Ein Teil des Proteins scheint aber auch im Zytosol lokalisiert zu sein. Die Immunfärbung von RNASET2 in den Zellen JL-34 kann kein Protein detektieren. Dieses Ergebnis war zu erwarten, da in der Expressionsanalyse im Western Blot ebenfalls kein Protein nachgewiesen werden konnte. Das mt-RNASET2-Protein wird entweder nicht exprimiert oder es ist instabil (Abbildung 4.26 C).

\subsubsection{Prozessierung der RNASET2}

Zur Untersuchung der proteolytischen Prozessierung des RNASET2-Proteins in voller Länge, wurden Proteinextrakte von RNASET2-Myc-Tag transfizierten HEK 293 Zellen im Western Blot mit Hilfe des RNASET2-Antiserums oder eines Myc-Antikörpers analysiert.
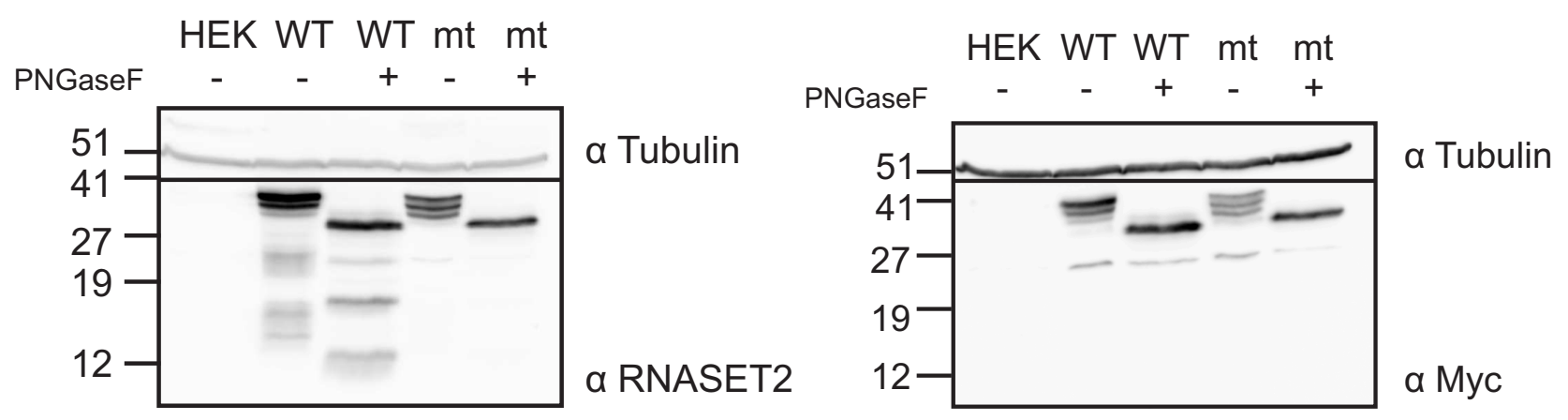

Abbildung 4.27.: Immundetektion der Prozessierung von RNASET2-WT- und RNASET2-mtC184R-Proteinen mittels Western Blot. Zur Analyse der Prozessierung von RNASET2-WT- und RNASET2-mtC184R-Proteinen wurden jeweils $30 \mu \mathrm{g}$ Proteinextrakt von untransfizierten HEK 293 Zellen (HEK), von RNASET2-WT (WT) und von RNASET2-mtC184R (mt) transfizierten HEK 293 Zellen eingesetzt. Die Detektion der glykosylierten und deglykosylierten (- und + PNGase F) Signale erfolgte mittels RNASET2-Antiserum (Verdünnung 1:20000) bzw. mittels Myc-Antikörper (1:1000). Als Ladekontrolle wurde das Tubulin-Protein mit einem $\alpha$ Tubulin-Antikörper nachgewiesen (Verdünnung 1:50000). Der Größenstandard wurde in kDa angegeben.

Das RNASET2-Antiserum und der Myc-Antikörper detektieren in RNASET2-Wildtyp wie auch in RNASET2-mtC184R transfizierten Zellen die drei unterschiedlich stark glykosylierten Formen des "Volle-Länge" RNASET2-Proteins (Abbildung 4.27). Durch die PNGase F Behandlung kann die N-Glykosylierung bestätigt werden. Eine Bande in Höhe von etwa $25 \mathrm{kDa}$ wird von beiden Antikörpern in glykosylierten wie auch in deglykosylierten Wildtyp und Mutanten Proteinextrakten nachgewiesen. Diese Bande könnte die N-terminal prozessierte Form der 
RNASET2 repräsentieren. Die berechnete Größe des Proteins ohne das Signalpeptid von 24 Aminosäuren am N-Terminus und ohne jegliche Modifikationen entspricht dem Molekulargewicht des Signals von $25 \mathrm{kDa}$ im Western Blot. Das RNASET2-Antiserum detektiert noch mindestens drei weitere Banden im Wildtyp Zelllysat. Diese Banden werden auch in KontrollLymphozyten vom RNASET2-Antiserum nachgewiesen (4.23). Teilweise scheint es sich um glykosylierte Formen der RNASET2 zu handeln, da es zu einer Größenverschiebung nach PNGase F Behandlung kommt. Aufgrund der Tatsache, dass der Myc-Tag am C-Terminus lokalisiert ist, und diese Proteine vom Myc-Antikörper nicht detektiert werden, ist davon auszugehen, dass es bei der RNASET2 zur proteolytischen Prozessierung am C-Terminus kommt.

\subsubsection{RNASET2-Interaktionsstudien}

Um das RNASET2-Protein näher zu charakterisieren, wurde in Interaktionsstudien nach möglichen RNASET2-Bindungspartnern gesucht. Durch einen GST-pulldown sollten direkte und indirekte Interaktionen nachgewiesen werden.

Das GST-Fusionsprotein wurde hergestellt, indem der die Aminosäuren 110-256 kodierende Bereich der RNASET2-cDNA (Nukleotide 328-771) mit einer humanen Kontroll-cDNA als Matrize amplifiziert, in den prokaryontischen Expressionsvektor pGEX-KG kloniert (Tabelle 2.5) und als GST-RNASET2-Fusionsprotein (GST-19, GST N-terminal) exprimiert wurde (3.4.6.1). Die an Glutathion-Sepharose gebundenen GST-RNASET2-Fusionsproteine wurden mit humanem Gehirnextrakt (Großhirn oder Kleinhirn, je 20 mg) oder HeLa-Zellextrakt (acht bis zehn konfluent gewachsene $10 \mathrm{~cm}^{2}$-Schalen) inkubiert (3.4.7). Als Kontrolle diente GST mit Zelllysatinkubation und GST-RNASET2-Fusionsprotein ohne Zelllysatinkubation.

Aus dem Coomassie-gefärbten SDS-Gel des GST-pulldowns mit Großhirnlysat wurden vier Banden putativer Bindungspartner auf Höhe von 15 bis 90 kDa ausgeschnitten und massenspektrometrisch analysiert. Die Daten wurden mit einer humanen Datenbank abgeglichen und sind in Tabelle 4.3 zusammengefasst. Weitere vier Banden wurden vom Kleinhirn-GST-pulldown untersucht. Als putativer Bindungspartner der RNASET2 im Kleinhirn wurde jedoch nur der ADP-Ribosylation Faktor 5 detektiert. Dieser konnte aber auch im Großhirnlysat nachgewiesen werden. Die Ergebnisse der massenspektrometrischen Analyse von drei Banden des HeLaZelllysats GST-pulldowns sind ebenfalls in der Tabelle 4.3 aufgelistet. Mögliche Bindungspartner der RNASET2 sind z.B. Hitzeschockproteine oder Mitglieder der Ras-Superfamilie. 
Tabelle 4.3.: Massenspektrometrische Analyse des GST-pulldowns.

\begin{tabular}{|c|c|c|}
\hline Protein & GenBank-Zugriffsnummer & Bandengröße \\
\hline $\begin{array}{l}\text { Dihydropyrimidinase-like 2 } \\
\text { (DPYSL2) }\end{array}$ & NP_001377.1 & $55 \mathrm{kDa}$ (Großhirn) \\
\hline Glutathion Peroxidase & CAB37833.1 & $20 \mathrm{kDa}$ (Großhirn) \\
\hline Proteolipid Protein 1 Isoform 2 & NP_955772.1 & $20 \mathrm{kDa}$ (Großhirn) \\
\hline Tubulin 5-beta & CAA25318.1 & $55 \mathrm{kDa}$ (Großhirn) \\
\hline $\begin{array}{l}\text { RAB1A, member RAS oncogene fami- } \\
l y\end{array}$ & NP_004152.1 & $20 \mathrm{kDa}$ (Großhirn) \\
\hline $\begin{array}{l}\text { RAB33B, member RAS oncogene fa- } \\
\text { mily }\end{array}$ & NP_112586.1 & 20 kDa (Großhirn) \\
\hline ADP-Ribosylierungsfaktor 5 & NP_ 001653.1 & $\begin{array}{l}15 \mathrm{kDa} \text { (Großhirn) } \\
15 \mathrm{kDa} \text { (Kleinhirn) }\end{array}$ \\
\hline Heat-shock 90kDa protein-1, alpha & NP_005339.1 (NM_005348) & 80-90 kDa (HeLa) \\
\hline Heat-shock 90kDa protein-1, beta & NP_031381.1 (NM_007355) & 80-90 kDa (HeLa) \\
\hline $\begin{array}{l}\text { Chaperonin containing TCP1, subunit } \\
3 \text { (gamma) }\end{array}$ & NP_005989.1 (NM_005998) & 60-70 kDa (HeLa) \\
\hline Ras-related nuclear protein & NP_006316.1 (NM_006325) & $25 \mathrm{kDa}(\mathrm{HeLa})$ \\
\hline
\end{tabular}





\section{Diskussion}

\subsection{Pathogenese der GJA12-assoziierten PMLD}

\subsubsection{Mutationsanalyse der PMLD-Patienten}

Im Rahmen dieser Arbeit konnten 13 neue Mutationen bei der genetischen Analyse von 195 PMLD-Patienten aus 184 Familien identifiziert werden (Tabelle 4.1). Diese 13 neuen Mutationen wurden bei 20 Patienten aus 16 Familien festgestellt. Demnach sind nur 10,3\% der PMLDPatienten, die anhand ihrer klinischen und radiologischen Befunde der PMLD-Krankheitsentität zugeordnet wurden, positiv für eine Cx46.6-kodierende Mutation. Diese Ergebnisse zeigen, dass Mutationen im Cx46.6-Gen eine eher seltene Ursache der PMLD sind. Es handelt sich bei dieser Krankheitsentität offenbar um eine genetisch heterogene Gruppe von Patienten. Neben PLP1 und Cx46.6 müssen noch weitere zu diesem klinischen Phänotyp führende Krankheitsgene existieren. Von Magen et al. wurde 2008 ein weiteres Krankheitsgen für die PMLD identifiziert. Im HSPD1-Gen, welches das Hitzeschockprotein 60 (HSP60) kodiert, wurde die Mutation Asp29Gly bei Patienten aus einer konsanguinen israelischen Familie nachgewiesen. Klinische und radiologische Befunde dieser Patienten stimmen mit dem Phänotyp der PMLD weitestgehend überein (Magen et al., 2008). Die Patienten, die im Rahmen dieser Arbeit untersucht wurden und keine Mutationen im Cx46.6/GJA12-Gen aufweisen, müssen in zukünftigen Analysen auf Sequenzveränderungen im HSPD1-Gen untersucht werden.

Bis heute sind zusammen mit den im Rahmen dieser Arbeit identifizierten 13 Sequenzveränderungen, insgesamt 23 verschiedene Cx46.6-Mutationen beschrieben (Bugiani et al., 2006; Henneke et al., 2008; Orthmann-Murphy et al., 2008; Salviati et al., 2006; Uhlenberg et al., 2004; Wolf et al., 2006). Ein Sequenzbereich (hot spot) des Cx46.6-Gens an dem sich Mutationen häufen, konnte nicht lokalisiert werden (vgl. Abbildung 4.1). Sieben Mutationen wurden in den vier Transmembrandomänen lokalisiert, sechs in der intrazellulären und vier in der zweiten extrazellulären Schleife, sowie sechs weitere Mutationen im zytoplasmatischen C-Terminus. Die 13 beschriebenen Nonsense und Frameshift Mutationen führen zu verkürzten oder überlangen Proteinen mit wahrscheinlich teilweisem oder vollständigem Verlust der Proteinfunktion. 
In fünf Patienten konnte nur ein mutiertes Cx46.6-Allel identifiziert werden. Die Mutationsanalyse der Eltern von Patienten G218 und G588 ergab, dass die nicht erkrankten Mütter Trägerinnen der jeweiligen heterozygoten Mutation sind. Die bei den Patienten heterozygot vorliegenden Sequenzvarianten können allein nicht für die Ausprägung des Phänotyps verantwortlich gemacht werden, da die GJA12-assoziierte PMLD nach heutigem Kenntnisstand autosomal rezessiv vererbt wird. Es ist anzunehmen, dass bei diesen Patienten Mutationen in nicht analysierten Genregionen auf dem zweiten Allel vorliegen. Diese könnten sich z.B. in nicht kodierenden Bereichen, regulatorischen Promotor- oder Intron-Bereichen oder in einem gewebespezifischen alternativ gespleißten und somit unbekannten Exon, welches zu einem alternativen Promotor oder der 5'-untranslatierten Region (5'UTR) gehört, befinden. Eine variable Promotorregion und alternatives Spleißen wurde von Anderson et al. (2005) für das murine Gja12 beschrieben.

Eine alternative Hypothese wäre eine dominante Segregation der Mutation mit unvollständiger einseitiger Penetranz oder variablem Expressionsniveau. Zwei unterschiedliche Formen der Mutationssegregation innerhalb eines Gens wurden z.B. auch für humane Cx26 (GJB2)Mutationen beschrieben (Rabionet et al., 2000). Es könnte sich bei diesen Patienten aber auch um eine digen-vererbte Erkrankung handeln, bei der eine weitere Mutation in einem anderen in Oligodendrozyten exprimierten Connexin-Gen, GJB1 (Cx32), GJB2(Cx26) oder GJE1 (Cx29), vorliegt (Nakase und Naus, 2004). Eine digen-vererbte, zwei Gene betreffende Erkrankungsursache konnte für die Nichtsyndromale Taubheit (GJB2 [Cx26] und GJB6 [Cx30]) und für die Hidrotische Ektodermale Dysplasie (GJA1 [Cx43] und GJB2 [Cx26]) festgestellt werden (Frei et al., 2004; Kellermayer et al., 2005). Weitere Studien der Familien sowie weitere Sequenzanalysen im Cx46.6-Gen und anderen Connexin-Genen sind notwendig, um andere Segregationsmuster der PMLD aufzudecken.

\subsubsection{Untersuchungen zur Funktionalität der Cx46.6-Mutanten}

Alle Missense Mutationen, bis auf die Sequenzvariante Gly149Ser, betreffen hoch konservierte Aminosäuren, was darauf hinweist, dass es sich um evolutionär wichtige Strukturen für die Proteinfunktion handelt (Abbildung 5.1). Zur Funktionsanalyse von sechs Cx46.6-Mutationen (Pro90Ser; Thr398Ile; Gly149Ser; Ala98Gly_Val99insThr; Gly236Arg; Thr265Ala) wurden elektrophysiologische Messungen in Xenopus laevis Oozyten durchgeführt (4.1.2). Die Expression des endogenen Xenopus laevis Connexin 38 wurde mittels Antisense Oligonukleotiden (asCx38) blockiert, um spezifisch Cx46.6-abhängige Ströme zu messen (Barrio et al., 1991; Bruzzone et al., 1993; Hennemann et al., 1992). Das Membranpotential der mit Cx46.6Wildtyp-RNA injizierten Oozyten ist im Vergleich zum Ruhemembranpotential der mit asCx38 injizierten Oozyten leicht depolarisiert. Dies könnte durch die Präsenz von Cx46.6-Halbkanälen 


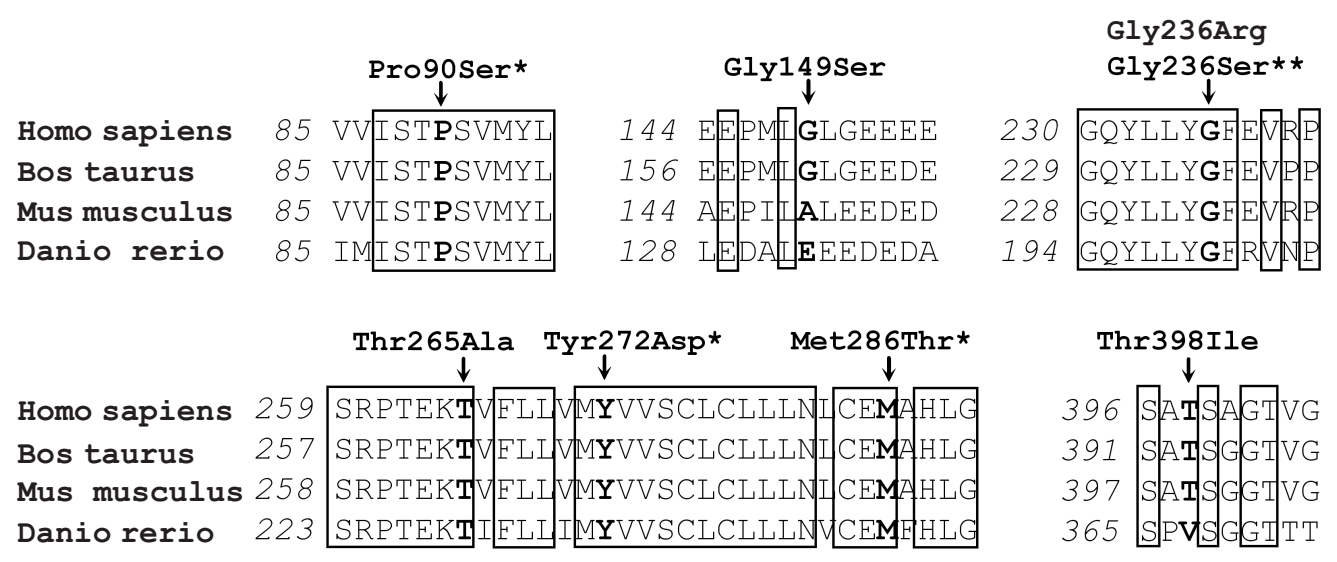

Abbildung 5.1.: Alignment der Bereiche des Cx46.6-Proteins, in denen die Missense Mutationen lokalisiert sind. Die humane Cx46.6-Sequenz wurde mit homologen Bereichen anderer Spezies (Bos taurus, Mus musculus und Danio rerio) verglichen. Die Positionen der Mutationen sind durch Pfeile markiert. Die eingerahmten Bereiche sind in allen vier Spezies konserviert. $*$ Mutationen beschrieben von Uhlenberg et al. (2004). ** Mutation beschrieben von Bugiani et al. (2006).

in der Plasmamembran der Wildtyp Oozyten bedingt sein. Eine deutliche, statistisch hochsignifikante Depolarisation zeigt die Mutante Thr398Ile. Ein großer Teil der Halbkanäle könnte bei dieser Mutante schon bei einem Ruhemembranpotential in geöffnetem Zustand vorliegen und somit eine starke Depolarisation der Oozyten zur Folge haben. Auffällig bei Thr398Ile ist auch ein großer Calcium-sensitiver-Transmembranstrom, der bei einer Klemmspannung von $-40 \mathrm{mV}$ größer ist als der Wildtyp-Transmembranstrom. Dieses Ergebnis führt zur Hypothese eines Regulationsdefekts für Cx46.6-Thr398Ile Halbkanäle.

Alle anderen Mutanten zeigen eine deutliche Verminderung des Connexon induzierten Stroms bei beiden Klemmspannungen. Eine zusätzliche Aktivierung des Calcium-sensitiven-Transmembranstroms erfolgte nur bei den mit Wildtyp-RNA injizierten Oozyten nach Depolarisation. In den Mutanten-Oozyten konnte dieser Effekt nicht beobachtet werden. Möglicherweise bilden diese Oozyten nicht funktionelle Halbkanäle aus. Es könnte aber auch daran liegen, dass die Cx46.6-mt-Proteine nicht exprimiert oder nicht in die Plasmamembran eingebaut werden. Die gemessenen schwachen Transmembranströme bei nicht exprimierten oder nicht an die Membran transportierten Mutanten könnten Ströme von Cx46.6-unspezifischen Kanälen (z.B. Chloridkanäle, Natriumkanäle) repräsentieren, die in diesen Oozyten größer wären, als in den zur Normalisierung verwendeten Kontroll-Oozyten (nur asCx38 injiziert).

Zum Nachweis der Expression und Membranlokalisation wurden immunzytochemische Untersuchungen an Gefrierschnitten von mit Cx46.6-WT-GFP-RNA injizierten Oozyten durchgeführt. Eine partielle Lokalisation der Connexine an der Oozyten Plasmamembran konnte nachgewiesen werden, aber der Großteil verblieb im Zytosol (Abbildung 4.5). Der Transport zur Membran und der Einbau der Connexone wird in der Oozyte scheinbar durch den GFP-Tag 
behindert. Untersuchungen an GFP-Connexin Mutanten wurden aufgrund dessen nicht weiter verfolgt. Ein Connexin spezifischer Antikörper stand zunächst nicht zur Verfügung, um Untersuchungen zur Lokalisation der Wildtyp und Mutanten Connexine ohne GFP-Tag in Oozyten durchführen zu können. Nachdem ein funktionelles Antiserum synthetisiert worden war, sollten Oozytenmembranextrakte im Western Blot analysiert werden. Eine spezifische Detektion von Cx46.6-Proteinen wurde mit diesem Cx46.6-Antiserum jedoch nicht erreicht.

Um eine generelle Aussage zur Expression der Wildtyp und Mutanten Connexine treffen zu können, wurde eine Western Blot-Analyse in HeLa Zellen durchgeführt. Mit Ausnahme des Cx46.6-Gly236Arg-Proteins wurden alle Cx46.6-Proteine in einer Western Blot-Analyse detektiert. Das Signal für das Cx46.6-Thr398Ile und Cx46.6-Gly149Ser war deutlich stärker als das Cx46.6-WT Signal (Abbildung 4.8). Diese unterschiedlichen Signalstärken könnten durch eine variable Transfektionseffizienz bedingt sein oder einen Effekt der Mutationen widerspiegeln.

Zur Untersuchung der subzellulären Lokalisation wurden transfizierte HeLa Zellen in der Immunfluoreszenz analysiert (Abbildung 4.9 und 4.10). Eine Lokalisation an der Plasmamembran wurde für das Cx46.6-WT-Protein, das Cx46.6-WT-2.ATG-Protein (mit dem zweiten alternativen Startcodon) und für das Cx46.6-Thr398Ile-Protein gezeigt. Das Cx46.6-Gly149SerProtein scheint nur partiell an die Plasmamembran transportiert zu werden. Ein großer Teil ist im ER lokalisiert. Eine vollständige ER-Kolokalisation konnte für die Cx46.6-Proteine Pro90Ser, Ala98Gly_Val99insThr und Thr265Ala gezeigt werden. Eine Expression von Cx46.6Gly236Arg-Proteinen konnte, wie erwartet, in den HeLa Zellen nicht detektiert werden.

\subsubsection{Charakterisierung des PMLD-Pathomechanismus}

Die im ER verbleibenden Mutanten Pro90Ser, Ala98Gly_Val99insThr und Thr265Ala, die signifikant reduzierte Halbkanal-Ströme aufwiesen, sind in den hoch konservierten Bereichen der zweiten und vierten Transmembrandomäne des Connexin 46.6 lokalisiert. Von OrthmannMurphy et al. (2007a) wurde ebenfalls für die Cx46.6-Mutante Pro90Ser und für zwei weitere Mutanten (Tyr272Asp und Met286Thr), die auch in den oder im Anschluss an die Transmembrandomänen lokalisiert sind, eine Ansammlung von mutierten Proteinen im ER gezeigt. Es scheint also ein Zusammenhang zwischen der Mutationslokalisation in den Transmembrandomänen des Cx46.6 und dem inhibierten Proteintransport zur Plasmamembran zu bestehen. In anderen Connexinen führen Mutationen in den Transmembrandomänen ebenfalls zu einem beeinträchtigten Transport der Connexine zur Membran. Beispielsweise wurde für die Transmembrandomänen drei und vier des Connexin 32 von Deschenes et al. (1997) eine entscheidende Rolle im Protein Trafficking beschrieben. 
Orthmann-Murphy et al. (2007a) zeigten weiterhin, dass von den Mutanten Pro90Ser, Tyr272Asp und Met286Thr keine funktionellen homotypischen Gap Junctions gebildet werden. Die Mutationen haben somit einen Funktionsverlust der Proteine (loss-of-function) zur Folge. Von Orthmann-Murphy et al. (2007b) wurde gezeigt, dass diese drei Mutationen auch zu einem Funktionsverlust der heterotypischen Cx46.6/Cx43 Gap Junctions, die die Oligodendrozyten und Astrozyten verbinden, führen. Da homotypische Gap Junction vermittelte Kommunikation in Oligodendrozyten scheinbar nicht stattfindet, wird angenommen, dass der Funktionsverlust der heterotypischen Cx46.6/Cx43 Gap Junctions krankheitsverursachend ist.

Die Mutationen Pro90Ser, Ala98Gly_Val99insThr und Thr265Ala, die im Rahmen der vorliegenden Arbeit untersucht wurden, führen ebenfalls zu einem Cx46.6-Funktionsverlust durch Abwesenheit von Halbkanälen an der Plasmamembran und somit auch zu einem Verlust der Kommunikation zwischen Oligodendrozyten und Astrozyten. Die im ER lokalisierten Cx46.6mt-Proteine, die nicht degradiert werden, könnten durch ihre Ansammlung im ER aber auch zur Apoptose oder abnormaler Differenzierung der Oligodendrozyten führen (Kim und Arvan, 1998) und somit eine Hypomyelinisierung bedingen. Es liegen derzeit jedoch keine experimentellen Untersuchungen vor, die diese Hypothese unterstützen könnten.

Die homozygote Mutation Gly236Arg, für die kein Proteinprodukt nachgewiesen werden konnte, betrifft die zweite hoch konservierte extrazelluläre Domäne, die durch drei Cysteinreste über Disulfidbrücken die Tertiärstruktur des Proteins stabilisiert. Den konservierten 6 Cysteinresten der beiden extrazellulären Schleifen wird eine essentielle Rolle für die Connexinstabilität, die Connexin-Anordnung und Connexon-Anlagerung zugeschrieben (Foote et al., 1998; Rahman und Evans, 1991). Durch die Punktmutation c.706G $>$ C wird das neutrale Glycin durch ein basisches Arginin ersetzt. Glycin ist die kleinste proteinogene $\alpha$-Aminosäure und Arginin die $\alpha$ Aminosäure mit dem höchsten Massenanteil an Stickstoff. Durch diesen Aminosäureaustausch kommt es zu einer Ladungsänderung und wahrscheinlich auch zu einer Konformationsänderung, wobei eventuell die konservierte Disulfidbrücke des nahegelegenen Cysteins 245 verändert wird. Möglicherweise wird das Cx46.6-Gly236Arg-Protein durch eine Konformationsänderung bedingt, direkt bei oder nach der Synthese degradiert. Die Degradation im ER führt zur Abwesenheit des Cx46.6-Proteins, so dass eine Kommunikation zwischen Oligodendrozyten und Astrozyten über Cx46.6/Cx43 heterotypische Gap Junctions nicht erfolgen kann. In anderen Connexinen führen Mutationen in der zweiten extrazellulären Schleife ebenfalls zum vollständigen Funktionsverlust der Proteine. Beispielsweise wird das Connexin 43 mit den Mutationen Phe199Leu, Arg202Glu und Glu205Arg nicht zur Plasmamembran transportiert, sondern verbleibt im Zytoplasma (Olbina und Eckhart, 2003).

Die Mutation Gly149Ser betrifft die variable nicht konservierte intrazelluläre Domäne des Cx46.6 und hat eine Beeinträchtigung des Proteintransports zur Plasmamembran zur Folge. 
In der Immunfluoreszenz zeigte sich eine ER-Kolokalisation, aber auch eine partielle Plasmamembran Lokalisation. Es stellt sich die Frage, ob die Mutante dort auch funktionelle Gap Junctions bildet. In der elektrophysiologischen Untersuchung der Halbkanalaktivität zeigten sich stark verminderte Transmembranströme. Der minimale gemessene Transmembranstrom könnte durch partiell gebildete, nicht funktionelle Halbkanäle in der Plasmamembran, durch die Ansammlung im ER und somit durch eine geringe Bildung von funktionellen Halbkanälen oder durch Connexin-unspezifische Ströme verursacht werden. Da selbst für die Mutante Gly236Arg, die kein Proteinprodukt aufweist, ein minimaler Transmembranstrom in den Oozyten gemessen wurde, ist anzunehmen, dass der minimale Stromfluss Connexin-unspezifische Ströme (wie z.B. Chloridkanäle, Natriumkanäle) repräsentiert und somit ein Proteinfunktionsverlust für die Mutante Gly149Ser sehr wahrscheinlich ist. Die PMLD wird durch diese Mutation scheinbar auch durch die Beeinträchtigung von Cx46.6/Cx43 vermittelter Kommunikation verursacht.

Die Mutation Thr398Ile befindet sich im nicht konservierten C-Terminus des Connexins. Von Omori et al. (1996) wurde in Betracht gezogen, dass der C-Terminus von Connexinen in die funktionelle Regulation von Gap Junctions involviert ist. Die häufigste posttranslationale Modifikation der Connexine ist die Phosphorylierung von Serin-, Tyrosin- und Threoninresten am zytoplasmatischen C-Terminus durch verschiedene Proteinkinasen. Man geht davon aus, dass die Phosphorylierungen zu einer Feinjustierung der Regulation von Gap Junction Kanälen beitragen, um damit eine Anpassung der Zelle an sich verändernde Bedingungen zu gewährleisten. Betroffen sind davon unter anderem auch das Öffnen und Schließen der Kanäle, sowie die Degradation von Connexin-Proteinen (Lampe und Lau, 2004). C-terminale Mutationen im Connexin 43, die zum Austausch verschiedener Serin- und Threoninreste führen, wurden von Britz-Cunningham et al. (1995) untersucht. Die Autoren zeigten für transfizierte Zellen mit mutierten Proteinen im Vergleich zu Cx43-Wildtyp transfizierten Zellen ein "normales" Niveau an Gap Junction vermittelter interzellulärer Kommunikation. Daher entstand die Hypothese einer beeinträchtigten Regulation der Kanalfunktion. Für Mutationen im C-Terminus des Connexin 32 (Cys217Stop, Arg220Stop, Arg265Stop und Ser281Stop) wurde eine reduzierte Fähigkeit von synthetisierten Halbkanälen zur Bildung funktioneller Gap Junctions festgestellt (Castro et al., 1999).

Die im Rahmen dieser Arbeit untersuchte Mutation Thr398Ile inhibiert ebenfalls nicht die Bildung von funktionellen Halbkanälen an der Plasmamembran. Es besteht kein signifikanter Unterschied des Transmembranstroms im Vergleich zur Messung der Cx46.6-WT-Halbkanäle bei einer Klemmspannung von $-40 \mathrm{mV}$. Da im Cx46.6-Thr398Ile-Protein auch ein Threonin im C-Terminus und somit eine mögliche Phosphorylierungsposition betroffen ist, scheint ein Regulationsdefekt der Kanalfunktion wahrscheinlich. Eine starke Depolarisation des Ruhemembranpotentials der Cx46.6-Thr398Ile injizierten Oozyten unterstützt diese Hypothese. Eine 
Mutanten Halbkanal-Öffnung scheint willkürlich aufzutreten und könnte die Oligodendrozyten schädigen. Eine Präsenz von offenen Halbkanälen kann ein möglicher Mechanismus der Zellbeschädigung und des Zellsterbens sein (Li et al., 1996) und konnte auch für andere Connexine gezeigt werden (Kondo et al., 2000; Liang et al., 2005).

Mutationen in Plasmamembran- oder sekretorischen Proteinen, die den Transport zur Zelloberfläche inhibieren, können generell durch zwei verschiedene Mechanismen Krankheiten hervorrufen (Aridor und Balch, 1999; Kim und Arvan, 1998). Nach der Definition von Aridor und Balch (1999) sind Mutationen der Klasse I Sequenzveränderungen, die den Transport von betroffenen Proteinen zur Plasmamembran verhindern, aber nicht die Degradation beeinträchtigen. Klasse I Mutationen führen also zur effizienten Proteasom assoziierten Degradation der mutierten Proteine. Die Krankheit resultiert aus der Abwesenheit des Wildtyp-Proteins und eventuell interagierender Proteine an der Zelloberfläche. Im Gegensatz dazu inhibieren Klasse II Mutationen den Protein-Umsatz (turnover) sowie den intrazellulären Transport von betroffenen Proteinen. Ansammlungen von nicht degradierten Proteinen können dann permanente ER Stress-Reaktionen (unfolded protein response: UPR) auslösen, die wiederum zu bedeutenden Veränderungen der Zellphysiologie, wie z.B. Apoptose, abnormale Differenzierung oder veränderte Proliferation, führen können. Ein Klasse II Mechanismus wurde für Mutationen im Proteolipid Protein (PLP1, Pelizaeus-Merzbacher Erkrankung) von Gow und Lazzarini (1996) diskutiert. Die Akkumulation von PLP1 im ER aktiviert die UPR und führt zur Apoptose der myelinisierenden Oligodendrozyten (McLaughlin et al., 2007; Southwood et al., 2002). Die toxische Akkumulation von Cx32 im ER wurde für einige Mutationen der Charcot-Marie-Tooth Erkrankung (CMTX) postuliert (Deschenes et al., 1997).

Die Pathogenese der PMLD scheint hauptsächlich durch den Funktionsverlust der Cx46.6Mutanten Pro90Ser, Gly149Ser, Ala98Gly_Val99insThr, Gly236Arg und Thr265Ala, also einen Klasse I Mechanismus, verursacht zu werden. Die Cx46.6/Cx43 Gap Junction vermittelte Kommunikation von Oligodendrozyten und Astrozyten wird dadurch beeinträchtigt. Die beschriebenen, nicht untersuchten Frameshift und Nonsense Mutationen, für die auch ein Proteinfunktionsverlust postuliert wird, unterstützen diese Aussage. Möglicherweise liegt auch ein Zusammenwirken dieses Klasse I Mechanismus mit dem Klasse II Mechanismus für Mutanten, die im ER lokalisiert sind, vor. Weiterhin könnten Connexine in Oligodendrozyten und Astrozyten eine Rolle neben der Gap Junction Bildung haben (Orthmann-Murphy et al., 2009).

Ein alternativer, neuer PMLD-Pathomechanismus wird durch einen Regulationsdefekt der Halbkanalfunktion verursacht. Die Mutante Thr398Ile, die in diesem Defekt resultiert, ist im zytoplasmatischen C-Terminus lokalisiert und betrifft ein phosphorylierbares Threonin. Weitere Analysen von Mutationen, die im C-Terminus identifiziert wurden, könnten einen Beitrag zum besseren Verständnis dieses Pathomechanismus der PMLD leisten. 


\subsection{Pathogenese der RNASET2 defizienten zystischen Leukoenzephalopathie}

Neben der GJA12-assoziierten PMLD wurde eine andere Form der Leukoenzephalopathie, die RNASET2 defiziente zystische Leukoenzephalopathie im Rahmen dieser Arbeit untersucht. Bei dieser Erkrankung treten bilaterale anteriore Temporalzysten sowie periventrikulär und unmittelbar an die Zysten angrenzende leukodystrophische Veränderungen auf. Die Patienten sind bei der Geburt asymptomatisch, fallen aber meist in den ersten 12 Lebensmonaten durch eine verzögerte psychomotorische Entwicklung und eine Bewegungsstörung auf. Ursache der Erkrankung sind Mutationen im RNASET2-Gen. 23 Patienten mit unklarer zystischer Leukoenzephalopathie wurden auf RNASET2-Mutationen untersucht. Bei sieben Patienten (30\%) wurden sechs verschiedene Mutationen identifiziert (Abbildung 5.2). Eine Deletionsmutation (c.87-1341_147+1181del2583), drei Punktmutationen (c.550T>C, c.262-2A>G, c.332+1delG) und zwei compound heterozygote Mutationen (c. [50_64del] $+[567 \mathrm{G}>\mathrm{A}])$.

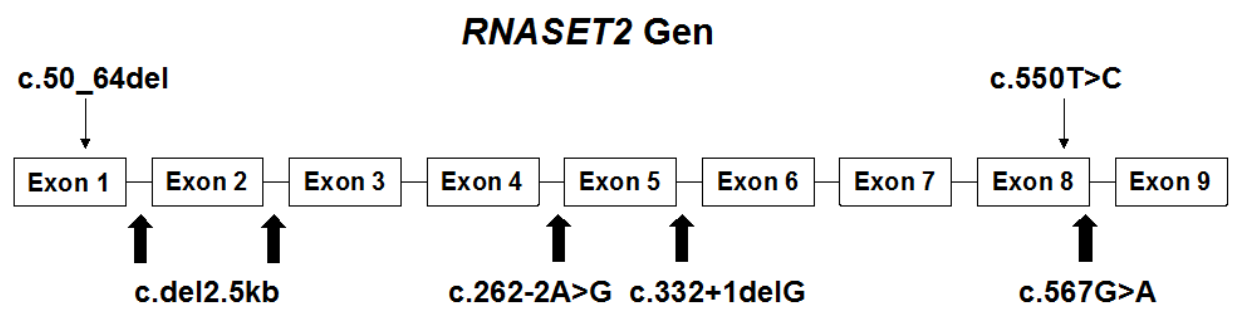

\section{RNASET2 Protein}

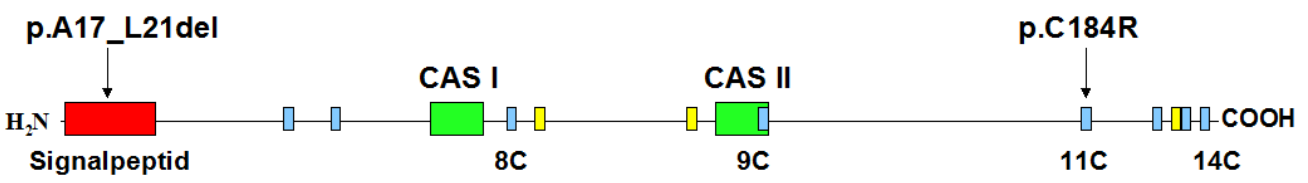

Abbildung 5.2.: Schematische Darstellung der RNASET2-Mutationen auf DNA-Ebene und funktionelle Bereiche und Modifikationen der RNASET2 auf Protein-Ebene. Mutationen, die den Spleißprozess beeinträchtigen (breiter gefüllter Pfeil) und eine Deletionsmutation und eine Punktmutation, die nicht den Spleißprozess beeinträchtigen (normaler Pfeil) sind auf DNA-Ebene dargestellt. Das Signalpeptid (rote Markierung), mögliche Glykosylierungspositionen (gelbe Markierung), hoch konservierte Cysteinreste (blaue Markierung) und die aktiven Zentren CAS I und CAS II (grüne Markierung) sind mit ihrer ungefähren Lage im Protein abgebildet.

Für das sekretorische Glykoprotein RNASET2 (Acquati et al., 2005) konnte eine Sekretion in Western Blot-Analysen von Zellkulturüberstand transient transfizierter HEK 293 Zellen und lymphoblastoider Kontroll-Zellen bestätigt werden (Abbildung 4.16 und 4.24). Jedes Protein, 
das ins ER gelangt und richtig gefaltet ist, wird unkontrolliert durch den Golgi-Apparat zur Zelloberfläche transportiert. Trägt das Protein jedoch bestimmte Signale wird es entweder in einem früheren Kompartiment auf der Strecke zurückgehalten oder über den Golgi-Apparat zu den Lysosomen oder sekretorischen Vesikeln umgeleitet. Für den Übertritt in das ER besitzen kernkodierte Proteine grundsätzlich ein N-terminales, hydrophobes Signalpeptid. ER-residente Proteine tragen hochspezifische C-terminale Tetrapeptide wie K/HDEL bzw. HDEF (Köck et al., 1995; Pelham, 1989). Zwei Lysine, die fünf Reste vom C-Terminus entfernt positioniert sind (KKXXX), können als ER-Retrieval Signal agieren, aber auch als ER-Retentions-Signal (Andersson et al., 1999; Jackson et al., 1990). Die RNASET2 ist ein sekretorisches Glykoprotein, das ein N-terminales Signalpeptid von 24 Aminosäuren enthält, welches bei der Prozessierung abgespalten wird.

Im ER findet eine zelluläre Qualitätskontrolle statt, die für einen effektiven Transport funktioneller Proteine und ein nachhaltiges Erkennen und Aussortieren fehlgefalteter Proteine unerlässlich ist. Sie wird von den molekularen Chaperonen (z.B. BiP oder Calnexin) gewährleistet. Proteine, die in das ER synthetisiert werden, erhalten dort oder im Golgi-Apparat ihre post-translationalen Modifikationen (z.B. Glykosylierung). Eine dreifache Glykosylierung der intrazellulären Proteine konnte für die RNASET2 nachgewiesen werden (Abbildung 4.17 und $4.23)$.

\subsubsection{Charakterisierung der RNASET2-Mutationen}

Die sechs identifizierten Mutationen der RNASET2 wurden in weiteren Untersuchungen näher charakterisiert. Die Deletions-Mutation (c.87-1341_147+1181del2583) der Geschwister 28 und 37, bei der der Spleiß-Akzeptor von Intron 1 sowie der Spleiß-Donor von Intron 2 deletiert sind, eine Punktmutation (c.262-2A >G) von Individuum 4483, bei der der Spleißakzeptor von Intron 4 direkt betroffen ist, und eine den Spleißdonor von Intron 5 verändernde Punktmutation (c.332+1delG, Individuum 4853) wurden mittels TA-Klonierung analysiert (4.2.3.1). Bei den Geschwistern 28 und 37 wurde ein Verteilungsmuster der verschiedenen Spleißprodukte in einem Verhältnis von 1:1:4:9 beobachtet, in Individuum 4483 betrug das Verhältnis 3:3:4 und die beiden Spleißprodukte von Individuum 4853 wurden in einem Verhältnis von 5:2 nachgewiesen. Dieses Ergebnis ist rein zufällig und spiegelt nicht den wirklichen Ist-Zustand der mRNA-Spleißprodukte der Patienten wieder, da nur eine kleine Stichprobe analysiert wurde. Möglicherweise führt der Spleißdefekt zu weiteren in dieser Spleiß-Variantenanalyse nicht erfassten Spleißprodukten. Ein zellspezifischer Spleißvorgang kann ebenfalls nicht ausgeschlossen werden, da zur Analyse lediglich mRNA aus lymphoblastoiden Zellen der Patienten verwendet wurde. In anderen Geweben könnten durch zellspezifische Faktoren weitere Spleißprodukte entstehen. Ein auffälliger Aspekt dieser Spleißmutanten ist, dass der Spleißdefekt nicht nur auf 
das unmittelbar benachbarte Exon beschränkt ist, sondern auch weitere Exons mit deletiert werden. Weiterhin auffällig bei der Spleißvariantenanalyse ist, dass die drei unterschiedlichen Spleißmutationen alle eine Deletion von Exon 2-5 zur Folge haben, obwohl sie an unterschiedlichen Positionen im RNASET2-Gen lokalisiert sind. Da auch Kontroll-cDNA untersucht wurde, die nur ein spezifisches RNASET2-Produkt generierte, kann ausgeschlossen werden, dass es sich um eine alternative gewebespezifische Spleißvariante der Wildtyp-RNASET2 handelt.

Eine Western Blot-Analyse der Proteinprodukte von lymphoblastoiden Patienten-Zellen zeigte bei Individuum 37 ein Signal bei einer Größe von ca. 32 kDa (Abbildung 4.22). Diese Proteinbande entspricht in etwa der erwarteten Größe für das Produkt der Spleißvariante, die zur Deletion von Exon zwei und drei führt (r.86_203del; p.Asp30_Trp68del). Eine zweite ca. 2 kDa kleinere Bande repräsentiert eine weniger stark glykosylierte Form des verkürzten Proteins. Die anderen nachgewiesenen Spleißvarianten scheinen kein Protein zu exprimieren. Eine Sekretion des Proteins wurde nicht nachgewiesen. In den lymphoblastoiden Patienten-Zellen wurde das Protein in Immunfluoreszenzuntersuchungen im ER, im Golgi-Apparat und im Zytosol lokalisiert (Abbildung 4.26). Dem entstehenden RNASET2-Protein p.Asp30_Trp68del fehlt durch die Deletion eine der beiden hoch konservierten Peptidsequenzen, die CAS I-Domäne, in denen katalytisch wichtige Aminosäuren enthalten sind (Irie, 1997). Durch die Deletion kommt es sehr wahrscheinlich zur Konformationsänderung des Proteins und somit zu einer Fehlfaltung. Ein Teil der fehlgefalteten Proteine könnte aus dem ER ins Zytosol transportiert und dort vom Proteasom degradiert werden. Ein anderer Teil scheint zum Golgi-Apparat zu gelangen, wird von dort jedoch nicht sekretiert. Möglicherweise gelangen die Proteine vom Golgi nach erfolgter Prozessierung der N-Glykane wieder zurück ins ER.

Im Lymphozytenproteinextrakt von Patient 4483 (c.262-2A>G) konnte im Western Blot kein Protein nachgewiesen werden. Auch in der Immunfluoreszenz wurde durch das RNASET2Antiserum kein Signal in den lymphoblastoiden Zellen detektiert (Abbildung 4.26). Ob die verschiedenen Spleißprodukte nicht translatiert werden oder die entstehenden Proteine direkt degradiert werden, ist unklar. Die Spleißvariantenanalyse der homozygoten Mutation c.332+1delG (Individuum 4853) ergab zwei verschiedene Spleißprodukte, deren eventuelle Protein-Expression nicht untersucht werden konnte, da kein weiteres Patientenmaterial zur Verfügung stand.

Der Transport der RNASET2 an die Zelloberfläche, also die Sekretion, wird für die beschriebene Deletionsmutante der Patienten 28 und 37 inhibiert, aber die Degradation ist nicht beeinträchtigt. Die Krankheit resultiert in diesem Fall, wie auch bei Patient 4483, aus der Abwesenheit des Wildtyp-Proteins und eventuell interagierender Proteine im Extrazellularraum. Zusätzlich kommt es bei den Patienten 28 und 37 zu Ansammlungen des mutierten Proteins im ER und im Golgi (Abbildung 4.26 B.1 und B.2). Die ER Stress-Reaktionen (UPR) könnten Veränderungen 
der Zellphysiologie, wie z.B. Apoptose, abnormale Differenzierung oder veränderte Proliferation, bedingen. Bei diesen Patienten könnte durch ein Zusammenwirken beider Mechanismen, die fehlende Sekretion und die Ansammlung der Proteine im ER, die RNASET2 defiziente zystische Leukoenzephalopathie verursacht werden.

Untersuchungen zur Expression und Lokalisation der RNASET2 von Patient 4853 und Patient 3306 konnten nicht durchgeführt werden, da kein Patientenmaterial zur Verfügung stand. Das Proteinprodukt Asp30_Trp111del von Patient 4853 wird sehr wahrscheinlich nicht gebildet. Für Patient 4483 wurde auf mRNA-Ebene dieselbe Spleißvariante nachgewiesen, im Western Blot konnte aber kein Protein detektiert werden. Bei der zweiten Proteinvariante von Individuum 4853 Pro69_Trp111 sind eine mögliche Glykosylierungsposition und zwei hoch konservierte Aminosäuren des katalytischen Zentrums CAS II deletiert. Eine Konformationsänderung und somit eine Fehlfaltung, die den Transport zum Extrazellularraum inhibiert, wäre denkbar. Die zwei heterozygoten Mutationen von Patient 3306 bedingen zum einen die Deletion der Aminosäuren 17 bis 21 des Signalpeptids (AS 1-25) und zum anderen einen Spleißdefekt. Der Spleißdefekt wurde mittels Minigenkonstrukt charakterisiert (4.2.3.2) und führt zur Deletion von Exon 8 (p.Val165_Gln189del). Durch diese Deletion ist, wie auch bei Patient 327 und 330, das 11C der hoch konservierten Disulfidbrücke 11C-14C (Abbildung 5.3) betroffen. Eine Destabilisierung des Proteins ist die Folge. Einerseits wird möglicherweise der korrekte Transport zum Bestimmungsort der RNASET2 durch die Deletion im Signalpeptid inhibiert. Andererseits könnte die Destabilisierung des RNASET2-Proteins durch den Verlust der Disulfidbrücke dazu führen, dass das Protein nicht sezerniert wird und im ER verbleibt.

$\begin{array}{lll}\text { GVIPKIQCLPPSQDEEVQTIGQ } & 198 & \text { Homo sapiens } \\ \text { GVVPKIQCLMPEQGESVQTVGQ } & 202 & \text { Mus musculus } \\ \text { KVVPKVQCFLLEKGQEVQLLGQ } & 345 & \text { Bos taurus } \\ \text { GVIPKIQCLPPQQGEEVTIGQ } & 156 & \text { Canis lupus } \\ \text { GITPKIQCLPPEEGEEAQTLGQ } & 201 & \text { Gallus gallus } \\ \text { GVLPKIQCLPPHQGETAQTLGQ } & 192 & \text { Xenopus laevis } \\ \text { GVKPKIQCVHPGQGGQVQILGQ } & 187 & \text { Danio rerio } \\ \text { GKNPSIHCLYDGKHG-ISYLSE } & 249 & \text { Drosophila melanogaster } \\ \text { GKTFQFHCLRD-KKTKQFLLGD } & 196 & \text { Caenorhabditis elegans } \\ \text { GFTPWVECNRDGSGN--SQLYQ } & 198 \text { Arabidopsis thaliana }\end{array}$

Abbildung 5.3.: Alignment des RNASET2-Proteinbereichs, in dem die Missense Mutation Cys184Arg lokalisiert ist. Die humane RNASET2-Proteinsequenz wurde mit homologen Bereichen anderer Spezies verglichen. Die Position der Mutation Cys184Arg ist rot markiert.

Die Mutation (c.550C>T), die zum Basenaustausch von Cystein 184 gegen Arginin führt, wurde in zwei Geschwistern (327 und 330) konsanguiner Eltern türkischer Abstammung nachgewiesen. Diese Substitution betrifft das hoch konservierte Cystein 184 (Abbildung 5.3), welches eine Disulfidbrücke mit dem ebenfalls konservierten Cystein 241 bildet. Die beiden Cysteine werden in der Abfolge aller Cysteine vom N- zum C-Terminus als 11C und 14C bezeichnet. 
Diese konservierte Disulfidbrücke (11C-14C) ist zusammen mit einer weiteren (8C-9C) in allen RNasen der T2-Familie von grundlegender Bedeutung für den Erhalt der aktiven Konformation (Irie, 1999). Durch die Mutation kommt es zu einem Sekretionsdefekt, wie im Western Blot mit Zellkulturüberständen von transfizierten HEK 293 Zellen und von Patientenlymphozyten gezeigt werden konnte (Abbildung $4.16 \mathrm{~b}$ und 4.24). In lymphoblastoiden Patienten-Zellen und stabil transfizierten HEK 293 Zellen ist die mutierte RNASET2 im ER lokalisiert (Abbildungen 4.21 B und 4.26 A). Die Destabilisierung des RNASET2-Proteins durch den Verlust der Disulfidbrücke führt dazu, dass das Protein nicht sezerniert wird und im ER verbleibt. Zum einen gelangt das Protein also nicht an seinen eventuellen Wirkungsort im Extrazellularraum, zum anderen kann es durch den Verbleib im ER eine UPR auslösen, die zu Veränderungen der Zellphysiologie führen kann. Ein Zusammenwirken beider Mechanismen könnte, wie in den Patienten 28 und 37, die RNASET2 defiziente zystische Leukoenzephalopathie verursachen.

Es ist anzunehmen, dass die Sequenzveränderungen im RNASET2-Gen im Allgemeinen zu einem Funktionsverlust (loss-of-function) des Proteins führen. Allerdings ist nicht klar, welche Auswirkungen dieser Funktionsverlust der sekretierten RNASET2 hat. Der Pathomechanismus der RNASET2 defizienten zystischen Leukoenzephalopathie könnte auch durch ein Zusammenwirken von fehlender Sekretion und Ansammlung der mutierten Proteine im ER, verursacht werden.

\subsubsection{Charakterisierung der RNASET2}

Die meisten RNasen der T2-Familie sind sekretorische Proteine, die entweder extrazellulär oder in Kompartimenten des Endomembransystems lokalisiert sind. Der Kontakt zu zellulärer RNA wird dadurch minimiert. Die generelle zelluläre Funktion dieser RNasen ist bisher unbekannt. Für die RNY1, die einzige T2-Typ RNase von Saccharomyces cerevisiae, wird eine Beteiligung an der Regulation der Membranpermeabilität oder -stabilität vermutet. Die Genexpression wird durch Hitzeschock und Osmotischen Stress kontrolliert (MacIntosh et al., 2001).

Das sekretorische Endomembransystem bildet die Grundlage der Kompartimentierung der meisten Komponenten eukaryontischer Zellen und ist Teil wichtiger biosynthetischer Wege für Proteine, Lipide und Kohlenhydrate. Strukturell umfasst der sekretorische Weg neben der Kernhüllmembran das ER, den Golgi-Apparat, die Plasmamembran und eine große Zahl von Transportvesikeln (Pimpl und Denecke, 2002). Der vesikuläre Transport führt zu einer hohen Dynamik im sekretorischen System und ist durch Abschnürung bzw. Verschmelzung verschiedener Membrankomponenten gekennzeichnet. Auf dem biosynthetisch-sekretorischen Weg werden Proteinmoleküle vom ER zur Plasmamembran oder (über späte Endosomen) zu den Lysosomen transportiert (Abbildung 5.4). Proteine die zur Sekretion bestimmt sind, ge- 
langen über cotranslationale Translokation ins ER. Diese Proteine werden dann in COP-II Vesikeln zum Golgi-Apparat transportiert. Über COP-I Vesikel können die Proteine wieder zum ER zurückgelangen. Vom trans-Golgi Netzwerk werden die Proteine zur Plasmamembran transportiert (Miller und Krijnse-Locker, 2008). Beim Endozytose-Weg werden Proteine von Clathrin-umhüllten Vesikeln aufgenommen, die von der Plasmamembran stammen, und von den frühen Endosomen über späte Endosomen zu den Lysosomen befördert.

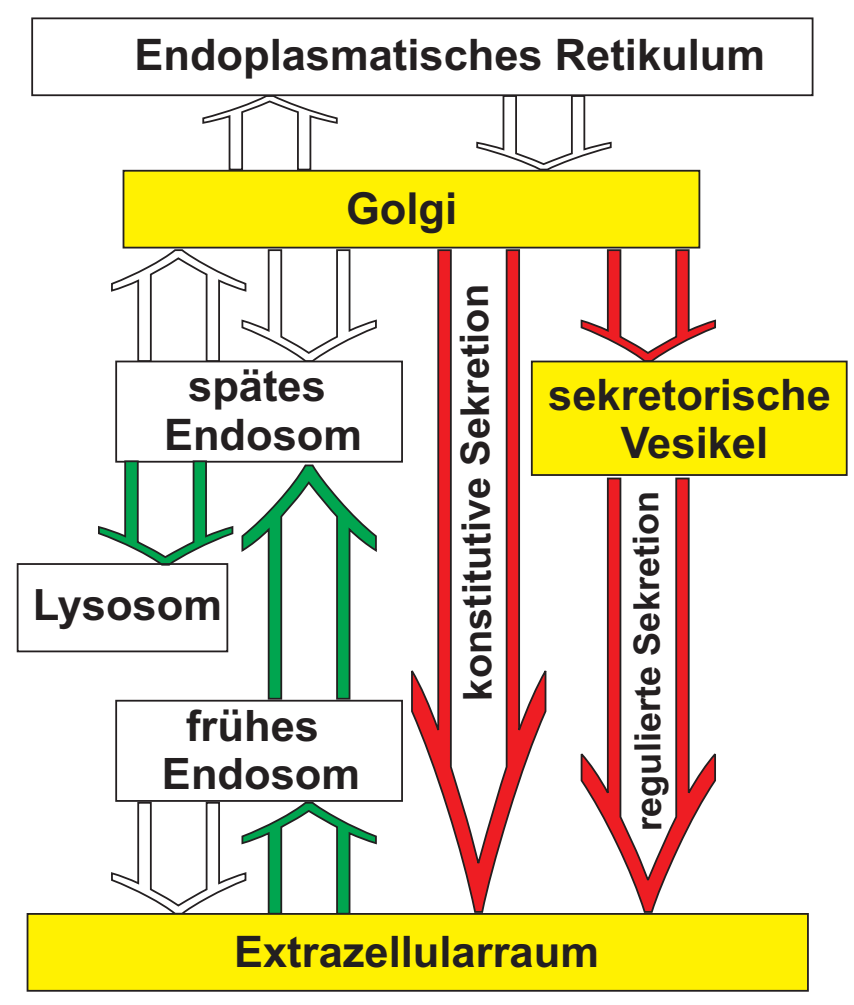

Abbildung 5.4.: Schematische Darstellung des sekretorischen Wegs. Der regulierte und der konstitutive sekretorische Weg sind rot markiert. Über den Endozytose-Weg (grüne Pfeile) gelangen externe Proteine, in Vesikeln verpackt, über das frühe und späte Endosom zum Lysosom. (Abbildung modifiziert nach Alberts et al., 1995)

Untersuchungen zur subzellulären Lokalisation der Wildtyp-RNASET2 wurden in stabil transfizierten HEK 293 Zellen und in lymphoblastoiden Kontroll-Zellen durchgeführt (Abbildung 4.21 und 4.25). Die RNASET2 wurde im ER, im Golgi und teilweise auch in Lysosomen detektiert. Punktförmige Färbungen der RNASET2, die nicht mit dem lysosomalen Marker kolokalisieren, könnten sekretorische Vesikel der regulierten Sekretion auf dem Weg zur Plasmamembran repräsentieren (Abbildung 5.4). Es könnte sich auch um Endosomen handeln, die über Endozytose die RNASET2 aus dem Extrazellularraum in die Lysosomen transportieren. Ein direkter Weg der RNASET2 vom Golgi-Apparat in die Lysosomen wäre auch denkbar.

Von Campomenosi et al. (2006) wurde in einer Ovarkarzinom-Zelllinie (Hey4) eine Lokalisation des RNASET2-Proteins in Lysosomen durch subzelluläre Fraktionierung und Markeren- 
zymuntersuchungen gezeigt. Das Protein wird in das ER synthetisiert und erhält dort oder im Golgi-Apparat initiale posttranslationale Modifikationen (z.B. Abspaltung des Signalpeptids, Glykosylierung). Anschließend folgt das Protein entweder dem sekretorischen Weg oder einer proteolytischen Reifung entlang des endozytotischen Wegs. Die sekretierten Proteine könnten durch Endozytose aufgenommen werden und erreichen so das Lysosom oder sie erfüllen im Extrazellularraum ihre physiologische oder pathophysiologische Funktion. Die Annahme von Campomenosi et al. (2006) der Beteiligung der RNASET2 im sekretorischen Weg scheint mit den Ergebnissen dieser Arbeit zur subzellulären Lokalisation in HEK 293 und lymphoblastoiden Kontroll-Zellen übereinzustimmen.

Die RNASET2 wird während des Transports zum Lysosom oder nach dem Transport ins Lysosom am C-Terminus proteolytisch prozessiert (Campomenosi et al., 2006). Zur Untersuchung der Prozessierung in HEK 293 Zellen wurden Proteinextrakte von RNASET2-Myc-Tag transfizierten HEK 293 Zellen im Western Blot mit Hilfe des RNASET2-Antiserums oder eines Myc-Antikörpers analysiert (Abbildung 4.27). Die N-terminal prozessierte Form der RNASET2 scheint durch eine Bande in Höhe von etwa $25 \mathrm{kDa}$ repräsentiert zu werden. Die berechnete Größe des Proteins ohne das Signalpeptid von 24 Aminosäuren am N-Terminus und ohne weitere Modifikationen entspricht in etwa dem Molekulargewicht des Signals im Western Blot. Aufgrund der Tatsache, dass der Myc-Tag am C-Terminus lokalisiert ist und das RNASET2Antiserum drei Banden detektiert, die der Myc-Antikörper nicht erkennt, kann davon ausgegangen werden, dass es bei der RNASET2 in HEK 293 Zellen zur proteolytischen Prozessierung am C-Terminus kommt. Da in den lymphoblastoiden Kontroll-Zellen Banden in gleicher Höhe detektiert wurden, kann postuliert werden, dass auch diese Proteine proteolytisch prozessiert werden.

\subsubsection{Pathomechanismus der RNASET2 defizienten zystischen Leukoenzephalopathie}

In diversen humanen Geweben und auch im Gehirn wird die RNASET2 ubiquitär exprimiert (Acquati et al., 2001; Liu et al., 2002). Untersuchungen im Rahmen dieser Arbeit zur RNASET2-Expression in verschiedenen Hirnregionen und Geweben zeigten eine hohe relative RNASET2-Expression im Temporallappen (250\% im Vergleich zur Capsula interna) und im fetalen Gehirn (180\% im Vergleich zur Capsula interna, Abbildung 4.15). Dies könnte die zystischen und leukodystrophen Veränderungen im Bereich des Temporallappens, die bei RNASET2-defizienten Individuen wahrscheinlich bereits bei der Geburt vorliegen, begründen (Henneke et al., 2005). Eine auffällig niedrige relative RNASET2-Expression wurde in der Amygdala nachgewiesen. Dies könnte erklären, dass die zum großen Teil aus grauer Substanz 
bestehende Amygdala, als Kerngebiet des Gehirns im medialen Teil des Temporallappens, bei der Erkrankung scheinbar nicht betroffen ist.

Eine Differenzierung des Phänotyps der RNASET2 defizienten zystischen Leukoenzephalopathie von der konnatalen Infektion durch das humane Cyto-Megalie-Virus (CMV) gestaltet sich als sehr schwierig. Die meisten Patienten mit intrauteriner CMV-Infektion sind asymptomatisch bei der Geburt (Istas et al., 1995). Der Verlauf der Erkrankung ist, wie auch bei der RNASET2 defizienten zystischen Leukoenzephalopathie, nicht progredient. 25\% der CMV infizierten Neugeborenen entwickeln in den ersten Lebensmonaten einen Mikrozephalus und neurologische Symptome wie psychomotorische Retardierung, Epilepsie und sensorineurale Hörstörungen (Barkovich und Lindan, 1994; Henneke et al., 2005; Steinlin et al., 1996). Infizierte immunkompetente Erwachsene bleiben in der Regel asymptomatisch, wohingegen eine Infektion ungeborener Kinder schwere Folgen haben kann (Griffiths, 2002). Cytomegalie ist die häufigste Infektion, die während der Schwangerschaft von der Mutter auf den Fötus übertragen wird (intrauterin). Die Inzidenz beträgt weltweit 0,5-3\% der Lebendgeburten (Hassan und Connell, 2007). Zur Abgrenzung der RNASET2 defizienten zystischen Leukoenzephalopathie von der congenitalen CMV Infektion ist eine CMV-DNA-Analyse aus Blut einer Guthriekarte aus dem Neugeborenen-Screening mittels PCR (van der Knaap et al., 2004) bzw. der Ausschluss einer RNASET2-Mutation notwendig.

Gemeinsamkeiten im Pathomechanismus der beiden Erkrankungen wären daher vorstellbar. Der Pathomechanismus für die CMV-Infektion ist bisher nicht geklärt. Neben mononukleären Leukozyten wurden vaskuläre Endothelzellen als Zielzellen des Virus in vivo identifiziert, die an der Ausbreitung des Cytomegalievirus über den Blutkreislauf beteiligt sein könnten (Sinzger et al., 1995). Im Verlauf einer akuten CMV-Infektion kann sich das Virus im gesamten Organismus verbreiten und anschließend praktisch jedes Organ infizieren (Bissinger et al., 2002). Durch eine virale Angiitis (Entzündung von Blut- oder Lymphgefäßen) wird auch die Durchblutung des sich entwickelnden Gehirns beeinträchtigt (van der Knaap und Valk, 2005). Für die RNASET2 wurde ebenfalls eine Beteiligung in der Angiogenese beschrieben. Sie zeigte einen konzentrationsabhängigen Antiangiogenese-Effekt durch eine Inhibierung von Angiogenin-, $B a-$ sic fibroblast growth factor (bFGF)- und Vascular Endothelial Growth Factor (VEGF)- induzierter Gefäßneubildung (Smirnoff et al., 2006). Die RNASET2-Funktionsstörung könnte das anfällige Gleichgewicht der pro- und antiangiogenen Faktoren während der Entwicklung des ZNS modifizieren und eine irreguläre Angiogenese mit beeinträchtigter Gefäßversorgung für bestimmte Hirnregionen, ähnlich wie durch eine Angiitis nach einer fetalen CMV Infektion, zur Folge haben.

Alternativ könnte der primäre Pathomechanismus mit der Hydrolyse von Einzelstrang-RNA Metaboliten durch RNASET2 bzw. RNaseL verknüpft sein (Deshpande und Shankar, 2002; 
Irie, 1999). Nach einer CMV Infektion ist eine Aktivierung der humanen RNaseL durch Oligoadenylat-Synthetasen ein bekannter antiviraler Mechanismus zur Degradation von viraler und zellulärer Einzelstrang-RNA, der jedoch durch den Virus blockiert werden kann (Knipe et al., 2007). Während der Gehirn-Entwicklung würde sowohl ein angeborener Verlust der RNASET2Aktivität als auch eine RNaseL-Inaktivierung durch eine CMV-Infektion, eine reduzierte Hydrolyse von Einzelstrang-RNA und somit ein erhöhtes Einzelstrang-RNA-Niveau zur Folge haben. Ansammlungen von Einzelstrang-RNA können eine vergleichbare Immunantwort mit ähnlichen neuropathologischen Konsequenzen auslösen (Ishii und Akira, 2005). Die entscheidende Rolle des RNA Metabolismus in der Gehirnentwicklung wird durch eine andere angeborene Leukoenzephalopathie, das Aicardi-Goutières Syndrom, bestätigt. Diese Erkrankung imitiert phänotypisch auch eine congenitale virale Gehirninfektion und ist mit einem RNAProzessierungsdefekt assoziiert (Crow et al., 2006).

\subsubsection{RNASET2-Interaktionsstudien}

Erste Untersuchungen zu möglichen Bindungspartnern der RNASET2 wurden mittels GSTpulldown durchgeführt. Es wurden unter anderem die Dihydropyrimidinase DPYSL2, das Tubulin 5-beta Protein und zwei Chaperone (TCP1, HSP90), die eine Rolle in der Proteinfaltung im ER übernehmen, als putative Bindungspartner der RNASET2 identifiziert (Tabelle 4.3). Des Weiteren wurden vier Mitglieder der Ras-Superfamilie, die Funktionen im sekretorischen Vesikeltransport haben, nachgewiesen. Ausserdem wurden noch das PLP1 und eine Glutathionperoxidase identifiziert. Es soll an dieser Stelle kurz erläutert werden, welche Funktionen diese putativen Bindungspartner der RNASET2 haben.

Eine Interaktion der Dihydropyrimidinase-like 2 (DPYSL2) mit Tubulin-Dimeren wurde in verschiedenen Zelllinien und Expressionskonstrukten von Fukata et al. (2002) gezeigt. Eine Überexpression von DPYSL2 in Neuronen fördert das axonale Wachstum und die Verzweigung. Von Fukata et al. (2002) wird vermutet, dass DPYSL2 die Axon-Entwicklung und -Verzweigung als Interaktionspartner von Tubulin-Heterodimeren reguliert. Das Tubulin 5-beta wird in fetalem Gehirn exprimiert, in anderen Zelllinien vieler anderer Gewebe wurde keine Expression nachgewiesen (Lee et al., 1983). Das homologe Mausprotein, M-beta-4, wird spezifisch im Gehirn exprimiert (Lewis und Cowan, 1990). Die Zusammenlagerung von Tubulin, einem bedeutenden zytosolischen Protein, zu Mikrotubuli ist entscheidend für viele zelluläre Prozesse.

Chaperonin containing T-Complex Polypeptide 1 (TCP1) ist ein zytosolisches Chaperon, das eine Rolle in der Tubulin-Biosynthese einnimmt (Yaffe et al., 1992). Als ein weiteres Chaperon wurde das Heat-shock 90kDa Protein 1 (HSP90) im GST-pulldown identifiziert. Chaperone sind hoch konservierte Proteine mit Schlüsselfunktionen in Signaltransduktion, Proteinfaltung, 
Proteindegradation und morphologischer Evolution. HSP90 Proteine assoziieren normalerweise mit anderen Cochaperonen und spielen eine große Rolle in der Faltung neusynthetisierter Proteine oder bei der Stabilisierung rückgefalteter denaturierter Proteine nach Stress. HSP90B1 ist ein endoplasmatisches HSP90 Protein (Chen et al., 2005) und könnte zur Faltung der in das ER synthetisierten RNASET2 einen Beitrag leisten. Durch eine Mutation der RNASET2 könnte diese Interaktion verhindert werden und somit zur Fehlfaltung der RNASET2 führen. Diese missgefalteten Proteine könnten im ER akkumulieren und eine ER-Stress-Antwort (UPR) auslösen (Kohno et al., 1993; Kozutsumi et al., 1988).

Vier Mitglieder der Ras-Superfamilie wurden im GST-pulldown in HeLa-Zelllysat und in GehirnLysat identifiziert: der ADP-Ribosylierungsfaktor 5 (ARF5), die GTPase RAB1, das Rasrelated nuclear protein (RAN) und RAB33B. Die Ras-Superfamilie kleiner GTP-bindender Proteine ist gekennzeichnet durch eine inaktive GDP-gebundene und eine aktive GTP-gebundene Form (Allan et al., 2000). Die kleinen GTP-bindenden Proteine haben intrinsische GTP-hydrolysierende Aktivität, die GTP in GDP und Phosphat umsetzt. Sie werden deshalb als GTPasen (Guanosintriphosphatasen) bezeichnet. Es handelt sich um monomere Proteine mit Molekularmassen zwischen 20 und $40 \mathrm{kDa}$ (Bourne et al., 1991). Die für die Ras-Proteine (von rat sarcoma) kodierenden Gene wurden erstmals von Shih et al. (1978) als Onkogene in Harvey- und Kirsten-Sarkom-Viren beschrieben, die bei ihrem Wirt, der Ratte, Sarkome induzieren. Ras-Proteine sind für die Zellteilung, Proliferation und Differenzierung bedeutsam (Spaargaren et al., 1995).

Der ADP-Ribosylierungsfaktor 5 (ARF5) ist Mitglied der ARF-Familie der GTP-bindenden Proteine der Ras-Superfamilie. Die ARF-Proteine haben eine Funktion beim Vesikeltransport (COP-umhüllte Vesikel). Die GTPase RAB1 kontrolliert den Vesikeltransport vom ER zum Golgi Apparat. RAB1 rekrutiert p115 (Vesikeldocking Protein), um als Protein-Komplex COP II-Vesikel während der Knospung vom ER zu ummanteln. Dabei bildet RAB1 zusammen mit COP II-Vesikel assoziierten SNARE-Proteinen einen Cis-SNARE Komplex, der den Transport zum Golgi-Apparat steuert (Allan et al., 2000). RAN (Ras-related nuclear protein) ist essentiell für die Translokation von RNA und Proteinen durch den nukleären Porenkomplex (Ren et al., 1993). RAN ist außerdem in die Kontrolle der DNA-Synthese und der Zellzyklusprogression involviert. Da RAB33B in der medialen Golgi Zisterne lokalisiert ist, wird von Zheng et al. (1998) angenommen, dass RAB33B eine Rolle im intra-Golgi-Transport einnimmt. Eine Interaktion mit diesen am Vesikeltransport beteiligten Proteinen könnte durch Mutationen der RNASET2 inhibiert werden und durch den resultierenden Sekretionsdefekt am Pathomechanismus der Erkrankung beteiligt sein.

Das Proteolipidprotein (PLP1) ist das Hauptstrukturprotein des Myelins im zentralen Nervensystem. Es spielt sowohl eine Rolle in der Verdichtung, Stabilisierung und Aufrechterhaltung 
des Myelins als auch in der Oligodendrozyten-Entwicklung und Axon-Erhaltung (Gow und Lazzarini, 1996; Gudz et al., 2002; Mar und Noetzel, 2008). Da dieses Protein als Hauptstrukturprotein des Myelins im Hirnlysat in großer Menge vorhanden ist, kann eine unspezifische RNASET2-Interaktion nicht ausgeschlossen werden.

Glutathionperoxidasen katalysieren die Glutathion-abhängige Reduktion von organischen Peroxiden und Wasserstoffperoxid. Besondere Bedeutung erlangen Glutathion-Peroxidasen als Bestandteil der zellulären Abwehr gegen die Folgen von oxidativem Stress. Störungen in der Funktion solcher Selenoproteine gehen mit Mangelsyndromen wie der Keshan- und Kashin-BeckKrankheit einher und spielen eine Rolle bei der Tumorentstehung, bei der Atheriosklerose und in Konjugation mit 4-Hydroxynonenal - bei neurodegenerativen Erkrankungen (Aoyama et al., 2006). Ein Zusammenhang dieser RNASET2-Interaktion mit ihrer von Acquati et al. (2005) und Smirnoff et al. (2006) beschriebenen Tumor- und Metastasen-suppremierenden Wirkung und einem Antiangiogenese-Effekt könnte bestehen.

Die im GST-pulldown bislang identifizierten putativen Interaktionspartner der RNASET2 müssen nun in weiteren Experimenten untersucht und verifiziert werden.

\subsection{Fazit}

Die Myelinisierung ist ein komplexer Prozess, an dem verschiedenste Proteine beteiligt sind. Kommt es zu Veränderungen dieser Proteine durch z.B. Gen-Mutationen findet keine regelrechte Myelinisierung statt. Die GJA12-assoziierte PMLD und die RNASET2 defiziente zystische Leukoenzephalopathie repräsentieren nur zwei der bekannten, humanen Leukoenzephalopathien. Sie sind charakterisiert durch sehr unterschiedliche molekulare Defekte mit entsprechend unterschiedlichen Auswirkungen wie Hypomyelinisierung und Dysmyelinisierung. Obwohl inzwischen eine Vielzahl von Krankheitsgenen für Leukoenzephalopathien bekannt ist, sind die für zukünftige Therapiestrategien wichtigen Zusammenhänge zwischen Gendefekt und resultierender Funktionsstörung des Myelins noch weitestgehend unbekannt. Die funktionellen Konsequenzen der Mutationen der GJA12-assoziierten PMLD und der RNASET2 defizienten zystischen Leukoenzephalopathie müssen zukünftig in geeigneten Zell- und Tiermodellen näher untersucht werden, um pathophysiologische Mechanismen zu identifizieren oder zu bestätigen. Dies ist die Voraussetzung, um später therapeutische Strategien für Leukoenzephalopathien im Allgemeinen ableiten zu können. 


\section{Zusammenfassung}

Leukoenzephalopathien bilden eine Gruppe von angeborenen, meist neurodegenerativen Erkrankungen. Eine Leukoenzephalopathie mit primärer Hypomyelinisierung ist die GJA12assoziierte Pelizaeus-Merzbacher ähnliche Erkrankung (PMLD). Die Pathogenese dieser und der RNASET2 defizienten zystischen Leukoenzephalopathie, die bisher auch als zystische Leukoenzephalopathie ohne Megalenzephalie (CLminusM) bezeichnet wurde, waren Gegenstand der vorliegenden Arbeit.

Von Uhlenberg et al. wurde 2004 das Connexin 46.6/GJA12 als neues Krankheitsgen der GJA12-assoziierten PMLD identifiziert. Im Rahmen der vorliegenden Arbeit wurde ein Kollektiv von 195 Patienten aus 184 betroffenen Familien mit PMLD auf Connexin 46.6-Mutationen untersucht. Bei 20 Patienten konnten 13 verschiedene, neue Mutationen identifiziert werden. Die funktionellen Auswirkungen von fünf Missense Mutationen und einer Missense Insertion Mutation wurden näher charakterisiert. Eine Expression der Cx46.6-Proteine in Hela Zellen konnte für alle Mutanten, bis auf Cx46.6-Gly236Arg, gezeigt werden. Das Wildtypprotein wurde mittels Immunfluoreszenz regelrecht an der Plasmamembran detektiert. Im Gegensatz dazu zeigten die mutierten Proteine Cx46.6-Pro90Ser, Cx46.6-Ala98Gly_Val99insThr und Cx46.6Thr265Ala, die Veränderungen in der zweiten oder vierten Transmembrandomäne tragen, eine vollständige ER-Kolokalisation. Diese Ansammlung der Proteine im ER führt zum Funktionsverlust der Cx46.6-Halbkanäle und kann zur Apoptose oder abnormaler Differenzierung der Oligodendrozyten führen und eine Hypomyelinisierung bedingen. Ein Zusammenhang zwischen der Mutationslokalisation in der zweiten und vierten Transmembrandomäne mit dem inhibierten Proteintransport zur Zellmembran kann postuliert werden. Eine partielle Membranlokalisation konnte für Cx46.6-Gly149Ser in HeLa Zellen nachgewiesen werden. In elektrophysiologischen Untersuchungen der Halbkanalaktivität zeigte sich ein stark verminderter Transmembranstrom, von dem anzunehmen ist, dass er Connexin-unspezifische Ströme repräsentiert und somit ein Proteinfunktionsverlust für die Mutante Gly149Ser wahrscheinlich ist. Für die Mutante Thr398Ile konnte vor allem eine Ansammlung der Connexine in der Plasmamembran und partiell auch im ER nachgewiesen werden. Ein Verlust der Steuerungsfähigkeiten (gating) der Thr398Ile-Connexone/Gap Junctions wird vermutet. 
Insgesamt zeigt sich eine große Variabilität an Cx46.6-Mutationen bei Patienten mit GJA12assoziierter PMLD. Die Pathogenese der PMLD scheint hauptsächlich durch den Funktionsverlust der mutierten Cx46.6-Proteine verursacht zu werden. Die Cx46.6/Cx43 Gap Junction vermittelte Kommunikation von Oligodendrozyten und Astrozyten wird dadurch beeinträchtigt. Die beschriebenen, nicht näher untersuchten Frameshift und Nonsense Mutationen, für die auch ein Proteinfunktionsverlust angenommen wird, unterstützen diese Aussage. Ein alternativer, neuer PMLD-Pathomechanismus, verursacht durch einen Regulationsdefekt der Halbkanalfunktion, kann postuliert werden.

Basierend auf den Vorarbeiten unserer Arbeitsgruppe, in denen als Krankheitsgen in vier Patienten mit einer unklaren zystischen Leukoenzephalopathie das RNASET2-Gen identifiziert werden konnte, wurden 19 weitere Patienten im Rahmen dieser Arbeit auf Mutationen hin untersucht. Insgesamt konnten bei sieben Patienten (30\%) sechs verschiedene Mutationen im RNASET2-Gen nachgewiesen werden. Drei Punktmutationen (c.550T >C, c.262-2A $>$ G, c.332+1delG), zwei compound heterozygote Mutationen (c. [50_64del]+[567G>A]) und eine Deletionsmutation (c.87-1341_147+1181del2583). Die Mutation c.550T >C führt dazu, dass ein hoch konserviertes Cystein substituiert wird (p.Cys184Arg). Es kommt zur Destabilisierung des RNASET2-Proteins durch den Verlust einer über dieses Cystein ausgebildeten Disulfidbrücke, so dass das Protein nicht sezerniert wird und im ER verbleibt. Durch die Punktmutationen c. $262-2 \mathrm{~A}>\mathrm{G}$, c. $.332+1 \mathrm{delG}$, c.567G $>$ A und die Deletionsmutation c.87-1341_147+1181del2583 kommt es zu unterschiedlichen Spleißdefekten. Das RNASET2-Protein mit der Mutation c.262$2 \mathrm{~A}>\mathrm{G}$ konnte in lymphoblastoiden Patienten-Zellen nicht nachgewiesen werden. Die Proteine werden demnach nicht stabil exprimiert oder direkt nach Entstehung degradiert. Die Deletionsmutation, bei der das Exon 2 und Bereiche von Intron 1 und 2 deletiert sind, führt zu verschiedenen RNASET2-Spleißvarianten. Das Proteinprodukt einer dieser Varianten wurde im Western Blot detektiert, eine Sekretion des mutierten Proteins konnte jedoch nicht nachgewiesen werden. In weiteren Analysen wurde bestätigt, dass es sich bei der Wildtyp-RNASET2 um ein sekretorisches Glykoprotein handelt, das am C-Terminus prozessiert wird.

Die RNASET2 defiziente zystische Leukoenzephalopathie scheint vor allem durch Abwesenheit und Funktionsverlust der RNASET2 im Extrazellularraum bedingt zu sein. Eine Expressionsanalyse der RNASET2 in verschiedenen Gehirngeweben zeigte eine deutlich erhöhte Expression im Temporallappen und im fetalen Gehirn. Dies könnte die intrauterine Entstehung, der bei Geburt bereits nachweisbaren bilateralen anterioren Temporallappenzysten der Patienten erklären.

Zur weiteren Klärung der Pathogenese der GJA12-assoziierten PMLD und der RNASET2 defizienten zystischen Leukoenzephalopathie sind die Etablierung von entsprechenden Tiermodellen und weitere funktionelle Analysen im Zellmodell erforderlich. 


\section{Literaturverzeichnis}

F. Acquati, C. Morelli, R. Cinquetti, M.G. Bianchi, D. Porrini, L. Varesco, V. Gismondi, R. Rocchetti, S. Talevi, L. Possati, C. Magnanini, M.G. Tibiletti, B. Bernasconi, M.G. Daidone, V. Shridhar, D.I. Smith, M. Negrini, G. Barbanti-Brodano, and R. Taramelli. Cloning and characterization of a senescence inducing and class II tumor suppressor gene in ovarian carcinoma at chromosome region 6q27. Oncogene., 22:980-988, 2001. 1.4.3, 5.2.3

F. Acquati, L. Possati, L. Ferrante, P. Campomenosi, S. Talevi, S. Bardelli, C. Margiotta, A. Russo, E. Bortoletto, R. Rocchetti, R. Calza, R. Cinquetti, L. Monti, S. Salis, G. BarbantiBrodano, and R. Taramelli. Tumor and metastasis suppression by the human RNASET2 gene. Int. J. Oncol., 26(5):1159-68, 2005. 1.4.3, 5.2, 5.2.4

B. Alberts, D. Bray, J. Lewis, M. Raff, K. Roberts, and J.D. Watson. Molekularbiologie der Zelle. VCH Verlagsgesellschaft mbH., 3.Auflage:709, 1995. 5.4

B.B. Allan, B.D. Moyer, and W.E. Balch. Rab1 recruitment of p115 into a cis-SNARE complex: programming budding COPII vesicles for fusion. Science., 289:444-448, 2000. 5.2.4

B.M. Altevogt and D.L. Paul. Four classes of intercellular channels between glial cells in the CNS. J. Neurosci., 24:4313-4323, 2004. 1.3.1.2

P. Amiguet, M.V. Gardinier, J.P. Zanetta, and J.M. Matthieu. Purification and partial structural and functional characterization of mouse myelin/oligodendrocyte glycoprotein. J. Neurochem., 58:1676-82, 1992. 1.2

C.L. Anderson, M.A. Zundel, and R. Werner. Variable promoter usage and alternative splicing in five mouse connexin genes. Genomics., 85:238-244, 2005. 5.1.1

H. Andersson, F. Kappeler, and H.P. Hauri. Protein targeting to endoplasmic reticulum by dilysine signals involves direct retention in addition to retrieval. J. Biol. Chem., 274:1508015084, 1999. 5.2

K. Aoyama, K. Matsubara, and S. Kobayashi. Aging and oxidative stress in progressive supranuclear palsy. Eur. J. Neurol., 13(1):89-92, 2006. 5.2.4 
L. Aravind and E.V. Koonin. A natural classification of ribonucleases. Methods Enzymol., 341: 3-28, 2001. 1.4.2

M. Aridor and W.E. Balch. Integration of endoplasmic reticulum signaling in health and disease. Nature Med., 5:745-751, 1999. 5.1.3

M.E. Barish. A transient calcium-dependent chloride current in the immature xenopus oocyte. J. Physiol., 342:309-325, 1983. 4.1.2

A.J. Barkovich and C.E. Lindan. Congenital cytomegalovirus infection of the brain: imaging analysis and embryologic considerations. AJNR Am. J. Neuroradiol., 15(4):703-15, 1994. 5.2 .3

L.C. Barrio, T. Suchyna, T. Bargiello, L.X. Xu, R. Roginsky, M.V.L. Bennett, and B.J. Nicholson. Voltage dependence of homo- and heterotypic cx26 and cx32 gap junctions expressed in xenopus oocytes. Proc. Natl. Acad. Sci. USA., 88:8410-8414, 1991. 3.3.5.2, 4.1.2, 5.1.2

N. Baumann and D. Pham-Dinh. Biology of oligodendrocyte and myelin in the mammalian central nervous system. Physiol. Rev., 81:871-927, 2001. 1.2

M. Bielschowsky and R. Henneberg. Über familiäre diffuse Sklerose (leukodystrophia cerebri progressiva hereditaria). J Psychol Neurol., 36 (1928):131-181, 1928. 1.1

A.L. Bissinger, C. Sinzger, E. Kaiserling, and G. Jahn. Human cytomegalovirus as a direct pathogen: correlation of multiorgan involvement and cell distribution with clinical and pathological findings in a case of congenital inclusion disease. J. Med. Virol., 67:200-206, 2002. 5.2 .3

H.R. Bourne, D.A. Sanders, and F. McCormick. The GTPase superfamily: conserved structure and molecular mechanism. Nature., 349(6305):117-127, 1991. 5.2.4

P.E. Braun, D. De Angelis, W.W. Shtybel, and L. Bernier. Isoprenoid modification permits 2',3'-cyclic nucleotide 3'-phosphodiesterase to bind to membranes. J. Neurosci. Res., 30: 540-544, 1991. 1.2

S.H. Britz-Cunningham, M.M. Shah, C.W. Zuppan, and W.H. Fletcher. Mutations of the connexin 43 gap-junction gene in patients with heart malformations and defects of laterality. New Engl. J. Med., 332:1323-1329, 1995. 5.1.3

C. Brunner, H. Lassmann, T.V. Waehneldt, J.M. Matthieu, and C. Linington. Differential ultrastructural localization of myelin basic protein, myelin/oligodendroglial glycoprotein, and 2',3'-cyclic nucleotide 3'-phosphodiesterase in the cns of adult rats. J. Neurochem., 52: 296-304, 1989. 1.2 
R. Bruzzone, J.-A. Haeffliger, R.L. Gimlich, and D.L. Paul. Connexin40, a component of gap junctions in vascular endothelium, is restricted in its ability to interact with other connexins. Mol. Biol. Cell., 4:7-20, 1993. 1.3.1.1, 3.3.5.2, 4.1.2, 5.1.2

R. Bruzzone, T.W. White, and D.L. Paul. Connections with connexins: the molecular basis of direct intercellular signaling. Eur. J. Biochem., 238:1-27., 1996. 1.3.1

M. Bugiani, S. Al Shahwan, E. Lamantea, A. Bizzi, E. Bakhsh, I. Moroni, M.R. Balestrini, G. Uziel, and M. Zeviani. GJA12 mutations in children with recessive hypomyelinating leukoencephalopathy. Neurology., 67(2):273-9, 2006. 4.1, 4.1, 5.1.1, 5.1

P. Campomenosi, S. Salis, C. Lindqvist, D. Mariani, T. Nordström, F. Acquati, and R. Taramelli. Characterization of RNASET2, the first human member of the Rh/T2/S family of glycoproteins. Arch. Biochem. Biophys., 449(1-2):17-26, 2006. 1.4.2, 1.4.3, 5.2.2

M. Cascio, N.M. Kumar, R. Safarik, and N.B. Gilula. Physical characterization of gap junction membrane connexons (hemi-channels) isolated from rat liver. J. Biol. Chem., 270(31):1864318648, 1995. 1.3.1

C. Castro, J.M. Gómez-Hernandez, K. Silander, and L.C. Barrio. Altered formation of hemichannels and gap junction channels caused by c-terminal connexin-32 mutations. J. Neurosci., 19(10):3752-60, 1999. 5.1.3

B. Chen, W.H. Piel, L. Gui, E. Bruford, and A. Monteiro. The HSP90 family of genes in the human genome: insights into their divergence and evolution. Genomics., 86:627-637, 2005. 5.2 .4

P. Chomczynski. A reagent for the single-step simultaneous isolation of RNA, DNA and proteins from cell and tissue samples. Biotechniques., 15(3):532-4, 536-7, 1993. 3.2.1

P. Chomczynski and N. Sacchi. Single-step method of RNA isolation by acid guanidinium thiocyanate-phenol-chloroform extraction. Anal Biochem., 162(1):156-9, 1987. 3.2.1

D.M. Church, C.J. Stotler, J.L. Rutter, J.R. Murrell, J.A. Trofatter, and A.J.. Buckler. Isolation of genes from complex sources of mammalian genomic DNA using exon amplification. Nature Genet., 6:98-105, 1994. 4.2.3.2

T.A. Cooper. Use of minigene system to dissect alternative splicing elements. Methods., 37(4): 331-40, 2005. 4.2.3.2

Y.J. Crow, A. Leitch, B.E. Hayward, A Garner, R. Parmar, E. Griffith, M. Ali, C. Semple, J. Aicardi, R. Babul-Hirji, C. Baumann, P. Baxter, E. Bertini, K.E. Chandler, D. Chitayat, D. Cau, C. Déry, E. Fazzi, C. Goizet, M.D. King, J. Klepper, D. Lacombe, G. Lanzi, H. Lyall, 
M.L. Martínez-Frías, M. Mathieu, C. McKeown, A. Monier, Y. Oade, O.W. Quarrell, C.D. Rittey, R.C. Rogers, A. Sanchis, J.B. Stephenson, U. Tacke, M. Till, J.L. Tolmie, P. Tomlin, T. Voit, B. Weschke, C.G. Woods, P. Lebon, D.T. Bonthron, C.P. Ponting, and A.P. Jackson. Mutations in genes encoding ribonuclease H2 subunits cause Aicardi-Goutières syndrome and mimic congenital viral brain infection. Nature Genet., 38(8):910-916, 2006. 5.2.3

J. Das Sarma, F. Wang, and M. Koval. Targeted gap junction protein constructs reveal connexin-specific differences in oligomerization. J. Biol. Chem., 277(23):20911-8, 2002. 1.3.1.1

J.T. den Dunnen and S.E. Antonarakis. Mutation nomenclature extensions and suggestions to describe complex mutations: a discussion. Hum. Mutat., 15:7-12, 2000. 1.3, 4.1

J.T. den Dunnen and M.H. Paalman. Standardizing mutation nomenclature: why bother?. Hum. Mutat., 22:181- 182, 2003. 1.3, 4.1

S.M. Deschenes, J.L. Walcott, T.L. Wexler, S.S. Scherer, and K.H. Fischbeck. Altered trafficking of mutant connexin32. J. Neurosci., 17:9077-9084, 1997. 5.1.3

R.A. Deshpande and V. Shankar. Ribonucleases from T2 Family. Critical Reviews in Microbiology., 28(2):79-122, 2002. 1.4.1, 1.4.2, 5.2.3

M.P. Deutscher. The metabolic role of RNases. Trends Biochem. Sci., 13:136, 1988. 1.4.1

S. Diestel, R. Eckert, D. Hülser, and O. Traub. Exchange of serine residues 263 and 266 reduces the function of mouse gap junction protein connexin31 and exhibits a dominantnegative effect on the wild-type protein in HeLa cells. Exp. Cell Res., 294(2):446-57, 2004. 1.3.1.1

J.N. Dumont. Oogenesis in Xenopus laevis (Daudin). I. Stages of oocyte development in laboratory maintained animals. J. Morphol., 136(2):153-79, 1972. 3.3 .5

L. Ebihara. New roles for connexons. News Physiol. Sci., 18:100-103, 2003. 1.3.1, 4.1.2

W.H. Evans, S. Ahmad, J. Diez, C.H. George, J.M. Kendall, and P.E. Martin. Trafficking pathways leading to the formation of gap junctions. Novartis Found. Symp., 219:44-59, 2000. 1.3 .1

M.M. Falk, L.K. Buehler, N.M. Kumar, and N.B. Gilula. Cell-free synthesis and assembly of connexins into functional gap junction membrane channels. EMBO J., 16:2703-2716, 1997. 1.3.1 
C.I. Foote, L. Zhou, X. Zhu, and B.J. Nicholson. The pattern of disulfide linkage in the extracellular loop regions of connexin 32 suggests a model for the docking interface of gap junctions. J. Cell Biol., 140:1187-1197, 1998. 1.3.1, 5.1.3

A. Forge, D. Becker, S. Casalotti, J. Edwards, N. Marziano, and G. Nevill. Gap junctions in the inner ear: comparison of distribution patterns in different vertebrates and assessement of connexin composition in mammals. J. Comp. Neurol., 467(2):207-231, 2003. 1.3.1.1

K. Frei, R. Ramsebner, T. Lucas, W.D. Baumgartner, C. Schoefer, F.J. Wachtler, and K. Kirschhofer. Screening for monogenetic del(GJB6-D13S1830) and digenic del(GJB6D13S1830)/GJB2 patterns of inheritance in deaf individuals from Eastern Austria. Hear. Res., 196:115-118, 2004. 5.1.1

Y. Fukata, T.J. Itoh, T. Kimura, C. Menager, T. Nishimura, T. Shiromizu, H. Watanabe, N. Inagaki, A. Iwamatsu, H. Hotani, and K. Kaibuchi. CRMP-2 binds to tubulin heterodimers to promote microtubule assembly. Nature Cell Biol., 583-591:4, 2002. 5.2.4

G. Gaietta, T.J. Deerinck, S.R. Adams, J. Bouwer, O. Tour, D.W. Laird, G.E. Sosinsky, R.Y. Tsien, and M.H. Ellisman. Multicolor and electron microscopic imaging of connexin trafficking. Science., 296:503-507, 2002. 1.3.1.1

J. Garbern, F. Cambi, M. Shy, and J. Kamholz. The molecular pathogenesis of PelizaeusMerzbacher disease. Arch. Neurol., 56(10):1210-4, 1999. 1.3

D.A. Goodenough, J.A. Goliger, and D.L. Paul. Connexins, connexons, and intercellular communication. Annu. Rev. Biochem., 65:475-502, 1996. 1.3.1

A. Gow and R.A. Lazzarini. A cellular mechanism governing the severitiy of PelizaeusMerzbacher disease. Nature Genet., 13:422-428, 1996. 1.2, 5.1.3, 5.2.4

P.D. Griffiths. Strategies to prevent CMV infection in the neonate. Semin. Neonatol., 7: 293-299, 2002. 5.2.3

T.I. Gudz, T.E. Schneider, T.A. Haas, and W.B. Macklin. Myelin proteolipid protein forms a complex with integrins and may participate in integrin receptor signaling in oligodendrocytes. J. Neurosci., 22:7398-7407, 2002. 1.2, 5.2.4

A.L. Harris. Emerging issues of connexin channels: biophysics fills the gap. Q. Rev. Biophys., 34(3):325-472, 2001. 1.3.1.1

J. Hassan and J. Connell. Translational mini-review series on infectious disease: congenital cytomegalovirus infection: 50 years on. Clin. Exp. Immunol., 149(2):205-10, 2007. 5.2.3 
M. Henneke, P. Combes, S. Diekmann, E. Bertini, K. Brockmann, A.P. Burlina, J. Kaiser, A. Ohlenbusch, B. Plecko, D. Rodriguez, O. Boespflug-Tanguy, and J. Gärtner. GJA12 mutations are a rare cause of Pelizaeus-Merzbacher-like disease. Neurology., 70(10):748-54, 2008. 4.1.1, 5.1.1

M. Henneke, N. Preuss, V. Engelbrecht, F. Aksu, E. Bertini, G. Bibat, K. Brockmann, C. Hübner, M. Mayer, V. Mejaski-Bosnjak, S. Naidu, E. Neumaier-Probst, D. Rodriguez, W. Weisz, A. Kohlschütter, and J. Gärtner. Cystic leukoencephalopathy without megalencephaly: a distinct disease entity in 15 children. Neurology., 64:1411-1416, 2005. 1.4, 5.2.3

H. Hennemann, T. Suchyna, H. Lichtenberg-Frate, S. Jungbluth, E. Dahl, H.-J. Schwarz, B.J. Nicholson, and K. Willecke. Molecular cloning and functional expression of mouse connexin40, a second gap junction gene preferentially expressed in lung. J. Cell Biol., 117:12991310, 1992. 3.3.5.2, 4.1.2, 5.1.2

B. Hertlein, A. Butterweck, S. Haubrich, K. Willecke, and O. Traub. Phosphorylated carboxy terminal serine residues stabilize the mouse gap junction protein connexin45 against degradation. J. Membr. Biol., 162(3):247-57, 1998. 1.3.1.1

H. Horiuchi, K. Yanai, M. Takagi, K. Yano, E. Wakabayashi, A. Sanda, S. Mine, K. Ohgi, and M. Irie. Primary structure of a base non-specific ribonuclease from Rhizopus niveus. J. Biochem., 103:408-418, 1998. 1.4.2

N. Inokuchi, H. Kobayashi, J. Hara, T. Itagaki, T. Koyama, M. Iwama, K. Ohgi, and M. Irie. Amino acid sequence of an unique ribonuclease with a C-terminus rich in O-glycosylated serine and threonine from culture medium of Lentinus edodes. Biosci. Biotechnol. Biochem., $64: 44,2000$. 1.4 .2

M. Irie. RNase T1/RNase T2 family RNases. In G D'Alessio, JF Riordan, eds, Ribonucleases: Structures and functions. Academic Press, New York., pages 101-130, 1997. 1.4.2, 5.2.1

M. Irie. Structure-function relationships of acid ribonucleases: Lysosomal, vacuolar, and periplasmic enzymes. Pharmacol. Ther., 81(2):77-89, 1999. 1.4.1, 1.4.2, 5.2.1, 5.2.3

K.J. Ishii and S. Akira. Innate immune recognition of nucleic acids: Beyond toll-like receptors. Int. J. Cancer., 117:517-523, 2005. 5.2.3

A.S. Istas, G.J. Demmler, J.G. Dobbins, and J.A. Stewart. Surveillance for congenital cytomegalovirus disease: a report from the National Congenital Cytomegalovirus Disease Registry. Clin. Infect. Dis., 20(3):665-70., 1995. 5.2.3 
M.R. Jackson, T. Nilsson, and P.A. Peterson. Identification of a consensus motif for retention of transmembrane proteins in the endoplasmic reticulum. The EMBO Journal., 9(10):31533162, 1990. 5.2

K. Jordan, R. Chodock, A.R. Hand, and D.W. Laird. The origin of annular junctions: a mechanism of gap junction internalization. J. Cell. Sci., 114:763-773, 2001. 1.3.1.1

W. Jost, K. Bak, H. abd Glund, P. Terpstra, and J. Beintema. Amino acid sequence of an extracellular, phosphate-starvation-induced ribonuclease from cultured tomato (Lycopersicon esculentum) cells. Eur. J. Biochem., 198:1, 1991. 1.4 .2

M.R. Kaplan, A. Meyer-Franke, S. Lambert, V. Bennett, I.D. Duncan, S.R. Levinson, and B.A. Barres. Induction of sodium channel clustering by oligodendrocytes. Nature., 386: 724-8, 1997. 1.2

Y. Kawata, F. Sakiyama, and H. Tamaoki. Amino acid sequence of ribonuclease T2 from Aspergillus oryzae. European Journal of Biochemistry, 176:683-697, 1988. 1.4.2

R. Kellermayer, M. Keller, and Ratajczak P. Bigenic connexin mutations in a patient with hidrotic ectodermal dysplasia. Eur. J. Dermatol., 15:75-79, 2005. 5.1.1

P.S. Kim and P. Arvan. Endocrinopathies in the family of endoplasmic reticulum (ER) storage diseases: disorders of protein trafficking and the role of ER molecular chaperones. Endocr. Rev., 19:173-202, 1998. 5.1.3

D.M. Knipe, P. Howley, D. Griffin, R.A. Lamb, M.A. Martin, B. Roizman, and S.E. Straus. Fields virology. Lippincott, Williams and Wilkins., 5th ed.:Ch. 69, 2007. 5.2.3

H. Kobayashi, M. Imanaka, N. Inokuchi, T. Koyama, and M. Irie. Characterization of ribonucleases from culture medium of Lentinus edodes. Biosci. Biotechnol. Biochem., 62:1604, 1998. 1.4 .2

M. Köck, A. Löffler, S. Abel, and K. Glund. cDNA structure and regulatory properties of a family of starvation-induced ribonucleases from tomato. Plant Mol. Biol., 27:477-485, 1995. $1.4 .3,5.2$

K. Kohno, K. Normington, J. Sambrook, M.J. Gething, and K. Mori. The promoter region of the yeast KAR2 (BiP) gene contains a regulatory domain that responds to the presence of unfolded proteins in the endoplasmic reticulum. Mol. Cell Biol., 13:877-890, 1993. 5.2.4

T. Komiyama and M. Irie. Purification and properties of a ribonuclease from Rhizopus species. J. Biochem. (Tokyo), 70:765, 1971. 1.4.2 
R.P. Kondo, S.Y. Wang, S.A. John, J.N. Weiss, and J.I. Goldhaber. Metabolic inhibition activates a non-selective current through connexin hemichannels in isolated ventricular myocytes. J. Mol. Cell Cardiol., 32:1859-1872, 2000. 5.1.3

Y. Kozutsumi, M. Segal, K. Normington, M.J. Gething, and J. Sambrook. The presence of malfolded proteins in the endoplasmic reticulum signals the induction of glucose-regulated proteins. Nature., 332:462-464, 1988. 5.2.4

und Gilula N. B. Kumar, N. M. The gap junction communication channel. Cell., 84:381-388, 1996. 1.3 .1

P. Kursula. The current status of structural studies on proteins of the myelin sheat. Int. J. Mol. Med., 8(5):475-479, 2001. 1.2

U.K. Laemmli. Cleavage of structural proteins during the assembly of the head of bacteriophage T4. Nature., 227:680-685, 1970. 3.4.4

J.G. Laing and E.C. Beyer. The gap junction protein connexin43 is degraded via the ubiquitin proteasome pathway. J. Biol. Chem., 270:26399-403, 1995. 1.3.1.1

D.W. Laird, M. Castillo, and L. Kasprzak. Gap junction turnover, intracellular trafficking, and phosphorylation of connexin43 in brefeldin A-treated rat mammary tumor cells. J. Cell Biol., 131:1193-1203, 1995. 1.3.1, 1.3.1.1

P.D. Lampe and A.F. Lau. The effects of connexin phosphorylation on gap junctional communication. Int. J. Biochem. Cell Biol., 36:1171-1186, 2004. 1.3.1, 5.1.3

U. Lauf, B.N. Giepmans, P. Lopez, S. Braconnot, S.C. Chen, and M.M. Falk. Dynamic trafficking and delivery of connexons to the plasma membrane and accretion to gap junctions in living cells. Proc. Natl. Acad. Sci. USA., 99(16):10446-51, 2002. 1.3.1.1

R. Lebar, C. Lubetzki, C. Vincent, P. Lombrail, and J.M. Boutry. The M2 autoantigen of central nervous system myelin, a glycoprotein present in oligodendrocyte membrane. Clin. Exp. Immunol., 66:423-34, 1986. 1.2

M.G.-S. Lee, S.A. Lewis, C.D. Wilde, and N.J. Cowan. Evolutionary history of a multigene family: an expressed human beta-tubulin gene and three processed pseudogenes. Cell., 33: 477-487, 1983. 5.2.4

S.A. Lewis and N.J. Cowan. Tubulin genes: structure, expression, and regulation. In: Avila, J. (ed.) : Microtubule proteins., Boca Raton: CRC Press, Inc.:37-66, 1990. 5.2.4 
H. Li, T.F. Liu, A. Lazrak, C. Peracchia, G.S. Goldberg, P.D. Lampe, and R.G. Johnson. Properties and regulation of gap junctional hemichannels in the plasma membranes of cultured cells. J. Cell Biol., 134(4):1019-30, 1996. 5.1.3

X. Li, A.V. Ionescu, B.D. Lynn, S. Lu, N. Kamasawa, M. Morita, K.G.V. Davidson, T. Yasumura, J.E. Rash, and J.I. Nagy. Connexin47, connexin29 and connexin32 co-expression in oligodendrocytes and $\mathrm{Cx} 47$ association with zonula occludens-1 (ZO-1) in mouse brain. Neuroscience., 126:611-630, 2004. 1.3.1.2

G.S. Liang, M. de Miguel, J.M. Gómez-Hernández, J.D. Glass, S.S. Scherer, M. Mintz, L.C. Barrio, and K.H. Fischbeck. Severe neuropathy with leaky connexin32 hemichannels. Ann. Neurol., 57(5):749-54, 2005. 5.1.3

S. Liu, S. Taffet, L. Stoner, M. Delmar, M.L. Vallano, and J. Jalife. A structural basis for the unequal sensitivity of the major cardiac and liver gap junctions to intracellular acidification: the carboxyl tail length. Biophys. J., 64:1422-1433, 1993. 1.3.1

Y. Liu, G. Emilion, A.J. Mungall, I. Dunham, S. Beck, V.G. Le Meuth-Metzinger, A.N. Shelling, F.M. Charnock, and T.S. Ganesan. Physical and transcript map of the region between D6S264 and D6S149 on chromosome 6q27, the minimal region of allele loss in sporadic epithelial ovarian cancer. Oncogene., 21(3):387-99, 2002. 1.4.3, 5.2.3

K.J. Livak and T.D. Schmittgen. Analysis of relative gene expression data using real-time quantitative pcr and the $2^{[- \text {deltadeltaCT] }}$ method. Methods., 25(4):402-408, 2001. 4.2.1

G.C. MacIntosh, P.A. Bariola, E. Newbigin, and P.J. Green. Characterization of Rny1, the Saccharomyces cerevisiae member of the T2 RNase family of RNases: Unexpected functions for ancient enzymes? Proc. Natl. Acad. Sci. USA., 98(3):1018-1023, 2001. 1.4.2, 5.2.2

D. Magen, C. Georgopoulos, P. Bross, D. Ang, Y. Segev, D. Goldsher, A. Nemirovski, E. Shahar, S. Ravid, A. Luder, B. Heno, R. Gershoni-Baruch, K. Skorecki, and H. Mandel. Mitochondrial hsp60 chaperonopathy causes an autosomal-recessive neurodegenerative disorder linked to brain hypomyelination and leukodystrophy. Am. J. Hum. Genet., 83(1):30-42, 2008. 5.1 .1

S. Mar and M.J. Noetzel. Gap junction protein 12: 'connexing' the pieces in the puzzle of myelination and leukodystrophy. Neurology., 70:744-745, 2008. 1.2, 5.2.4

M. McLaughlin, S.A. Karim, P. Montague, J.A. Barrie, D. Kirkham, I.R. Griffiths, and J.M. Edgar. Genetic background influences UPR, but not PLP, processing in the rumpshaker model of PMD/SPG2. Neurochem. Res., 32:167-176, 2007. 5.1.3 
N.S. McNutt and R.S. Weinstein. The ultrastructure of the nexus. A correlated thin-section and freeze-cleave study. J. Cell Biol., 47(3):666-688, 1970. 1.3.1.1

D.M. Menichella, D.A. Goodenough, E. Sirkowski, S.S. Scherer, and D.L. Paul. Connexins are critical for normal myelination in the CNS. J. Neurosci., 23(13):5963-73, 2003. 1.3.1, 1.3.1.2

S. Miller and J. Krijnse-Locker. Modification of intracellular membrane structures for virus replication. Nat. Rev. Microbiol., 6(5):363-74, 2008. 5.2.2

A.P. Moreno and A.F. Lau. Gap junction channel gating modulated through protein phosphorylation. Prog. Biophys. Mol. Biol., 94(1-2):107-19, 2007. 1.3.1

G.E. Morley, S.M. Taffet, and M. Delmar. Intramolecular interactions mediate ph regulation of connexin43 channels. Biophys. J., 70:1294-1302, 1996. 1.3.1

E. Mugnaini. Cell junctions of astrocytes, ependyma, and related cells in the mammalian central nervous system, with emphasis on the hypothesis of a generalized functional syncytium of supporting cells. Astrocytes. New York, Academic., 1986. 1.2, 1.3.1.2

L.S. Musil and D.A. Goodenough. Multisubunit assembly of an integral plasma membrane channel protein, gap junction connexin43, occurs after exit from the ER. Cell., 74:10651077, 1993. 1.3.1, 1.3.1.1

L.S. Musil, A.C. Le, J.K. VanSlyke, and L.M. Roberts. Regulation of connexin degradation as a mechanism to increase gap junction assembly and function. J. Biol. Chem., 275(33): 25207-15, 2000. 1.3.1.1

J.I. Nagy, F.E. Dudek, and J.E. Rash. Update on connexins and gap junctions in neurons and glia in the mammalian nervous system. Brain Res. Brain Res. Rev., 47(1-3):191-215, 2004. $1.3 .1,1.3 .1 .2$

J.I. Nagy, A.V. Ionescu, B.D. Lynn, and J.E. Rash. Coupling of astrocyte connexins cx26, cx30, cx43 to oligodendrocyte cx29, cx32, cx47: implications from normal and connexin32 knockout mice. Glia., 44:205-218, 2003. 1.3.1.2

T. Nakase and C.C. Naus. Gap junctions and neurological disorders of the central nervous system. Biochim. Biophys. Acta., 1662:149-158, 2004. 5.1.1

A. Nicholson. Escherichia coli Ribonucleases: Paradigms for understanding cellular RNA metabolism and regulation. In G D'Alessio, JF Riordan, eds, Ribonuclease: Structures anf functions. Academic Press, New York., pages 1-49, 1997. 1.4.2

B.J. Nicholson, R. Dermietzel, D. Teplow, O. Traub, K. Willecke, and J.-P. Revel. Two homologous protein components of hepatic gap junctions. Nature., 329:732-734, 1987. 1.3.1 
W. T. Norton and W. Cammer. Isolation and characterization of myelin. Myelin. New York, Plenum Press., 1984. 1.2

B. Odermatt, K. Wellershaus, A. Wallraff, G. Seifert, J. Degen, C. Euwens, B. Fuss, H. Büssow, K. Schilling, C. Steinhäuser, and K. Willecke. Connexin 47 (Cx47)-deficient mice with enhanced green fluorescent protein reporter gene reveal predominant oligodendrocytic expression of Cx47 and display vacuolized myelin in the CNS. J. Neurosci., 23(11):4549-59, 2003. 1.3.1.2

G. Olbina and W. Eckhart. Mutations in the second extracellular region of connexin 43 prevent localization to the plasma membrane, but do not affect its ability to suppress cell growth. Mol. Cancer Res., 1(9):690-700, 2003. 5.1.3

Y. Omori, M. Mesnil, and H. Yamasaki. Connexin 32 mutations from X-linked Charcot-MarieTooth disease patients: functional defects and dominant negative effects. Mol. Biol. Cell., $7(6): 907-16,1996.5 .1 .3$

J.L. Orthmann-Murphy, C.K. Abrams, and S.S. Scherer. Gap junctions couple astrocytes and oligodendrocytes. J. Mol. Neurosci., 35(1):101-16, 2008. 1.3.1.2, 4.1, 5.1.1

J.L. Orthmann-Murphy, A.D. Enriquez, C.K. Abrams, and S.S. Scherer. Loss-of-function GJA12/Connexin47 mutations cause Pelizaeus-Merzbacher-like disease. Mol. Cell Neurosci., 34(4):629-41, 2007a. 4.1.5, 5.1.3

J.L. Orthmann-Murphy, M. Freidin, E. Fischer, S.S. Scherer, and C.K. Abrams. Two distinct heterotypic channels mediate gap junction coupling between astrocyte and oligodendrocyte connexins. J. Neurosci., 27(51):13949 -13957, 2007b. 1.3.1.2, 5.1.3

J.L. Orthmann-Murphy, E. Salsano, C.K. Abrams, A. Bizzi, G. Uziel, M.M. Freidin, E. Lamantea, M. Zeviani, S.S. Scherer, and D. Pareyson. Hereditary spastic paraplegia is a novel phenotype for GJA12/GJC2 mutations. Brain., 132(Pt2):426-438, 2009. 1.3, 5.1 .3

H.R. Pelham. Control of protein exit from the endoplasmic reticulum. Annu. Rev. Cell Biol., $5: 1-23,1989.5 .2$

G.A. Perkins, D.A. Goodenough, and G.E. Sosinsky. Formation of the gap junction intercellular channel requires a 30 degree rotation for interdigitating two apposing connexons. J. Mol. Biol., 277(2):171-177, 1998. 1.3.1.1

M.W. Pfaffl. A new mathematical model for relative quantification in real-time RT-PCR. Nucleic Acids Research., 29:2002-2007, 2001. 4.2.4 
P. Pimpl and J. Denecke. Protein-protein interactions in the secretory pathway, a growing demand for experimental approaches in vivo. Plant Mol. Biol., 50:887-902, 2002. 5.2.2

M. Poltorak, R. Sadoul, G. Keilhauer, C. Landa, T. Fahrig, and M. Schachner. Myelinassociated glycoprotein, a member of the L2/HNK-1 family of neural cell adhesion molecules, is involved in neuron-oligodendrocyte and oligodendrocyte-oligodendrocyte interaction. $J$. Cell Biol., 105:1893-9, 1987. 1.2

H. Qin, Q. Shao, S.A. Igdoura, M.A. Alaoui-Jamali, and D.W. Laird. Lysosomal and proteasomal degradation play distinct roles in the life cycle of cx43 in gap junctional intercellular communication-deficient and -competent breast tumor cells. J. Biol. Chem., 278:30005-14, 2003. 1.3.1.1

R. Rabionet, P. Gasparini, and X. Estivill. Molecular genetics of hearing impairment due to mutations in gap junction genes encoding beta connexins. Hum. Mutat., 16:190-202, 2000. 5.1 .1

S. Rahman and W.H. Evans. Topography of connexin32 in rat liver gap junctions. Evidence for an intramolecular disulphide linkage connecting the two extracellular peptide loops. $J$. Cell Sci., 100:567-578, 1991. 1.3.1, 5.1.3

R.T. Raines. Ribonuclease A. Chem. Rev., 98(3):1045-1066, 1998. 1.4.1

J. E. Rash, H.S. Duffy, F.E. Dudek, B.L. Bilhartz, L.R. Whalen, and T. Yasumura. Gridmapped freeze-fracture analysis of gap junctions in gray and white matter of adult rat central nervous system, with evidence for a panglial syncytium that is not coupled to neurons. J. Comp. Neurol., 388:265-92, 1997. 1.2

J.E. Rash, T. Yasumura, F.E. Dudek, and Nagy J.I. Cell-specific expression of connexins and evidence of restricted gap junctional coupling between glial cells and between neurons. $J$. Neurosci., 21:1983-2000, 2001. 1.3.1.2

R. Rasmussen. Quantification on the LightCycler. In:Meuer, S, Wittwer, C, and Nakagawara, K, eds. Rapid Cycle RealtimePCR, Methods and Applications Springer Press, Heidelberg., ISBN 3-540-66736-9:21-34, 2001. 4.2.1

M. Ren, G. Drivas, P. D'Eustachio, and M.G. Rush. Ran/TC4: a small nuclear GTP-binding protein that regulates DNA synthesis. J. Cell Biol., 120:313-323, 1993. 5.2.4

L. Salviati, E. Trevisson, M.C. Baldoin, I. Toldo, S. Sartori, M. Calderone, R. Tenconi, and A. Laverda. A novel deletion in the GJA12 gene causes Pelizaeus-Merzbacher-like disease. Neurogenetics., 8(1):57-60, 2006. 4.1, 4.1, 5.1.1 
J. Sambrook, E. F. Fritsch, and T. Maniatis. Molecular cloning. A laboratory manual (2nd Ed.). Cold Spring Harbor Laboratory Press, Cold Spring Harbor, USA., 1989. 3.1.1, 3.1.13

F. Sanger, S. Nicklen, and A. R. Coulson. DNA sequencing with chain-terminating inhibitors. Proc. Natl. Acad. Sci. USA., 74:5463-5467, 1977. 3.1.14

S.S. Scherer and K.A. Kleopa. X-linked Charcot-Marie-Tooth disease. In: Peripheral neuropathy, Ed 4 (Dyck PJ, Thomas PK, eds), page 1791-1804, 2005. 1.3.1.2

R. Schiffmann and O. Boespflug-Tanguy. An update on the leukodystrophies. Curr. Opin. Neurol., 14:789-794, 2001. 1.3

C. Schwarzer. Expression von humanem Typ-1 Porin in Xenopus Oozyten und Studien zu seiner Funktionalität. Dissertation., 2000. 3.1

T.Y. Shih, D.R. Williams, M.O. Weeks, J.M. Maryak, W.C. Vass, and E.M. Scolnick. Comparison of the genomic organization of Kirsten and Harvey sarcoma viruses. J. Virol., 27(1): $45-55,1978.5 .2 .4$

H. Shimada, N. Inokuchi, H. Okuwaki, T. Koyama, and M. Irie. Purification and characterization of a base non-specific and adenylic acid preferring ribonuclease from the fruit bodies of Lentinus edodes. Agric. Biol. Chem., 55:1167, 1991. 1.4.2

C. Sinzger, A. Grefte, B. Plachter, A.S. Gouw, T.H. The, and G. Jahn. Fibroblasts, epithelial cells, endothelial cells and smooth muscle cells are major targets of human cytomegalovirus infection in lung and gastrointestinal tissues. J. Gen. Virol., 76:741-750, 1995. 5.2.3

P. Smirnoff, L. Roiz, B. Angelkovitch, B. Schwartz, and O. Shoseyov. A recombinant human RNASET2 glycoprotein with antitumorigenic and antiangiogenic characteristics: expression, purification, and characterization. Cancer., 107(12):2760-9, 2006. 1.4.3, 5.2.3, 5.2.4

G. Söhl, S. Maxeiner, and K. Willecke. Expression and functions of neuronal gap junctions. Nat. Rev. Neurosci., 6(3):191-200, 2005. 1.1

G. Söhl and K. Willecke. An update on connexin genes and their nomenclature in mouse and man. Cell Commun. Adhes., 10:173-180, 2003. 1.3.1

C.M. Southwood, J. Garbern, W. Jiang, and A. Gow. The unfolded protein response modulates disease severity in Pelizaeus-Merzbacher disease. Neuron., 36:585-596, 2002. 5.1.3

M. Spaargaren, J.R. Bischoff, and F. McCormick. Signal transduction by Ras-like GTPases: a potential target for anticancer drugs. Gene Expr., 4(6):345-356, 1995. 5.2.4 
E.M. Stadlan and J.H. Sung. Congenital rubella encephalopathy. J. Neuropathol. Exp. Neurol., 26(1):115, 1967. 1.4

M.I. Steinlin, D. Nadal, G.F. Eich, E. Martin, and E.J. Boltshauser. Late intrauterine cytomegalovirus infection: clinical and neuroimaging findings. Pediatr. Neurol., 15(3):249-53, 1996. $1.4,5.2 .3$

B. Teubner, B. Odermatt, M. Guldenagel, G. Sohl, J. Degen, F. Bukauskas, J. Kronengold, V.K. Verselis, Y.T. Jung, C.A. Kozak, K. Schilling, and K. Willecke. Functional expression of the new gap junction gene connexin 47 transcribed in mouse brain and spinal cord neurons. J. Neurosci., 21(4):1117-26, 2001. 1.3.1.2

O. Traub, J. Look, R. Dermietzel, F. Brümmer, D. Hülser, and K. Willecke. Comparative characterization of the 21-kd and 26-kd gap junction protein in murine liver and cultured hepatocytes. J. Cell Biol., 108:1039-1059, 1989. 1.3.1

M. Trubia, L. Sessa, and R. Taramelli. Mammalian Rh/T2/S-glycoprotein ribonuclease family genes: cloning of a human member located in a region of chromosome 6 (6q27) frequently deleted in human malignancies. Genomics., 42:342-344, 1997. 1.4.1, 1.4.3

B. Uhlenberg, M. Schuelke, F. Rüschendorf, N. Ruf, A.M. Kaindl, M. Henneke, H. Thiele, G. Stoltenburg-Didinger, F. Aksu, H. Topaloglu, P. Nürnberg, C. Hübner, B. Weschke, and J. Gärtner. Mutations in the gene encoding gap junction protein alpha 12 (connexin 46.6) cause Pelizaeus-Merzbacher-like disease. Am. J. Hum. Genet., 75:251-260, 2004. 1.1, 1.3.1.2, $4.1,5.1 .1,5.1$

V.M. Unger, N.M. Kumar, N.B. Gilula, and M. Yeager. Three-dimensional structure of a recombinant gap junction membrane channel. Science., 283:1176-1180, 1999. 1.3.1, 1.3.1.1

M.S. van der Knaap, P.G. Barth, H. Stroink, O. van Nieuwenhuizen, W.F. Arts, F. Hoogenraad, and J. Valk. Leukoencephalopathy with swelling and a discrepantly mild clinical course in eight children. Ann Neurol., 37(3):324-34, 1995. 1.2

M.S. van der Knaap and J. Valk. Magnetic resonance of myelination and myelin disorders. Springer., 3rd ed.:Ch. 85, 2005. 5.2.3

M.S. van der Knaap, G. Vermeulen, F. Barkhof, A.A. Hart, J.G. Loeber, and J.F. Weel. Pattern of white matter abnormalities at MR imaging: use of polymerase chain reaction testing of Guthrie cards to link pattern with congenital cytomegalovirus infection. Radiology., 230(2): 529-36, 2004. 5.2.3

R. Virchow. Über das granulierte Aussehen der Wandungen der Gehirnventrikel. Allg. Z. Psychiat., 3:242-50, 1846. 1.2 
B. Vogelstein and D. Gillespie. Preparative and analytical purification of DNA from agarose. Proc. Natl. Acad. Sci. USA., 76:615-619, 1979. 3.1.4.1, 3.1.7, 3.1.13

C.A. Wagner, B. Friedrich, I. Setiawan, F. Lang, and S. Bröer. The use of xenopus laevis oocytes for the functional characterization of heterologously expressed membrane proteins. Cell Physiol. Biochem., 10(1-2):1-12, 2000. 3.3.5

H. Watanabe, A. Naitoh, Y. Suyama, N. Inokuchi, H. Shimada, T. Koyama, K. Ohgi, and M. Irie. Primary structure of a base non-specific and adenylic acid preferential ribonuclease from Aspergillus saitoi. J. Biochem., 108:303-310, 1990. 1.4.2

K. Willecke, J. Eiberger, J. Degen, D. Eckardt, A. Romualdi, M. Guldenagel, U. Deutsch, and G. Söhl. Structural and functional diversity of connexin genes in the mouse and human genome. Biol. Chem., 383:725-737, 2002. 1.3.1

N.I. Wolf, M. Cundall, P. Rutland, E. Rosser, R. Surtees, S. Benton, W.K. Chong, S. Malcolm, F. Ebinger, M. Bitner-Glindzicz, and K.J. Woodward. Frameshift mutation in GJA12 leading to nystagmus, spastic ataxia and CNS dys-/demyelination. Neurogenetics., 8(1):39-44, 2006. $4.1,4.1,5.1 .1$

M.B. Yaffe, G.W. Farr, D. Miklos, A.L. Horwich, M.L. Sternlicht, and H. Sternlicht. TCP1 complex is a molecular chaperone in tubulin biogenesis. Nature., 358:245-248, 1992. 5.2.4

P.I. Yakovlev and A.R. Lecours. The myelogenetic cycles of regional maturation of the brain. In: Minowski A. (ed): Regional development of the brain in early life, Blackwell Oxford:pp 3-70, 1967. 1.2

M. Yeager, V.M. Unger, and M.M. Falk. Synthesis, assembly and structure of gap junction intercellular channels. Curr. Opin.Struct. Biol., 8:517-524, 1998. 1.3.1

H. Yoshida. The ribonuclease T1 family. Methods Enzymol., 341:28-41, 2001. 1.4.1

J. Y. Zheng, T. Koda, T. Fujiwara, M. Kishi, Y. Ikehara, and M. Kakinuma. A novel Rab GTPase, Rab33B, is ubiquitously expressed and localized to the medial Golgi cisternae. J. Cell Sci., 111:1061-1069, 1998. 5.2.4 



\section{Abbildungsverzeichnis}

1.1. Strukturmodell von Gap Junction-Kanälen und Connexinen . . . . . . . . . . 7

1.2. Homotypische und heterotypische Gap Junction Kanäle . . . . . . . . . . . . . 9

3.1. Darstellung des TEVC-Aufbaus . . . . . . . . . . . . . . . . 47

4.1. Membrantopologie und Lokalisation aller Mutationen im Connexin 46.6 . . . . 58

4.2. Elektrophysiologische Untersuchung des Ruhemembranpotentials . . . . . . . . 60

4.3. Versuchsverlauf der elektrophysiologischen Messung . . . . . . . . . . . . . . 61

4.4. Elektrophysiologische Untersuchung des Transmembranstroms . . . . . . . . 62

4.5. Lokalisation und Expressionsanalyse von Cx46.6-WT-GFP in Oozyten . . . . 63

4.6. Charakterisierung des Cx46.6-Antiserums im Western Blot . . . . . . . . . 64

4.7. Charakterisierung des Cx46.6-Antiserums in der Immunfluoreszenz . . . . . . . 65

4.8. Immundetektion der Expression von Cx46.6 in HeLa Zellen . . . . . . . . . . . 65

4.9. Subzelluläre Lokalisation von Cx46.6-WT in HeLa Zellen . . . . . . . . . . . . 67

4.10. Subzelluläre Lokalisation von Cx46.6-mt in HeLa Zellen . . . . . . . . . . . . . 69

4.11. RNASET2-Expressionsanalyse der Familien 1 und 2 mittels RealTime-PCR . . 72

4.12. Chromatogramm der genomischen Sequenzanalyse von Patient 3306 . . . . . . 76

4.13. Minigenkonstrukt (RNASET2-Exon 8) zur Spleißeffizienz-Analyse . . . . . . . 77

4.14. Agarose-Gelelektrophorese zur Spleißeffizienz-Analyse . . . . . . . . . . . . . 77

4.15. Ergebnisse der RNASET2-Expressionsanalyse in verschiedenen Geweben . . . 79

4.16. Immundetektion der Expression und Sekretion von RNASET2 . . . . . . . . 80

4.17. Immunoblot zur Untersuchung der Glykosylierung von RNASET2 . . . . . . . 81

4.18. Charakterisierung des RNASET2-Antiserums im Western Blot . . . . . . . . 81

4.19. Charakterisierung des RNASET2-Antiserums in der Immunfluoreszenz . . . 82

4.20. Immundetektion der Expression von RNASET2 in stabilen HEK 293 Zellen . . 83

4.21. Subzelluläre Lokalisation von RNASET2 in stabilen HEK 293 Zellen . . . . . . 84

4.22. Immundetektion der RNASET2-Expression in Patienten-Lymphozyten . . . 86

4.23. Immundetektion der RNASET2-Glykosylierung in Patienten-Lymphozyten . 86

4.24. Immundetektion der RNASET2-Sekretion von Patienten-Lymphozyten . . . 88

4.25. Subzelluläre Lokalisation von RNASET2 in lymphoblastoiden Kontroll-Zellen . 89

4.26. Subzelluläre Lokalisation von RNASET2 in lymphoblastoiden Patienten-Zellen 90 
4.27. Immundetektion der Prozessierung von RNASET2 mittels Western Blot . . . . 91

5.1. Alignment der Cx46.6-Bereiche mit Missense Mutationen . . . . . . . . . . . 97

5.2. Schematische Darstellung der RNASET2 . . . . . . . . . . . . . . . . 102

5.3. Alignment des RNASET2-Proteinbereichs mit der Mutation Cys184Arg . . . 105

5.4. Schematische Darstellung des sekretorischen Wegs . . . . . . . . . . . . . . 107 


\section{Tabellenverzeichnis}

1.1. Mutationen der GJA12-assoziierten PMLD . . . . . . . . . . . 5

2.1. Übersicht der eingesetzten Antikörper und ihre Verdünnung . . . . . . . . . . 17

2.2. Übersicht der verwendeten Bakterienstämme, Zelllinien und Tiere . . . . . . . 18

2.3. Übersicht der Lösungen zur Herstellung verschiedener Trenngele . . . . . . . . 21

2.4. Übersicht der Lösungen zur Herstellung des Sammelgels . . . . . . . . . . . . . 21

2.5. Übersicht der verwendeten Ausgangsvektoren und konstruierten Plasmide . . . 23

3.1. Amplifikationsbedingungen der FlipFlop Site-Directed-Mutagenese . . . . . . . 30

4.1. Daten der Patienten mit neu identifizierten Cx46.6-Mutationen . . . . . . 56

4.2. Daten der Patienten mit neu identifizierten RNASET2-Mutationen . . . . . 74

4.3. Massenspektrometrische Analyse des GST-pulldowns . . . . . . . . . . 93

A.1. Sequenzen der verwendeten Oligonukleotide $\left(5^{\prime} \rightarrow 3^{\prime}\right)$ für $\mathrm{Cx} 46.6$. . . . . A

A.2. Sequenzen der verwendeten Oligonukleotide $\left(5^{\prime} \rightarrow 3^{\prime}\right)$ für RNASET2 . . . . B B 



\section{Anhang}

\section{A.1. Sequenzen der Oligonukleotide}

Tabelle A.1.: Sequenzen der verwendeten Oligonukleotide $\left(5^{\prime} \rightarrow 3^{\prime}\right)$ für Connexin 46.6

\begin{tabular}{|c|c|c|}
\hline Oligonukleotid & Sequenz & $\begin{array}{l}\text { Produkt- } \\
\text { größe }\end{array}$ \\
\hline \multicolumn{3}{|c|}{ Klonierung und Sequenzierung } \\
\hline $\begin{array}{l}\text { Cx46.6 sense } \\
\text { Cx46.6 antisense }\end{array}$ & $\begin{array}{l}\text { CCCGGATCCATGACCAACATGAGCTGGAGC } \\
\text { CCACTCGAGTCAGATCCACACGGTGGTCTTCC }\end{array}$ & $1320 \mathrm{bp}$ \\
\hline $\begin{array}{l}\text { Cx46.6-15 sense } \\
\text { Cx46.6-15 antisense }\end{array}$ & $\begin{array}{l}\text { CGCGGATCCCGTGCGTCTGAGC } \\
\text { CCGGAATTCTCATTGCCCGG }\end{array}$ & $282 \mathrm{bp}$ \\
\hline $\begin{array}{l}\text { Cx46.6-GFP sense } \\
\text { Cx46.6-GFPantisense }\end{array}$ & $\begin{array}{l}\text { GCAGAATTCATGACCAACATGAGCTGGAGC } \\
\text { GAGGGGATCCGCGATCCACACGGTGGTCTTCC }\end{array}$ & $2047 \mathrm{bp}$ \\
\hline $\begin{array}{l}\text { Cx46.6-F1 sense } \\
\text { Cx46.6-F1 antisense }\end{array}$ & $\begin{array}{l}\text { TTTAAGGCGGTAAGCTCCAC } \\
\text { GCCATCTCACAGAGGTTGAG }\end{array}$ & $1015 \mathrm{bp}$ \\
\hline $\begin{array}{l}\text { Cx46.6-F2 sense } \\
\text { Cx46.6-F2 antisense }\end{array}$ & $\begin{array}{l}\text { CCGACCGGGCAACACGATG } \\
\text { GAGTCTGCCTGAGGCCACCG }\end{array}$ & $853 \mathrm{bp}$ \\
\hline Cx46.6-F1.1 antisense & CAGCATGGGCTCCTCCTC & \\
\hline Cx46.6-F1.2 sense & CTGCGACAACGTCTGCTATG & \\
\hline Cx46.6-F1.2i antisense & GACACGAAGCAGTCCACCACG & \\
\hline $\begin{array}{l}\text { MCS-pGEX-KG sense } \\
\text { MCS-pGEX-KG antisense }\end{array}$ & $\begin{array}{l}\text { CGTATTGAAGCTATCCCAC } \\
\text { CACCGTCATCACCGAAACGC }\end{array}$ & \\
\hline \multicolumn{3}{|l|}{ Mutagenese } \\
\hline $\begin{array}{l}\mathrm{C} 268 \mathrm{~T} \text { sense } \\
\mathrm{C} 268 \mathrm{~T} \text { antisense }\end{array}$ & $\begin{array}{l}\text { GTCATCTCCACGTCCTCGGTCATGTAC } \\
\text { GTACATGACCGAGGACGTGGAGATGAC }\end{array}$ & \\
\hline $\begin{array}{l}\text { C1193T sense } \\
\text { C1193T antisense }\end{array}$ & $\begin{array}{l}\text { CGGACGGGCAGTGCTATCTCTGCGGGCACTGTC } \\
\text { GACAGTGCCCGCAGAGATAGCACTGCCCGTCCG }\end{array}$ & \\
\hline G445A sense & GAGCCCATGCTGAGCCTGGGCGAGGAG & \\
\hline
\end{tabular}




\begin{tabular}{|l|l|l|}
\hline Oligonukleotid & Sequenz & $\begin{array}{l}\text { Produkt- } \\
\text { größe }\end{array}$ \\
\hline \hline G445A antisense & CTCCTCGCCCAGGCTCAGCATGGGCTC & \\
\hline 292_293insGTA sense & GTACCTGGGCTACGGTACCGTGCACCGCCTG & \\
292_293insGTA antisense & CAGGCGGTGCACGGTACCGTAGCCCAGGTAC & \\
G706C sense & GTACCTGCTGTACCGCTTCGAGGTGC & \\
G706C antisense & GCACCTCGAAGCGGTACAGCAGGTAC & \\
\hline A793G sense & CCTACTGAAAAGGCGGTCTTCCTGC & \\
A793G antisense & GCAGGAAGACCGCCTTTTCAGTAGG & \\
\hline Antisense Cx38 & GCTTTAGTAATTCCCATCCTGCCATGTTTC & \\
\hline
\end{tabular}

Tabelle A.2.: Sequenzen der verwendeten Oligonukleotide $\left(5^{\prime} \rightarrow 3^{\prime}\right)$ für RNASET2

\begin{tabular}{|c|c|c|}
\hline Oligonukleotid & Sequenz & $\begin{array}{l}\text { Produkt- } \\
\text { größe }\end{array}$ \\
\hline \multicolumn{3}{|l|}{ RealTime-PCR } \\
\hline Amplikon1 sense & CCATGAGTGGAAAAAACTAATTATGG & $336 \mathrm{bp}$ \\
\hline Amplikon1 antisense & CCTGTAGAGTTCCAGGCTTCTG & Exon 2-6 \\
\hline Amplikon2 sense & CTATGGCCCGATAAAAGTAAG & $231 \mathrm{bp}$ \\
\hline Amplikon2 antisense & CCTGTAGAGTTCCAGGCTTCTG & Exon 4-6 \\
\hline Amplikon3 sense & CAGAAGCCTGGAACTCTACAGG & $235 \mathrm{bp}$ \\
\hline Amplikon3 antisense & GGTGCAGTTTTGCAGCTGC & Exon 6-9 \\
\hline GAPDH sense & GAGTCAACGGATTTGGTCGT & $185 \mathrm{bp}$ \\
\hline GAPDH antisense & GACAAGCTTCCCGTTCTCAG & \\
\hline \multicolumn{3}{|c|}{ Klonierung und Sequenzierung } \\
\hline RNASET2 sense & GCTGGCTAGCACCATGCGCCCTGCAGCCCTGCG & $771 \mathrm{bp}$ \\
\hline RNASET2 antisense & CGCAAGCTTCTAGATGCTTGGTCTTTTTAGGTGGGG & \\
\hline RNASET2-19 sense & TTTGGATCCTTCTGGAAGCATGAGTGG & $444 \mathrm{bp}$ \\
\hline RNASET2-19 antisense & TATGGATTCTCAATGCTTGGTCTTTTTAG & \\
\hline Exon 1 sense & GCTGCTGCAGCGGAGGGAG & $373 \mathrm{bp}$ \\
\hline Exon 1 antisense & GGTCACCCCGGAGCGTGCTC & \\
\hline Exon 2 sense & CCTTCCTCACGGGAGTGTGTGC & $500 \mathrm{bp}$ \\
\hline Exon 2 antisense & GGTTGAAACTTCCCCTTCCAGGAC & \\
\hline Exon 3 sense & GTGCAGTACCTGTATCTCGTTGG & $353 \mathrm{bp}$ \\
\hline Exon 3 antisense & CAAGAGAATCAGGGTTCTGC & \\
\hline Exon 4 sense & TTCTAAGGTCATGTAGAAGCCACCC & $375 \mathrm{bp}$ \\
\hline
\end{tabular}




\begin{tabular}{|c|c|c|}
\hline Oligonukleotid & Sequenz & $\begin{array}{l}\text { Produkt- } \\
\text { größe }\end{array}$ \\
\hline Exon 4 antisense & GACTTTGAAGGTACGCTTGTGAAGAAAAG & \\
\hline Exon 5 sense & GCAGAGCTCAATTCTTTGGTG & $311 \mathrm{bp}$ \\
\hline Exon 5 antisense & GGTTGTTCAAACTGCTCAGCC & \\
\hline Exon 6 sense & CTGAGTAGCTGGGATCTCAGGCAC & $372 \mathrm{bp}$ \\
\hline Exon 6 antisense & CTCTGCACCCACTCTGTGTGATGC & \\
\hline Exon 7 sense & CTGGGAACCATGTATTTGCAGTC & $312 \mathrm{bp}$ \\
\hline Exon 7 antisense & GGCAATTTACAGCCCATTGACTC & \\
\hline Exon 8 sense & GTGGCGTTTCAGGTGAGACAGCTC & $500 \mathrm{bp}$ \\
\hline Exon 8 antisense & GCACAAATACAAGTCTGCCCCAGG & \\
\hline Exon 9 sense & GGGTCCGTTCTTGGAACCTAG & $372 \mathrm{bp}$ \\
\hline Exon 9 antisense & ACAGAATATTTCCAAAACTTGGGC & \\
\hline cDNA (5’UTR) sense & AGCGTTTCTCCCGGAAG & $853 \mathrm{bp}$ \\
\hline cDNA (3'UTR) antisense & ACAGAATATTTCCAAAACTTGGGC & \\
\hline Minigen_Ex8 sense & ATATATGAATTCAGGTGAGACAGCTCGGGG & $635 \mathrm{bp}$ \\
\hline Minigen_Ex8 antisense & TTTAAACTCGAGCCCACATGCATGTACACACAC & \\
\hline SD6 sense & TCTGAGTCACCTGGACAACC & \\
\hline SA2 antisense & ATCTCAGTGGTATTTGTGAGC & \\
\hline \multicolumn{3}{|l|}{ Mutagenese } \\
\hline T550C sense & CCAAAATCCAGCGCCTTCCACCAAGC & \\
\hline T550C antisense & GCTTGGTGGAAGGCGCTGGATTTTGG & \\
\hline G567A sense & GCCTTCCACCAAGCCAAGTTAGACAG & \\
\hline G567A antisense & CTGTCTAACTTGGCTTGGTGGAAGGC & \\
\hline
\end{tabular}





\section{Publikationen}

- GJA12 mutations are a rare cause of Pelizaeus-Merzbacher-like disease.

M. Henneke, P. Combes, S. Diekmann, E. Bertini, K. Brockmann, A.P. Burlina, J. Kaiser, A. Ohlenbusch, B. Plecko, D. Rodriguez, O. Boespflug-Tanguy, and J. Gärtner. Neurology, 70(10):748-54, 2008.

- RNASET2 deficient cystic leukoencephalopathy resembles congenital cytomegalovirus brain infection.

M. Henneke, S. Diekmann, A. Ohlenbusch, J. Kaiser, V. Engelbrecht, A. Kohlschütter, R. Krätzner, M. Madruga-Garrido, M. Mayer, L. Opitz, D. Rodriguez, F. Rüschendorf, J. Schumacher, H. Thiele, S. Thoms, R. Steinfeld, P. Nürnberg, and J. Gärtner.

Nature Genetics, im Druck.

- Pelizaeus-Merzbacher like disease is caused not only by a loss of Connexin47 function but also by a regulation defect of hemichannel function.

S. Diekmann, M. Henneke, A. Hahn, F. Kok, B.C. Burckhardt, and J. Gärtner.

Manuskript in Vorbereitung. 



\section{Danksagung}

Herzlichen Dank an Frau Prof. Dr. J. Gärtner für die Möglichkeit, diese Arbeit in der Abteilung für Neuropädiatrie in der Universitätsmedizin Göttingen anzufertigen, für die Überlassung des Dissertationsthemas und für ihre fachliche Unterstützung.

Herrn Prof. Dr. R. Heinrich danke ich für die Betreuung der Arbeit seitens der Biologischen Fakultät und für sein wissenschaftliches Interesse am Fortgang dieser Arbeit. Bei Herrn Prof. Dr. O. Einsle bedanke ich mich für die Bereitschaft, das Korreferat zu übernehmen.

Mein besonderer Dank gilt Herrn Dr. M. Henneke für das Vertrauen in meine Arbeit und für seine fachliche Unterstützung.

Zudem danke ich Frau Prof. Dr. B. C. Burckhardt für die wissenschaftliche Betreuung meiner elektrophysiologischen Untersuchungen wie auch allen Mitarbeitern der Abteilung für Vegetative Physiologie und Pathophysiologie für ihre Hilfsbereitschaft und freundliche Atmosphäre.

Weiterhin möchte ich Herrn Dr. O. Valerius und seinen Mitarbeitern danken, die im AnalytikLabor des Instituts für Mikrobiologie und Genetik der Universität Göttingen die massenspektrometrischen Analysen durchgeführt haben.

Nicht zuletzt vielen Dank auch an meine Kollegen für ihre große Hilfsbereitschaft und stets freundschaftliche Atmosphäre. Ganz besonders möchte ich Frau Dr. C. Brendel, Frau Dr. M. Hillebrand und Herrn Dr. A. Ohlenbusch für ihre Bereitschaft danken, mir bei Problemen mit Rat und Tat zur Seite zu stehen. Vielen Dank auch an Jens Kaiser für seine tatkräftige Unterstützung.

Abschließend möchte ich meiner Familie, insbesondere meinen Eltern sowie meinem Freund für das entgegengebrachte Verständnis danken und dafür, dass sie immer unterstützend für mich da sind. 



\title{
Wissenschaftlicher Werdegang
}

\author{
Simone Diekmann \\ geboren 1980 in Warburg \\ Schulausbildung/Studium
}

2000 Abitur am Hüffertgymnasium mit den Leistungskursen Mathematik und Biologie

10/2000-07/2001 Physiotherapieschule Göttingen

10/2001-12/2005 Studium der Biologie an der Georg-August-Universität in Göttingen mit den Schwerpunkten Biochemie, Mikrobiologie und Organische Chemie

02/2005-12/2005 Diplomarbeit bei Prof. Dr. Dr. h.c. K. von Figura im Zentrum für Biochemie und Zellbiologie der Medizinischen Fakultät der Georg-AugustUniversität Göttingen „Transkriptomanalyse bei Fucosesubstitution in CDG-II c Fibroblasten“

\section{Promotion}

01/2006-05/2009 Promotion bei Prof. Dr. J. Gärtner in der Neuropädiatrie der Universitätsmedizin Göttingen

„Studien zur Pathogenese humaner Leukoenzephalopathien“

Göttingen, im Mai 2009 